\title{
Risk Reduction and Soil Ecosystem Restoration in an Active Oil Producing Area in an Ecologically Sensitive Setting
}

\section{Final Report}

Reporting period: November 1, 2000 - December 31, 2005

\author{
Principal authors: \\ Kerry L. Sublette \\ Greg Thoma \\ Kathleen Duncan
}

Report Issued: January 2006

\section{DE-FC26-01BC15332}

\section{Submitting Organizations:}

\author{
Kerry L. Sublette \\ Depts. of Chemical Engineering and Geosciences \\ University of Tulsa \\ 600 S. College Ave. \\ Tulsa, OK 74104 \\ Greg Thoma \\ Dept. of Chemical Engineering \\ University of Arkansas \\ 3202 Bell Engineering Center \\ Fayetteville, AR 72702 \\ Kathleen Duncan \\ Dept. of Botany and Microbiology \\ University of Oklahoma \\ 770 Van Vleet Oval \\ Norman, OK 73019
}




\section{DISCLAIMER}

This report was prepared as an account of work sponsored by an agency of the United States Government. Neither the United States Government nor any agency thereof, nor any of their employees, makes and warranty, expressed of implied, or assumes any legal liability or responsibility for the accuracy, completeness, or usefulness of any information, apparatus, product, or process disclosed, or represents that its use would not infringe privately owned rights. Reference herein to any specific commercial product, process, or service by trade name, trademark, manufacturer, or otherwise does not necessarily constitute or imply its endorsement, recommendation, or favoring by the United States Government or any agency thereof. The views and opinions of authors expressed herein do not necessarily state or reflect those of the United States Government or any agency thereof. 


\begin{abstract}
Soil Ecosystem Restoration:

The empowerment of small independent oil and gas producers to solve their own remediation problems will result in greater environmental compliance and more effective protection of the environment as well as making small producers more self-reliant. In Chapter 1 we report on the effectiveness of a low-cost method of remediation of a combined spill of crude oil and brine in the Tallgrass Prairie Preserve in Osage County, OK. Specifically, we have used hay and fertilizer as amendments for remediation of both the oil and the brine. No gypsum was used. Three spills of crude oil plus produced water brine were treated with combinations of ripping, fertilizers and hay, and a downslope interception trench in an effort to demonstrate an inexpensive, easily implemented, and effective remediation plan. There was no statistically significant effect of treatment on the biodegradation of crude oil. However, TPH reduction clearly proceeded in the presence of brine contamination. The average TPH half-life considering all impacted sites was 267 days. The combination of hay addition, ripping, and a downslope interception trench was superior to hay addition with ripping, or ripping plus an interception trench in terms of rates of sodium and chloride leaching from the impacted sites. Reductions in salt inventories (36 months) were $73 \%$ in the site with hay addition, ripping and an interception trench, $40 \%$ in the site with hay addition and ripping only, and $<3 \%$ in the site with ripping and an interception trench.
\end{abstract}

The effect of fertilizer as an amendment in the bioremediation of a terrestrial crude oil spill has been investigated and reported in Chapter 2 in terms of the subsequent recovery of the soil ecosystem following bioremediation. Two different spills in the 
same area with different initial hydrocarbon concentrations $\left(33,500 \mathrm{mg} \mathrm{kg}^{-1}\right.$ and 4,800 $\mathrm{mg} \mathrm{kg}^{-1}$ ) were compared. Fertilizer increased the rate of bioremediation resulting in the more rapid recovery of soil bacteria (numbers, community structure, diversity) and nematodes (trophic diversity and community structure). This effect was more significant at the higher initial concentration of crude oil hydrocarbons presumably due to greater depletion of soil nutrient pools in the absence of the fertilizer amendment. A second objective of this work was to identify sensitive ecological indicators useful in monitoring the recovery of soil ecosystems impacted by crude oil in a cost-effective manner. Ecological indicators used included microbial numbers, community structure, and activity as revealed by biomarker analysis (phospholipid fatty acids), nitrogen availability, nematode numbers and community structure, and ultimately plant community structure and diversity. All ecological indicators investigated were sensitive to disturbances in the soil food web in a hydrocarbon-impacted site; however, nematode community structure analysis offered the greatest sensitivity coupled with low cost and readily available sources for the analysis.

Characterization of the soil microbial community in tallgrass prairie soil and its response to oil-field contamination and remediation treatments was assessed in the two sites described above by sequencing $16 \mathrm{~S}$ rRNA libraries derived from soil samples taken at various points in the contamination-remediation-recovery process (Chapter 3). Undisturbed prairie was found to have high proportions of Actinobacteria, $\alpha$ Proteobacteria, and Acidobacteria, lower proportions of Firmicutes, Bacteroidetes, $\beta$ and $\delta$ Proteobacteria, a few representatives from a wide variety of candidate divisions, but was noteworthy for the low proportion of $\gamma$ Proteobacteria. Tilling was found to have the 
least effect on these proportions, sites contaminated with crude oil had decreased representation of Actinobacteria and Acidobacteria and an increased proportion of Firmicutes and $\gamma$ Proteobacteria, especially the latter. Brine-contaminated sites were similar to but more extreme than oil contaminated sites, with the addition of a bloom of Bacteroidetes. Groups that increased in contaminated sites were those containing cultured members able to respond rapidly (r-selected) to an influx of readily degraded hydrocarbons and/or were hypothesized to be more salt-tolerant, while those that decreased grow more slowly (Actinobacteria, Acidobacteria) or may be less tolerant of conditions in brine-impacted soil (Acidobacteria). Discriminant function analysis was applied in order to create a model that categorized samples as uncontaminated, oilimpacted, or brine-impacted. A high percentage of assignments were made correctly when model factors included weighted functions of percent Acidobacteria, Actinobacteria, and Bacteroidetes. The application of $\mathrm{N}$-containing fertilizer appeared to lessen the imbalance due to oil-contamination and substantial recovery was seen four years after contamination had occurred. In contrast, the brine-impacted sites showed much less change after three years of treatment.

Characterization of the $\beta$ Proteobacteria ammonium-oxidizing portion of the soil microbial community in tallgrass prairie soil and its response to oil-field contamination and remediation treatments described above was assessed by sequencing amo $A$ libraries derived from soil samples taken at various points in the contamination-remediationrecovery process (Chapter 4). Sites that had been disturbed by tilling, contamination by a spill of crude oil or by a spill of oil-field brine were compared. Sequences with high similarity to Nitrosomonas sp. were found only in the brine-contaminated sites. 
Sequences from undisturbed prairie, tilled, and oil-impacted all had highest similarity to Nitrosospira sp., but differed in the relative proportions affiliated with different clades of Nitrosospira. The great majority of sequences (approximately 95\%) from tilled and native prairie samples were most similar to a clade of sequences previously derived from soil and/or associated with plant roots.

\section{Risk Reduction:}

The aging domestic oil production infrastructure represents a high risk to the environment because of the type of fluids being handled (oil and brine) and the potential for accidental release of these fluids into sensitive ecosystems. Currently, there is not a quantitative risk model directly applicable to oil exploration and production $(\mathrm{E} \& \mathrm{P})$ facilities. In Chapter 5 we report on a model developed for direct applicability to E\&P facilities. Reliability theory, Failure Modes and Effects Analysis (FMEA), and event trees were used to develop the model estimates of the failure probability of typical oil production equipment. Monte-Carlo simulation was used to translate the input parameter uncertainty to the model output. The model predicted failure rates were calibrated to available failure rate information through the use of Monte-Carlo simulations. The mean and standard deviation of normal variate distributions from which the Weibull distribution characteristic life was chosen were used as adjustable parameters in the model calibration. The model was applied to oil production leases in the Tallgrass Prairie Preserve, Oklahoma. We present the estimated failure probability due to the combination of the most significant failure modes of each type of equipment (pumps, tanks, and pipes). The results showed that the estimated probability of failure for tanks was about the same as that for pipes, but that pumps have much lower failure probability. The 
model can provide necessary equipment reliability information for risk management through allocation of maintenance resources to minimize both lost production and ecosystem damage.

In Chapter 6 we present a method aimed at reducing the likelihood of contaminant releases into the environment through a proactive risk management strategy. This proactive risk management strategy has the potential of increasing revenue through avoidance of lost production and post-spill remediation expenses. A physical transport model was developed to quantify the extent of a spill on soil surface. The governing continuity equation for the 2-Dimensional surface flow of constant fluid density including infiltration was solved numerically using the method of lines. Model validation was performed through comparison of predicted spill areas from both artificial surface and real topography tests. When applied to an historic brine scar, physical transport model prediction for the areal extent of the release, on a digital elevation model of the site, was within $30 \%$ of the actual scar area. A sensitivity analysis was performed to determine the effect of input parameters on model output that showed the infiltration rate was the principal factor affecting the areal extent of brine spills, but that more complex surface flow factors were important for oil spill spreading.

Coupling the probability of an equipment failure with the predicted areal spill extent and a natural resources damage assessment for the predicted spill can be used to generate a ranked risk index for a particular production lease. In this paper we report on linking the spill model to a geographic information system that provides a platform for generation of a consistent risk-ranked map of two active oil production leases located in the Tallgrass Prairie Preserve, located in Osage county, Oklahoma. The model is readily 
exportable to other E\&P sites for which the necessary input information is available or can be generated. 


\title{
Risk Reduction and Soil Ecosystem Restoration in an Active Oil Producing Area in an Ecologically Sensitive Setting
}

\author{
TABLE OF CONTENTS
}

Executive Summary................................................. 8

Chapter 1: Remediation of a Spill of Crude Oil and Brine Without Gypsum......16

Chapter 2: Monitoring Soil Ecosystem Recovery Following Bioremediation of a Terrestrial Crude Oil Spill With and Without a Fertilizer Amendment.

Chapter 3: Changes in Microbial Communities During Remediation of Crude Oil and Brine Spills.......................................86

Chapter 4: The Effect of Oil and Oil-field Brine Contamination on Ammonium-Oxidizing Bacteria in Tallgrass Prairie Soil

Chapter 5: Probabilistic Reliability Modeling for Oil Exploration and Production in the Tallgrass Prairie Preserve...

Chapter 6: Consequence Analysis of Produced Fluids and Risk Generation for the Tallgrass Prairie Preserve. 


\section{Executive Summary}

- Three spills of crude oil plus produced water brine were treated with combinations of ripping, fertilizers and hay amendments, and a downslope interception trench in an effort to demonstrate an inexpensive, easily implemented, effective remediation plan. The presence of brine components and loss of vegetation in the impacted sites resulted in lower concentrations of soil microbes growing at slower rates and experiencing greater stress than communities in an unimpacted control. However, over time microbial community structures originally impacted by brine approached those of the unimpacted control as salt was leached out of the site. There was no effect of treatment on the biodegradation of crude oil. However, TPH reduction clearly proceeded in the presence of brine contamination. The average half-life considering all impacted sites was 267 days. The combination of hay addition, ripping, and downslope interception trench was superior to hay addition with ripping, or ripping plus an interception trench in terms of rates of sodium and chloride leaching from the impacted sites. From this study, the remediation of produced fluids spills with ripping (or tilling), hay and fertilizer addition, and an interception trench has been shown to be effective in bioremediation of the hydrocarbons and removal of brine components. This methodology can easily and inexpensively implemented by small independent oil and gas producers without hiring outside contractors and without the purchase, transportation, and spreading of gypsum. With access to a tractor and tiller and a local source of hay an independent producer can remediate a one acre site for about $\$ 200$. Hiring a contractor to remediate the site with 
gypsum can cost ten times that amount. Neither of these cost estimates include the cost of an interception trench which would depend somewhat on the topography of the site. The interception trench is basically a French drain which can also be installed by the independent producer as needed.

- PLFA analysis of soil bacteria, analysis of nematode numbers and community structure, and analysis of nitrogen availability have all shown that the addition of fertilizer during bioremediation of a terrestrial crude oil spill accelerates the subsequent restoration of the soil ecosystem. The effect of the fertilizer was more significant at higher concentrations of crude oil hydrocarbons due to greater depletion of soil nutrient pools under these conditions in the absence of fertilizer. Initial re-vegetation of oil-impacted sites was not affected by fertilizer but the original hydrocarbon contamination and subsequent bioremediation process did impact species richness during initial re-vegetation more than that observed in the tilled control. Re-vegetation appeared to be slowed by higher initial hydrocarbon concentrations. Nematode analysis proved to be the most sensitive ecological indicator in regard to disturbance of the soil food web in a hydrocarbon-impacted site. Community structure analysis using c-p classes was capable of discerning the effect of fertilizer addition on soil ecosystem recovery even at the lower hydrocarbon concentrations in J6S. The results of a nematode analysis are also much easier for a lay person (like a small independent oil producer) to understand and, in the U.S., readily obtained through university agricultural extension services for a very reasonable cost. Nematologists at these institutions can provide nematode counts by trophic group and c-p class at a relatively low cost. 
With minimal training a small producer can interpret temporal trends in these data and make comparisons to target ecosystems. Nematode analyses have a long tradition and body of knowledge exists with respect to agricultural systems. However, to our knowledge this work represents the first use of a nematode analysis to monitor recovery of soil ecosystems following the bioremediation of a crude oil spill.

- Contamination by oil spills and by oil-field brine each were shown to have profound effects on the soil microbial community of the tallgrass prairie, shifting the eubacterial community from one dominated by Actinobacteria, $\alpha$ Proteobacteria, and Acidobacteria, to communities in which the slow-growing Actinobacteria and Acidobacteria are poorly represented and the faster-growing, contamination-tolerant $\gamma$ proteobacteria, Firmicutes, and Bacteroidetes (in the case of brine-contamination) rise to prominence. Tilling the soil, necessary for treatment of the contaminated sites with hay and $\mathrm{N}$-containing fertilizer, has little effect on the community in comparison to the chemical contamination. Ncontaining fertilizer appears to ameliorate the effects of oil contamination on the community. Discriminant function analysis model, incorporating a weighted function of $\%$ Acidobacteria, Actinobacteria, and Bacteroidetes correctly categorized samples as uncontaminated, oil-impacted, or brine-impacted. The community in the fertilizer-treated, oil-contaminated site was similar to that in the prairie after four years, but the brine-impacted sites showed substantial differences three years after treatment began. 
- Native tallgrass prairie soils and tilled but uncontaminated tallgrass soilswere shown to be very similar in their dominance by one clade of Nitrosospira, related to sequences obtained from grassland and plant-associated soils. Oil and brine contamination of tallgrass prairie soil alters the AOB population in significant and characteristic ways. Brine-impacted soils contain a high percentage of sequences related to those of Nitrosomonas, which were not found in our samples of uncontaminated soil, and no Nitrosospira sequences of the dominant prairie soil clade were obtained from the brine-impacted samples. Oil-impacted sites had a more even diversity of sequences related to major Nitrosospira clades, which include the typical prairie clade. These findings suggest that it may be less difficult to restore the ammonium-oxidation capacity of oil-impacted than brineimpacted soil to that of the native prairie.

- A quantitative risk model directly applicable to oil exploration and production (E\&P) facilities was developed. Reliability theory, Failure Modes and Effects Analysis (FMEA), and event trees were used to develop the model estimates of the failure probability of typical oil production equipment. The model is capable of estimating cumulative failure and failure within a future time horizon.

However, the calculated failure probabilities for the equipment at a reference site (Tallgrass Prairie Preserve) were larger than the limited historical information available suggest they should be. This can be attributed to the fact that the corrosion model used for tanks is the same that for pipes. In the model, tanks are exposed to similar failure modes of pipes, and corrosion is the biggest cause of failure. Nevertheless, both the order of magnitude and some of the 
characteristics of an Oklahoma Corporation Commission (OCC) complaint data set are reproduced in the TPP lease simulation: Oil service is less likely to fail than brine service, pumps are less likely to fail than pipes and tanks. The one characteristic that is not yet properly captured is that the OCC data show that brine injection well pipelines have the highest likelihood of failure, and the model does not show this behavior. Not surprisingly, plastic pipelines are significantly less risky than the aging steel infrastructure at the site. The code is highly functional and easily expandable to accommodate additional equipment, failure modes, and event trees. It is of course critical that site specific information regarding the equipment history is available. For future work an inclusion of a more site-specific and equipment-specific corrosion models should allow more accurate probability of failure estimations. Additionally, the model needs to be validated with information from databases of equipment and equipment failure for similar sites to the one under study.

- Procedures have been described for quantifying the consequences of a terrestrial produced fluid spill and for calculating a Risk Index for oil E\&P equipment located in the Tallgrass Prairie Preserve, Oklahoma. A physical transport model is the main quantitative tool developed for consequence analysis. Given suitable base data sets, the physical transport model can be used to estimate the extent of a produced fluid release and is able to predict terrestrial flow paths. The spill model is robust, producing results that correspond to expected results on artificial surfaces and real topography. The physical transport model was also designed to predict the extent of a spill on surfaces having different surface characteristics, 
and variable density of standing vegetation and organic litter. This model also includes the freedom to change the fluid viscosity for different types of spilled fluids such as brine, crude oil, or processed products such as gasoline, diesel or jet fuel. An ecological risk factor estimation model defines a risk category for each simulated accidental release incident which in turn determines the necessary cleanup level for that spill. A cost estimation module is called to estimate the expense of cleanup to the required level. Risk is defined as the product of financial consequence and probability of failure of an item of equipment at a particular location. The risk is normalized across the lease to provide a simple comparison of the risks so that limited maintenance resources can be allocated to those locations and equipment that will result in the most significant reduction in overall lease level risk. The proposed proactive risk management approach should result in both cost savings to the independent producer as well as lead to a reduction in the ecological impact of exploration and production activities in sensitive ecosystems. 


\title{
Chapter 1
}

\section{Remediation of a Spill of Crude Oil and Brine Without Gypsum}

\author{
Kerry L. Sublette* \\ Center for Applied Biogeosciences \\ University of Tulsa \\ 600 S. College Ave. \\ Tulsa, OK 74104 \\ (918)631-3085 Phone \\ (918)631-3268 Fax \\ kerry-sublette@utulsa.edu \\ Aditya Moralwar and Laura Ford \\ Department of Chemical Engineering \\ University of Tulsa \\ Kathleen Duncan \\ Department of Botany and Microbiology \\ University of Oklahoma \\ Greg Thoma \\ Department of Chemical Engineering \\ University of Arkansas \\ Josh Brokaw \\ Department of Botany \\ Oklahoma State University
}

* Corresponding author

\section{ACKNOWLEDGEMENTS}

This work was funded by the National Energy Technology Laboratory of the U.S. Department of Energy under cooperative agreement number DE-FC26-01BC15332. The authors also wish to express their gratitude to the Oklahoma Chapter of the Nature Conservancy for access to the study site in the Tallgrass Prairie Preserve and particularly to Robert Hamilton, Director of Stewardship for the Preserve, for his valuable assistance in this project. 


\section{ABSTRACT}

The empowerment of small independent oil and gas producers to solve their own remediation problems will result in greater environmental compliance and more effective protection of the environment as well as making small producers more self-reliant. Here we report on the effectiveness of a low-cost method of remediation of a combined spill of crude oil and brine in the Tallgrass Prairie Preserve in Osage County, OK. Specifically, we have used hay and fertilizer as amendments for remediation of both the oil and the brine. No gypsum was used. Three spills of crude oil plus produced water brine were treated with combinations of ripping, fertilizers and hay, and a downslope interception trench in an effort to demonstrate an inexpensive, easily implemented, and effective remediation plan. There was no statistically significant effect of treatment on the biodegradation of crude oil. However, TPH reduction clearly proceeded in the presence of brine contamination. The average TPH half-life considering all impacted sites was 267 days. The combination of hay addition, ripping, and a downslope interception trench was superior to hay addition with ripping, or ripping plus an interception trench in terms of rates of sodium and chloride leaching from the impacted sites. Reductions in salt inventories (36 months) were $73 \%$ in the site with hay addition, ripping and an interception trench, $40 \%$ in the site with hay addition and ripping only, and $<3 \%$ in the site with ripping and an interception trench.

\section{INTRODUCTION}

The smallest independent oil producers, produce from the marginal or stripper wells in fields with an aging infrastructure left behind by the majors. Yet these marginal 
wells account for $20 \%$ of domestic crude oil production (IPAA). However, unlike the majors there is no vertical depth to their businesses- they are totally dependent on the sale of oil and gas. They are vulnerable to the instability of crude oil prices and, without a technical staff, they are often easy prey for "snake oil" salesmen who promise them quick fixes or cheap solutions. The bottom line is that a critical fraction of our domestic energy needs is supplied by small businesses that are often operating with a thin profit margin from an aging infrastructure. A recent analysis of the Oklahoma Corporation Commission's complaint database, covering 1993 to 2002, revealed that in Oklahoma alone $620,000 \mathrm{bbl}$ of crude oil and over a million bbls of produced water brine were reported spilled during this ten-year period (Fisher and Sublette, 2005). With an average TDS of about $150,000 \mathrm{mg} / \mathrm{L}$ TDS, that's 2800 tons of salt entering Oklahoma's environment each year during this period. Further analysis of the database revealed that about $80 \%$ of these spills were due to corrosion in tanks and pipelines.

There is no doubt that these spills harm Oklahoma's environmental quality. Especially troublesome are spills of saltwater which can result in erosion and loss of topsoil as well as salt contamination of surface waters and groundwater. This problem needs to be addressed on two fronts. The first is obviously prevention. Preventive maintenance, particularly the replacement of old gathering lines with new polymer pipe, would go a long way toward preventing these spills. However, given the instability of crude oil prices, preventive maintenance is seen by small producers as pure expense. Overcoming this perception is a matter of education concerning the economic value of being proactive. States could also help by providing tax credits or other incentives for replacing aging equipment. The second front is the development and demonstration of 
low-cost methods for treatment of oil and brine spills that are easy for small producers to understand and implement. The empowerment of small independent producers to solve their own remediation problems will result in greater environmental compliance and more effective protection of the environment as well as making small producers more self-reliant.

Here we report on the effectiveness of a low-cost method of remediation of a combined spill of crude oil and brine. Specifically, we have used hay and fertilizer as amendments for remediation of both the oil and the brine. No gypsum was used. Gypsum typically adds significantly to the cost of brine spill remediation due to both the cost of the gypsum and the cost of transportation and spreading. However, the effect of gypsum in mobilizing sodium from clays is manifested only to the depth to which it is applied (Robbins, 1986). Further, the addition of large amounts of gypsum to the soil has the potential to interfere with phosphorous cycling (Sample et al., 1980). We propose that reducing the salinity of brine-impacted soils by using hay and fertilizer will generally allow revegetation with salt-tolerant native plants in 1-2 years. Hay increases macropores in the soil and fertilizer addition supports biodegradation of hay which provides products that increase the stability of soil aggregates. Plant roots exude organic compounds increasing the stability of soil aggregates and build soil structure which increases the hydraulic conductivity of the soil and further increases rates of salt removal by natural precipitation. In addition, in calcareous soils, $\mathrm{CO}_{2}$ production from both microbial biodegradation and root respiration will increase the solubility of calcite in the soil producing soluble $\mathrm{Ca}^{+2}$ displacing $\mathrm{Na}^{+}$from clays. Unlike gypsum the effect of plant roots on soil structure extends to the depths of the root zone (Robbins, 1986). Salt- 
tolerant plants give way to less tolerant and often more desirable vegetation as salinity is further reduced. If crude oil is spilled along with the brine (a common occurrence) hay and fertilizer also stimulate the biodegradation of the oil by increasing oxygen penetration into the soil and providing nutrients for microorganisms.

\section{SITE DESCRIPTION}

The site used in this work is located in the Tallgrass Prairie Preserve in Osage County, Oklahoma. During the fall of 1999 three different spills of produced fluids (oil + brine) caused by corrosion in a single steel gathering line resulted in three separate lobes of contamination which extended west from the gathering line down a slope of about $5 \%$. The immediate effect of each spill was a loss of vegetation cover. The three contaminated sites are very close together separated by a strip of unimpacted native grass about 3-5 m wide. The amount of crude oil and brine spilled is not known, but most of the crude oil was retained in the upper two thirds of each spill area by vegetation. The three lobes of contamination are referenced here according to their respective positions. The contaminated site which is north most is referred to as the North site $(\mathrm{N})$, the one that is furthest south is the South site (S), and the third which was between these two is the Middle site (M). The North site was the first one to be contaminated, around September 18, 1999. The Middle site was contaminated between September 18 and 24, 1999 and the South site was discovered in early January, 2000. An area adjacent to the South site was used as an unimpacted control. The unimpacted control is dominated by tallgrass prairie climax vegetation. The dimensions of each site are as follows: North, $80 \mathrm{~m}$ x $7.5 \mathrm{~m}(600$ $\left.\mathrm{m}^{2}\right)$; Middle, $33 \mathrm{~m}$ x $7 \mathrm{~m}\left(230 \mathrm{~m}^{2}\right)$; South, $60 \mathrm{~m}$ x $16 \mathrm{~m}\left(960 \mathrm{~m}^{2}\right)$. 
This area of the Preserve is very rocky and the topsoil is on average about $15 \mathrm{~cm}$ deep at the top of the hill and thicker at the bottom of the hill. Soil textures at the site are given in Table 1. As noted above the volumes of oil and brine spilled in each case is unknown; however, typically in this area the water:oil ratio in produced fluids is $10-15: 1$. Produced water brine in this area typically has a TDS of about 105,000 mg/L (USGS) and the composition of oil produced in this area is shown in Table 2. As will be discussed below, TPH biodegradation and leaching of $\mathrm{Na}^{+}$and $\mathrm{Cl}^{-}$were modeled as first-order reactions and linear regressions were performed on $\ln [\mathrm{TPH}], \ln \left[\mathrm{Na}^{+}\right]$, and $\ln \left[\mathrm{Cl}^{-}\right] \mathrm{vs}$. time data for each site. Estimates of initial TPH and brine component concentrations were obtained from the intercepts at $\mathrm{t}=0$. These initial concentrations with $95 \%$ confidence intervals are given in Tables 3 and 4.

\section{REMEDIATION PROTOCOL}

As shown in Figure 1 this area is extremely rocky. Initially enough rocks were removed by hand on June 13, 2000 to allow the sites to be ripped to blend in amendments on the following two days. Tilling was not possible; therefore, mixing of amendments with the contaminated soil was not optimal. Amendments were added to the North and South sites as shown in Table 5 and ripped in. Hay application rates were approximately 6 small square bales per $100 \mathrm{~m}^{2}$. Fertilizers were added based on initial estimates of TPH using a field analytical method which was subsequently shown to be unreliable. The Middle site was ripped as well but no amendments were added.

Salt must have a pathway out of the root zone if vegetation is to be reestablished. The slope of these sites provided a natural pathway for lateral movement and overland transport of brine components. However, given the significant slope of 
these sites there was the potential for transport of brine components into the unimpacted areas downslope at a rate which could be damaging. In order to be protective of the downslope areas an interception trench was installed at the bottom of the North and Middle sites. No trench was installed at the bottom of the South site in order to determine whether the trenches had any effect on the rate of leaching of salt from the soil in the impacted areas. Trenches were about $7.5 \mathrm{~m}$ long, $0.15 \mathrm{~m}$ wide and $0.6 \mathrm{~m}$ deep. In each trench was placed a $10.2-\mathrm{cm}$ diameter slotted drainage pipe covered with a polyethylene fiber sock to prevent clogging of the pipe. The whole assembly was surrounded by limestone gravel to create a highly permeable zone around the slotted pipe. A small $15-\mathrm{cm}$ earthen berm was also constructed just below the interception trench to restrict the flow of the water. A polymer pipe $5 \mathrm{~cm}$ in diameter was used to connect the interception trench to a natural drainage area (a gully system which eventually drained into an intermittent creek). The lengths of the pipes from the bottom of the North and Middle contaminated sites to the natural drainage area were about $61 \mathrm{~m}$ and $91.5 \mathrm{~m}$, respectively. Natural precipitation was the only source of water to leach brine components from the site. Figure 2 provides monthly precipitation levels from June 2000 through August 2003 compared to historical normal precipitation. As seen in Figure 2 there were two significant periods of below normal rainfall or drought during this experiment: July - December 2000 and June 2001 through March 2002. This leaves about 23 months with sufficient rainfall to potentially produce effective leaching of brine components from the soil in the impacted sites. Biodegradation of hydrocarbons was also likely to have been negatively affected during periods of insufficient rainfall. 


\section{SAMPLING AND ANALYSIS}

Sites of this type are highly heterogeneous even after tilling. Nicknamed "the rock garden", these three sites were even more heterogeneous due to the rocky conditions that prevented tilling with mixing of amendments accomplished by ripping only. In order

to account for as much heterogeneity as possible at each sampling event, four-fold composite samples were collected from three regions of each impacted site. Each composite sample was composed of soil taken from four holes adjacent to a line perpendicular to the axis of each impacted site. Sampling lines were approximately equally spaced along the axis of the impacted sites (North sampling lines: 8.0-9.5 m, 32.5-33.5 m, and 60.5-62.0 m from the pipeline; Middle sampling lines: 3.5-4.5 m, 14.515.5 m, and 27.0-28.0 $\mathrm{m}$ from the pipeline; and South sampling lines: 12.0-14.0 $\mathrm{m}, 32.5-$ 34.0 $\mathrm{m}$, and 59.5-61.0 $\mathrm{m}$ from the pipeline). Samples for analysis of brine components $\left(\mathrm{Na}^{+}\right.$and $\left.\mathrm{Cl}^{-}\right)$were collected from both the 0-15 $\mathrm{cm}$ and $15-30 \mathrm{~cm}$ depth intervals. Brine components were extracted from approximately $120 \mathrm{~g}$ of homogenized, oven-dried (110 $\left.{ }^{\circ} \mathrm{C}\right)$ soil with de-ionized water using a 1:1 ratio of dried soil:de-ionized water. Extracts were allowed to settle overnight and then vacuum filtered. The electrical conductivities of the extracts were used to calculate appropriate dilutions for analysis of $\mathrm{Na}^{+}$and $\mathrm{Cl}^{-}$by ion chromatography (IC) using a DX-120 ion chromatograph (Dionex Corp.) (Harris, 1998). The anion buffer solution was prepared by diluting $9 \mathrm{~mL}$ of a 3.5:1.0 mixture of $0.5 \mathrm{M}$ sodium bicarbonate and $0.5 \mathrm{M}$ sodium carbonate solution to $1 \mathrm{~L}$ with de-ionized water. The cation buffer solution was prepared by dissolving $1.9822 \mathrm{~g}$ of methanesulfonic acid in $1 \mathrm{~L}$ of de-ionized water. An ionPac AS14 4-mm column was used for the anions, while an ionPac CS12A 4-mm column was used for the cations. The calibration standards 
used for the IC were Five Anion Standard and Six Cation Standard (Dionex Corp.) for the anions and cations, respectively.

TPH samples were collected in the impacted areas and unimpacted control from the $0-15 \mathrm{~cm}$ depth interval in glass jars with Teflon-lined lids. Sample bottles were placed immediately on ice in the field and later shipped overnight cold to Continental Laboratories in Salina, KS for analysis (EPA 418.1).

At each sampling event six-fold composite samples (two places each on three sampling lines) were also collected from each impacted site and the unimpacted control in a 1-gal Ziploc ${ }^{\circledR}$ bag and homogenized. Composited samples were transferred to sterile Whirl-pak ${ }^{\circledR}$ bags (Fisher-Scientific) and were placed immediately on ice in the field. Samples were stored at $4^{\circ} \mathrm{C}$ until shipped overnight on ice to Microbial Insight, Inc. (Rockford, TN) for analysis for phospholipid fatty acid analysis (PLFA). Phospholipid fatty acid (PLFA) analysis is based on the extraction and separation of lipid classes, followed by quantitative analysis using gas chromatography/mass spectrometry. Lipids are essential components of the cell membranes of all microbial cells. This method is superior to plate counts since both culturable and non-culturable microorganisms are enumerated and characterized. Signature lipid biomarker analysis provides quantitative insight into three important attributes of microbial communities: viable biomass, community structure and nutritional/physiological status (White et al., 1997).

\section{RESULTS AND DISCUSSION}

\section{The Impact of Brine on Soil Microbiology}

Conventional wisdom in the oil and gas industry is that a brine spill "sterilizes" soil. PLFA analysis of soil samples from these impacted sites certainly challenges that 
belief. Soil microbial populations are greatly influenced by soil moisture and season as well as a disturbance such as oil or brine contamination. Comparisons between different treatments or simply different sites can only be made with sets of soil samples taken at the same time so that for each set soil moistures will be similar and seasons will be the same. A Repeated Measures Analysis of Variance was used to test whether or not there was a significant difference between the samples in terms of prokaryotic (bacteria) and eukaryotic (fungi, protozoa, algae) PLFA when compared for each sample date. Table 6 presents the mean concentrations of prokaryotic and eukaryotic PLFA observed over the June 2000 through August 2003 period. Also presented (Table 7) is a statistical comparison of the log-transformed means from April 2001 through August 2003 using a Tukey-Kramer multiple comparisons test. As seen in Table 7 none of the impacted sites (North, Middle, South) were different from each other at a 95\% confidence level. However, the log-transformed means of prokaryote and eukaryote PLFA concentrations in the impacted sites were statistically different from the unimpacted control. Although PLFA concentrations in the impacted sites were on average about $50 \%$ lower than in the corresponding control samples these concentrations represent cell counts of over $10^{8}$ viable cells/g dry wt. of soil (White et al., 1997). The lower concentrations of soil microbes in the brine-impacted sites are not necessarily the direct result of the presence of salt alone. The lack of vegetation, particularly the root structure, caused by the brine spill also directly affects the numbers of soil microbes.

Bacteria tend to produce cyclopropyl fatty acids when cells enter stationary phase (a period of slow or zero growth) (Guckert et al., 1986). If these cyclopropyl fatty acids and their monoenoic precursors are enumerated a picture emerges of the overall or 
average turnover number in the bacterial population in a given soil sample. Overall metabolic status is given by the summation of two ratios of fatty acids derived from

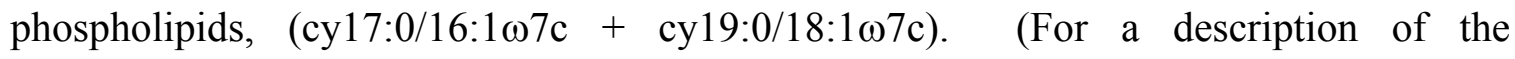
nomenclature for fatty acids see www.microbe.com.) Larger values of this ratio indicate slower growth rates. Table 6 provides the mean values of this ratio for bacteria in all sites over the period June 2000 through August 2003 and Table 7 compares these means for the period from April 2001 through August 2003 using a Tukey-Kraemer multiple comparisons test. As seen here the impacted sites do not differ from each other at the 95\% confidence level. However, the metabolic status indicators in the impacted sites are statistically greater than the control at the $95 \%$ confidence level indicating slower growth in the impacted sites compared to the unimpacted control.

Many bacteria also respond to environmental stress with a change in the fatty acid composition of their cytoplasmic membranes converting certain cis monoenoics to corresponding trans versions to modify membrane permeability (Guckert et al., 1986). This effect is also quantified by computing the summation of two ratios, $(16: 1 \omega 7 \mathrm{t} / 16: 1 \omega 7 \mathrm{c}+18: 1 \omega 7 \mathrm{t} / 18: 1 \omega 7 \mathrm{c})$. Elevated values of this ratio reflect greater adaptation to stress. Table 6 provides the mean values of this ratio for bacteria in all sites over the period June 2000 through August 2003 and compares these means for the period April 2001 through August 2003 using a Tukey-Kraemer multiple comparisons test. As seen here the impacted sites do not differ from each other at the $95 \%$ confidence level (Table 7). However, in the impacted sites environmental stress indicators are statistically greater than the unimpacted control at the $95 \%$ confidence level indicating elevated stress levels in the North and Middle impacted sites compared to the unimpacted control. 
The community structure of a soil microbial community is frequently reflected in the fatty acids enumerated in the PLFA analysis (White et al., 1997). Different structural classes of fatty acids are indicative of different types of bacteria and eukaryotes that make up the community. These structural classes are C16 monoenoics, C18 monoenoics, branched saturated fatty acids, mid-branched fatty acids, terminally branched fatty acids, n-saturated fatty acids, and polyenoics. Using these structural groups a cluster analysis was performed to make gross comparisons of microbial community structure in the impacted sites relative to the control during the June 2000 through August 2003 period (Figure 3). Samples taken in 2000 and 2001 from the impacted areas were similar to each other and different from the majority of the control 2001 samples. The community structures of the impacted sites were clearly impacted by oil and brine spill and subsequent loss of vegetation. But samples taken from the impacted sites in 2003, especially the September 2003 samples (indicated by an arrow), had greater similarity to the control area. This demonstrates that the impacted sites have become more similar to the unimpacted control over time in terms of microbial community structure.

In summary, the presence of brine components and loss of vegetation in the impacted sites resulted in fewer soil microbes growing at slower rates and experiencing greater stress than microbial communities in the control site. Over time community structures impacted by brine approached those of the unimpacted control as salt was leached out of the site.

\section{Biodegradation of Hydrocarbons in the Brine-impacted Sites}

The North site was somewhat oil-stained over its entire length by the original

spill. After amendments were added crude oil was detected as TPH at each sampling line 
in this impacted site. The South and Middle sites were oil-stained over the top two-thirds of the sites by the original spills. Removal rates were estimated only where TPH was detected. TPH concentrations were far from uniform in any of the impacted sites at any sampling event given the heterogeneity of the original oil distribution and minimal amendment mixing. At each sampling event an average TPH concentration was determined for each impacted site from the TPH composite samples.

Biodegradation was assumed to be the operative mechanism for removal of TPH from the impacted sites. No bloom in numbers of soil microbes was observed in the impacted sites with hay and fertilizer additions using PLFA to document viable biomass. Blooms of hydrocarbon degraders that result from the introduction of hydrocarbons or nutrients, like fertilizers, are typically documented by methods that directly enumerate culturable degraders (plate counts) or hydrocarbon-degrading activity (assays of specific genes for enzymes involved in hydrocarbon biodegradation). PLFA is a measure of the total culturable and non-culturable biomass in the soil. The hydrocarbon-degrading component can be a small fraction of the total soil community. In a related study we documented a relationship between numbers of hydrocarbon-degraders as determined by plate counts and TPH but no such relationship existed between TPH and PLFA concentrations. In this related study the hydrocarbon degraders were only about $5 \%$ of the total soil community (Sublette et al., 2002).

Biodegradation of crude oil was modeled as a first order reaction and a linear regression on the natural logarithm of $[\mathrm{TPH}]$ versus time was performed for each site. First order rate constants were obtained from the slopes of these lines and estimates of initial TPH concentrations obtained from the intercepts at $t=0$. First order rate constants 
are given in Table 8. A statistical comparison of the slopes using a t test showed that there was no significant difference in the rate constants at the $95 \%$ confidence level. Therefore, treatment had no significant effect on the biodegradation of crude oil. However, TPH reduction clearly proceeded in the presence of brine contamination. The average half-life considering all impacted sites was 267 days.

\section{Treatment Effects in the Removal of Brine Components from Brine-impacted Sites}

Leaching of brine components from the brine-impacted sites was also modeled as a first order reaction and a linear regression on the natural logarithm of $\left[\mathrm{Na}^{+}\right]$or $\left[\mathrm{Cl}^{-}\right] \mathrm{vs}$. time was performed for each site (see Figure 4 for North as example). $\left[\mathrm{Na}^{+}\right]$and $\left[\mathrm{Cl}^{-}\right]$ concentrations used in this analysis were averaged across each site and over the entire 0$30 \mathrm{~cm}$ depth interval. No significant differences between the $\mathrm{Na}^{+}$and $\mathrm{Cl}^{-}$removal rate constants within the same sites were observed in any of the impacted sites. (North: $t=$ 0.44, Middle: $\mathrm{t}=0.046$, South: $\mathrm{t}=0.02, \mathrm{p}>0.02$ for all three). First order rate constants for the removal of brine components were compared between pairs of sites usinf a t test. Comparisons between north, the site with the highest rate of removal of brine components, and Middle, the site with the lowest rate, were significant at $\mathrm{p}<0.05$. Comparisons of North or Middle with South, the site with the intermediate rates of removal, were not significant at $\mathrm{p}<0.05$.

The purpose of gypsum as an amendment in the remediation of brine spills is to mobilize $\mathrm{Na}^{+}$by displacing $\mathrm{Na}^{+}$with $\mathrm{Ca}^{+2}$ in clay lattices. All of the impacted sites have clay concentrations in the range of $22.7-25 \%$. Evidently at this clay concentration the removal of $\mathrm{Na}^{+}$was not retarded by interaction with clay lattices since $\mathrm{Na}^{+}$and $\mathrm{Cl}^{-}$ leached at comparable rates. The first order rate constants for $\mathrm{Na}^{+}$and $\mathrm{Cl}^{-}$removal were 
significantly greater in the North site than in the Middle site at the $95 \%$ confidence level (Tables 8 and 9). $\mathrm{Na}^{+}$and $\mathrm{Cl}^{-}$removal rate constants were also greater in the North site than the South site at about the $90 \%$ confidence level. Rate constants for $\mathrm{Cl}^{-}$removal in the South and Middle sites were significantly different at the $80 \%$ confidence level. Rate constants for removal of $\mathrm{Na}^{+}$in the South and Middle sites were not significantly different.

As shown in Table 5 the North and South sites differed in fertilizer application rates. Nutrients $\left(\mathrm{NO}_{3}{ }^{-}-\mathrm{N}\right.$ and $\left.\mathrm{NH}_{4}{ }^{+}-\mathrm{N}\right)$ were monitored in all of the impacted sites and the control from March 2002 through August 2003 (Table 10). As seen in Table 10 the mean concentrations of these nutrients did not differ significantly in the impacted sites but all were greater than in the control during this period. Therefore, during the period of most significant rainfall (Figure 2) there was little difference between the North and South sites in terms of fertilizer nitrogen concentrations and there may have been significant transfer of nutrients from the North and South sites to the Middle site by wind during fertilizer application since the sites are so close together. It must also be noted that the study site is within the bison enclosure in the Tallgrass Prairie Preserve. Bare ground attracts bison, which leave manure and urine behind as sources of organic nitrogen in the soil that are converted to $\mathrm{NH}_{4}{ }^{+}$and $\mathrm{NO}_{3}{ }^{-}$by soil bacteria. Given these observations no conclusions as to the effect of fertilizer addition on the remediation process can be drawn.

The data suggest that the combination of hay addition, ripping, and an interception trench at the low end of the site (North) was superior to hay addition with ripping (South) or ripping alone (no hay amendment) and a downslope interception 
trench (Middle). Based on other work (unpublished data) we believe that the South and Middle sites may continue to diverge with time, more clearly delineating the effects of hay addition in this difficult remediation environment. However, it is clear that the interception trench at the bottom of the site had a pronounced effect on the rate of both $\mathrm{Na}^{+}$and $\mathrm{Cl}^{-}$leaching with the limited mixing of amendments that characterized this site. The trench may have acted to more effectively drain the North site resulting in greater infiltration rates following rainfall events and more effective transport of brine components. Subsurface drainage systems similar to the trench employed in this study have been shown to enhance the lateral subsurface transport of brine components during the remediation of historic brine scars (Weathers et al., 1994). The lack of a similar enhancement in the removal of brine components in the Middle site, which also employed a downslope interception trench, can be attributed to the absence of the hay amendment in this site and insufficient hydraulic conductivity.

The North site experienced a $73 \%$ reduction in salt inventory (total amount of salt in the $0-30 \mathrm{~cm}$ interval) in 36 months without the addition of gypsum and by August 2003 about one-third of the North site had re-vegetated with Bermuda grass and mixed forbs. In contrast very little re-vegetation was observed in the South and Middle sites and the 36-month reductions in salt inventory were $40 \%$ and $<3 \%$, respectively.

\section{CONCLUSIONS}

Three spills of crude oil plus produced water brine have been treated with combinations of ripping, fertilizers and hay amendments, and a downslope interception trench in an effort to demonstrate an inexpensive, easily implemented, effective remediation plan. The presence of brine components and loss of vegetation in the 
impacted sites resulted in lower concentrations of soil microbes growing at slower rates and experiencing greater stress than communities in an unimpacted control. However, over time microbial community structures originally impacted by brine approached those of the unimpacted control as salt was leached out of the site.

There was no effect of treatment on the biodegradation of crude oil. However, TPH reduction clearly proceeded in the presence of brine contamination. The average half-life considering all impacted sites was 267 days.

The combination of hay addition, ripping, and downslope interception trench was superior to hay addition with ripping, or ripping plus an interception trench in terms of rates of sodium and chloride leaching from the impacted sites.

From this study, the remediation of produced fluids spills with ripping (or tilling), hay and fertilizer addition, and an interception trench has been shown to be effective in bioremediation of the hydrocarbons and removal of brine components. This methodology can easily and inexpensively implemented by small independent oil and gas producers without hiring outside contractors and without the purchase, transportation, and spreading of gypsum. With access to a tractor and tiller and a local source of hay an

independent producer can remediate a one acre site for about $\$ 200$. Hiring a contractor to remediate the site with gypsum can cost ten times that amount. Neither of these cost estimates include the cost of an interception trench which would depend somewhat on the topography of the site. The interception trench is basically a French drain which can also be installed by the independent producer as needed.

\section{REFERENCES}

Fisher, J.B. and K.L. Sublette, 2005, Oil and Saltwater Releases from E\&P Operations in 
Oklahoma: Type, Volume, Causes, and Prevention: Environmental Geosciences, This volume.

Guckert, J.B., M.A. Hood, D.C. White, 1986, Phospholipid, ester-linked fatty acid profile changes during nutrient deprivation of Vibrio cholerae: Increases in trans/cis ratio and proportions of cyclopropyl fatty acids: Appl. Environ. Microbiol., v. 52, p. 794-801.

Harris, T.M., 1998, Brine impacted soils, remediation, in: Ed. R.A. Meyers, Encyclopedia of Environmental Analysis and Remediation: New York, John Wiley and Sons, p 823-829.

Robbins, C.W., 1986, Sodic calcareous soil reclamation as affected by different amendments and crops: Agron. J., v. 78, p. 916-920.

Sample, E.C., R.J. Roper, and G.J. Racz, 1980, Reactions of phosphate fertilizers with soil, in Eds. F.E. Khasawneh, E.C. Sample, and E.J. Kamprath, The Role of Phosphorous in Agriculture: Madison, WI, American Society of Agronomy, Chapter 11.

Sublette, K.L., R. Kolhatkar, K. Pim, A. Kolhatkar, K.E. Duncan, B. Miller, R. Fogg, P. Rider, A. Stepp, M. Carey, T. Todd, and A. Cross, 2002, Long-term impacts of a crude oil spill on a pristine soil ecosystem: Proceedings of the $25^{\text {th }}$ Arctic and Marine Oilspill Program Technical Seminar, Calgary, Alberta, Volume v. 2, p. 979-1011.

Weathers, M.L., K.R. Moore, D.L. Ford, and C.K. Curlee, 1994, Reclamation of saltwater contaminated soil in Big Lake Field: Transactions of the Gulf Coast Association of Geological Societies, v. 44, p. 737-743.

White, D.C., H.C. Pinkart, and D.B. Ringelberg, 1997, Biomass measurements: 
biochemical approaches, in: Eds. C.J. Hurst el at., Manual of Environmental Microbiology: ASM Press, Washington, D.C

Table 1. Soil textures at the brine and oil contaminated sites

Plot

North

Middle

South

Control
Sand(\%)

29.6

34.2

37.7

36.9
Silt(\%)

45.0

41.1

39.6

38.1

\section{$\operatorname{Clay}(\%)$}

25.4

24.8

22.7

25.0

Table 2. Approximate composition of oil spilled at the study site

\section{Component}

Aliphatics

$>\mathrm{C} 6$ to $\mathrm{C} 8$

$>\mathrm{C} 8$ to $\mathrm{C} 10$

$>\mathrm{C} 10$ to $\mathrm{C} 12$

$>\mathrm{C} 12$ to $\mathrm{C} 16$

$>\mathrm{C} 16$ to $\mathrm{C} 21$

$>\mathrm{C} 21$ to $\mathrm{C} 35$

Aromatics

$>\mathrm{C} 7$ to $\mathrm{C} 8$

$>\mathrm{C} 8$ to $\mathrm{C} 10$

$>\mathrm{C} 10$ to $\mathrm{C} 12$

$>\mathrm{C} 12$ to $\mathrm{C} 16$

$>\mathrm{C} 16$ to $\mathrm{C} 21$

$>\mathrm{C} 21$ to $\mathrm{C} 35$

* Remainder $>$ C35
\% by wt.*

0.5

7.5

8.7

18.8

15.3

16.7

trace

2.2

3.2

4.8

3.1

9.0 
Table 3. Estimated initial TPH concentrations in the brine impacted sites

$\begin{array}{ccc}\text { Site } & {[\mathrm{TPH}]_{\mathrm{o}}} & 95 \% \text { Confidence } \\ & (\mathrm{mg} / \mathrm{kg}) & \text { Intervals }\end{array}$

$\begin{array}{lll}\text { North } & 1300 & 130-13,000 \\ \text { Middle } & 5200 & 1040-27,700 \\ \text { South } & 2100 & 270-13,000\end{array}$

Table 4. Estimated initial $\mathrm{Na}^{+}$and $\mathrm{Cl}^{-}$concentrations in the brine impacted sites

\begin{tabular}{|c|c|c|c|c|}
\hline Site & {$\left[\mathrm{Na}^{+}\right]_{\mathrm{o}}(\mathrm{mg} / \mathrm{kg})$} & $\begin{array}{c}\text { 95\% Confidence } \\
\text { Intervals } \\
\text { (mg/kg) }\end{array}$ & {$\left[\mathrm{Cl}^{-}\right]_{\mathrm{o}}(\mathrm{mg} / \mathrm{kg})$} & $\begin{array}{l}\text { 95\% Confidence } \\
\text { Intervals } \\
(\mathrm{mg} / \mathrm{kg})\end{array}$ \\
\hline North & 1400 & $1,130-1,800$ & 2,600 & $1,600-4,160$ \\
\hline Middle & 1100 & $780-1,600$ & 1,600 & $1,030-2,500$ \\
\hline South & 1580 & $980-2,450$ & 3,000 & $2,100-4,200$ \\
\hline
\end{tabular}

Table 5. Amendments to the North and South lobes of the study site

Amendment North South

$\begin{array}{ccc}\text { Hay (equivalent small square bales)** } & 32-36 & 48-54 \\ \mathrm{NH}_{4} \mathrm{NO}_{3}(\mathrm{~kg}) & 90.7 & 45.4 \\ \mathrm{P}_{2} \mathrm{O}_{5}(\mathrm{~kg}) & 7.0 & 3.5 \\ \mathrm{~K}_{2} \mathrm{O}(\mathrm{kg}) & 3.7 & 1.5\end{array}$

* Native prairie hay in round bales was used. Approximate conversion to small square bales in provided (8-10 square small square bales per round bale). 
Table 6. Microbial parameters in impacted sites and the unimpacted control

\begin{tabular}{lcccc} 
& $\mathbf{N}$ & $\mathbf{M}$ & $\mathbf{S}$ & $\begin{array}{c}\text { Control } \\
\text { Prokaryote } \\
\text { PLFA }\end{array}$ \\
$\begin{array}{lccc}\text { Eukaryote } \\
\text { PLFA }\end{array}$ & $15,300 \pm 7600^{*}$ & $17,800 \pm 12,000$ & $17,800 \pm 8100$ & $34,000 \pm 23,000$ \\
Metabolic status & $3.98^{* *}$ & 3.61 & 3.68 & 2.91 \\
$\begin{array}{l}\text { Environmental } \\
\text { stress }\end{array}$ & $0.11^{* * *}$ & 0.10 & 0.09 & 0.04 \\
\hline
\end{tabular}

*PLFA: Phospholipid fatty acids (pmoles/g dry wt. soil)

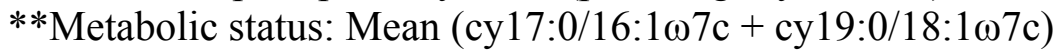

***Environmental stress: Mean $(16: 1 \omega 7 \mathrm{t} / 16: 1 \omega 7 \mathrm{c}+18: 1 \omega 7 \mathrm{t} / 18: 1 \omega 7 \mathrm{c})$

Table 7. Comparison of the microbial parameters, April 2001 - August 2003

\begin{tabular}{|c|c|c|c|c|}
\hline $\begin{array}{c}\text { Site } \\
\text { comparisons }\end{array}$ & $\begin{array}{l}\text { Prokaryote } \\
\text { PLFA }\end{array}$ & $\begin{array}{l}\text { Eukaryote } \\
\text { PLFA }\end{array}$ & $\begin{array}{l}\text { Metabolic } \\
\text { status }\end{array}$ & $\begin{array}{l}\text { Environmental } \\
\text { stress }\end{array}$ \\
\hline N-M & $0.45^{\mathrm{a}}$ & 1.05 & 0.95 & 0.34 \\
\hline $\mathrm{N}-\mathrm{S}$ & 1.26 & 1.12 & 0.52 & 1.26 \\
\hline M-S & 1.72 & 2.17 & 1.65 & 0.92 \\
\hline $\mathrm{N}-\mathrm{C}$ & $5.51^{* *}$ & $6.80^{* * *}$ & $11.00 * * *$ & $4.81^{*}$ \\
\hline $\mathrm{M}-\mathrm{C}$ & $5.96^{* *}$ & $7.85 * * *$ & $10.00 * * *$ & $4.47^{*}$ \\
\hline $\mathrm{S}-\mathrm{C}$ & $4.24 *$ & $5.68^{* *}$ & $11.51^{* * *}$ & 3.55 \\
\hline \multicolumn{5}{|c|}{$\begin{array}{l}\mathrm{N}-\mathrm{M} \text { is a comparison of the North and Middle sites; } \mathrm{C}=\text { unimpacted } \\
\text { control. Values for the site were compared using a Tukey-Kramer multiple } \\
\text { comparisons. } \\
\text { a } \mathrm{q} \text { values for Tukey-Kramer, } \mathrm{q}>3.9 \text { is equal to } \mathrm{p}<0.05 \\
{ }^{*} \mathrm{p}<0.05, * * \mathrm{p}<0.01, * * * \mathrm{p}<0.001 \\
\text { Prokaryote PLFA, eukaryote PLFA: comparison of means of } \\
\text { log-transformed values }\left(\log _{10} \text { pmoles/g dry wt soil) }\right. \\
\text { Metabolic status: (cy17:0/16:1 } \omega 7 \mathrm{c}+\mathrm{cy} 19: 0 / 18: 1 \omega 7 \mathrm{c}) \\
\text { Environmental stress: }(16: 1 \omega 7 \mathrm{t} / 16: 1 \omega 7 \mathrm{c}+18: 1 \omega 7 \mathrm{t} / 18: 1\end{array}$} \\
\hline
\end{tabular}


Table 8. First order rate constants for TPH biodegradation and removal of brine components in the brine impacted sites

Site $\quad \mathrm{TPH}$ removal $\left(\mathrm{day}^{-1}\right) \quad \mathrm{Na}^{+} \operatorname{removal}\left(\right.$ day $\left.^{-1}\right) \quad \mathrm{Cl}^{-}$removal $\left(\right.$day $\left.^{-1}\right)$

$\begin{array}{llcc}\text { North } & 2.0 \times 10^{-3 *} & 1.1 \times 10^{-3} & 1.3 \times 10^{-3} \\ \text { Middle } & 2.5 \times 10^{-3} & 3.0 \times 10^{-5} & 0 \\ \text { South } & 3.9 \times 10^{-3} & 5.0 \times 10^{-4} & 5.0 \times 10^{-4}\end{array}$

Table 9. Comparison of first order rate constants of $\mathrm{Na}^{+}$and $\mathrm{Cl}^{-}$removal between treatments

$$
\mathrm{Na}^{+} \text {removal } \mathrm{Cl}^{-} \text {removal }
$$

N-M

$3.51^{*}, \mathrm{p}<0.05$

$3.00, \mathrm{p}<0.05$

N-S

$1.7,0.10<\mathrm{p}<0.02$

$1.91,0.10<\mathrm{p}<0.02$

M-S

$0.95, \mathrm{p}>0.20$

$1.41,0.10<\mathrm{p}<0.02$

*Student's t-test

Table 10. Mean concentrations ( \pm std. dev.) of nitrate and ammonium nitrogen in the impacted and control sites over the period March 2002 through August 2003

$$
\mathrm{NO}_{3}{ }^{-}-\mathrm{N}(\mathrm{mg} / \mathrm{kg}) \quad \mathrm{NH}_{4}^{+}-\mathrm{N}(\mathrm{mg} / \mathrm{kg})
$$

$\begin{array}{lrr}\text { North } & 22.7 \pm 10.8 & 9.7 \pm 5.7 \\ \text { Middle } & 20.0 \pm 5.1 & 14.8 \pm 6.3 \\ \text { South } & 31.9 \pm 6.8 & 12.3 \pm 7.5 \\ \text { Control } & 2.2 \pm 1.4 & 8.1 \pm 4.4\end{array}$




\section{Figure captions}

Figure 1. Close-up photo of rocks in the South impacted site. Note ink pen for scale.

Figure 2. Monthly precipitation levels compared to historical normal precipitation from June 2000 through August 2003.

Figure 3. Cluster analysis of PLFA structural groups from samples taken from June 2000 through August 2003. Sites are designated by "N" (north), "M" (Middle), "S" (South), and "C" (Control, uncontaminated prairie). The sample month is indicated vertically underneath the site $(\mathrm{apr}=$ April, oct $=$ October, etc $)$, and the sample year is underneath the sample month (" $00 "=2000$, " $01 "=2001$, " $02 "=$ 2002 , “03” = 2003). The arrow indicates a cluster of similar samples taken April or September 2003.

Figure 4. Leaching of a) $\mathrm{Na}^{+}$and b) $\mathrm{Cl}^{-}$from the North site during remediation 


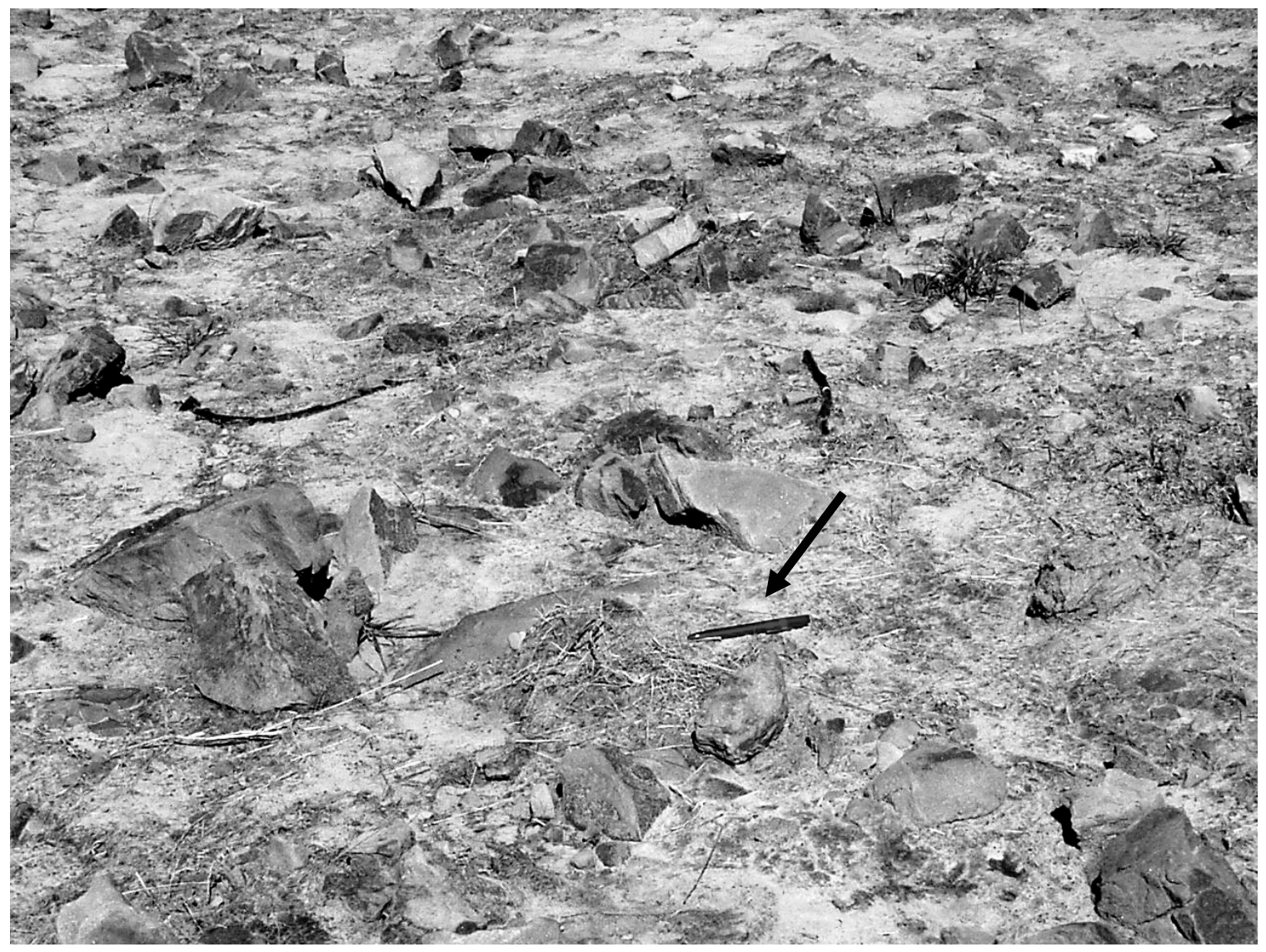

Fig. 1 


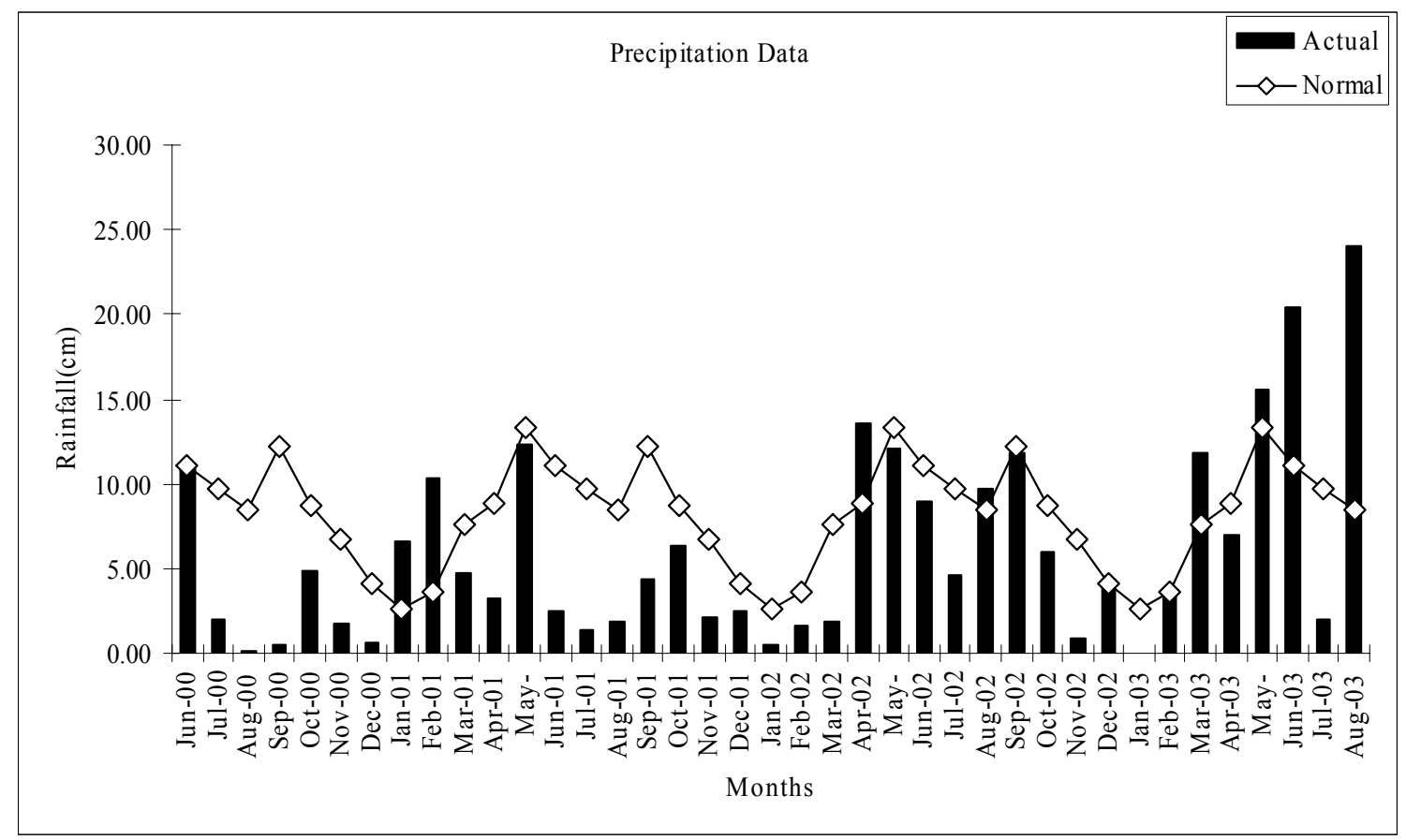

Fig. 2 


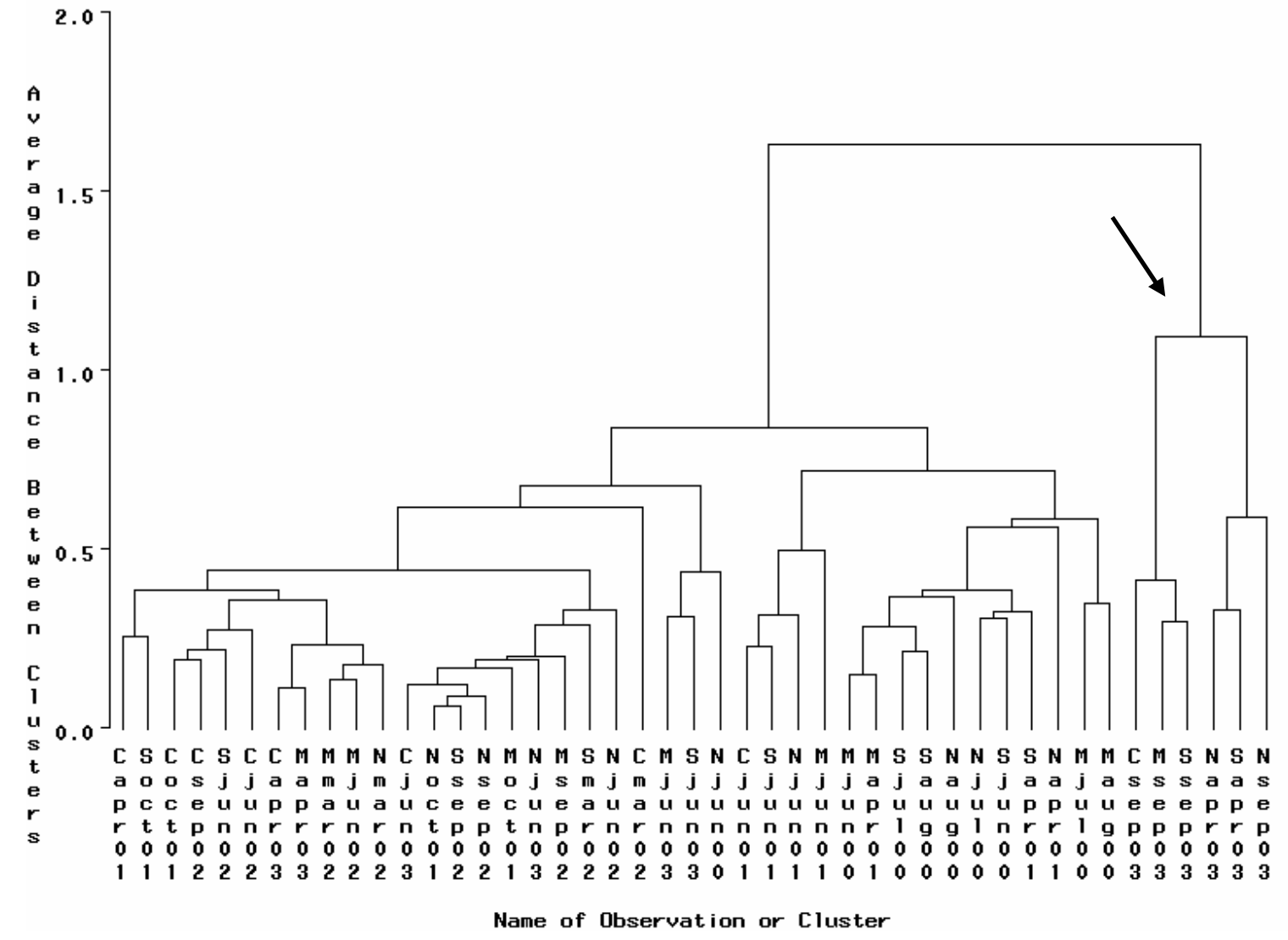

Fig 3. 
a)

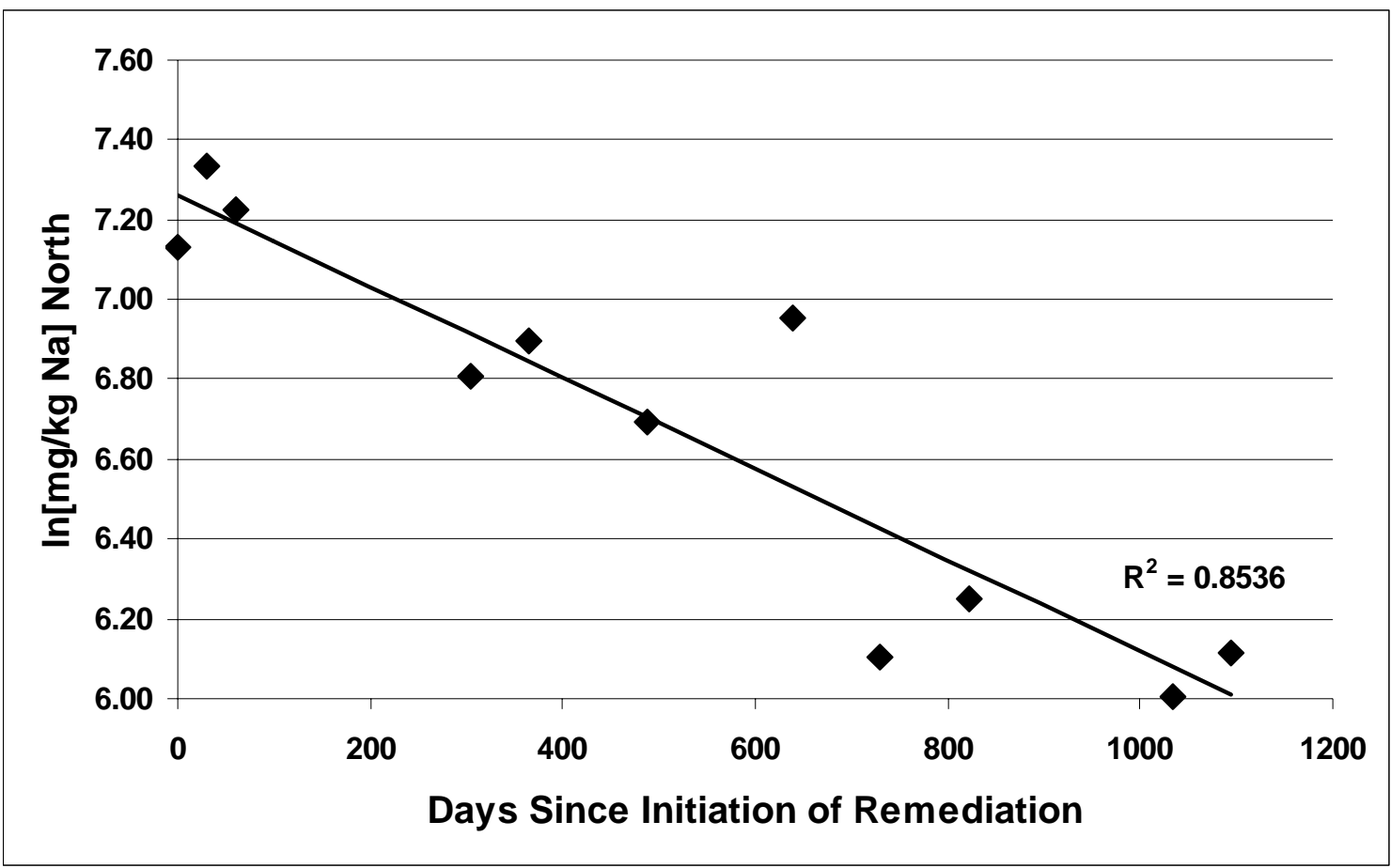

b)

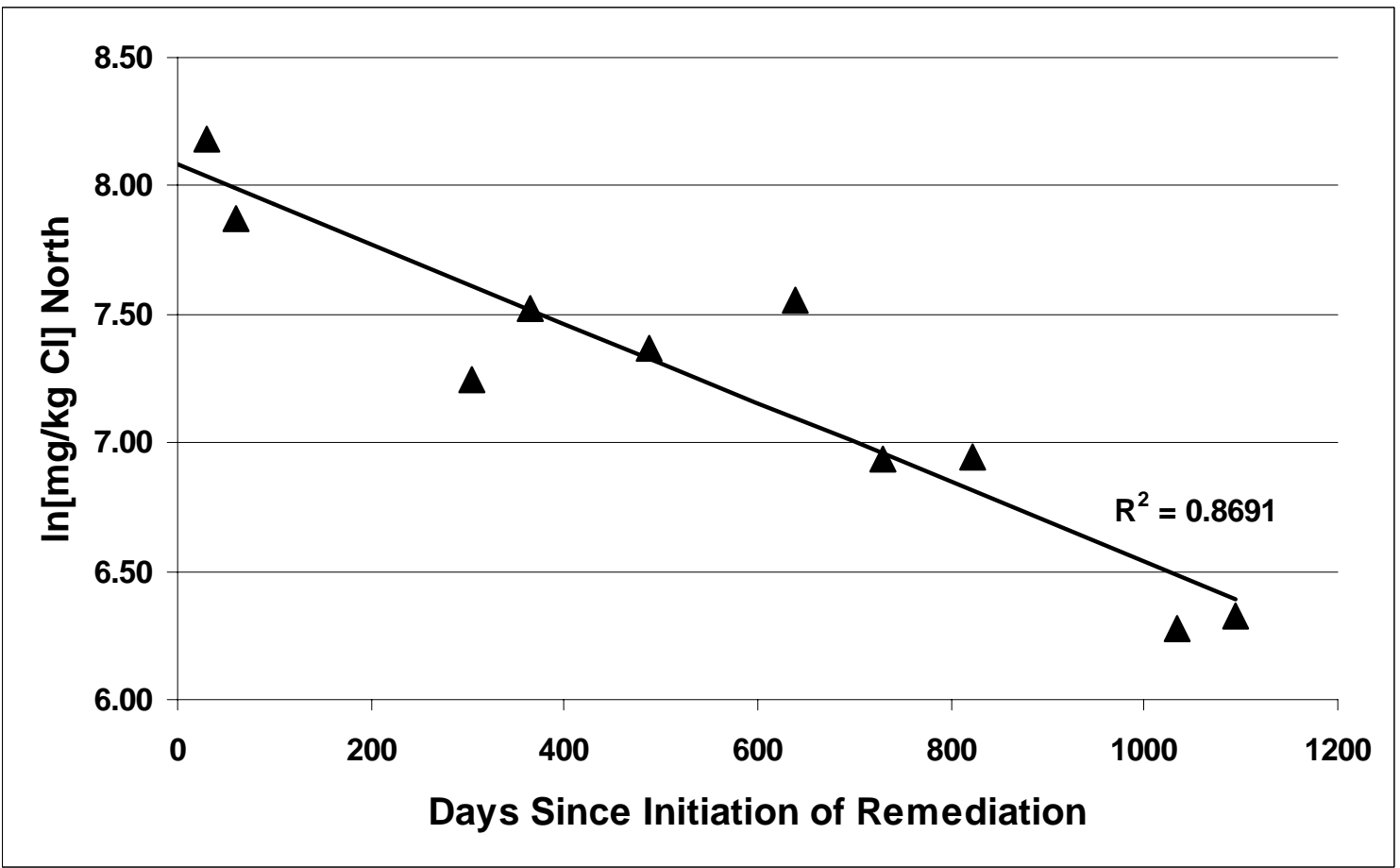

Fig 4.

Monitoring Soil Ecosystem Recovery Following Bioremediation of a Terrestrial Crude Oil Spill With and Without a Fertilizer Amendment 


\section{Chapter 2}

Chintan Mehta, Aditya Moralwar, Kerry Sublette*, Eleanor Jennings Center for Applied Biogeosciences

University of Tulsa

Kathleen Duncan

Dept. of Botany and Microbiology

University of Oklahoma

Joshua Brokaw

Oklahoma State University

Dept. of Botany

Tim Todd

Kansas State University

Dept. of Plant Pathology

Greg Thoma

University of Arkansas

Dept. of Chemical Engineering

* Corresponding author

600 S. College Ave.

Phone 9186313085

Fax: 9186313268

E-mail address: kerry-sublette@utulsa.edu

Key words: crude oil/bioremediation/soil microbiology/fertilizer/nematodes

Running Title: Monitoring Soil Ecosystem Recovery Following Bioremediation 


\begin{abstract}
The effect of fertilizer as an amendment in the bioremediation of a terrestrial crude oil spill has been investigated in terms of the subsequent recovery of the soil ecosystem following bioremediation. Two different spills in the same area with different initial hydrocarbon concentrations $\left(33,500 \mathrm{mg} \mathrm{kg}^{-1}\right.$ and 4,800 $\left.\mathrm{mg} \mathrm{kg}^{-1}\right)$ were compared. Fertilizer increased the rate of bioremediation resulting in the more rapid recovery of soil bacteria (numbers, community structure, diversity) and nematodes (trophic diversity and community structure). This effect was more significant at the higher initial concentration of crude oil hydrocarbons presumably due to greater depletion of soil nutrient pools in the absence of the fertilizer amendment. A second objective of this work was to identify sensitive ecological indicators useful in monitoring the recovery of soil ecosystems impacted by crude oil in a cost-effective manner. Ecological indicators used included microbial numbers, community structure, and activity as revealed by biomarker analysis (phospholipid fatty acids), nitrogen availability, nematode numbers and community structure, and ultimately plant community structure and diversity. All ecological indicators investigated were sensitive to disturbances in the soil food web in a hydrocarbon-impacted site; however, nematode community structure analysis offered the greatest sensitivity coupled with low cost and readily available sources for the analysis.
\end{abstract}

\title{
Introduction
}

Cost-effective remediation of recent terrestrial oil spills is within the grasp of most independent oil and gas producers who dominate domestic on-shore production in the U.S. outside of Alaska. However, the restoration of soil ecosystems following remediation and the effect of the remediation process on subsequent restoration efforts 
remain a mystery to most producers. For example, most producers know that soil microorganisms that can biodegrade the hydrocarbons found in crude oil are usually already present in soil and that the oil must be well mixed with the soil for effective remediation. However, all too often a producer will ignore the nutritional requirements of the microbes $(\mathrm{N}, \mathrm{P})$ in an effort to save money. This is sometimes referred to as the "natural attenuation" approach and requires hydrocarbon-degrading soil microbes to draw on soil nutrient pools to support hydrocarbon biodegradation. The effect that this may have on ultimate restoration of the soil ecosystem is not considered.

State and federal clean-up standards for contaminated soil and water began as technology-based standards. With the recognition that this approach led to a lot of money being spent on remediation that did little to actually protect society, risk-based standards based on human health were developed. Risk-based standards are now in the process of evolving into eco-based standards which intend to afford protection not only to human health but also to ecosystems. But how do you assess ecosystem damage and restoration in an oil and gas exploration and production environment? A lack of information on the ecological risk of oil spills can lead to overly conservative and unnecessarily costly eco-based regulations, or conversely, too little protection for ecosystems found to be extremely sensitive. The oil and gas industry, as well as state and federal regulators, need to be able to measure ecological risk and ecosystem recovery in a cost-effective manner that is also scientifically sound. Cost-effectiveness is not simply an economic issue for the industry, it is a requirement for achieving the goals of an ecobased regulatory system. Low-cost methods of ecosystem assessment will save the U.S. 
domestic petroleum industry precious resources which can be redirected to where the greatest need exists for repairing ecosystem damage.

In the work described here we have remediated a spill of crude oil on soil in an active oil-producing area of Osage County, Oklahoma using in situ landfarming, with and without a fertilizer amendment. A number of parameters were monitored, from nitrogen availability, soil microbiology (numbers, community structure, diversity), nematodes (numbers, trophic diversity, community structure), and ultimately plant community analysis and diversity during initial revegetation. The objectives of this work were twofold: 1) determine the effect of a fertilizer amendment on subsequent recovery of the soil ecosystem impacted by crude oil and 2) identify sensitive ecological indicators useful in monitoring the recovery of soil ecosystems impacted by crude oil.

\section{Site description}

In January 1999 a pipeline break resulted in a spill of approximately $11 \mathrm{~m}^{3}$ of dewatered crude oil in the Tallgrass Prairie Preserve (The Nature Conservancy) in Osage County, OK. Pooled crude oil retrieved from the site two days after the spill had the following composition: aliphatics (\% by wt.), $4 \% \mathrm{C}_{10}-\mathrm{C}_{12}, 28.7 \% \mathrm{C}_{12}-\mathrm{C}_{16}, 27.5 \% \mathrm{C}_{16}-\mathrm{C}_{21}$, $24.6 \% \mathrm{C}_{21}-\mathrm{C}_{35}$; aromatics, $4.8 \% \mathrm{C}_{12}-\mathrm{C}_{16}, 4.7 \% \mathrm{C}_{16}-\mathrm{C}_{21}, 5.5 \% \mathrm{C}_{21}-\mathrm{C}_{35}$. The immediate effect of the spill was contamination of a $930-\mathrm{m}^{2}$ area (designated $\mathrm{J} 6 \mathrm{~N}$ ) of once-pristine, tallgrass prairie grassland on a gentle slope. As crude oil flowed over the site it ultimately entered a lease road where it continued to flow in a gulley until re-entering pristine prairie about $100 \mathrm{~m}$ away. Thus an additional $450 \mathrm{~m}^{2}$ of grassland (designated J6S) was contaminated before the pipeline break could be isolated and the spill stopped. J6N has a slope of $4.5 \%$ and average soil texture of $30 \%$ sand, $51 \%$ silt, and $19 \%$ clay. 
The soil on this site is a complex mixture of the Coweta series and Bates series soils. The Coweta series soils are formed in material weathered from sandstone under a cover of grasses, are well-drained, and have moderate permeability. Available water capacity is low. The Bates series soils are also formed in material weathered from sandstone under a cover of grasses and are similar to the Coweta series in permeability but exhibit better moisture retention (Soil Survey of Osage County, Oklahoma).

J6S has a slope of $4.8 \%$ and an average soil texture of $29 \%$ sand, $37 \%$ silt, and $33 \%$ clay. The soil found on this site is in-between the boundary of the Coweta-Bates complex and the Steedman-Coweta complex, with the Steedman-Coweta complex in the downslope area. The Steedman soils are formed in material weathered from shales interbedded with thin layers of sandstone under a cover of grasses. The Steedman soils are well drained to moderately well drained and have slow permeability. Available water capacity is medium (Soil Survey of Osage County, Oklahoma).

Being nearest the source the larger impacted site $(\mathrm{J} 6 \mathrm{~N})$ had the highest initial Total Petroleum Hydrocarbon (TPH) concentration (EPA 418.1) of about 33,500 mg/kg (dry wt. basis) when remediation was initiated (following tilling). The smaller secondary site (J6S) had an initial TPH concentration of about 4,800 mg/kg.

The natural vegetation in this tallgrass prairie ecosystem consists of a mixture of plant species such as big bluestem (Andropogon gerardii), little bluestem (Schizachyrium scoparium), Indian grass (Sorghastrum nutans), and switch grass (Panicum virgatum). Historically, the tallgrass prairie ecosystem in this area has never been plowed and used only for grazing and ranching purposes. As a result very few exotic plant species have grown here compared to the other tallgrass prairie ecosystems in the North America. 
Historically, grazing by bison and periodic fire shaped and sustained the growth of these native grasses and prevented the encroachment of trees. Today, The Nature Conservancy employs bison and cattle grazing as well as random burning to recreate a pre-settlementtype prairie landscape in the Tallgrass Prairie Preserve.

\section{Materials and Methods}

\section{Remediation Protocol}

Both of the impacted sites were divided in half with buried $(50-\mathrm{cm})$ corrugated PVC sheeting to isolate the fertilized (downslope) and unfertilized (upslope) sections of J6N and J6S. To improve soil permeability and retain moisture, initially there was a one-time addition of prairie hay in May 1999. About 5.4 small square bales of hay per $100 \mathrm{~m}^{2}$ were applied on all impacted areas of J6N and J6S. Each small square bale corresponded to about $38.6 \mathrm{~kg}$ of native prairie hay. Beginning in May 1999 fertilizers were added with tilling (to a depth of $15 \mathrm{~cm}$ ) to the fertilized sections of both impacted sites in four increments over two years to give an overall C:N:P:K weight ratio of 100:1:0.2:0.2. Concentrations of hydrocarbon carbon were assumed to be $80 \%$ of the $\mathrm{TPH}$ concentration. The fertilizers used were ammonium nitrate $\left(\mathrm{NH}_{4} \mathrm{NO}_{3}\right)$, diphosphorus pentoxide $\left(\mathrm{P}_{2} \mathrm{O}_{5}\right)$ and potassium oxide $\left(\mathrm{K}_{2} \mathrm{O}\right)$. The last application of fertilizer was in April 2001. The last tilling event (no addition of fertilizer) was October 2001. When fertilizer was added to the downslope sections of J6N and J6S the upslope unfertilized sections were also tilled. Natural rainfall was the only source of moisture. The average annual rainfall in this area is $91 \mathrm{~cm}$ occurring mostly in the spring and fall. Actual rainfall amounts were monitored by a weather station located in the Preserve. The 
fertilized and unfertilized sections of J6N and J6S were designated as follows: J6N-F, J6N-NF, J6S-F, and J6S-NF.

Two types of controls were used in this project as target soil ecosystems. One was a $430-\mathrm{m}^{2}$ section of pristine tallgrass prairie that was tilled but not fertilized. This control was designated J6C. Hay was added to this section at the same loading rate as the impacted sites in May 1999 with tilling. Subsequently, when the impacted sites were tilled or tilled and fertilized J6C was only tilled. $\mathrm{J} 6 \mathrm{C}$ was located just $30 \mathrm{~m}$ from $\mathrm{J} 6 \mathrm{~N}$, had very little slope, and had an average soil texture of $31 \%$ sand, $45 \%$ silt, and $24 \%$ clay. The second type of control or target soil ecosystem was unimpacted, native tallgrass prairie. Two areas of native prairie were used, one $20 \mathrm{~m}$ from J6N and one $20 \mathrm{~m}$ from J6S. These are designated here as J6N-NP and J6S-NP. The soils in J6N, J6C, and J6N-NP were all similar. The soil in J6S-NP was comparable to J6S.

\section{Sampling and Analytical}

All impacted and non-impacted sites were sampled three times a year (spring, summer, and fall) starting in May 1999 and concluding in October 2003. All samples consisted of 5-fold composites taken in the $0-15 \mathrm{~cm}$ interval. Samples were analyzed for a number of parameters including soil moisture, nitrogen availability, TPH, soil microbiology (numbers, community structure, diversity in terms pf phospholipids fatty acid (PLFA) analysis), nematodes (numbers, trophic diversity, community structure), and ultimately plant community structure and diversity following initial revegetation. Nitrogen availability was analyzed only after tilling was concluded in October of 2001.

Soil moisture was determined gravimetrically following drying at $105{ }^{\circ} \mathrm{C}$ overnight. TPH samples were shipped by overnight delivery service (on ice) in 
completely-filled glass jars with Teflon ${ }^{\circledR}$-lined lids to Continental Laboratories (Salina, KS) for analysis by extraction with Freon and measurement of IR absorption (EPA 418.1).

All nitrogen analysis was done by the Soil, Water and Forage Analytical Laboratory at Oklahoma State University (Stillwater, OK). Soil samples were immediately stored on ice in the field and transported back to the laboratory for analysis. Soils were stored at $4{ }^{\circ} \mathrm{C}$ and extracted within $48 \mathrm{hrs}$ with $2 \mathrm{M} \mathrm{KCl}$ for inorganic nitrogen analysis as described by Maynard and Kalra (1993). After centrifugation and filtering extracts were analyzed by the using the cadmium reduction method for nitrate-nitrogen (EPA, 1979). Ammonium-nitrogen was analyzed by the same laboratory using the salicylic acid method (EPA, 1979). Nitrogen mineralization potential was determined by bringing $25 \mathrm{~g}$ of soil to an estimated field-capacity (Cassel et al., 1986) with deionized water in a $50-\mathrm{mL}$ beaker in the bottom of a $500-\mathrm{mL}^{-M_{a s o n}{ }^{\circledR}}$ jar. A glass vial containing $5.0 \mathrm{~mL}$ of $2.0 \mathrm{~N} \mathrm{NaOH}$ was also placed in the vial to serve as a trap for $\mathrm{CO}_{2}$ respired by soil microbes (Schimel, 1986). The Mason ${ }^{\circledR}$ jars were then incubated at $25^{\circ} \mathrm{C}$ for $30 \mathrm{~d}$ in the dark. After $30 \mathrm{~d}$, soils were extracted with $2.0 \mathrm{M} \mathrm{KCl}$ solution as described above. The net nitrogen mineralization rate was calculated as the difference between the initial and the incubated values (Vinton and Burke, 1995). All nitrogen availability data were obtained from March 2002 through October 2003 after tilling had ceased.

Phospholipid fatty acids are found within the membranes of all living cells but decompose quickly upon cell death. Thus, measuring PLFA content provides a quantitative measure of the viable microbial biomass present and includes both culturable and nonculturable bacteria and fungi (Balkwill et al., 1988; White and Ringelberg, 1995 
and 1998). To relate the complex mixture of phospholipid fatty acids to community structure, a structural group interpretation was employed (Dowling et al., 1986; Tunlid and White, 1992). Composite soil samples for PLFA analysis were taken in sterile Whirl-pak ${ }^{\mathrm{TM}}$ bags, packed in ice, and shipped overnight to Microbial Insights, Inc. (Rockford, TN) for analysis. The PLFA method extracts "signature" lipid biomarkers with organic solvents from within the cell membranes and cell walls of soil microbes. Extracted lipids are fractionated by silica acid column chromatography into neutral lipids, polar lipids, and glycolipids. Mild alkaline methanolysis transesterifies polar lipids to fatty acid methyl esters (FAME), which are then analyzed by gas chromatography-mass spectroscopy (GC/MS) to identify the individual fatty acids (Tunlid and White, 1992; White and Ringelberg, 1995 and 1998). Relative proportions of different fatty acids identified were documented as picomoles of PLFA per g dry wt. of soil.

For the analysis of nematode community structure, two five-fold composite samples were taken from each impacted plot, the tilled control, and both native prairie controls, packed in 4-L Ziploc ${ }^{\circledR}$ bags, placed on ice, and shipped overnight to Kansas State University for nematode analysis. Nematodes were extracted from $100-\mathrm{cm}^{3}$ subsamples of soil using a standard centrifugal-flotation procedure (Jenkins, 1964). The soil was suspended in $3.8 \mathrm{~L}$ of water, settled for $1 \mathrm{~min}$ and poured through a $38-\mu \mathrm{m}$ pore sieve. Sievings were washed into a $50-\mathrm{mL}$ centrifuge tube and a layer of $45 \%$ sucrose injected at the bottom of the tube. Following centrifugation at $1800 \mathrm{rpm}$ for $1 \mathrm{~min}$, the suspended nematodes were recollected on a $38-\mu \mathrm{m}$ pore sieve for counting. Nematodes were identified to genus or family taxanomic levels based on characters discernible at $\times 100$ magnification, and assigned to a trophic group (e.g. herbivore, fungivore, 
microbivore, omnivore, predator) based on reported feeding behavior (Yeates et al., 1993) and to a colonizer-persister (c-p) class (Bongers, 1990; Bongers et al., 1998; Bongers and Bongers, 1994). Nematode sampling began in April 2001.

Plant community structure and diversity were determined in all test plots in July 2003. Plant species abundance was quantified by estimating percent cover (Palmer et al., 2002). Nomenclature for plant species follows Diggs et al. (1999). Shannon's diversity index and evenness were calculated from plant cover data (Hartnett and Fay, 1998). Statistical analysis

All statistical analyses (except principal component analysis) were done using Statistica Version 7.0 (StatSoft, Tulsa, OK). Independent $t$ tests were used for comparison of means of pairs of data sets. Temporal data sets were analyzed using repeated measures ANOVA with Tukey HSD post-hoc test for significance and homogenous groups (Winer et al., 1991). Slope comparisons used a univariate test of significance of slopes (ANOVCA). For the purpose of analysis certain data were blocked based on whether tilling was still occurring (the remediation phase) or tilling had ceased (the restoration phase). The remediation phase then represented data collected through October $2001(\mathrm{~N}=7)$ and the restoration phase represented data collected after this date $(\mathrm{N}=6)$.

Principal component analyses (PCA) of PLFA data based on fatty acid structural groups were conducted using SPSS ${ }^{\circledR}$ statistical software. Structural groups used were terminally branched saturated fatty acids (TerBrSats), mid-branched saturated fatty acids (MidBrSats), branched monoenoics (BrMonos), (C16 monoenoic fatty acids + cy 17:0), 
(C18 monoenoic fatty acids + cy19:0), normal saturated fatty acids (nSats), and polyunsaturated fatty acids (Polys).

\section{Results and Discussion}

\section{TPH removal}

Figure 1 shows the TPH concentrations over time in the J6N impacted sites. TPH concentrations in J6N-F were significantly below $2,500 \mathrm{mg} / \mathrm{kg}$ by June 2001 . This is lower than the regulatory requirement of $10,000 \mathrm{mg} / \mathrm{kg}$ for a low-risk site in Oklahoma (Oklahoma Corporation Commission, 2002). J6N-NF appeared to take somewhat longer to reach comparable levels. Modeling the biodegradation of hydrocarbons as a first-order

reaction yielded rate constants of 0.0033 days $^{-1}(\mathrm{~J} 6 \mathrm{~N}-\mathrm{F})$ and 0.002 days $^{-1}(\mathrm{~J} 6 \mathrm{~N}-\mathrm{NF})$. A statistical comparison of the slopes of plots of $\ln [\mathrm{TPH}]$ vs. time showed that the slopes (i.e, the rate constants) were significantly different at only $p<0.2$. Similar treatment of TPH data from J6S showed that TPH levels were below $2500 \mathrm{mg} / \mathrm{kg}$ by April 2001 in both the fertilized and unfertilized plots. Rate constants for TPH biodegradation in J6S-F $\left(0.0023\right.$ days $\left.^{-1}\right)$ and J6S-NF (0.0020 days $\left.{ }^{-1}\right)$ were not significantly different.

\section{Nitrogen availability}

Direct measures of nitrogen availability include inorganic nitrogen concentrations and nitrogen mineralization rates. Nitrate concentrations during the restoration period are shown in Figure 2. J6C received a one-time addition of hay that was tilled into the soil along with existing vegetation, followed by repeated tilling when other test plots were tilled. The initial influx of this organic matter likely resulted in net immobilization of nitrogen as microbes degraded the new nutrients and increased microbial biomass. During the first year of the remediation period (June 1999 - July 2000) there was an 
increase in microbial biomass (in terms of total PLFA) detected in J6C. However, as will be discussed subsequently, temporal trends in PLFA concentration were difficult to interpret due to a strong dependence on soil moisture. As readily bioavailable nutrients were consumed, degradation of the microbial biomass likely resulted in a period of net mineralization and increased levels of inorganic nitrogen. Disturbances such as tilling can also result in periods of rapid mineralization. The overall result was elevated nitrate$\mathrm{N}$ concentrations in $\mathrm{J} 6 \mathrm{C}$ compared to native prairie for some time after tilling ceased. Nitrate-N concentrations became comparable to native prairie in June 2003, twenty months after the last tilling event reflecting the long-term effects of tilling on soil nitrogen pools.

Concentrations of nitrate- $\mathrm{N}$ were significantly higher $(\mathrm{p}<0.05)$ in the fertilized section of J6N (J6N-F) than in all other test plots or native prairie until October 2003. At this time nitrate- $\mathrm{N}$ concentrations in all plots were approaching those of the native prairie (J6N-NP) and levels within J6N-F and J6N-NF became comparable to one another. The nitrate levels in J6N-F were likely a result of fertilizer addition and possibly the subsequent mineralization of the microbial biomass which used this fertilizer to support the biodegradation of hydrocarbons although a temporal decrease in PLFA concentration in J6N-F could not be confirmed during this time period.

Nitrate-N concentrations in J6N-NF were initially (March 2002) quite low, perhaps reflecting the slower (in comparison to J6N-F) biodegradation of hydrocarbons and the unmet nitrogen demand of the hydrocarbon-degrading microbes. After March 2002, nitrate-N concentrations in J6N-NF rebounded in the warm summer of 2002 before following the pattern of general nitrate- $\mathrm{N}$ reduction over time that was seen in all test 
plots. After June 2002, nitrate-N concentrations in J6N-NF were either comparable to or even significantly higher $(\mathrm{p}<0.05)$ than levels in the fertilized section of J6S. This could have been due to the mineralization of a large pool of hydrocarbon degraders in late 2002 and 2003. A large population would be reflective of the high concentrations of hydrocarbons originally present in J6N-NF in comparison to J6S-F. Throughout most of the restoration phase levels of nitrate- $\mathrm{N}$ in J6N-NF were not significantly different $(\mathrm{p}<0.05)$ from J6C in terms of nitrate-N. Both of these plots received a large influx of organic matter with large $\mathrm{C}: \mathrm{N}$ ratios (about 400:1 for crude oil and 30:1 for hay) without receiving any fertilizer additions.

Nitrate-N was significantly lower $(\mathrm{p}<0.05)$ in J6S-NF than J6C in most cases although J6S also received an input of organic matter (hay + hydrocarbon) without fertilizer. However, the hydrocarbon impact in J6S was much lower than in J6N. Nitrate-N concentrations in J6S-F were significantly higher $(\mathrm{p}<0.05)$ than in J6S-NF only until October 2002 and were comparable thereafter. Overall nitrate-N concentrations in all fertilized and/or tilled plots decreased with time but did not become comparable to levels found in native prairie until two years or more after the last tilling event. This decrease over time is attributed to nitrate losses by wash out, denitrification, and utilization by plants (revegetation began in March 2002 following cessation of tilling in the previous fall).

Although no seasonality could be discerned in nitrate-N concentrations, ammonium-N concentrations in native prairie were seen to be highest in spring and fall and lowest in the mid-growing season. Except for J6N in March 2002, fertilized and non-fertilized sections of both J6N and J6S were generally comparable to one another 
throughout this period. Seasonal effects were evident. Mean seasonal ammonium-N concentrations ( $\mathrm{mg} / \mathrm{kg}$, considering all plots and native prairie) were: spring, $6.04 \pm 2.92$; summer, $3.03 \pm 2.26$; fall, $4.73 \pm 1.90$.

At each sampling time nitrogen mineralization rates were observed to be comparable in all plots and native prairie with one exception, J6N-NF in 2002. During 2002 mineralization rates (Table 1) in J6N-NF were significantly lower than in J6N-F. ( $<<0.07$ in June, $p<0.05$ in March and October). In spring and fall of that year a net immobilization of nitrogen was observed in J6N-NF. It appears that microbes in J6NNF microbes were still degrading a large carbon inventory with large C:N ratio in 2002. This is consistent with TPH data given in Figure 1. It should be noted that TPH measurements by EPA Method 418.1 were not available after March 2002 due to the phasing out of Freon use by Continental Laboratories. A replacement TPH measurement (EPA Method 1664) was found to not be comparable to 418.1; however, the new method did show higher concentrations of hydrocarbons in J6N-NF than J6N-F through 2002.

In summary, tilling alone clearly had a significant effect on nitrogen availability as has been previously reported for no-till vs. plowed agricultural systems (Hendrix et al., 1986). Superimposed on the tilling effects were the effects of an influx of biodegradable organic matter, hay and vegetation (in the case of J6C) and hay and crude oil (in the case of J6N and J6S). In J6N, the large influx of crude oil resulted in a decrease nitrogen availability during 2002 in the absence of supplemental nitrogen fertilizer. This effect was not as significant in J6S (initially $4800 \mathrm{mg} / \mathrm{kg}$ ) due to the lower hydrocarbon concentrations compared to J6N (initially $33,500 \mathrm{mg} / \mathrm{kg} \mathrm{TPH}$ ). It is likely that the reduced nitrogen availability was due to an increase in the $\mathrm{C}: \mathrm{N}$ ratio and not to a toxic 
effect of hydrocarbons on the microbial community. A similar response, e.g. an increase in the microbial biomass and a decrease in nitrogen mineralization, producing reduced nitrogen availability, was observed when excess carbon in the form of sawdust was added to recently restored tallgrass prairie soils (Baer et al., 2003).

\section{PLFA analysis}

Mean soil moisture levels at the time of sampling in all impacted plots and controls are shown in Table 2. Although there was no significant difference in mean values $(p=0.41, N=13)$ during the course of the project there were variations of $\pm 20-25 \%$ over time in any given plot. As a result temporal trends in PLFA concentrations in the different sites were difficult to interpret because of the strong influence of soil moisture on numbers of soil microbes (positive linear correlation, $\mathrm{r}=0.4, \mathrm{p}<0.05, \mathrm{~N}=65$ overall and $\mathrm{r}=0.6, \mathrm{p}<0.05, \mathrm{~N}=35$ while tilling was still occurring). At any given sampling time the soil moisture levels in the different plots were comparable. In an effort to limit the effect of soil moisture and differentiate between treatments, total PLFA concentrations were analyzed using a repeated measures ANOVA which takes into account the relatedness (soil moisture) of PLFA concentration measurements at the time of sampling. Results are shown in Table 3. During the remediation phase the total PLFA concentration in J6S-F was seen to be significantly lower than in J6N-NP. Total PLFA concentrations in all other plots were not significantly different from each other or J6NNP. During the restoration phase total PLFA concentrations in J6N-NF and J6S-NF were significantly lower that J6N-P or J6S-NP in 2002. In 2003 the total PLFA concentration in J6N-NF was significantly different from only that in J6N-NP. In both years the total PLFA concentration in the tilled control (J6C) was not significantly different from that 
found in any other plot or native prairie control. Using total PLFA concentration as an ecological indicator, the impact of the biodegradation of a large influx of hydrocarbon without a fertilizer amendment was only discernible in comparison to native prairie. These observations led to the conclusion that total PLFA concentration lacked the desired sensitivity as an ecological indicator or measure of the impact of disturbance on a soil ecosystem.

Several other attributes of the PLFA data were also investigated to compare different plots within each treatment phase (remediation or restoration). Datasets collected at the same sampling times were analyzed using repeated measures ANOVA. These parameters included Shannon's diversity index based on individual fatty acids, relative proportions of different PLFA structural groups, and indicators of metabolic status. During the remediation period Shannon's diversity index was negatively correlated with soil moisture (linear $\mathrm{r}=0.65, \mathrm{p}<0.05, \mathrm{~N}=43$ ) while during the restoration phase diversity negatively correlated with time (linear $\mathrm{r}=0.62, \mathrm{p}<0.05, \mathrm{~N}=$ 42).

During the remediation phase when plots were periodically tilled and TPH concentrations were relatively elevated, increases in soil moisture made nutrients more accessible. Thus soil microbes could more efficiently compete for nutrients leading to a decrease in diversity. Lower soil moistures helped maintain a variety of environmental niches where less competition led to increased diversity. However, when TPH concentrations were reduced and the plots were no longer tilled, the effect of soil moisture on diversity was no longer discernible. The negative correlation with time during the restoration phase could be due to the absence of the major oxygen infusions 
that had occurred with tilling. As microenvironments in soil aggregates became more anaerobic, diversity declined. When the two phases of treatment were compared using an independent $\mathrm{t}$ test it was seen that Shannon's diversity indices in impacted plots were higher during the restoration phase $(3.13 \pm 0.14)$ than in the remediation phase $(2.95 \pm$ $0.17)$ reflecting the reduced effect of hydrocarbon on diversity $(\mathrm{N}=35, \mathrm{p}=0.00005)$.

Table 4 gives the mean relative proportions of branched fatty acids with all impacted plots in the remediation phase and restoration phase. Terminally branched fatty acids (TerBrSats) and branched monoenoic fatty acids (BrMonos) are commonly associated with anaerobes, while in a soil environment mid-branched saturated fatty acids (MidBrSats) are generally associated with Actinomycetes (White and Ringelberg, 1995 and 1998). In order to understand the differences seen between plots it is instructive to first look at the differences between phases (i.e., remediation vs. restoration). When all oil-impacted plots and the tilled control within each phase were considered as one sample set and the remediation and restoration phases then compared for significant differences using an independent $t$ test, it was observed that the proportions of TerBrSats and MidBrSats in the restoration phase were significantly higher than in the remediation phase $($ TerBrSats as $\%$ of total PLFA, $21.8 \pm 4.2$ vs $17.5 \pm 3.0, \mathrm{p}=0.00001, \mathrm{~N}=35$; MidBrSats $14.2 \pm 3.9$ vs $9.9 \pm 4.6, \mathrm{p}=0.00015, \mathrm{~N}=35$ ). Differences in proportions of BrMonos were less significant, $4.5 \pm 0.53$ in the restoration phase vs. $4.0 \pm 1.4$ in the remediation phase $(\mathrm{p}=0.14, \mathrm{~N}=35)$. The picture that emerges is one of more microaerophilic/anaerobic activity in the restoration phase. This reflects oxygen diffusion limitations in soil aggregates (no more tilling events) and perhaps a greater proportion of available carbon and energy sources being amenable to anaerobic 
biodegradation including products of partial hydrocarbon biodegradation, fermentable substrates from decaying microbial biomass, and humic substances. Increases in proportions of MidBrSats during the restoration phase also indicate a change in the principal carbon sources in the soil. Actinomycetes are particularly associated with the decomposition of macropolymers such as bacteria, fungal, and plant cell walls. An increase in the proportion of MidBrSats in the restoration phase could also be due to decomposition of the microbial biomass that resulted from the degradation of hydrocarbons, hay, and vegetation.

Comparing different plots within each phase of treatment using a repeated measures ANOVA we see that proportions of TerBrSats within the remediation phase were lowest at the higher hydrocarbon concentrations (J6N-F and J6N-NF) and at the lower hydrocarbon concentration in the absence of fertilizer (J6S-NF) (Table 4). This reflects more sustained aerobic hydrocarbon biodegradation activity throughout this period. In the restoration phase the proportions of TerBrSats increased in each plot compared to the remediation phase but the statistical relationship between the different impacted plots remained the same. The lower proportions of TerBrSats in J6N-F and J6N-NF (with the greatest hydrocarbon impact) and J6S-NF (less hydrocarbon impact but no fertilizer amendment) suggest continuing hydrocarbon biodegradation in these plots. Proportions of MidBrSats were significantly lower $(\mathrm{p}<0.05)$ in J6N-NF during both the remediation and restoration phases. This may reflect a difference in proportions of Actinomycetes. With large amounts of highly degradable carbons sources available (i.e., hydrocarbons) the Actinomycetes would be less competitive for resources since their growth rate is typically less than that of hydrocarbon degraders such as Pseudomonas sp. 
There was an increase in proportion of MidBrSats as the remediation phase progressed into the restoration phase, but proportions of MidBrSats were still significantly lower in J6N-NF during the restoration phase. Thus the influx of organic matter was not processed as quickly in J6N-NF as in J6N-F.

These trends in the proportions of branched fatty acids were also evident in the results of the principal component analysis of J6N data based on fatty acid structural groups. In Figure 3 lower values of Factor 1 were associated with higher proportions of MidBrSats and TerBrSats while higher values were associated with higher proportions of (C16 monoenoics + cy17:0) and nSats. The lowest proportion of these branched fatty acids was seen early in the remediation phase in 1999-2000. Later in the remediation phase (2001) the proportions of these branched fatty acids increased in J6N-F and J6C while levels in J6N-NF lagged. Proportions of these branched fatty acids increased in J6N-NF in early restoration (2002) but were still lower than those found in J6N-F and J6C. In the later restoration phase (2003) there was an increase in Factor 2. Higher values of Factor 2 were associated with increased proportions of BrMonos and (C18 monoenoics + cy19:0). Except for J6N-NF the higher values of Factor 2 were associated with only the October 2003 sampling and primarily due to increased proportions of cy19:0. The 2003 fall sample was taken later in the month $\left(22^{\text {nd }}\right)$ than previous fall samples $\left(1^{\text {st }}-14^{\text {th }}\right)$. As will be discussed subsequently higher proportions of cy 17:0 and cy19:0 are often associated with slower microbial growth. Perhaps the results of this late sampling were indicative of the onset of dormant conditions in the plant communities. A similar principal component analysis of data from the J6S site showed similar trends over time (data not shown) including the increase in Factor 2 in October 2003. The only 
exception in comparison to J6N was that there was very little separation between J6S-F and J6S-NF throughout the remediation and restoration phases.

When the growth rates of certain Gram-negative bacteria slow due to nutrient limitations and the organisms enter into stationary growth phase, this transition is often marked by the conversion of certain membrane phospholipids fatty acids such as $16: 1 \omega 7 \mathrm{c}$

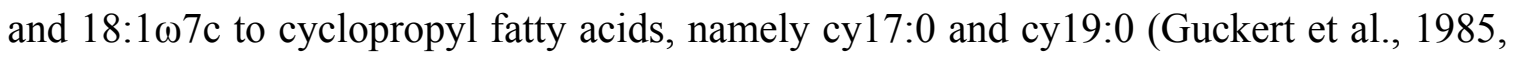

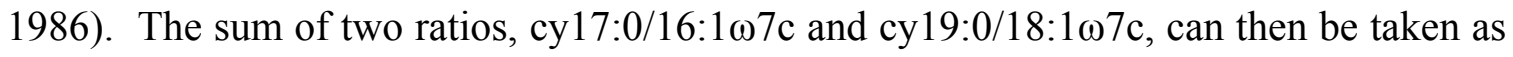
an indicator of metabolic status. The ratio is inversely proportional to the mean turnover rate in the community of bacteria sampled. In all oil-impacted sites and the tilled control this sum was seen to be positively correlated with time $(r=0.57, p=0.00001)$. This indicates that the highest microbial growth rates were observed early in the remediation phase. These growth rates subsequently slowed as hydrocarbons and other easily degradable organics were depleted and oxygen levels decreased within soil aggregates when tilling was suspended. In terms of the remediation and restoration phases this sum was significantly greater (independent $t$ test) in the restoration phase $(2.73 \pm 0.73)$ that in the remediation phase $(2.01 \pm 1.03)(\mathrm{N}=35$ and $\mathrm{p}=0.002)$ again reflecting reduced growth rates after hydrocarbon concentrations were significantly reduced.

\section{Nematode Analysis}

Figures 4 and 5 show nematode trophic diversity and total nematode counts for the observation period of April 2001 through October 2003. As seen from Figure 3 native prairie was dominated by herbivores and fungivores. The prevalence of fungivores results from the fungal based decomposition processes characteristic of as undisturbed prairie (Knapp et al., 1998). Nematode numbers in J6C were significantly 
lower than in native prairie as expected from the repeated tilling through 2001 (Knapp et al., 1998). However, trophic diversity in J6C was similar to J6-NP. Nematode numbers in all oil-impacted sites were significantly depressed compared to J6N-NP or J6S-NP. J6N-F and J6N-NF were dominated by microbivores reflecting the large input of easily degradable carbon sources (hydrocarbon) and an increase in microbial activity. There was a significant decrease in microbivores in J6N-F after June 2001; however, microbivores remained elevated in J6N-NF throughout the observation period consistent with the slower loss of hydrocarbons. In J6S, which received a lesser input of crude oil, the ratio of microbivores to fungivores was much lower than that observed in J6N. Higher counts of herbivores in J6S reflected the earlier re-vegetation of these sites compared to J6N. Average family-level Shannon's diversity indices for the impacted plots and controls during 2003 were consistent with trophic diversities (Figure 4): J6N-F, $1.17 \pm 0.52 ; \mathrm{J} 6 \mathrm{~N}-\mathrm{NF}, 0.67 \pm 0.58 ; \mathrm{J} 6 \mathrm{C}, 1.48 \pm 0.09 ; \mathrm{J} 6 \mathrm{~N}-\mathrm{NP}, 1.80 \pm 0.21 ; \mathrm{J} 6 \mathrm{~S}-\mathrm{F}, 1.46 \pm$ $0.22 ; \mathrm{J} 6 \mathrm{~S}-\mathrm{NF}, 1.55 \pm 0.23 ; \mathrm{J} 6 \mathrm{~S}-\mathrm{NP}, 1.87 \pm 0.43$.

An examination of the distribution of nematodes in the various c-p classes over time can describe the successional status of a soil community in response to a disturbance. This approach is based on the fact that different genera or families have different sensitivities to disruption or stress based on the characteristics of the individual genera (Bongers, 1990). The colonizer-persister scale ranges from 1 to 5 and assigns taxa that represent the life-history characteristics of nematodes associated with $r$ and $k$ selection (Neher, 2001). Nematodes that are ' $r$ ' selected (also known as colonizers) have short life cycles, reproduce very quickly, have high nutrient requirements, and thus have a lower colonizer-persister value. On the other hand, nematodes that are ' $k$ ' selected 
(also known as persisters) have longer life cycles, reproduce slower, have lower nutrient requirements, and thus have a higher colonizer-persister value (Bongers and Ferris, 1999).

Taxa that fall under a common c-p class respond similarly to their surrounding environmental conditions (Bongers and Ferris, 1999). For example, nematodes that have a c-p value of 1 represent $r$-selected or colonizers have short-generation times, many fluctuations in their population, and high rates of reproduction (Bongers et al., 1995). The c-p 1 class is primarily made up of microbivores which bloom in food-rich conditions (Bongers, 1990; Bongers et al., 1995; Bongers and Bongers, 1998). Nematodes with a c-p value 5 represent $k$-selected or persisters. These produce fewer offspring and in general appear late in succession (Bongers and Bongers, 1998; Bongers and Ferris, 1999). The nematodes that have c-p values between 2 and 5 are considered fairly stable temporally thus providing long-term information about the environmental conditions (Neher, 2001).

Table 5 gives mean values of the nematode maturity index in each plot during the remediation and restoration phases. The maturity index is a weighted average of the c-p classes found in a sample (Bongers, 1990). During 2001, the last year of the remediation period, the only significant differences (at $\mathrm{p}<0.05$ ) in mean maturity indices were a lower maturity index in J6N-NF compared the tilled control and native prairie controls reflecting a greater abundance of c-p class 1 nematodes in J6N-NF. In the restoration period the maturity index of J6N-NF was significantly lower than that observed in any other plot except J6N-F in 2003. However, in $2003 \mathrm{~J} 6 \mathrm{~N}-\mathrm{NF}$ was lower than J6N-F at $p<0.11$ indicating a discernible difference at approximately the $90 \%$ confidence level. 
The interpretation of Table 5 then is that the plot impacted by the higher hydrocarbon concentration and bioremediated without a fertilizer amendment (J6N-NF) was exhibiting a relatively immature nematode community structure even two years after tilling ceased.

Although the above comparison of maturity indices indicated clear differences in nematode community structure and restoration of a functioning soil ecosystem, the untrained practitioner, such as a domestic oil and gas producer, is unlikely to calculate maturity indices from data obtained from an agricultural extension service and perform a statistical analysis. However, simple histogram plots of the c-p data obtained directly from the nematologist can yield the same conclusions and provide more temporal information. Histogram plots of c-p class data from the J6N and J6S sites are plotted in Figures 6 and 7. As seen Figure 6 nematodes in c-p class 1 dominated the nematode community in J6N-F until remediation was virtually complete in June 2001. After June 2001 c-p class 2 nematodes became abundant and even some nematodes in c-p classes 35 , which reflect a more mature community structure, began to appear. In contrast J6NNF was dominated by c-p class 1 throughout the observation period with c-p class 2 appearing in 2002. No members of c-p classes 3-5 were observed in any samples from J6N-NF. Nematode communities from J6C and J6N-NP both consisted almost entirely of c-p classes 2-5. It appears that the tilling in of hay and the original vegetation in J6C in May 1999 did not have a long-lasting effect on community structure in terms of c-p class or trophic diversity in contrast to the effects of crude oil on J6N-F and J6N-NF.

Figure 7 shows the nematode community structure in J6S in terms colonizerpersister classes. Nematode community structure shows that both J6S-F and J6S-NF were impacted by hydrocarb 
on when compared to J6C. Both of these plots show more rapid recovery of community structure that in impacted plots in J6N likely due to the lesser hydrocarbon impact in J6S. However, nematodes of c-p class 1 were more often seen in J6S-NF than in J6S-F.

\section{Plant Community Analysis}

The J6 site is within the area of the Tallgrass Prairie Preserve open to bison grazing. Bison are attracted to bare ground and were frequently observed wallowing in bare areas of $\mathrm{J} 6 \mathrm{~N}$ and $\mathrm{J} 6 \mathrm{C}$. Under natural conditions bison create and maintain 3-5 m wallows (Knapp et al., 1999) and two areas of bare ground in J6N matching this description persisted through 2003.

At the end of the 2002 growing season J6N-F and J6N-NF had between 70 and $90 \%$ bare ground. Plant cover in J6S and J6C was greater than 50\%. By the summer of $2003 \mathrm{~J} 6 \mathrm{~S}$ and J6C were nearly completely revegetated while significant bison wallows persisted in J6N-F and J6N-NF. Table 6 gives plant species characteristics and relative percent canopy cover in all $\mathrm{J} 6$ test plots. The prairie controls were dominated by grasses including Andropogen gerardii, Panicum virgatum, Sorghastrum nutans, and Festuca arundinacea, and in some areas by the forbs Solidago canadensis, Helianthus mollis, and Gutierrezia dracunculoides. The dominant recolonizing species in J6C, J6S-F, and J6SNF were ruderal forbs including Ambrosia artemisiifolia, Ambrosia psilostachya, Gutierrezia dracunculoides, and Xanthium strumarium with the exotic grass Bromus japonicus. In these plots colonization resulted in a fairly random distribution of individuals. In J6N-F and J6N-NF colonization appeared to progress from the edges through vegetative growth followed by seedling establishment. The edges of J6N-F and J6N-NF contained many of the same ruderals found in J6C, J6S-F, and J6S-NF. 
However, the exotic perennial grass Cynodon dactylon and the creeping forb Polygonum aviculare were the most common species toward the centers of J6N-F and J6N-NF. Both of these species are trampling tolerant (Dan and Liddle, 1991; Parker, 2004). Clearly revegetation of J6N-F and J6N-NF were affected by bison wallowing. However, the slow pace of re-vegetation of J6N-F and J6N-NF probably contributed to the persistent use of wallows on these plots. Bioremediation of crude oil hydrocarbons has been shown to result in significantly reduced toxicity (Salinitro et al., 1997). However, residual hydrocarbons following bioremediation are hydrophobic and plants growing in these soils may experience water stress even when rainfall is high (Ritsema and Dekker, 1994; Sawatsky and Li, 1997). This may have accounted for the slower re-vegetation in J6N-F and J6N-NF in 2003.

Species richness, Shannon's diversity index and species evenness in all test plots and controls in the summer of 2003 are given in Table 7. Species richness was comparable in all oil-impacted plots but considerably lower than that observed in the tilled control (J6C) or native prairie. All disturbed plots exhibited reduced species diversity in 2003 compared to native prairie with lowest diversity seen in J6S. Evenness followed the same trend. The reasons for the lower diversity and evenness in J6S are unknown but may be related to the different soil type and higher clay content in the J6S site (33\% vs. $19 \%$ in J6N). During initial re-vegetation it appears that species richness in the plant community was impacted by the effects of residual hydrocarbon or an impact on soil nutrient pools. However, with respect to the latter, no differences could be discerned between the fertilized and non-fertilized plots in both J6N and J6S. Longer-term observation of these sites will be more instructive. 


\section{Conclusion}

PLFA analysis of soil bacteria, analysis of nematode numbers and community structure, and analysis of nitrogen availability have all shown that the addition of fertilizer during bioremediation of a terrestrial crude oil spill accelerates the subsequent restoration of the soil ecosystem. The effect of the fertilizer was more significant at higher concentrations of crude oil hydrocarbons due to greater depletion of soil nutrient pools under these conditions in the absence of fertilizer. Initial re-vegetation of oilimpacted sites was not affected by fertilizer but the original hydrocarbon contamination and subsequent bioremediation process did impact species richness during initial revegetation more than that observed in the tilled control. Re-vegetation appeared to be slowed by higher initial hydrocarbon concentrations.

Nematode analysis proved to be the most sensitive ecological indicator in regard to disturbance of the soil food web in a hydrocarbon-impacted site. Community structure analysis using c-p classes was capable of discerning the effect of fertilizer addition on soil ecosystem recovery even at the lower hydrocarbon concentrations in J6S. The results of a nematode analysis are also much easier for a lay person (like a small independent oil producer) to understand and, in the U.S., readily obtained through university agricultural extension services for a very reasonable cost. Nematologists at these institutions can provide nematode counts by trophic group and c-p class at a relatively low cost. With minimal training a small producer can interpret temporal trends in these data and make comparisons to target ecosystems. Nematode analyses have a long tradition and body of knowledge exists with respect to agricultural systems. However, to our knowledge this 
work represents the first use of a nematode analysis to monitor recovery of soil ecosystems following the bioremediation of a crude oil spill.

\section{Acknowledgements}

This work was funded by the U.S. Department of Energy (DE-FC26-

01BC15332). We thank The Nature Conservancy for access to the field site in the Tallgrass Prairie Preserve.

\section{References}

Baer, S.G., Blair, J.M., Collins, S.L. and Knapp, A. 2003. Soil resources regulate productivity and diversity in newly established tallgrass prairie. Ecology. 84, 724-735.

Balkwill, D.L., Leach, F.R., Wilson, J.T., McNabb, J.F. and White, D.C. 1988. Equivalence of microbial biomass measures based on membrane lipid and cell wall components, adenosine triphosphate, and direct counts in subsurface sediments. Microbial Ecology. 16, 73-84.

Bongers, T. 1990. The maturity index: An ecological measure of environmental disturbance based on nematode species composition. Oecologia. 83, 14-19.

Bongers, T., de Goede, R.G.M., Korthals, G.W. and Yeates, G.W. 1995. Proposed changes of c-p classification for nematodes. Russ. J. Nemat. 3, 61-62.

Bongers, T., and Ferris, H., 1999. Nematode community structure as a bioindicator in environmental monitoring. Trends in Ecology and Evolution. 14, 224-228.

Bongers, T. and Bongers, M. 1998. Functional diversity of nematodes. Appl. Soil Ecology. 10, 239-251.

Cassel, D.K. and Nielson, D.R. 1986. Field capacity and available water capacity, In: Klute, A. (Ed.), Methods of Soil Analysis, Part 1, Soil Sci.Soc. Am. Book Series No. 5, Madison, pp 901-926.

Dan, S. and Liddle, M.J. 1991. Field occurrence, recovery, and simulated trampling resistance and recovery of two grasses. Biol. Conserv. 57, 187-203.

Diggs, Jr., G.M., Lipscomb, B.L. and O'Kennon, R.J. 1999. Illustrated Flora of North Texas, Botanical Research Institute of Texas, Ft. Worth, TX.

Dowling, N.J.E, Widdel, F. and White, D.C. 1986. Phospholipid ester-linked fatty acid biomarkers of acetate-oxidizing sulfate reducers and other sulfide forming bacteria. J. Gen. Micro. 132, 1815-1825. 
EPA, 1979. Methods for Chemical Analysis of Water and Wastes. EPA-600/4-79-020.

U.S. Environmental Protection Agency, U.S. Government Printing Agency, U.S.

Government Printing Office, Washington, D.C.

Guckert, J. B., Antworth, C. P., Nichols, P.D. and D.C. White, D.C. 1985. Phospholipid, ester-linked fatty acid profiles as reproducible assays for changes in prokaryotic community structure of estuarine sediments. FEMS (Federation of European Microbiological Societies) Microbiology Ecology. 31, 147-158.

Guckert, J. B., Hood, M.A. and White, D.C. 1986. Phospholipid ester-linked fatty acid profile changes during nutrient deprivation of Vibrio cholerae: Increases in the trans/cis ratio and proportions of cyclopropyl fatty acids. Applied and Environmental Microbiology. 52(4), 794-801.

Hartnett, D. C., and Fay, P.A. 1998. Plant populations: patterns and processes. In: Knapp, A. K., Briggs, J. M., Hartnett, D. C., and Collins, S. L. (Eds.) Grassland Dynamics: Long-term Ecological Research in Tallgrass Prairie. Pp. 81-100. Oxford University Press, New York.

Hendrix, P.F., Parmelee, R.W., Crossley, Jr., D.A.,Coleman, D.C., Odum, E.P. and Groffman, P.M. 1986. Detritus food webs in conventional and no-tillage agroecosystems. Bioscience. 36, 374-380.

Jenkins, W.R., 1964. A rapid centrifugal-flotation technique for extracting nematodes from soil. Plant Disease Reporter. 48, 692.

Knapp, A. K., Briggs, J. M., Hartnett, D. C., and Collins, S. L., (Eds.), 1998. Grassland Dynamics: Long-term Ecological Research in Tallgrass Prairie. Oxford University Press, New York.

Knapp, A.K., Blair, J.M., Briggs, J.M., Collins, S.L., Hartnett, D.C., Johnson, L.C. and Towne, G.E. 1999. The keystone role of bison in North American tallgrass prairie. Bioscience. 49, 39-44.

Maynard, D.G., and Kalra, Y.P. 1993. Nitrate and exchangeable ammonium nitrogen. In: M.R. Carter (Ed), Soil Sampling and Methods of Analysis. Lewis Publishers, Boca Raton, pp.25-38.

Neher, D. A., 2001. Role of nematodes in soil health and their use as indicators. Journal of Nematology. 33 (4), 161-168.

Palmer, M.W., Earls, P.G., Hoagland, B.W., White, P.S. and Wohlgemuth, T. 2002.

Quantitative tools for predicting species lists. Environmetrics. 13, 121-137.

Parker, K.F., 2004. Illustrated Guide to Arizona Weeds. University of Arizona Press, Tuscon, AZ.

Ritsema, C.J. and Dekker, L.W. 1994. How water moves in a water repellent sandy soil.

2. Dynamics of fingered flow. Water Resour.Res. 30, 2519-2531. 
Salinitro, J.P., Dorn, P.B., Huesemann, M.H., Moore, K.O., Rhodes, I.A., Jackson, L.M.R., Vipond, T.E., M.M. Western, M.M., Wisnieski, H.L. 1997. Crude oil hydrocarbon bioremediation and soil ecotoxicity assessment. Environ. Sci. Technol. 31, 1769-1776.

Sawatsky, N. and Li, X. 1997. Importance of soil-water relationships in assessing the endpoint of bioremediated soils. II. Water repellency in hydrocarbon contaminated soils. Plant Soil. 192, 227-236.

Schimel, D.S., 1986. Carbon and nitrogen turnover in adjacent grassland and cropland ecosystems. Biogeochemistry. 2, 345-357.

Tunlid, A. and White, D.C.1992. Biochemical analysis of biomass, community structure, nutritional status, and metabolic activity of the microbial communities in soil.

Soil Biochemistry (Bollag, J-M, and Stotzky, G. eds.). 7, 229-262.

Vinton, M.A., and Burke, I.C. 1995. Interactions between individual plant species and soil nutrient status in shortgrass steppe. Ecology. 76, 1116-1133.

Winer, B.J., Brown, D.R. and Michels, K.M. 1991. Statistical Principals in Experimental Design, $3^{\text {rd }}$ Ed., McGraw-Hill, NY.

White, D.C. and Ringelberg, D.B. 1998. Signature lipid biomarker analysis, Techniques in Microbial Ecology, R.S. Burlage, R. Atlas, D. Stahl, G. Geesey, and G. Sayler (Eds), Oxford University Press, New York, NY, 255-272.

White, D.C. and Ringelberg, D.B. 1995. Utility of signature lipid biomarker analysis in determining in situ viable biomass, community structure, and nutritional/physiological status of the deep subsurface microbiota., The Microbiology of the Terrestrial Subsurface, Amy, P. S. and Halderman, D. L. (Eds.), CRC Press, Boca Raton, FL.

Yeates, G.W., Bongers, T., de Goede, R.G.M., Freckman, D.W. and Georgieva, S.S. 1993. Feeding habits in soil nematode families and genera - an outline for soil ecologists. J. Nemat. 25,315-331. 
Table 1 . Mineralization rates in J6N in $2002(\mathrm{mg} / \mathrm{kg}-\mathrm{d})$

\begin{tabular}{|l|l|l|}
\hline Sampling Date & J6N-F & J6N-NF \\
\hline March 2002 & $0.58 \pm 0.11$ & $-0.06 \pm 0.25$ \\
\hline June 2002 & $0.72 \pm 0.35$ & $0.38 \pm .38$ \\
\hline October 2002 & $0.36 \pm 0.25$ & $-0.08 \pm .22$ \\
\hline
\end{tabular}

Table 2. Mean Soil Moistures in All Plots from June 1999 Through October 2003

\begin{tabular}{|l|l|}
\hline Plot & $\begin{array}{l}\text { Mean Soil Moisture } \\
\text { (\% by wt.) } \pm \text { std dev }\end{array}$ \\
\hline J6N-F & $17.6 \pm 4.0$ \\
\hline J6N-NF & $16.5 \pm 3.2$ \\
\hline J6C & $16.9 \pm 3.6$ \\
\hline J6N-NP & $17.3 \pm 3.7$ \\
\hline J6S-F & $16.4 \pm 3.6$ \\
\hline J6S-NF & $15.4 \pm 3.8$ \\
\hline J6S-NP & $14.4 \pm 2.8$ \\
\hline
\end{tabular}


Table 3. Comparison of Total PLFA Concentrations in Test Plots During

\section{Remediation and Restoration}

\begin{tabular}{|c|c|c|c|}
\hline Plot & $\begin{array}{l}\text { Remediation Phase } \\
\text { Mean } \pm \text { std. dev.* }\end{array}$ & $\begin{array}{c}\text { Restoration Phase } \\
2002 \\
\text { Mean } \pm \text { std. dev. }\end{array}$ & $\begin{array}{c}\text { Restoration Phase } \\
2003 \\
\text { Mean } \pm \text { std. dev. }\end{array}$ \\
\hline J6N-F & $32340 \pm 17587 \quad a b$ & $13194 \pm 5467 \mathrm{ab}$ & $30603 \pm 9400$ \\
\hline J6N-NF & $28454 \pm 12410 \mathrm{ab}$ & $11578 \pm 5831 \quad \mathrm{a}$ & $22583 \pm 12731 \quad \mathrm{a}$ \\
\hline J6C & $47941 \pm 28362 \mathrm{ab}$ & $17446 \pm 6800 \mathrm{abc}$ & $37559 \pm 17280 \mathrm{ab}$ \\
\hline J6S-F & $33370 \pm 19571 \mathrm{ab}$ & $19598 \pm 2738 \mathrm{abc}$ & $37583 \pm 20289 a b$ \\
\hline J6S-NF & $22842 \pm 13229 \quad \mathrm{a}$ & $11108 \pm 5340 \quad \mathrm{a}$ & $38925 \pm 23430 \quad a b$ \\
\hline J6N-NP & $66069 \pm 46787 \mathrm{~b}$ & $22022 \pm 2146 \mathrm{c}$ & $44517 \pm 22654 \quad b$ \\
\hline J6S-NP & $\begin{array}{l}\text { Samples not } \\
\text { collected at all time } \\
\text { points }\end{array}$ & $21964 \pm 2146 b c$ & $36781 \pm 18247 \quad a b$ \\
\hline
\end{tabular}

* Different letters beside values within the remediation phase or within a given year in the restoration phase indicate measurements that are significantly different from each other at $\mathrm{p}<0.05$.

Table 4. Relative Amounts of PLFA Structural Groups in Impacted Plots

\begin{tabular}{|c|c|c|c|c|c|c|}
\hline Plot & \multirow{2}{*}{\multicolumn{2}{|c|}{$\begin{array}{c}\text { TerBrSats } \\
\text { (\% of Total PLFA)* } \\
\pm \text { std. dev. }\end{array}$}} & \multirow{2}{*}{\multicolumn{2}{|c|}{$\begin{array}{c}\text { MidBrSats } \\
\text { (\% of Total PLFA) } \\
\pm \text { std. dev. }\end{array}$}} & \multirow{2}{*}{\multicolumn{2}{|c|}{$\begin{array}{c}\text { BrMonos } \\
\text { (\% of Total PLFA) } \\
\pm \text { std. dev. }\end{array}$}} \\
\hline $\begin{array}{l}\text { Remediation } \\
\text { Phase (N=7) }\end{array}$ & & & & & & \\
\hline J6N-F & $16.8 \pm 2.1$ & $\mathrm{ab}$ & $10.0 \pm 4.2$ & $\mathrm{~b}$ & $3.3 \pm 1.4$ & $\mathrm{a}$ \\
\hline J6N-NF & $14.8 \pm 2.5$ & $\mathrm{a}$ & $5.5 \pm 2.7$ & $\mathrm{a}$ & $3.9 \pm 2.2$ & $\mathrm{a}$ \\
\hline J6S-F & $19.1 \pm 3.1$ & bc & $11.7 \pm 5.6$ & $\mathrm{~b}$ & $4.0 \pm 2.4$ & $\mathrm{a}$ \\
\hline J6S-NF & $16.3 \pm 2.1$ & $\mathrm{ab}$ & $10.4 \pm 4.6$ & $\mathrm{~b}$ & $4.7 \pm 2.5$ & $\mathrm{a}$ \\
\hline J6C & $20.5 \pm 1.8$ & $\mathrm{c}$ & $12.0 \pm 3.1$ & $\mathrm{~b}$ & $3.9 \pm 1.5$ & $\mathrm{a}$ \\
\hline \multicolumn{7}{|c|}{$\begin{array}{l}\text { Restoration Phase } \\
(\mathrm{N}=6)\end{array}$} \\
\hline J6N-F & $21.5 \pm 2.4$ & $\mathrm{ab}$ & $13.1 \pm 3.1$ & $\mathrm{~b}$ & $4.5 \pm 0.17$ & $\mathrm{a}$ \\
\hline J6N-NF & $19.0 \pm 3.6$ & $\mathrm{a}$ & $9.8 \pm 1.5$ & $\mathrm{a}$ & $4.6 \pm 0.51$ & $\mathrm{a}$ \\
\hline J6S-F & $23.6 \pm 3.7$ & $\mathrm{bc}$ & $16.5 \pm 3.9$ & $\mathrm{c}$ & $4.3 \pm 0.48$ & $\mathrm{a}$ \\
\hline J6S-NF & $19.4 \pm 3.9$ & $\mathrm{a}$ & $14.9 \pm 2.2$ & $\mathrm{cb}$ & $4.9 \pm 0.87$ & $\mathrm{a}$ \\
\hline $\mathrm{J} 6 \mathrm{C}$ & $25.7 \pm 3.9$ & $\mathrm{c}$ & $16.9 \pm 4.1$ & $\mathrm{c}$ & $4.3 \pm 0.26$ & $\mathrm{a}$ \\
\hline
\end{tabular}

* Different letters beside values within a given phase and structural group indicate measurements that are significantly different from each other at $\mathrm{p}<0.05$. 
Table 5. Nematode Maturity Indices in Test Plots During Remediation and Restoration

\begin{tabular}{|c|c|c|c|}
\hline Plot & $\begin{array}{c}2001 \\
\text { Mean } \pm \text { std. dev.* }\end{array}$ & $\begin{array}{c}2002 \\
\text { Mean } \pm \text { std. dev. }\end{array}$ & $\begin{array}{c}2003 \\
\text { Mean } \pm \text { std. dev. }\end{array}$ \\
\hline J6N-F & $1.41 \pm 0.51 \mathrm{ab}$ & $2.05 \pm 0.08 \quad b$ & $1.76 \pm 0.42 \mathrm{a}$ \\
\hline J6N-NF & $1.02 \pm 0.02 \quad \mathrm{a}$ & $1.47 \pm 0.36$ & $1.24 \pm 0.21 \quad \mathrm{a}$ \\
\hline $\mathrm{J} 6 \mathrm{C}$ & $2.18 \pm 0.07 \quad b$ & $2.09 \pm 0.11$ & $2.39 \pm 0.24 \quad b$ \\
\hline J6S-F & $1.88 \pm 0.26 \quad \mathrm{ab}$ & $2.20 \pm 0.26$ & $2.31 \pm 0.28 \quad b$ \\
\hline J6S-NF & $1.91 \pm 0.65 \mathrm{ab}$ & $2.07 \pm 0.19$ & $2.44 \pm 0.18 \quad b$ \\
\hline J6N-NP & $2.27 \pm 0.06 \quad b$ & $2.29 \pm 0.16$ & $2.34 \pm 0.05 \quad b$ \\
\hline J6S-NP & $2.20 \pm 0.06 \quad b$ & $2.38 \pm 0.22$ & $2.42 \pm 0.08 \quad b$ \\
\hline
\end{tabular}

*Different letters beside values within a given year indicate measurements that are significantly different from each other at $\mathrm{p}<0.05$. 
Table 6. Plant species characteristics and relative percentage canopy cover of most abundant plant species and bare ground during summer 2003. Phenology and Life-span : $\mathrm{w}=$ warm season, $\mathrm{c}=$ cool season, $\mathrm{a}=$ annual, $\mathrm{p}=$ perennial (Diggs et al. 1999).

\section{Estimated relative canopy cover (\%)}

\begin{tabular}{|c|c|c|c|c|c|c|c|c|c|}
\hline $\begin{array}{l}\text { Species, } \\
\text { phenology }\end{array}$ & $\begin{array}{l}\text { Life- } \\
\text { span }\end{array}$ & Growth form & $\begin{array}{l}\text { J6N- } \\
\text { F }\end{array}$ & \begin{tabular}{|l} 
J6N- \\
NF
\end{tabular} & J6C & $\begin{array}{l}\text { J6N- } \\
\text { NP }\end{array}$ & $\begin{array}{l}\text { J6S- } \\
\text { F }\end{array}$ & $\begin{array}{l}\text { J6S- } \\
\text { NF }\end{array}$ & $\begin{array}{l}\text { J6S- } \\
\text { NP }\end{array}$ \\
\hline $\begin{array}{l}\text { Ambrosia } \\
\text { artemisiifolia }\end{array}$ & wa & Erect forb & 20 & 15 & 20 & 0.5 & 0.5 & 10 & \\
\hline $\begin{array}{l}\text { Ambrosia } \\
\text { psilostachya }\end{array}$ & wp & Erect forb & 0.5 & 1 & 20 & 3 & 40 & 10 & 1 \\
\hline $\begin{array}{l}\text { Gutierrezia } \\
\text { dracunculoides }\end{array}$ & wa & Erect forb & 1 & 5 & 15 & 0.5 & 10 & 20 & 7 \\
\hline $\begin{array}{l}\text { Andropogon } \\
\text { gerardii }\end{array}$ & wp & $\begin{array}{l}\text { Cespitose/rhizomatous } \\
\text { grass }\end{array}$ & & & 0.5 & 20 & & 0.5 & 7 \\
\hline $\begin{array}{l}\text { Bromus } \\
\text { japonicus }\end{array}$ & ca & Cespitose grass & 20 & 7 & 10 & 2 & 5 & 15 & 1 \\
\hline $\begin{array}{l}\text { Cynodon } \\
\text { dactylon }\end{array}$ & wp & $\begin{array}{l}\text { Stoloniferous/rhizomatous } \\
\text { grass }\end{array}$ & 2 & 1 & 0.5 & & 1 & 0.5 & \\
\hline $\begin{array}{l}\text { Digitaria } \\
\text { sanguinalis }\end{array}$ & wa & Stoloniferous grass & & 2 & 0.5 & & 0.5 & 3 & \\
\hline $\begin{array}{l}\text { Elymus } \\
\text { virginicus }\end{array}$ & $\mathrm{cp}$ & Cespitose grass & & & 0.5 & 0.5 & 0.5 & 0.5 & 3 \\
\hline $\begin{array}{l}\text { Festuca } \\
\text { arundincea }\end{array}$ & $\mathrm{cp}$ & Cespitose grass & 1 & 0.5 & 0.5 & 3 & 0.5 & 0.5 & 10 \\
\hline $\begin{array}{l}\text { Helianthus } \\
\text { mollis }\end{array}$ & wp & Erect/Rhizomatous forb & 0.5 & 0.5 & 0.5 & 30 & & & \\
\hline $\begin{array}{l}\text { Panicum } \\
\text { virgatum }\end{array}$ & wp & Rhizomatous grass & & & & 7 & 0.5 & & 5 \\
\hline $\begin{array}{l}\text { Polygonum } \\
\text { aviculare }\end{array}$ & wa & Prostrate forb & 15 & 1 & 0.5 & & & 0.5 & \\
\hline $\begin{array}{l}\text { Polygonum } \\
\text { lapathifolium }\end{array}$ & wa & Erect forb & & & & & & & \\
\hline $\begin{array}{l}\text { Seteria } \\
\text { parviflora }\end{array}$ & wp & Rhizomatous grass & 0.5 & & & 1 & & & 1 \\
\hline $\begin{array}{l}\text { Solidago } \\
\text { canadensis }\end{array}$ & wp & Erect/Rhizomatous forb & 0.5 & & 0.5 & 5 & 0.5 & & 20 \\
\hline $\begin{array}{l}\text { Sorghastrum } \\
\text { nutans }\end{array}$ & wp & Rhizomatous grass & & & & 3 & & & 3 \\
\hline $\begin{array}{l}\text { Xanthium } \\
\text { strumarium }\end{array}$ & wa & Erect forb & 3 & 2 & 5 & 0.5 & 30 & 50 & 0.5 \\
\hline $\begin{array}{l}\text { Bare } \\
\text { ground/rock }\end{array}$ & & & 35 & 50 & 2 & 0.5 & 10 & 10 & 10 \\
\hline
\end{tabular}


Table 7. Vegetation Characteristics in Summer 2003

\begin{tabular}{|c|c|c|c|}
\hline Plot & $\begin{array}{c}\text { Species } \\
\text { richness }\end{array}$ & $\begin{array}{c}\text { Shannon's } \\
\text { diversity } \\
\text { index }\end{array}$ & Evenness \\
\hline J6N-F & 34 & 2.28 & 0.68 \\
\hline J6N-NF & 29 & 2.63 & 0.78 \\
\hline J6C & 51 & 2.48 & 0.63 \\
\hline J6N-NP & 64 & 3.14 & 0.75 \\
\hline J6S-F & 37 & 1.92 & 0.53 \\
\hline J6S-NF & 34 & 1.98 & 0.56 \\
\hline J6S-NP & 63 & 3.14 & 0.76 \\
\hline
\end{tabular}




\section{Figure Captions}

Figure 1. TPH concentrations in the fertilized and unfertilized sections of J6N during bioremediation of hydrocarbons

Figure 2. Nitrate concentrations in a plots and controls during the restoration phase. Different letters indicate measurements that are significantly different from each other at $\mathrm{p}<0.05$ within a given sampling event.

Figure 3. Results of principal component analysis of J6N PLFA data based on structural groups

Figure 4. Nematode trophic diversity in all oil-impacted sites and controls

Figure 5. Total nematodes concentrations in all impacted sites and controls

Figure 6. Nematode community structure in J6N in terms of c-p classes

Figure 7. Nematode community structure in J6S in terms of c-p classes 


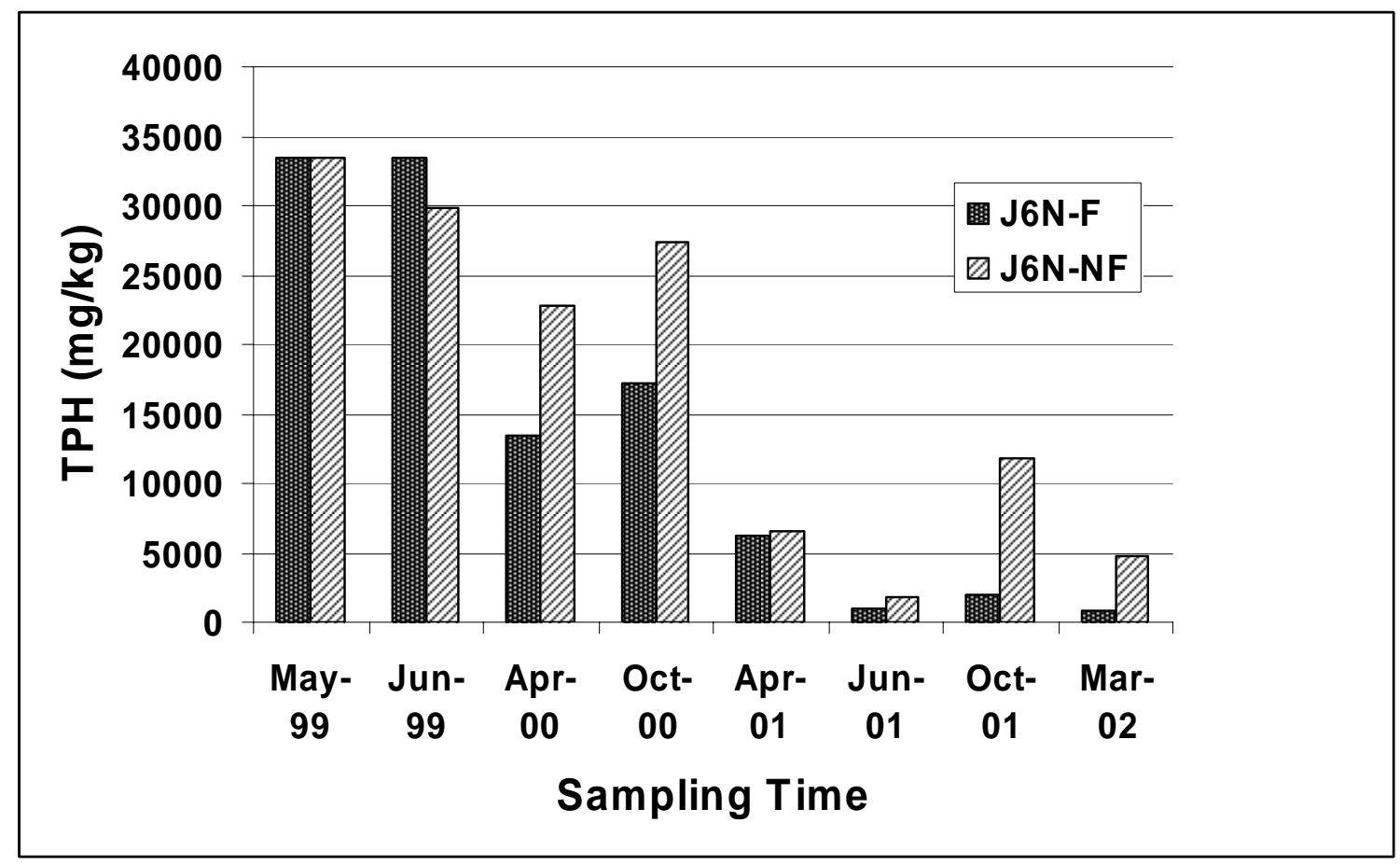

Figure 1 


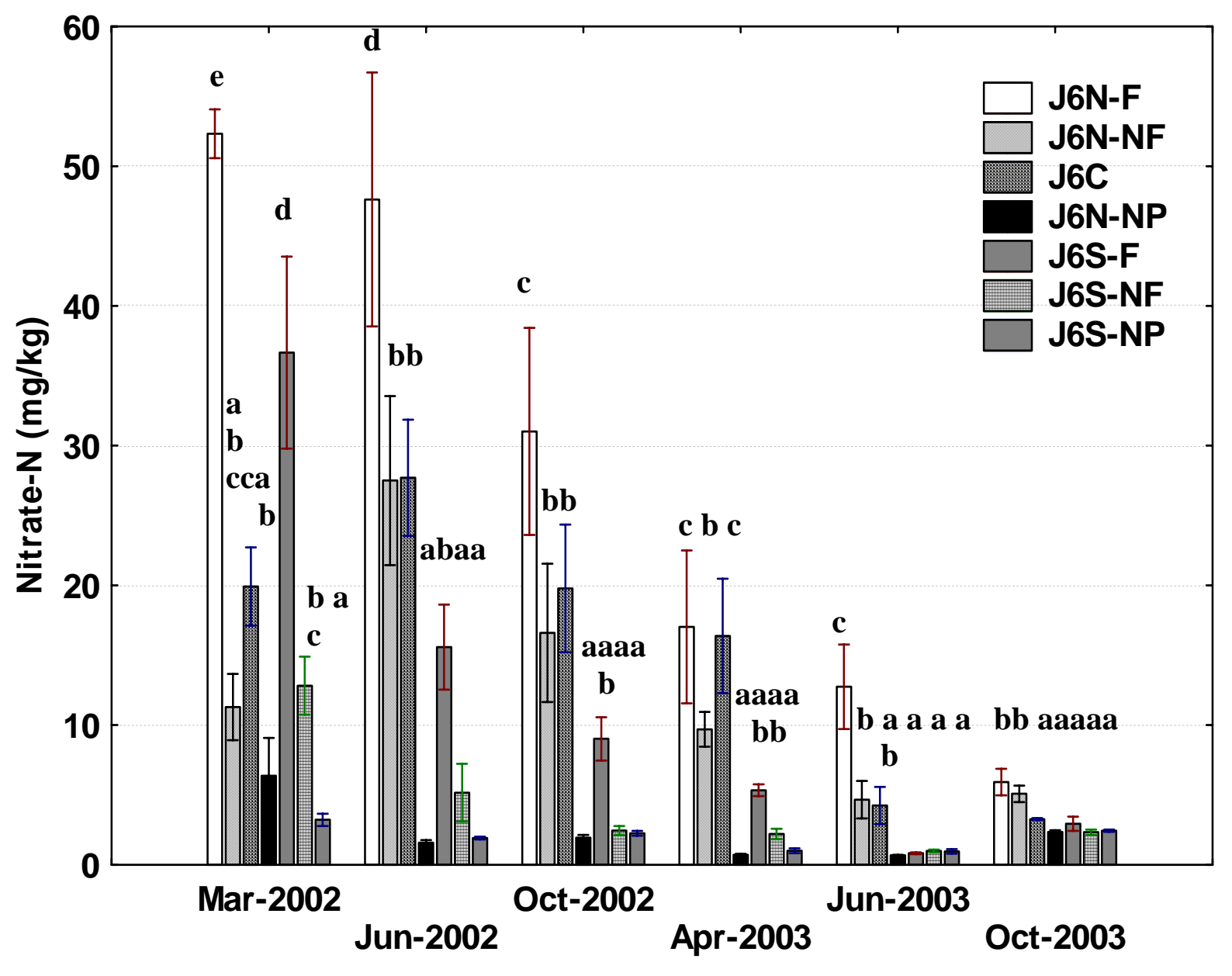

Figure 2 

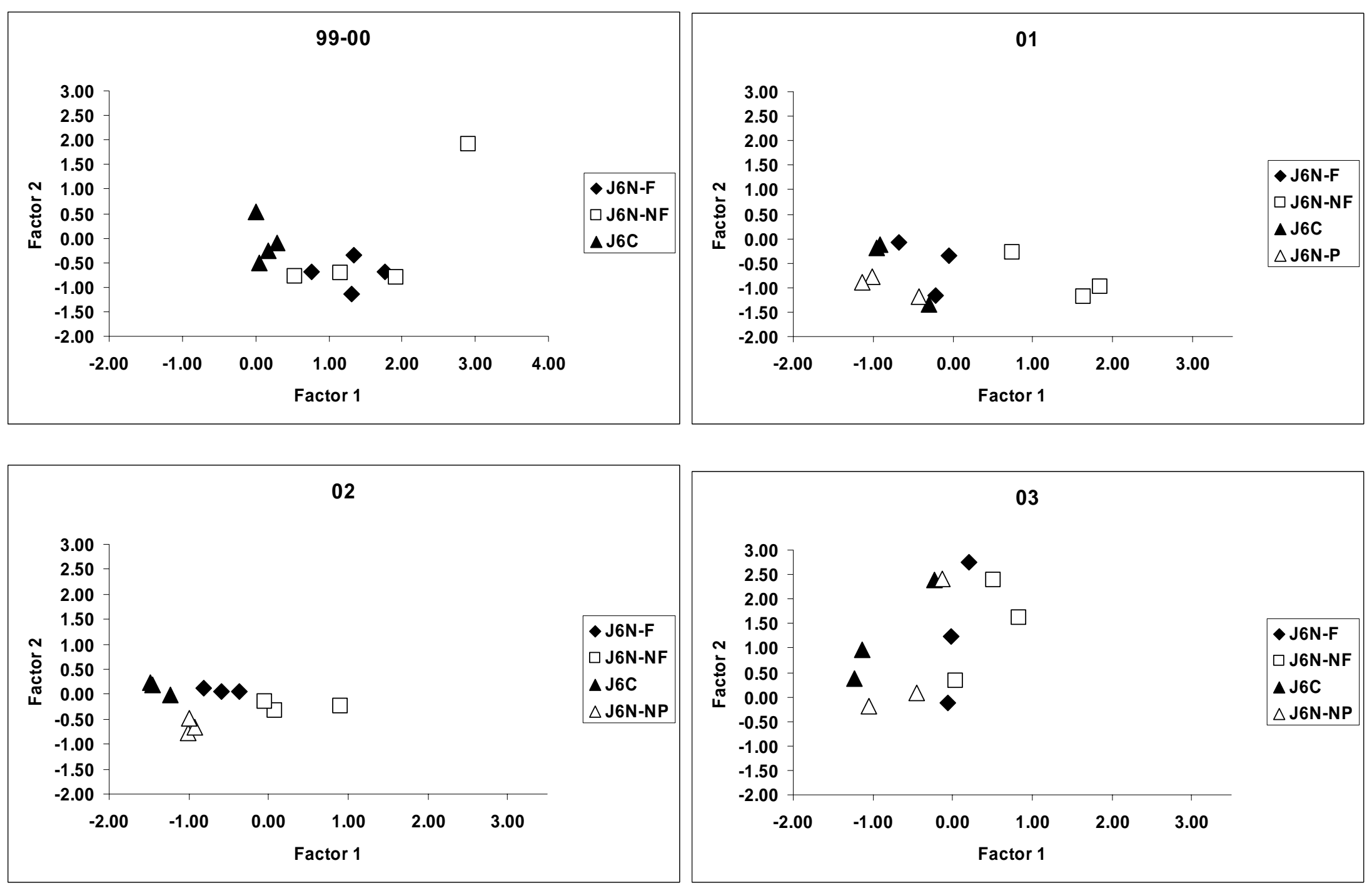

Figure 3 


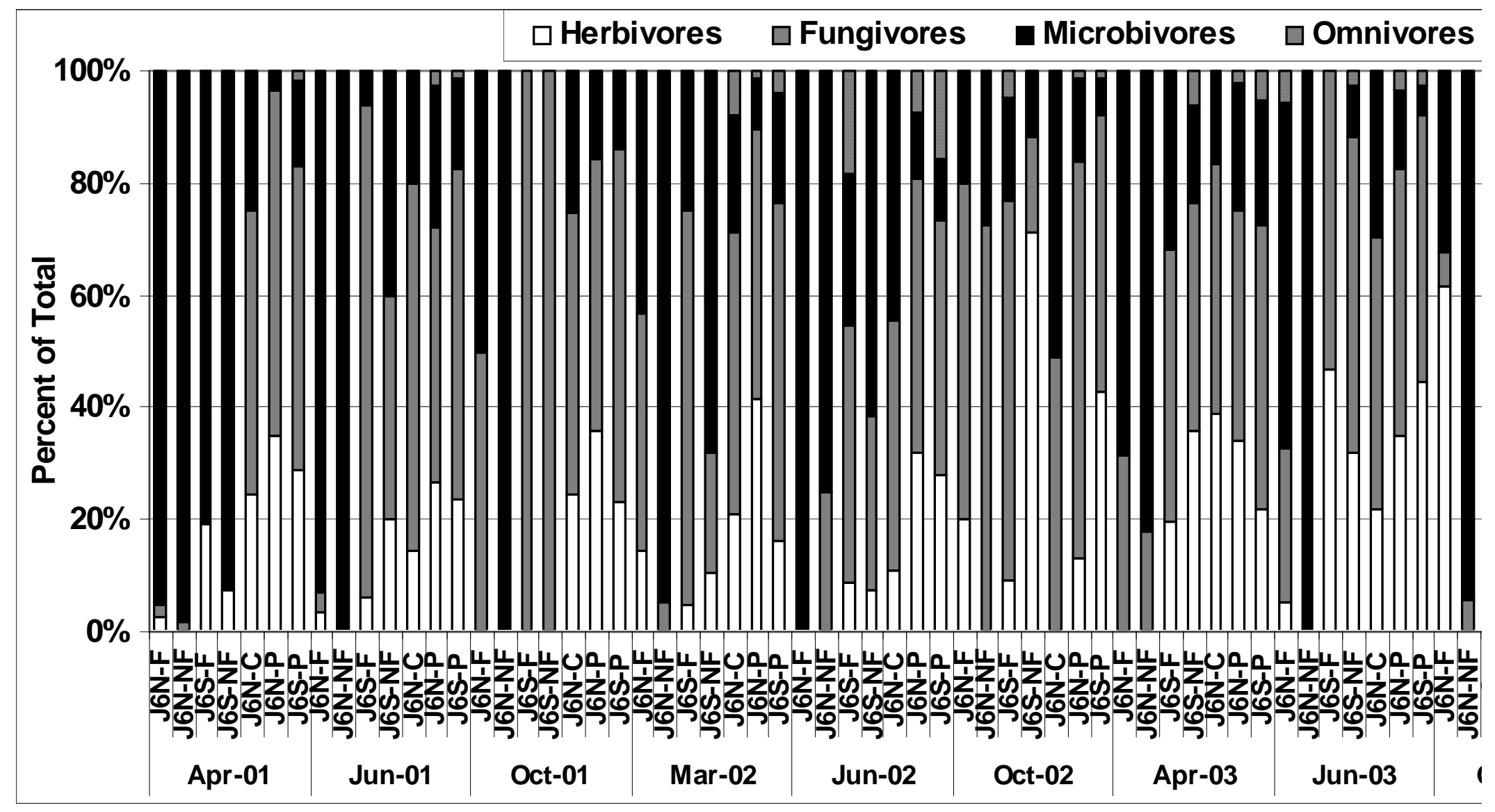

Figure 4 

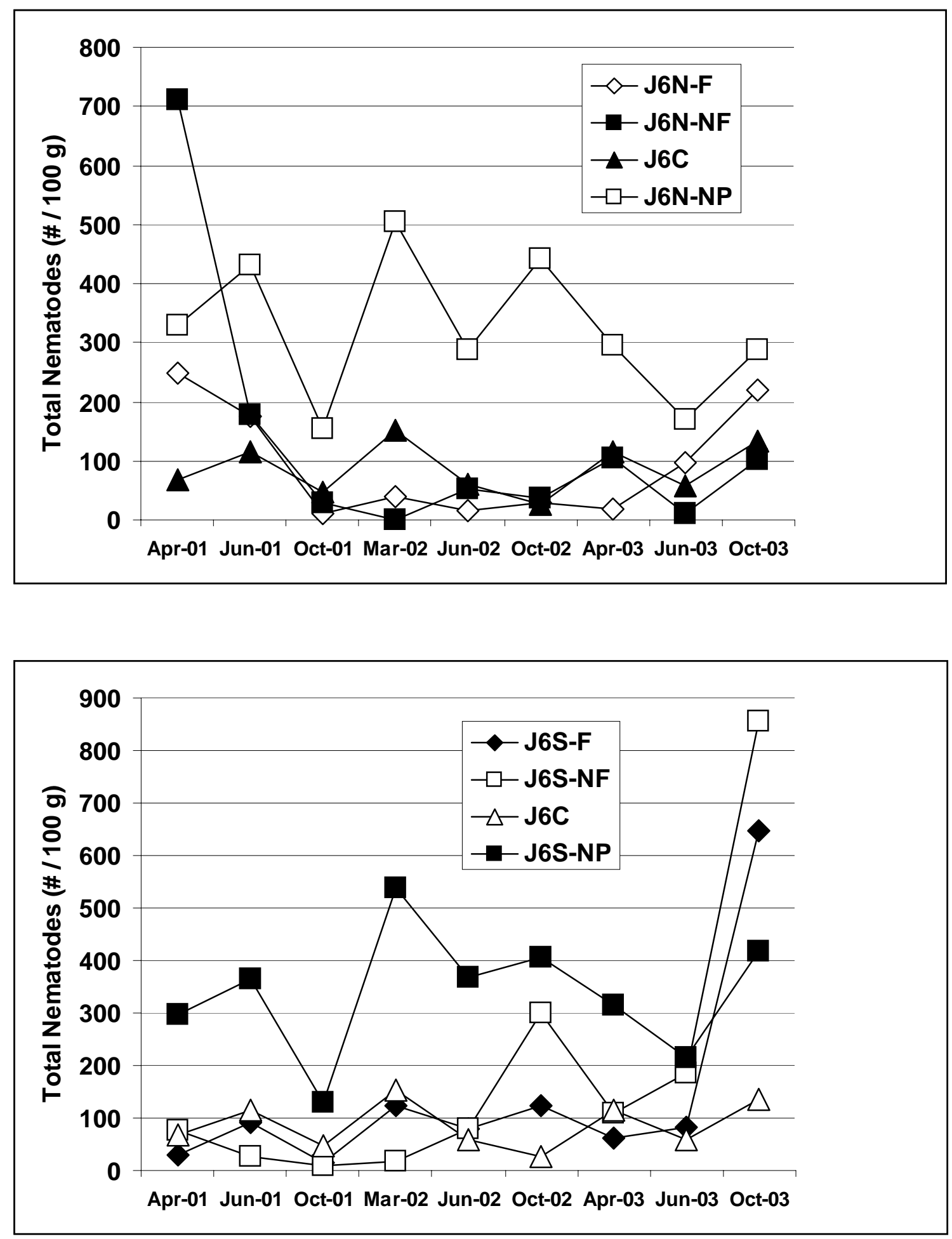

Figure 5 

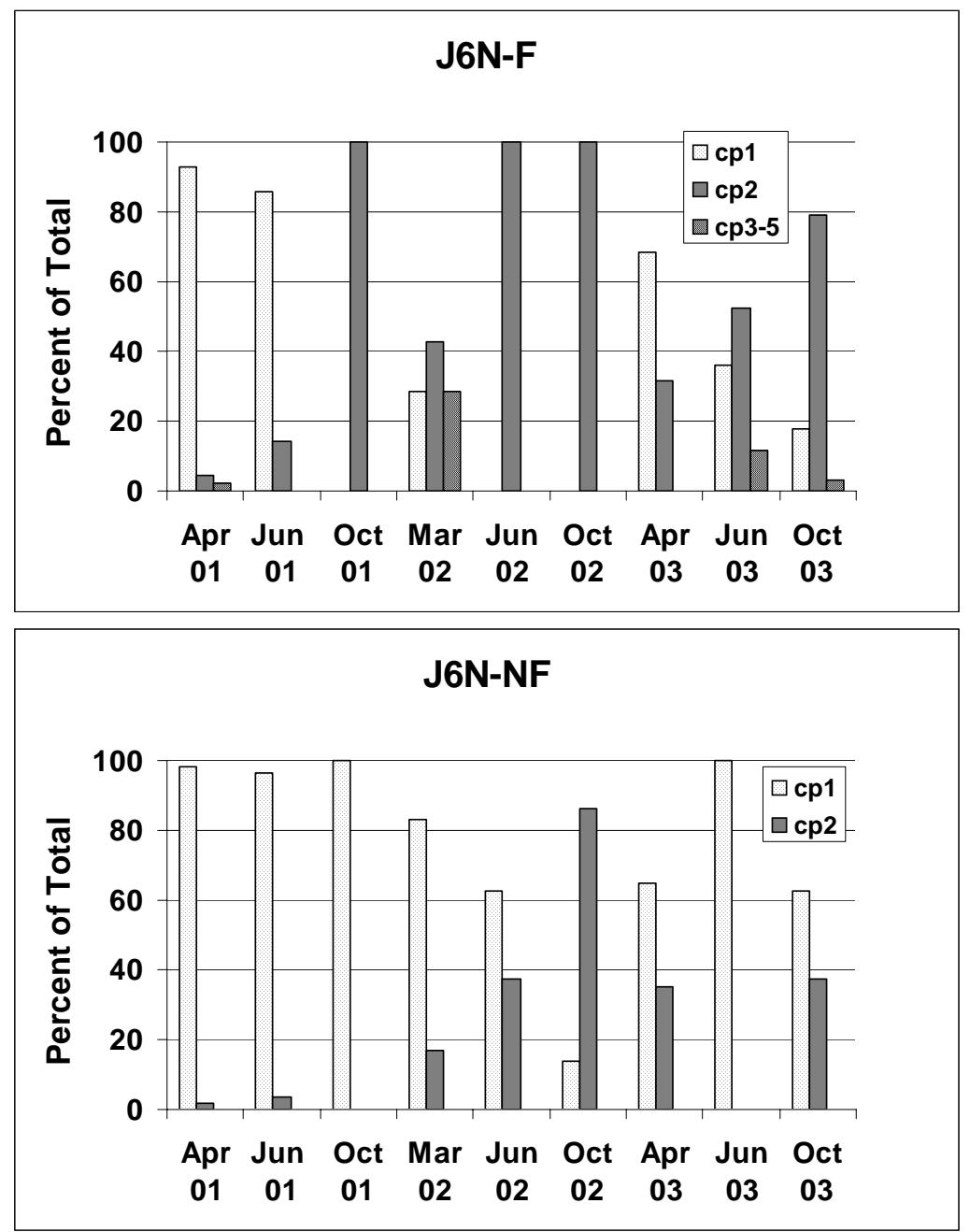

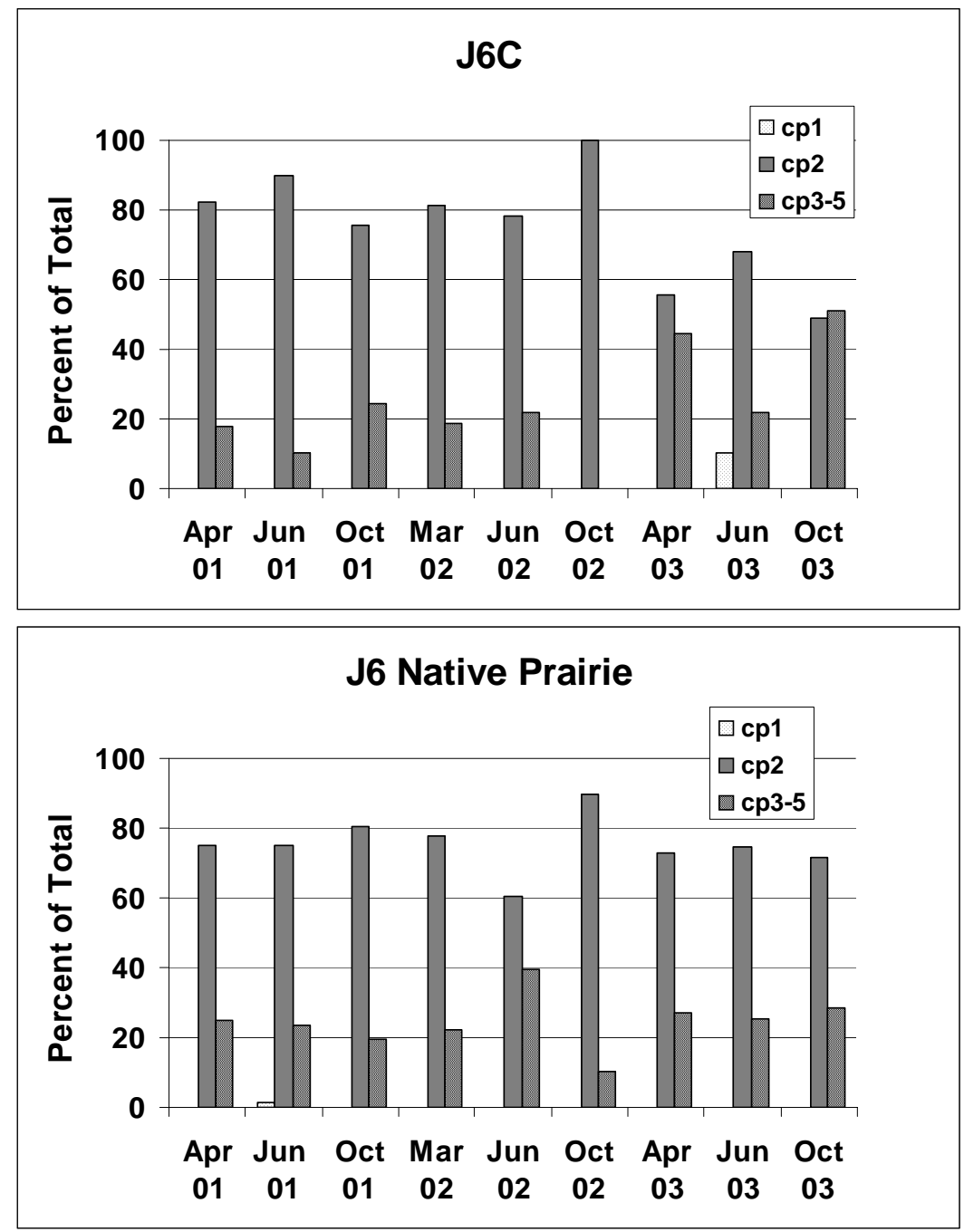

Figure 6 

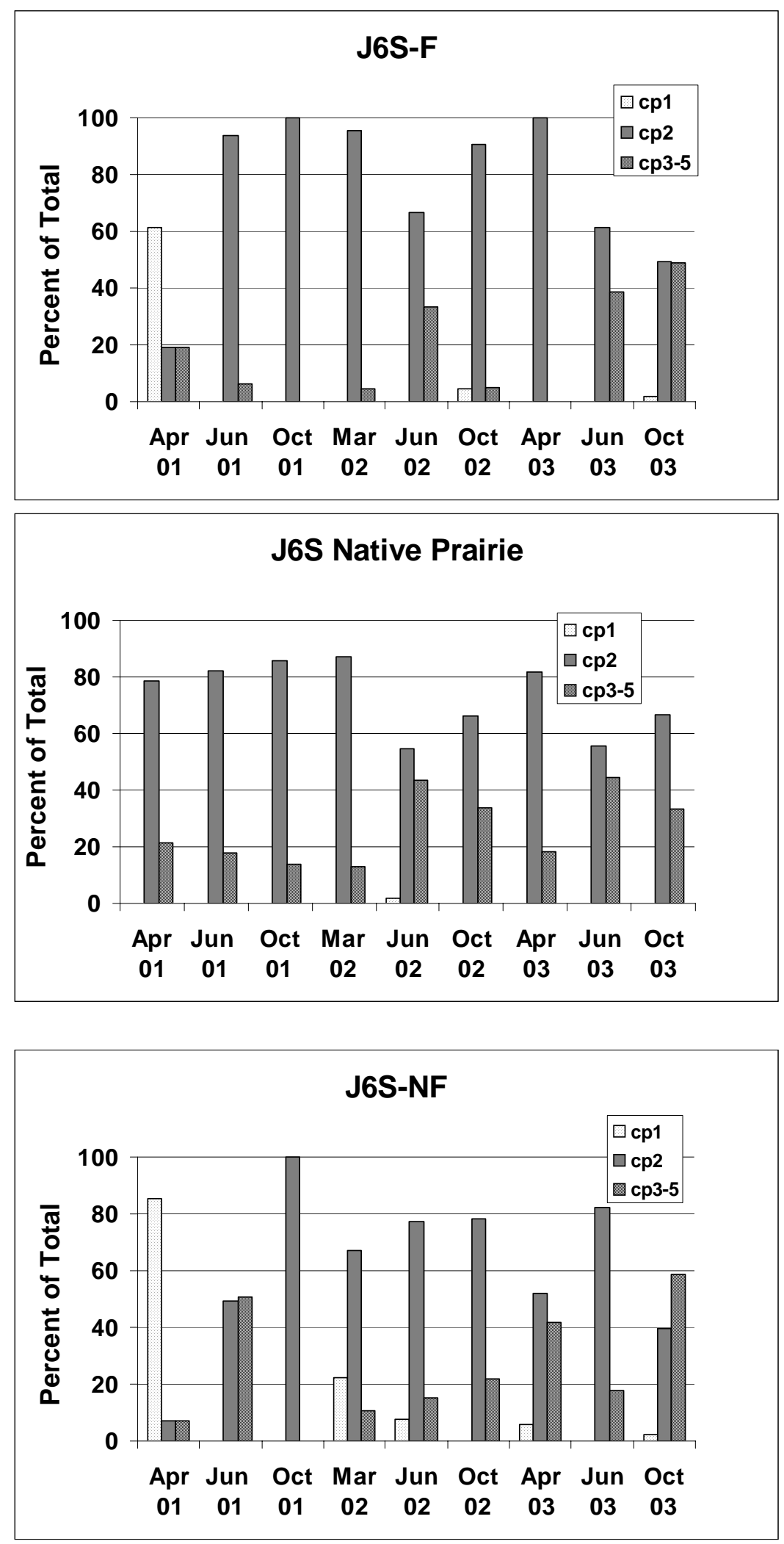

Figure 7 


\title{
Chapter 3
}

Changes in Microbial Communities During Remediation of Crude Oil and Brine Spills

\author{
Kathleen Duncan ${ }^{1 *}$, Elizabeth Charles ${ }^{1}$, Bruce Roe ${ }^{2}$, Fares Najar ${ }^{2}$ \\ ${ }^{1}$ Dept. of Botany and Microbiology, ${ }^{2}$ Dept. of Chemistry and Biochemistry, \\ University of Oklahoma \\ Chintan Mehta, Aditya Moralwar, Kerry Sublette \\ Center for Applied Biogeosciences \\ University of Tulsa \\ Joshua Brokaw \\ Oklahoma State University \\ Dept. of Botany \\ Tim Todd \\ Kansas State University \\ Dept. of Plant Pathology \\ Greg Thoma \\ University of Arkansas \\ Dept of Chemical Engineering
}

* Corresponding author
770 Van Vleet Oval
University of Oklahoma
Norman, OK 73019

Phone: 405-325-6927

Fax: 405-325-3180

E-mail address: kathleen.e.duncan-1@ou.edu

Key words: crude oil/brine/bioremediation/restoration/soil microbiology 


\begin{abstract}
Characterization of the soil microbial community in tallgrass prairie soil and its response to oil-field contamination and remediation treatments was assessed by sequencing 16S rRNA libraries derived from soil samples taken at various points in the contamination-remediation-recovery process. Sites that had been disturbed by tilling, contamination by a spill of crude oil or by a spill of oil-field brine were compared.

Undisturbed prairie was found to have high proportions of Actinobacteria, $\alpha$ Proteobacteria, and Acidobacteria, lower proportions of Firmicutes, Bacteroidetes, $\beta$ and $\delta$ Proteobacteria, a few representatives from a wide variety of candidate divisions, but was noteworthy for the low proportion of $\gamma$ Proteobacteria. Tilling was found to have the least effect on these proportions, sites contaminated with crude oil had decreased representation of Actinobacteria and Acidobacteria and an increased proportion of Firmicutes and $\gamma$ Proteobacteria, especially the latter. Brine-contaminated sites were similar to but more extreme than oil contaminated sites, with the addition of a bloom of Bacteroidetes. Groups that increased in contaminated sites were those containing cultured members able to respond rapidly (r-selected) to an influx of readily degraded hydrocarbons and/or were hypothesized to be more salt-tolerant, while those that decreased grow more slowly (Actinobacteria, Acidobacteria) or may be less tolerant of conditions in brine-impacted soil (Acidobacteria). Discriminant function analysis was applied in order to create a model that categorized samples as uncontaminated, oilimpacted, or brine-impacted. A high percentage of assignments were made correctly when model factors included weighted functions of percent Acidobacteria, Actinobacteria, and Bacteroidetes. The application of $\mathrm{N}$-containing fertilizer appeared to
\end{abstract}


lessen the imbalance due to oil-contamination and substantial recovery was seen four years after contamination had occurred. In contrast, the brine-impacted sites showed much less change after three years of treatment.

\section{Introduction}

Microorganisms play a central role in the functioning of soil ecosystems, through decomposition of complex organic compounds, formation of soil organic matter, biogeochemical cycling of nutrients essential for plant growth, such as nitrogen and phosphorus, and in direct and indirect interactions with plants and the soil meso- and meiofauna as competitors, prey, pathogens, commensals, and symbionts (Paul and Clark, 1989; Tate, 1995). When soils are damaged by spills of chemical contaminants, microbial communities are affected but in turn, microbes can be the means of restoring soil ecosystem functioning through degradation of contaminants, or in the case of brine contamination, can assist in recovery by rebuilding soil structure (Chorom and Rengasamy,1997;Nelson and Oades, 1998; Zahran, 1997). Because of its importance to agriculture, soil microbiology has long been a subject of research, and much is known about soil fertility and soil health (Arias et al. 2005; Paul and Clark, 1989; Tate, 1995). Likewise, because of the importance of bioremediation of chemical contaminants by microorganisms, much has been learned about the processes and microbes involved. However, an uncontaminated, undisturbed soil community, and a chemically contaminated, disturbed community are but two snapshots of extremes in a continuum of microbial communities. In particular, we would like to most efficiently decontaminate and restore a contaminated community to full functionality. In order to do this, we need to be able to ascertain the most important indicators of restoration, use them to examine 
the efficacy of interventions, and determine the time-scale for restoration. Determining the time-scale for restoration is an important parameter to include in making policy decisions on the environmental and human health impact of contamination events--a time-scale of 5 months for restoration of oil pipeline spills versus 50 years should influence the decision on when it is cost-effective to replace aging pipelines that are likely to have areas of weakness due to corrosion.

Our study sites are in the Tallgrass Prairie Preserve (TGPP, Pawhuska, OK), a land highly valued because of prior preservation and current active restoration by the Nature Conservancy of a once wide-spread, but now poorly represented tallgrass prairie ecosystem (Risser et al., 1981). The same land is also highly valued for its long-term production of oil, a principal source of income for the Osage Nation and a significant factor in the economy of the region. Long-term production translates into an aging infrastructure, with few resources available to prevent environmental damage from accidents and severe limitations on the types of remediation possible: a situation common to most parts of the USA and the world. Our treatment of the contaminated study sites, e.g. the application of hay and fertilizer in a modification of landfarming, are those that our previous research indicated are effective in enhancing the removal of petroleum hydrocarbons (Duncan et al. 1998; Duncan et al., 1999; Sublette et al., 2002) and are feasible under these types of circumstances. However, even the mechanical disturbance of the soil by tilling in hay and fertilizer and the addition of nitrogen-containing fertilizer are well-known to affect the soil ecosystem and subsequent establishment of plant communities (Hendrix et al., 1986; Inouye and Tilman, 1995; Wedin and Tilman, 1996; Foster and Gross, 1998). Long-term, extensive studies at the Konza Preserve (Manhattan, 
KS), a similar tallgrass prairie ecosystem, have noted the importance of the fungal community (itself very vulnerable to mechanical disruption) to tallgrass prairie decomposition processes and to plant competitive interactions (Harnett and Wilson, 1999), and the tight coupling of nitrogen and carbon cycling (Davidson et al., 1990; Baer et al., 2003). The timing and frequency of "natural" disturbances such as fire and grazing by large herbivores have also been found to be important in affecting below-ground processes such as nitrogen and carbon cycling (Groffman et al. 1993; Johnson and Matchett, 2001; Dell et al. 2005) and in maintaining the characteristic mosaic structure of tallgrass plant communities (Turner et al., 1997; Collins et al. 1998). In this study therefore, the effects of the treatments themselves are considered as a possible sources of ecosystem perturbation and compared to the degree and type of disturbance caused by surface spills of crude oil and of oil-field brine.

Specific questions addressed by the current study focus on the soil microbial community, in particular, identification of dominant eubacterial groups by $16 \mathrm{~S}$ rRNA sequence analysis; other reports describe the effects on the soil meiofauna, other aspects of the microbial community, nitrogen cycling, re-establishment of plant communities, and Probabilistic Reliability Modeling for Oil Exploration \& Production (E \& P) Facilities.

The questions addressed by the current study are: 1) What are the dominant eubacterial groups in undisturbed, uncontaminated tallgrass prairie soil? 2) In response to disturbance, do eubacterial groups increase their representation in the community, decrease, or stay the same? 3) Does the response reflect the type of disturbance? e.g. tilling, contamination by crude oil, or contamination by oil-field brine? 4) How does the 
addition of fertilizer affect the disturbance caused by oil contamination? 5) What are characteristics of groups that respond to disturbance? 6) How long does recovery/restoration take?

\section{Site description and remediation treatments}

The Tallgrass Prairie Preserve (Osage County, OK) is managed by The Nature Conservancy with controlled burns and a bison herd to restore a tallgrass prairie ecosystem. The area has been producing crude oil since the early 1900's, and production, primarily by small independent oil and gas producers, continues today. Two sites were chosen for remediation, one, J6, was contaminated in January 1999 by an accidental pipeline break. Two areas (north and south) were contaminated by the flowing oil, however, the current study is focused exclusively on the more heavily contaminated north site (approx. $930 \mathrm{~m}^{2}$ ). Initial Total Petroleum Hydrocarbon (TPH) contamination levels were estimated to be approximately $33,500 \mathrm{mg} / \mathrm{kg}$ (dry weight, EPA Method 418.1). The contamination was crude oil, no brine (e.g. $\mathrm{NaCl}$ ) components were detected. The contaminated area was divided into two portions, JN and JF, by burying a corrugated PVC sheeting. Prairie hay was applied to the contaminated areas in May 1999, followed by the addition of fertilizer (ammonium nitrate, diphosphorus pentoxide, and potassium oxide) to JF in May 1999 and on 3 additional dates over the next two years, with the final application being April 2001 (after the 4/01 sampling was performed). Tilling was performed immediately after fertilizer was applied, and the $\mathrm{JN}$ site was tilled at the same time as JF. October 2001 was the last date of tilling. A nearby area of uncontaminated, native prairie (JC) was tilled at the same time as JN and JF in order to control for the 
effects of mechanical disturbance. A nearby area of uncontaminated native prairie (JP) was left undisturbed except for sampling, in order to serve as the standard for restoration.

The second contaminated area, G5, contained three separate but adjacent lobes (GN, GM, GS) of prairie contaminated by spills of crude oil and brine (1:10 oil:brine) from a gathering line in the fall and winter of 1999. This sloped area was extremely rocky, and treatment in 2000 consisted of removing as many rocks by hand as possible, ripping the sites, adding hay and fertilizer (ammonium nitrate, diphosphorus pentoxide, and potassium oxide) to GN and GS, and installing an gravel-filled interception trench containing slotted drainage pipe at the bottom of GN and GM. A nearby area of uncontaminated prairie (GP) served as the standard for restoration. Samples were taken, but no additional manipulations were performed at these sites. Details of the treatments and remediation outcomes can be found in Sublette et al. (2005).

\section{Materials and methods}

Sampling and analytical

All J6 sites were sampled three times a year (spring, summer, fall) beginning May 1999 and ending October 2003. Additional samples were obtained in March 1999 from sites J6N, J6F, and J6P prior to beginning remediation. G5 sites were sampled three times a year (spring, summer, fall) beginning June 2000 and ending October 2003. Five-fold composite samples were made from near-surface soil $(0-15 \mathrm{~cm})$ and analyzed for a number of biological and chemical parameters (soil moisture, plant-available nutrients, TPH, brine components, phospholipid fatty acid analysis (PLFA), nematode numbers and diversity), as described in a previous section of this report, in addition to the DNA sequence analysis reported here. A subsample of the composite sample (approximately 
$300 \mathrm{~g}$ wet weight) was transported on ice back to the Norman, OK laboratory where it was homogenized aseptically and $0.5 \mathrm{~g}$ aliquots dispensed into sterile cryovials for storage at $-85^{\circ} \mathrm{C}$ until DNA was extracted. No more than forty-eight hours lapsed between sample collection and storage at $-85^{\circ} \mathrm{C}$. Total petroleum hydrocarbon levels (TPH) were analyzed by Continental Laboratories (Salina, KS) by EPA 418.1 (19992001) or EPA 1664 (2002-2003) after shipment of samples overnight on ice in completely-filled glass jars with Teflon lids. Analysis of the phospholipid fatty acid (PLFA) content of the soil samples was performed by Microbial Insights, Inc. (Rockford, TN) to determine the living microbial biomass. PLFAs are an essential component of cell membranes, but quickly decompose when cells die.

DNA isolation, PCR amplification, DGGE, cloning, and sequencing

The Fast DNA SPIN Kit for Soil (MP Biomedicals, Irvine, CA) was used to extract and purify DNA from soil using a bead-beating method (Mini Bead-Beater, BioSpec Products, Bartlesville, OK) to lyse bacterial cells and release DNA (Borneman et al. 1996, Duncan et al. 2003). To ensure the representation of DNA from cells that are more difficult to lyse, three successive bead-beating and extractions were performed on each sample. The three DNA extracts were pooled, the DNA concentration determined by fluorometry (Hoefer Inc., San Francisco, CA) and adjusted to $5 \mathrm{ng} / \mu \mathrm{L}$ with PCR-grade water. DNA fragment size was examined and the concentration verified by agarose gel electrophoresis of an aliquot of the DNA sample and viewing the ethidium bromidestained gel under UV transillumination. DNA extraction conditions resulted in fragments approximately $8-25 \mathrm{~kb}$ in size. Purity of the DNA extraction kit components and maintenance of aseptic conditions throughout the extraction procedure were assessed by 
extracting one "reagent control" blank (e.g. all reagents and kit components were used) for every seven samples processed. The reagent control blanks were examined by agarose gel electrophoresis and used as template DNA in PCR amplifications with universal eubacterial primers for 16S rRNA (GM5F and D907R, Muyzer et al., 1993). Primers were synthesized by Invitrogen Corp. (Carlsbad, CA). Other reagents and enzymes were purchased from Fisher Scientific or Sigma-Aldrich. PCR amplification was performed in a Stratagene Robocycler (Stragene, La Jolla, CA), and followed the touch-down procedure described in Muyzer et al. (1993).

Primers GM5F and D534 (Muzyer et al., 1993) were used to amplify a 220-bp region of eubacterial 16S rRNA for denaturing gradient gel electrophoresis (DGGE) analysis of differences among the sites in sequence diversity. DGGE was performed using a D-Code 16/16-cm gel apparatus (BioRad, Hercules, CA), at a constant voltage of $65 \mathrm{~V}$ for $16 \mathrm{~h}$ and a constant temperature of $60^{\circ} \mathrm{C}$. The gradient was formed of $8 \%$ polyacrylamide in TAE buffer with between 40 and $60 \%$ denaturant (7M urea and $40 \%$ formamide is defined as $100 \%$ denaturant). After electrophoresis, the gel was stained in a solution of ethidium bromide, destained in deionized water, and a permanent image captured by the NucleoCam Digital Image Documentation System (NucleoTech Corp., San Mateo, CA).

16S rRNA PCR products of approximately $550 \mathrm{bp}$ in size were obtained for cloning from the March 1999, April 2001, and April 2003 sites listed in Table 1 by amplification of 50 pg DNA per $25 \mu \mathrm{L}$ PCR reaction mix containing 5 pmol each of the primers GM5F and D907R (Muyzer et al., 1993), 1x PCR buffer (Fisher), $2.5 \mathrm{mM}$ $\mathrm{MgCl}$, , $0.5 \mathrm{M}$ betaine (Sigma-Aldrich, St. Louis, MO), $0.2 \mathrm{mM}$ of each deoxynucleoside 
triphosphate, and $0.625 \mathrm{U}$ Taq polymerase. PCR amplification was performed in a Stratagene Robocycler (Stragene, La Jolla, CA), and followed the touch-down procedure described in Muyzer et al. (1993). The quality and concentration of the PCR products were assessed by agarose gel electrophoresis, and if found to be single discrete bands of the correct size, were cloned into the TOPO-TA vector (Invitrogen) following the manufacturer's recommendations to increase the number of transformants when cloning from a pool of sequences. White colonies were transferred with sterile toothpicks into 96well microtiter plates containing $200 \mu \mathrm{L}$ TB medium (Elshahed et al., 2003), grown overnight at $37^{\circ} \mathrm{C}$ and stored at $-85^{\circ} \mathrm{C}$ until DNA isolation and sequencing was performed as described in detail in Elshahed et al. (2003). Two forward and two reverse trace files were generated and analyzed separately to generate a sequence. Phylogenetic analysis

Initial phylogenetic assignments were made following BLAST searches (Basic Local Alignment Search Tool, Altshuler et al.,1997). Sequencher (Windows Version 4.2, Gene Codes Corp., Ann Arbor, MI) was used to trim vector regions from the cloned sequences and to examine each cloned sequence for the presence of universally conserved regions. Three programs were used to check for the presence of putative chimeric sequences; Chimera-Check (Ribosomal Database Project, Maidak et al., 2001), Bellerophon (Huber et al., 2004), and Pintail (Ashelford, et al. 2005). Sequences were removed from the data set if chimeric. Phylogenetic placement of sequences was further examined using the Classifier program (RDP, Maidak et al., 2001) and by high (>92\%) sequence similarity to representatives of major eubacterial divisions or to classes of Proteobacteria. The sequences were aligned using ClustalX (Thompson et al. 1997) and 
alignments corrected manually as needed. An evolutionary distance tree was constructed using the neighbor-joining algorithm, and bootstrap support for branches assessed by 1000 repetitions. The evolutionary distance trees were used to provide a final examination of phylogenetic placement to divisions. Those sequences that were distant from described eubacterial divisions or whose divisions were represented in less than half the samples were assigned the category of "Other" for most of the analyses described in this manuscript.

\section{Statistical Analysis}

Statistical analyses were performed using SPSS for Windows (Rel.11.5.0, 2002). Cluster Analysis used the between group linkage method to group different samples together using the proportion (as \% of the total) of clones in each of nine major phylogenetic groups. One-way ANOVA was used to determine the significance of differences in mean values of the proportions of clones among various types of samples (e.g. prairie, tilled, oil-contaminated, brine-contaminated). Discriminant function analysis was used to construct a model for grouping samples into different classes based on their contaminant status.

\section{Results and Discussion}

\section{Time course of contamination, treatment, and sampling}

The DGGE profiles were used to monitor changes in sequence diversity over more time points than was feasible for the determination of eubacterial genetic diversity by DNA sequencing. Although the 16S rRNA partial sequence profile of the eubacterial communities was complex, as shown by Fig. 1, some general conclusions may be made. Uncontaminated sites, such as JP, showed little variation in their profile seasonally and 
over a period of several years (Fig. 1A). Profiles were comprised of many different bands, even though conditions were biased (amplification of $220 \mathrm{bp}$ fragment rather than $550 \mathrm{bp}$, narrow gradient range) to try to decrease the complexity of the profile. The DGGE profile complexity suggests many different eubacterial species were present in each soil sample, as has been found in previous studies (Torsvik et al., 1990). The DGGE profiles of the contaminated sites (Fig. 1B, 1C), show more variation over time in the position of their dominant bands and are characterized by several strongly staining bands, suggesting a less even sequence diversity than the uncontaminated sites. The uncontaminated prairie (JP) and tilled, uncontaminated (JC) sites have very similar profiles and fewer strongly staining bands than the contaminated sites, JN and JF (Fig. $1 \mathrm{D}, 1 \mathrm{E})$, again suggesting a more even sequence diversity in the uncontaminated sites. DNA Sequence Analysis

Samples chosen for investigation by DNA sequencing represent different stages in remediation and recovery (Table 1). March 1999 samples from the J6 site represent a time point two months post-contamination, before remediation treatments began in June 1999 and contain high levels of TPH. PLFA concentrations, reflecting the quantity of live microbial biomass, are at about half the concentration in the contaminated JN and JF sites in April 1999 as in the undisturbed prairie (PLFA samples were not obtained in March 1999). Remediation of the J site began June 1999, and included tilling of JN, JF, and JC, and the application of N-containing fertilizer to JF. J site samples collected in April 2001 represent almost two years of remediation treatment and JN and JF have substantially lower TPH levels and somewhat higher PLFA concentrations than in 1999. Tilling and fertilizer applications ended in October 2001. J site samples collected in April 2003 
represent the microbial communities after a two year period of recovery. TPH levels were much lower than in 2001, and PLFA concentrations in JC and JF were close to that in the prairie.

We were not able to obtain pre-remediation samples for G5, so the two samples represent approximately one year of remediation (April 2001) and three years of remediation (April 2003). Unlike the J6 site, there was no further application of fertilizer or soil disturbance after the initial treatment in June 2000. TPH levels, sodium, and chloride concentrations were lower in GN, GM, and GS 2003 samples than in 2001, but PLFA concentrations remained at about one-third that found in the nearby undisturbed prairie (GP). Additional information about the remediation of G5 is detailed in Sublette et al. (2005).

Fifty picograms DNA were used in each PCR amplification to produce the $550 \mathrm{bp}$ partial 16S rRNA sequences for cloning. Equivalent, dilute DNA concentrations were chosen to preferentially amplify the most dominant members of a very diverse community. The number of clones per sample was roughly equivalent, between 88 and 114 (Table 2), and all these clones had passed three different screens for chimeric sequences (see Materials and Methods). The samples however differed considerably in the fraction of clones with "unique" sequences (Table 2, Figure 2); both at the $100 \%$ level (counted as different sequences if any nucleotides were different) and the $99 \%$ level (considered as different sequences if $1 \%$ or more of the nucleotides were different). In agreement with the DGGE profiles, a greater proportion of unique clones, at both the $100 \%$ and $99 \%$ identity level, were found in the uncontaminated or less contaminated samples than in the samples from grossly contaminated sites, producing a more even 
distribution of sequence types, while some of the more contaminated samples (GS03, JN03) had many fewer unique clones, with some sequences strongly represented.

Three evolutionary distance trees, constructed by the neighbor-joining method, illustrate the differences in division-level and class-level (for Proteobacteria) affiliations seen for DNA sequences cloned from uncontaminated prairie (JP01, Fig. 3), oilcontaminated (JN01, Fig. 4), and brine-contaminated samples (GN01, Fig. 5). JP01 (Fig. 3, 91 sequences) has a high proportion of unique clones (Table 2, see also Fig. 2), a high proportion of sequences affiliated with Actinobacteria, Acidobacteria, and $\alpha$ Proteobacteria, and relatively few sequences similar to those of $\gamma$ Proteobacteria, Firmicutes, or Bacteroidetes (see also Table 3). JN01 (Fig. 4, 102 sequences), from an oil-contaminated site that had not been treated with fertilizer, has a higher proportion of clones with identical sequences, a much higher proportion of $\gamma$ Proteobacteria, and lower relative numbers of Actinobacteria and Acidobacteria. GN01 (Fig. 5, 91 sequences), sampled from a brine-contaminated site, also has a higher proportion of clones with identical sequences and a higher proportion of $\gamma$ Proteobacteria. GN01 differs from JN01 in having a higher proportion of sequences similar to those of Bacteroidetes and Firmicutes, and in being very deficient in Acidobacteria.

A hierarchical cluster analysis (Figure 6) was used to compare all samples for their degree of similarity in the proportion of $16 \mathrm{~S}$ rRNA sequences in the eubacterial divisions and classes listed in Table 3. Most samples clustered into two major groups, one containing primarily samples from the uncontaminated sites ("1", Figure 6), and the other containing samples from contaminated sites (“2”, Figure 6). Cluster 1 shows that samples collected in the same year tend to be more similar than samples collected in different 
years. Sites disturbed only by tilling (JC01 and JC03) and not by oil or brine contamination were associated with undisturbed prairie by this analysis, as was the JF01 oil-contaminated site that received fertilizer. Pre-treatment oil-contaminated samples (JN99 and JF99) were also more similar to uncontaminated sites than to the majority of contaminated sites. Cluster 2 can be divided into two subclusters, "a", brine-contaminated sites, and "b", primarily oil-contaminated sites. Two samples from brine-contaminated sites (GN03 and GM01, "3", Figure 6) diverged more strongly from the rest of the samples.

The effect of different types of disturbance versus no disturbance on the proportion of each eubacterial group listed in Table 3 was assessed by comparing the means of each group (one-way ANOVA). Figure 7 shows the mean values (and SD) of the various groups for each type of site. "Prairie" included the 5 samples from JP and GP, "tilled" samples were JC01 and JC03, "oil" were JN and JF for 1999, 2001, and 2003, and "brine" were the GN, GM, and GS samples for 2001 and 2003. Significant differences in mean values $\left(\mathrm{F}_{3,18}>3.6, \mathrm{p}<0.05\right)$ were found for Acidobacteria $(\mathrm{p}=0.000)$, Firmicutes $(\mathrm{p}=0.035)$, Actinobacteria $(\mathrm{p}=0.010), \gamma$ Proteobacteria $(\mathrm{p}=0.037)$, and Bacteroidetes $(\mathrm{p}=0.000)$. Tilling had the least effect, or no significant effect, on shifting the relative proportions of the eubacterial groups away from those seen in undisturbed prairie, oil contamination had a greater effect, while brine contamination had the greatest effect and uniquely selected for an increase in sequences affiliated with Bacteroidetes. Ecological characteristics of Acidobacteria and Actinobacteria

Other studies of eubacterial $16 \mathrm{~S}$ sequences from soil have found Acidobacterium to be among the dominant groups (Smit et al. 2001, Quaiser et al. 2003, references). 
Although few strains have been cultured, low-oxygen conditions (microaerophilic) and long incubation times appear to select for Acidobacteria while organic nutrient supplements select against them (Stevenson et al., 2004). Others (Janssen et al., 2002; Davis et al., 2005) have been able to culture Acidobacteria and Actinobacteria from soil using very dilute inocula, selected media, and long incubation times. These studies support the association of Acidobacteria and Actinobacteria with low nutrient conditions normally found in the prairie soil in the current study and the hypothesis that they will be k-selected, rather than r-selected.

\section{Discriminant function analysis}

Given that the eubacterial community in these tallgrass prairie soils appears to have distinctive characteristics, we can construct a statistical model to classify the eubacterial community in remediated sites as uncontaminated or still demonstrating the effects of contamination. Using discriminant function analysis (DFA), we have an additional tool, based on eubacterial community structure, to assess the recovery of the soil ecosystem. DFA derives a set of functions that best separates samples into groups based on the initial assignation of group membership to the set of samples used for constructing the model. Due to the small number of samples, we assigned them to one of three groups: Uncontaminated (JP99, JC01, JP01, JC03, JP03, GP01, GP03); Oilcontaminated (JN99, JF99, JN01, JF01, JN03, JF03); and Brine-contaminated (GN01, GM01, GS01, GN03, GM03, GS03). The best fit between the initial group designation and group membership after model construction was found by using the proportions of dominant eubacterial groups (Table 3 ) as variables and entering them in a stepwise fashion. The two canonical discriminant functions (DF) were based on the proportion of 
Acidobacteria, Actinobacteria, and Bacteroidetes. Mapping the samples with respect to the DF axes (Figure 8) shows one sample would be misclassified--JC01 (6) was considered to be an uncontaminated sample, but is classified as closer to samples from oil-contaminated sites. In the cross-validation tests (samples are removed singly and their placement is recalculated based on the remaining samples), JF03 (9), from an oilcontaminated site, was classified as a sample from an uncontaminated site. Both of these "misclassifications" in fact present an accurate picture of the particular samples--JC01, although not contaminated, shows the effect of disturbance due to tilling, a disturbance that was also applied to the oil-contaminated sites. JF03 is from an oil-contaminated site that is judged to have recovered more fully than the other sites (see Table 1, PLFA and TPH concentrations), as assessment that is borne out by other data such as nematode community structure and PLFA structural groups (Mehta et al., 2005).

This approach can be applied more generally to assess the degree of disturbance and extent of recovery of systems of interest, such as bioreactors and wastewater treatment systems. Another function for dissecting shifts in community composition, is to use this information to generate hypotheses about the role and function of different groups in the community, in order to increase our understanding of how diverse microbes function in communities.

\section{Conclusion}

Contamination by oil spills and by oil-field brine each have profound effects on the soil microbial community of the tallgrass prairie, shifting the eubacterial community from one dominated by Actinobacteria, $\alpha$ Proteobacteria, and Acidobacteria, to communities in which the slow-growing Actinobacteria and Acidobacteria are poorly 
represented and the faster-growing, contamination-tolerant $\gamma$ proteobacteria, Firmicutes, and Bacteroidetes (in the case of brine-contamination) rise to prominence. Tilling the soil, necessary for treatment of the contaminated sites with hay and N-containing fertilizer, has little effect on the community in comparison to the chemical contamination. $\mathrm{N}$-containing fertilizer appears to ameliorate the effects of oil contamination on the community. Discriminant function analysis model, incorporating a weighted function of $\%$ Acidobacteria, Actinobacteria, and Bacteroidetes correctly categorized samples as uncontaminated, oil-impacted, or brine-impacted. The community in the fertilizer-treated, oil-contaminated site was similar to that in the prairie after four years, but the brineimpacted sites showed substantial differences three years after treatment began.

\section{References}

Arias ME, Gonzalez-Perez JA, Gonzalez-Vila FJ, Ball AS. 2005. Soil health -- a new challenge for microbiologists and chemists. Int. Microbiol. 8(1):13-21.

Ashelford, Kevin E., Nadia A. Chuzhanova, John C. Fry, Antonia J. Jones, and Andrew J. Weightman. 2005. At least 1 in 20 16S rRNA sequence records currently held in public repositories is estimated to contain substantial anomalies. Appl. Envir. Microbiol. 2005 71: 7724-7736.

Baer, S. G., Blair, J. M., Collins, S. L., and Knapp, A. K. 2003. Soil resources regulate productivity and diversity in newly established tallgrass prairie. Ecology. 84: 724735.

Borneman, J., PW Skroch, KM O'Sullivan, JA Palus, NG Rumjanek, JL Jansen, J Nienhuis, and EW Triplett. 1996. Molecular microbial diversity of an agricultural soil in Wisconsin. Appl. Envir. Microbiol. 62: 1935-1943.

Chorom M. and Rengasamy P., 1997. Carbonate chemistry, pH, and physical properties of an alkaline sodic soil as affected by various amendments, Australian Journal of Soil Research 1997 35:149 - 161.

Collins, S. L., Knapp, A. K., Briggs, J. M., Blair, J. M., and Steinauer, E. M. 1998. Modulation of diversity by grazing and mowing in native tallgrass prairie. Science. 280: 745-747.

Davidson, E. A., Stark, J. M., and Firestone, M. K. 1990. Microbial production and consumption of nitrate in an annual grassland. Ecology. 71: 1968-1975.

Davis, K. E. R., Joseph, S. J., and Janssen, P. H. 2005. Effects of growth medium, inoculum size, and incubation time on culturability and isolation of soil bacteria. Appl Environ Microbiol. 71: 826-834. 
Dell, C. J., Williams, M. A., and Rice, C. W. 2005. Partitioning of nitrogen over five growing seasons in tallgrass prairie. Ecology. 86: 1280-1287.

Duncan, K. E., R. Kolhatkar, G. Subramanim, R. Narasimhan, E. Jennings, S. Hettenbach, A. Brown, C. McComas, W. Potter, K. Sublette. 1999. "Microbial dynamics in oil-impacted prairie soil". Applied Biochemistry and Biotechnology. 77-79: 421-434.

Duncan, K, E. Jennings, S. Hettenbach, W. Potter, K. Sublette, G. Subramaniam, and R. Narasimhan. 1998. "Nitrogen cycling and nitric oxide emissions in oil-impacted prairie soils". Bioremediation Journal. 1(3):195-208.

Elshahed MS, Senko JM, Najar FZ, Kenton SM, Roe BA, Dewers TA, Spear JR, Krumholz LR. 2003. Bacterial diversity and sulfur cycling in a mesophilic sulfide-rich spring. Appl Environ Microbiol. (9):5609-21.

Foster, B. L., and Gross, K. L. 1998. Species richness in a successional grassland: effects of nitrogen enrichment and plant litter. Ecology. 79: 2593-2602.

Groffman, P.M., Rice, C. W., and Tiedje, J. M. 1993. Denitrification in a tallgrass prairie landscape. Ecology. 74: 855-862.

Hartnett, D. C., and Wilson, G. W. T. 1999. Mycorrhizae influence plant community structure and diversity in tallgrass prairie. Ecology. 80: 1187-1195.

Hendrix, P. F., Parmelee, R. W., Crossley, D. A. Jr., Coleman, D. C., Odum, E. P., and Groffman, P. M. 1986. Detritus food webs in conventional and no-tillage agroecosystems. BioScience 36: 374-380.

Huber, T.,G. Faulkner and P. Hugenholtz. 2004. Bellerophon; a program to detect chimeric sequences in multiple sequence alignments, Bioinformatics. 20: 2317 2319.

Inouye, R. S., and Tilman, D. 1995. Convergence and divergence of oil-field vegetation after 11 yr. of nitrogen addition. Ecology. 76: 1872-1887.

Janssen, P. H., Yates, P. S., Grinton, B. E., Taylor, P. M., and Sait, M. 2002. Improved culturability of soil bacteria and isolation in pure culture of novel members of the divisions Acidobacteria, Actinobacteria, Proteobacteria, and Verrucomicrobia. Appl Environ Microbiol. 68: 2391-2396.

Johnson, L. C., and Matchett, J. R. 2001. Fire and grazing regulate belowground processes in tallgrass prairie. Ecology. 82: 3377-3389.

Maidak BL, Cole JR, Lilburn TG, Parker CT Jr, Saxman PR, Farris RJ, Garrity GM, Olsen GJ, Schmidt TM, Tiedje JM. 2001. The RDP-II (Ribosomal Database Project). Nucleic Acids Res. 29(1):173-4.

Muyzer, G., EC de Waal, and AG Uitterlinden. 1993. Profiling of complex microbial populations by denaturing gradient gel electrophoresis analysis of polymerase chain reaction-amplified genes coding for $16 \mathrm{~S}$ rRNA. Appl. Envir. Microbiol. 59: 695-700.

Mehta, C., Moralwar, A., Sublette, K., Jennings, E., Duncan, K.. Brokaw, J., Todd, T., and Thoma, G, 2005. Monitoring soil ecosystem recovery following bioremediation of a terrestrial crude oil spill with and without a fertilizer amendment. Final Report to the National Petroleum Technology Office of U.S. Department of Energy (DE-FC26-01BC15332). 
Nelson P.N. and Oades J.M. 1998. Organic Matter, Sodicity, and Soil Structure, in Sodic Soils Distribution, Properties, Management, and Environmental Consequences, Edited by M.E. Sumner and R. Naidu, Oxford University Press, New York.

Paul, E. A., and Clark, F. E. 1989. Soil microbiology and biochemistry. Academic Press, Inc. San Diego, CA.

Quaiser, A., Ochsenreiter, T., Lanz, C., Schuster, S. C., Treusch, A. H., Eck, J., and Schleper, C. 2003. Acidobacteria form a coherent but highly diverse group within the bacterial domain: evidence from environmental genomics. Mol. Microbiol. 50(2): 563-575.

Risser, P.G., Birney, E. C., Blocker, H. D., May, S. W., Parton, W. J., and Wiens, J. A. 1981. The True Prairie Ecosystem. Hutchinson Ross Publishing Co. Stroudsburg, PA.

Smit, E., Leeflang, P., Gommans, S., van den Broek, J., van Mil, S. and K. Wernars. 2001. Diversity and seasonal fluctuations of the dominant members of the bacterial soil community in a wheat field as determined by cultivation and molecular methods. Appl. Envir. Microbiol. 67: 2284-2291..

SPSS for Windows, Rel. 11.5.0. Sept. 2002. Chicago: SPSS Inc.

Stevenson, B. S., Eichorst, S. A., Wertz, J. T., Schmidt, T. M., and Breznak, J. A. 2004. New strategies for cultivation and detection of previously uncultured microbes. Appl. Environ. Microbiol. 70: 4748-4755.

Sublette, K.L., Kolhatkar, R., Pim, K., Kolhatkar, A., Duncan, K.E., Miller, B., Fogg, R., Rider, P., Stepp, A., Carey, M., Todd, T. and Cross, A. 2002. "Long-term impacts of a crude oil spill on a pristine soil ecosystem", Proceedings of the 25th Arctic and Marine Oilspill Program Technical Seminar, Calgary, Alberta, Volume 2, 979-1011.

Sublette, K. L., A. Moralwar, L. Ford, K. Duncan, G. Thoma, and J. Brokaw. 2005. Remediation of a spill of crude oil and brine without gypsum. Environ. Geosciences V. 12 (2): 115-125.

Tate, R. L. 1995. Soil Microbiology. John Wiley and Sons, New York, N.Y.

Thompson JD, Gibson TJ, Plewniak F, Jeanmougin F, Higgins DG.1997. The CLUSTAL_X windows interface: flexible strategies for multiple sequence alignment aided by quality analysis tools. Nucleic Acids Res. 25(24):4876-82.

Torsvik, V., Goksoyr, J., and Daae, F. L. 1990. High diversity in DNA of soil bacteria. Appl. Environ. Microbiol. 56: 782-787.

Turner, C.L., Blair, J. M., Schartz, R. J., and Neel, J. C. 1997. Soil N and plant responses to fire, topography, and supplemental $\mathrm{N}$ in tallgrass prairie. Ecology. 78: 18321843.

Wedin, D. A., and Tilman, D. 1996. Influence of nitrogen loading and species composition on the carbon balance of grasslands. Science. 274: 1720-1723.

Zahran H.H. 1997. Diversity, adaptation and activity of the bacterial flora in saline environments, Biology and Fertility of Soils 1997 25:211 - 223. 
Table 1. Chemical parameters and PLFA values

\begin{tabular}{|c|c|c|c|c|c|c|c|}
\hline Site & $\begin{array}{c}\text { Date } \\
\text { sampled } \\
\text { code }\end{array}$ & $\begin{array}{c}\text { Sample } \\
(\mathrm{mg} / \mathrm{kg})\end{array}$ & $\begin{array}{c}\mathrm{Na}^{+} \\
(\mathrm{mg} / \mathrm{kg})\end{array}$ & $\begin{array}{c}\mathrm{Cl}^{-} \\
(\mathrm{mg} / \mathrm{kg})\end{array}$ & $\begin{array}{c}\text { PLFA } \\
\text { (pmols/g dry } \\
\text { wt. })\end{array}$ & $\begin{array}{c}\text { \%PLFA/ } \\
\text { prairie*** }\end{array}$ \\
\hline \multicolumn{7}{|c|}{ Pre-treatment } \\
\hline J6N & Mar 1999 & JN99 & 33500 & ND & ND & $40366^{* *}$ & 50.2 \\
\hline J6F & Mar 1999 & JF99 & 33500 & ND & ND & $36769^{* *}$ & 45.7 \\
\hline J6P & Mar 1999 & JP99 & ND & ND & ND & $80420^{* *}$ & 100 \\
\hline \multicolumn{7}{|c|}{ Remediation } \\
\hline J6N & April 2001 & JN01 & 6600 & ND & ND & 42270 & 64.6 \\
\hline J6F & April 2001 & JF01 & 6200 & ND & ND & 34438 & 52.6 \\
\hline J6C & April 2001 & JC01 & 59 & ND & ND & 44350 & 67.8 \\
\hline J6P & April 2001 & JP01 & 0 & ND & ND & 65440 & 100 \\
\hline \multicolumn{7}{|c|}{ Recovery } \\
\hline J6N & April 2003 & JN03 & 2635 & ND & ND & 9349 & 41.8 \\
\hline J6F & April 2003 & JF03 & 1001 & ND & ND & 20839 & 93.2 \\
\hline J6C & April 2003 & JC03 & 0 & ND & ND & 19007 & 85.0 \\
\hline J6P & April 2003 & JP03 & 0 & ND & ND & 22361 & 100 \\
\hline \multicolumn{7}{|c|}{ Remediation for one year } \\
\hline G5N & April 2001 & GN01 & 283 & 911 & 1410 & 27413 & 41.3 \\
\hline G5M & April 2001 & GM01 & 645 & 1483 & 3036 & 23781 & 35.9 \\
\hline G5S & April 2001 & GS01 & 916 & 1124 & 1892 & 26441 & 39.9 \\
\hline G5P & April 2001 & GP01 & 51 & 23 & 0 & 66300 & 100 \\
\hline \multicolumn{7}{|c|}{ Remediation for three years } \\
\hline G5N & April 2003 & GN03 & 169 & 438 & 596 & 8629 & 35.1 \\
\hline G5M & April 2003 & GM03 & 627 & 1188 & 2311 & 9622 & 39.1 \\
\hline G5S & April 2003 & GS03 & 150 & 1062 & 1527 & 9733 & 39.6 \\
\hline G5P & April 2003 & GP03 & 100 & 29 & 0 & 24597 & 100 \\
\hline
\end{tabular}

J6 sites: J6N and J6F contaminated by a crude oil spill in January 1999.

$\mathrm{J} 6 \mathrm{C}$ was tilled, uncontaminated prairie. J6P was uncontaminated, undisturbed prairie.

Remediation (tilling, addition of hay and fertilizer) began June 1999 and continued through October 2001.

G5 sites: G5N, G5M, G5S were contaminated by separate brine:crude oil (10:1) spills during the fall and winter of 1999. G5P was uncontaminated, undisturbed prairie.

Remediation treatment (ripping, addition of hay and fertilizer, installation of an interception trench in GN and GS) was performed June 2000

ND: not determined, samples were not assayed for this parameter.

*TPH (EPA method 418.8) was used for samples taken in 1999-2001. EPA method 1664 was used for samples beginning 2002.

**PLFA values for JN99, JF99, and JP99 are for samples taken April 1999, as samples for PLFA were not taken in March 1999.

***\%PLFA/prairie: PLFA values for the sites are standardized to the JP or GP PLFA concentration on that date, expressed as a percentage. 
Table 2. Proportions of unique clones within samples.

\begin{tabular}{|c|c|c|c|}
\hline $\begin{array}{l}\text { Sample } \\
\text { code }\end{array}$ & $\begin{array}{l}\text { \# clones } \\
\text { sequenced }\end{array}$ & $\begin{array}{c}\text { \% unique clones } \\
(100 \% \text { identity })\end{array}$ & $\begin{array}{c}\text { \% unique clones } \\
\text { (99\% identity })\end{array}$ \\
\hline JN99 & 91 & 91.2 & 83.5 \\
\hline JF99 & 104 & 95.2 & 89.4 \\
\hline JP99 & 114 & 96.5 & 86.0 \\
\hline JN01 & 102 & 92.2 & 76.5 \\
\hline JF01 & 99 & 97.0 & 85.9 \\
\hline JC01 & 88 & 94.3 & 88.6 \\
\hline JP01 & 91 & 100.0 & 94.5 \\
\hline JN03 & 93 & 81.7 & 61.3 \\
\hline JF03 & 100 & 96.0 & 85.0 \\
\hline JC03 & 95 & 96.8 & 88.4 \\
\hline JP03 & 103 & 98.1 & 91.3 \\
\hline GN01 & 91 & 94.5 & 79.1 \\
\hline GM01 & 99 & 100.0 & 61.6 \\
\hline GS01 & 92 & 98.9 & 87.0 \\
\hline GP01 & 92 & 98.9 & 88.0 \\
\hline GN03 & 92 & 95.7 & 68.5 \\
\hline GM03 & 93 & 88.2 & 79.6 \\
\hline GS03 & 92 & 76.1 & 60.9 \\
\hline GP03 & 93 & 90.3 & 83.9 \\
\hline$\%$ unique c10nes
\end{tabular}

$\%$ unique clones (100\% identity): \# of unique sequences after two or more sequences with $100 \%$ match have been considered as one unique sequence.

$\%$ unique clones ( $99 \%$ identity): \# of unique sequences after two or more sequences with $99 \%$ or higher match have been considered as one unique sequence. 
Table 3. Proportions (\%) of dominant eubacterial divisions and classes.

\begin{tabular}{|c|c|c|c|c|c|c|c|c|c|}
\hline \multirow{2}{*}{$\begin{array}{l}\text { Sample } \\
\text { code }\end{array}$} & \multirow[t]{2}{*}{ Acidobacteria } & \multirow[t]{2}{*}{ Firmicutes } & \multirow[t]{2}{*}{ Actinobacteria } & \multicolumn{4}{|c|}{ Proteobacteria } & \multirow[t]{2}{*}{ Bacteroidetes } & \multirow[t]{2}{*}{ "Other" } \\
\hline & & & & $\alpha$ & $\beta$ & $\delta$ & $\gamma$ & & \\
\hline JN99 & 5.5 & 11.0 & 29.7 & 26.4 & 15.4 & 5.5 & 1.1 & 0.0 & 5.5 \\
\hline JF99 & 4.8 & 17.3 & 39.4 & 16.3 & 9.6 & 2.9 & 1.0 & 2.9 & 5.8 \\
\hline JP99 & 21.1 & 4.4 & 18.4 & 28.9 & 8.8 & 10.5 & 0.9 & 0.9 & 6.1 \\
\hline JN01 & 13.7 & 7.8 & 13.7 & 33.3 & 3.9 & 3.9 & 21.6 & 1.0 & 1.0 \\
\hline JF01 & 11.1 & 4.0 & 36.4 & 18.2 & 8.1 & 8.1 & 8.1 & 1.0 & 5.1 \\
\hline $\mathrm{JC} 01$ & 11.4 & 5.7 & 34.1 & 22.7 & 2.3 & 10.2 & 3.4 & 2.3 & 8.0 \\
\hline JP01 & 18.7 & 5.5 & 31.9 & 23.1 & 8.8 & 3.3 & 1.1 & 1.1 & 6.6 \\
\hline JN03 & 8.6 & 6.5 & 15.1 & 24.7 & 6.5 & 1.1 & 33.3 & 2.2 & 2.2 \\
\hline JF03 & 17.0 & 7.0 & 19.0 & 25.0 & 0.0 & 9.0 & 16.0 & 0.0 & 7.0 \\
\hline $\mathrm{JC} 03$ & 20.0 & 0.0 & 42.1 & 14.7 & 6.3 & 3.2 & 3.2 & 4.2 & 6.3 \\
\hline JP03 & 22.3 & 4.9 & 39.8 & 21.4 & 1.9 & 2.9 & 0.0 & 0.0 & 6.8 \\
\hline GN01 & 0.0 & 15.4 & 16.5 & 24.2 & 2.2 & 6.6 & 13.2 & 17.6 & 4.4 \\
\hline GM01 & 2.0 & 9.1 & 7.1 & 18.2 & 1.0 & 1.0 & 48.5 & 13.1 & 0.0 \\
\hline GS01 & 5.4 & 6.5 & 27.2 & 25.0 & 0.0 & 1.1 & 16.3 & 14.1 & 4.3 \\
\hline GP01 & 13.0 & 5.4 & 34.8 & 25.0 & 4.3 & 1.1 & 3.3 & 3.3 & 9.8 \\
\hline GN03 & 3.3 & 35.9 & 15.2 & 10.9 & 4.3 & 1.1 & 10.9 & 7.6 & 10.9 \\
\hline GM03 & 7.5 & 14.0 & 5.4 & 35.5 & 6.5 & 0.0 & 18.3 & 8.6 & 4.3 \\
\hline GS03 & 1.1 & 16.3 & 13.0 & 23.9 & 3.3 & 1.1 & 21.7 & 8.7 & 10.9 \\
\hline GP03 & 15.1 & 0.0 & 35.5 & 17.2 & 1.1 & 3.2 & 1.1 & 4.3 & 22.6 \\
\hline
\end{tabular}

Sample code: as in Table 1.

"Other": includes sequences most similar to divisions that occur in less than half the samples or in low numbers, such as Chloroflexi, OP10, etc., or have low similiarity $(<88 \%)$ to any described divisions or candidate divisions. 
Figure legends.

Figure 1. DGGE profiles over time. Partial fragments of 16S rRNA genes (220 bp) amplified from DNA extracted from soil samples collected at times listed below. PCR products were run for $16 \mathrm{~h}$ at $65 \mathrm{~V}, 60^{\circ} \mathrm{C}$ in $8 \%$ polyacrylamide in a gradient of $40-60 \%$ denaturant. Ladder: Partial 16S rRNA PCR products of (top to bottom) Pseudomonas aeruginosa, Methylmicrobium album, Bacillus subtilis, Clostridium ljungdahii, and Desulfobotulus sapovorans.

A. JP. Lane 1. ladder, 2. 3/99, 3. 4/00, 4. 4/01, 5. 6/01, 6. 10/01, 7. 3/02, 8. 6/02, 9. 9/02, 10. 4/03, 11. 6/03, 12. ladder.

B. JF. Lane 1. ladder, 2. 3/99, 3. 4/00, 4. 4/01, 5. 6/01, 6. 10/01, 7. 3/02, 8. 6/02, 9. 9/02, 10. 4/03, 11. 6/03, 12. ladder.

C. GN. Lane 1. ladder, 2. 4/01, 3. 6/01, 4. 10/01, 5. 3/02, 6. 6/02, 7. 9/02, 8. 4/03, 9. 6/03, 10. ladder.

D. Comparison of J sites sampled 4/01. Lane 1. ladder, 2. JN, 3. JF, 4. JP, 5. JC.

E. Comparison of J sites, sampled 4/03. Lane 1. ladder, 2. JN, 3. JF, 4. JP, 5. JC.

Figure 2. Sequence diversity. X-axis: \# of unique sequences (100\%), after two or more clones with $100 \%$ match have been considered as one unique sequence. Y axis: \# of unique sequences (99\%), after two or more clones with $99 \%$ matching nucleotides have been considered as one unique sequence. X,Y values can also be found in Table 2. Sample codes as in Table 1 and 2.

Figure 3. Evolutionary distance tree based on the neighbor-joining algorithm, approximately $550 \mathrm{bp} 16 \mathrm{~S}$ rRNA cloned from DNA extracted and PCR amplified from a native prairie site in 2001 (JP01). 91 sequences are represented. The boxes enclose sequences that are affiliated with the named groups.

Figure 4. Evolutionary distance tree based on the neighbor-joining algorithm, approximately $550 \mathrm{bp} 16 \mathrm{~S}$ rRNA cloned from DNA extracted and PCR-amplified from an oil-contaminated site in 2001 (JN01). 102 sequences are represented. The boxes enclose sequences that are affiliated with the named groups.

Figure 5. Evolutionary distance tree based on the neighbor-joining algorithm, approximately 550 bp 16S rRNA cloned from DNA extracted and PCR amplified from a brine-contaminated site in 2001 (GN01). 91 sequences are represented, The boxes enclose sequences that are affiliated with the named groups.

Figure 6. Hierarchical cluster analysis of all the samples grouped by the relative proportion of their $16 \mathrm{~S}$ sequences in the different eubacterial groups (see Table 3 ). Samples are designated by the code described in Table 1 . The numbers indicate groups of samples that share certain characteristics; e.g. "1": not contaminated, "2a": brinecontaminated, "' 2 b": oil-contaminated, with the exception of GM03, "3": brinecontaminated. 
Figure 7. Mean and standard deviation (SD) of the relative proportions of the dominant groups of eubacteria (see Table 3) in four types of soil samples. "Prairie": JP99, JP01, JP03, GP01, GP03. “Tilled": JC01, JC03. “Oil”: JN99, JF99, JN01, JF01, JN03, JF03. "Brine": GN01, GM01, GS01, GN03, GM03, GS03. 7A. Acidobacteria (open circles), Actinobacteria (filled squares), "Other" (filled circles). 7B. Firmicutes (open circles), $\gamma$ Proteobacteria (filled squares), Bacteroidetes (filled circles). 7C. $\alpha$ Proteobacteria (filled squares), $\beta$ Proteobacteria (open circles), $\delta$ Proteobacteria (filled circles).

Figure 8. Canonical Discriminant Function Analysis of the proportion of DNA sequences in nine dominant groups of eubacteria. The standardized canonical discriminant function coefficients for Function 1 were Acidobacteria (0.500), Actinobacteria (0.716), and Bacteroidetes (-0.712), for Function 2 were Acidobacteria (0.892), Actinobacteria (0.249), and Bacteroidetes (0.833). The numbers refer to the following samples: 1. JN99, 2. JF99, 3. JP99, 4. JN01, 5. JF01, 6. JC01, 7. JP01, 8. JN03, 9. JF03, 10. JC03, 11. JP03, 12. GN01, 13. GM01, 14. GS01, 15. GP01, 16. GN03, 17. GM03, 18. GS03, 19. GP03. Due to the small number of tilled, uncontaminated samples, these samples (JC01 and JC03) were designated as "uncontaminated", also they were altered in comparison to the prairie samples. 
Figure 1. DGGE profiles over time

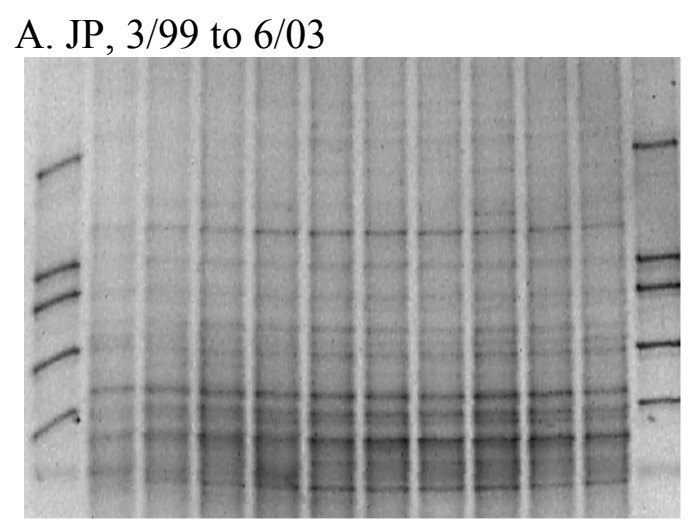

B. JF, 3/99 to $6 / 03$

C. $\mathrm{GN}, 4 / 01$ to $6 / 03$

D. J sites, 4/01
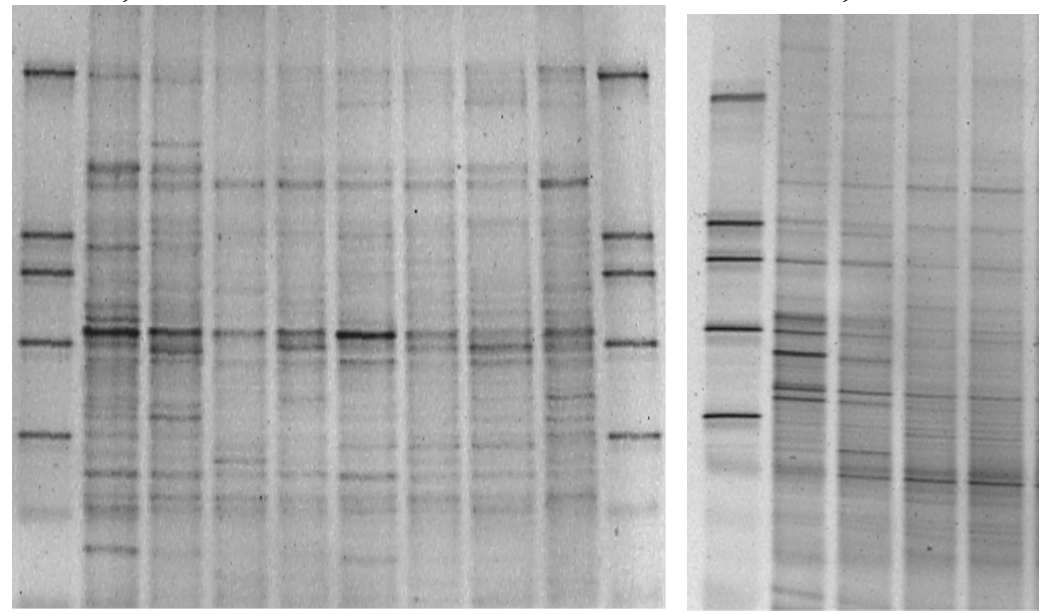

E. J sites, 4/03

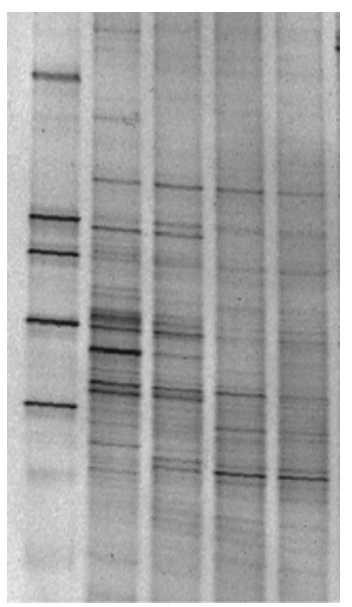


Figure 2. Sequence diversity.

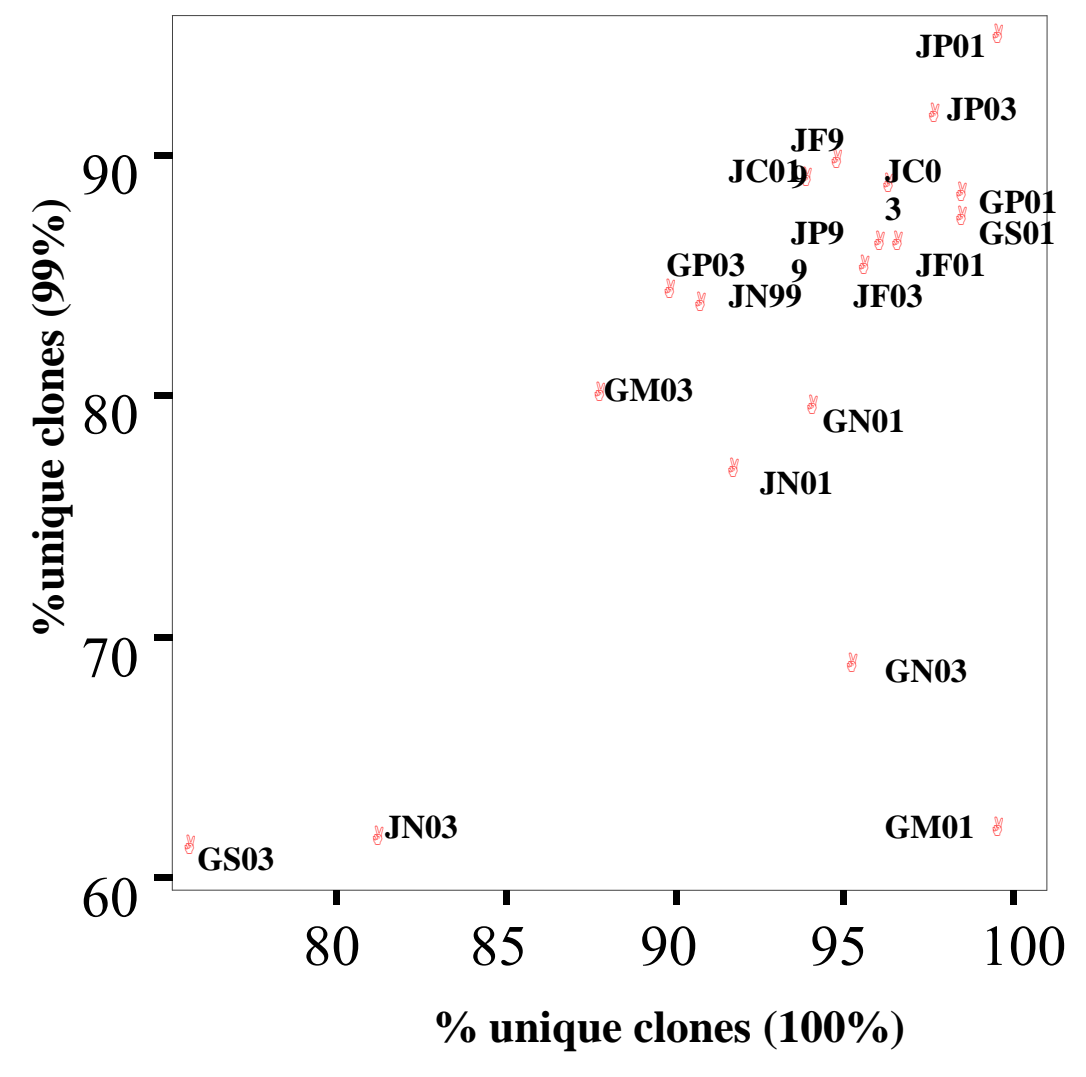


Figure 3. JP01, undisturbed prairie.

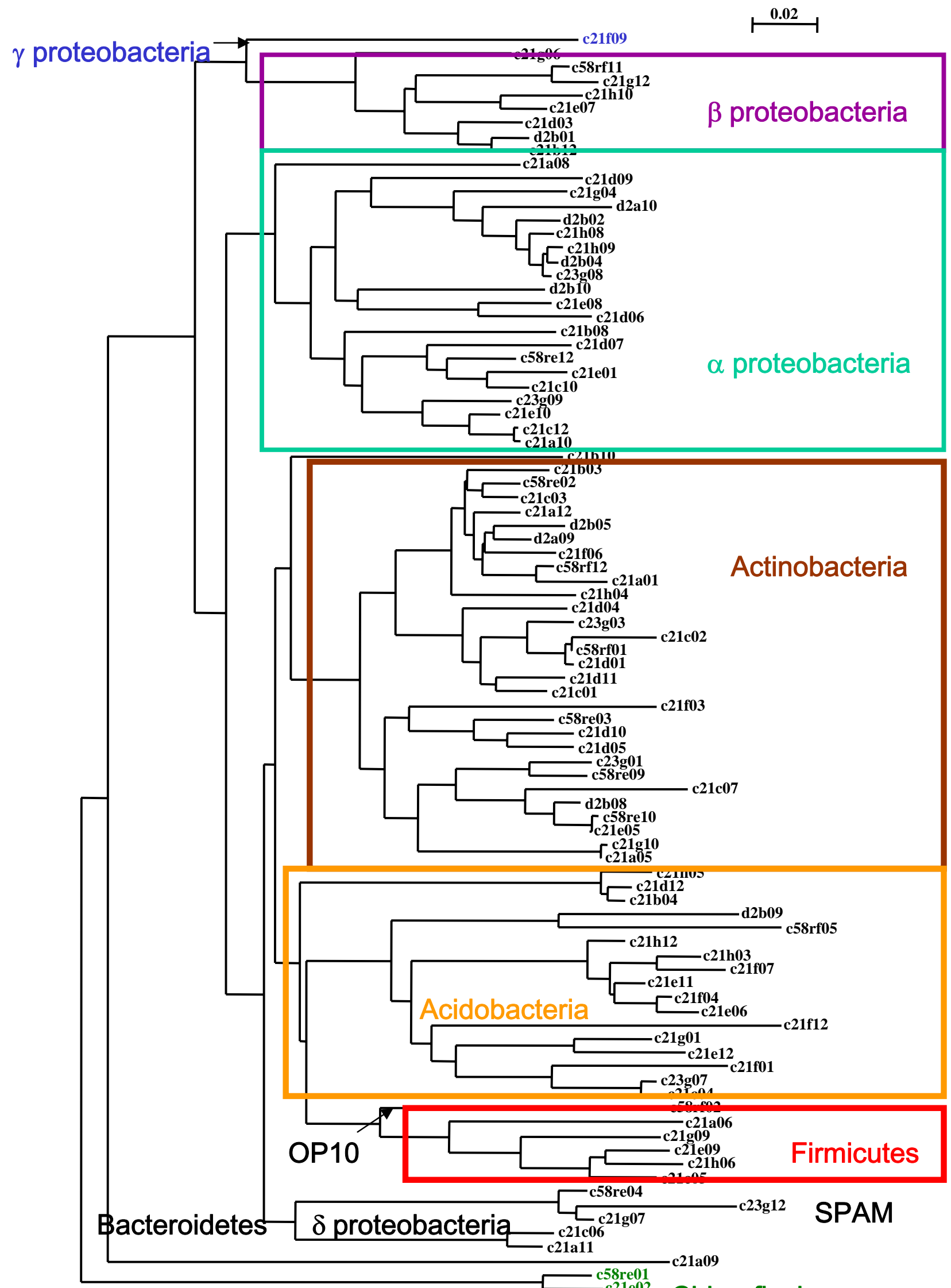


Figure 4. JN01, oil-contaminated.

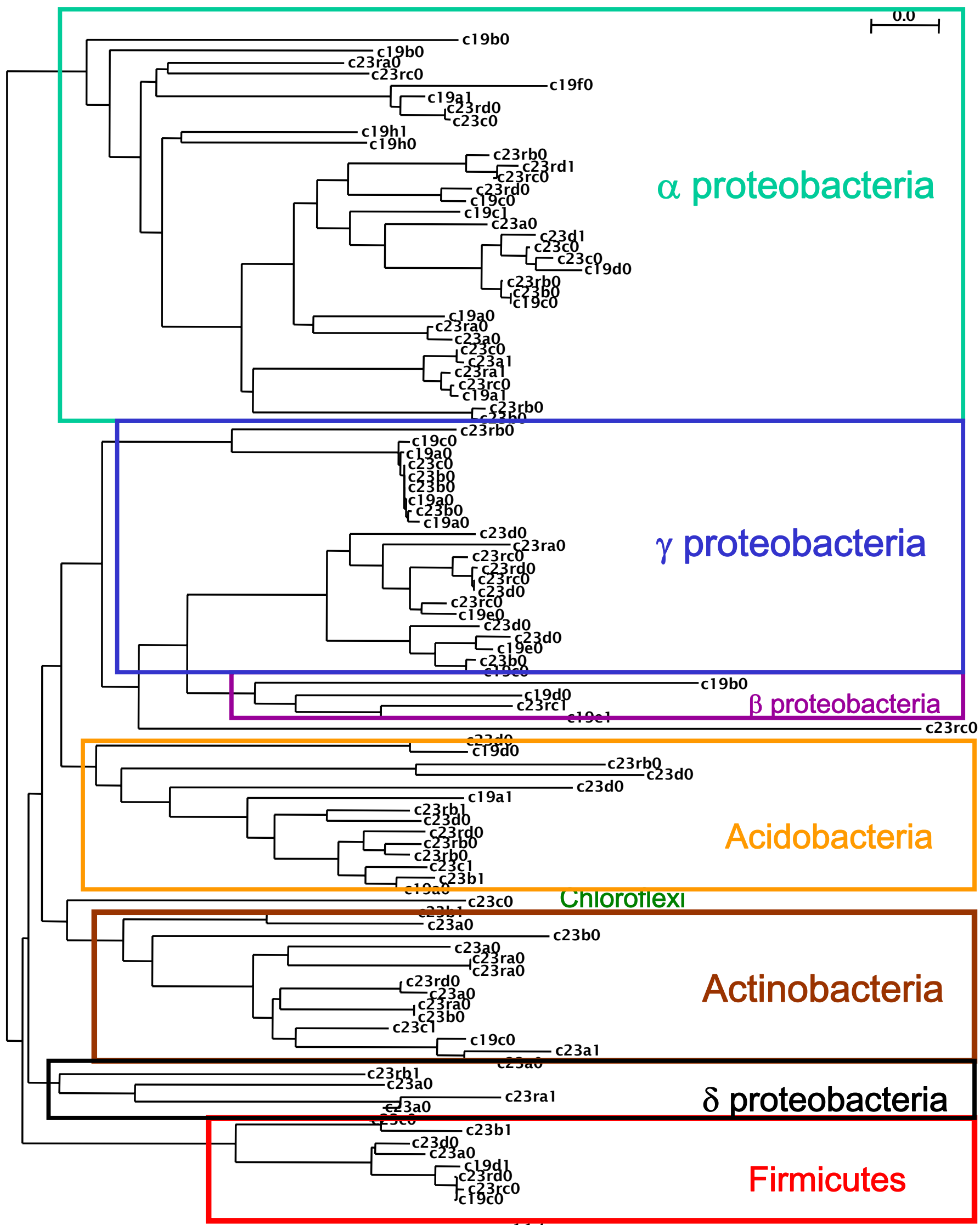


Figure 5. GN01, brine-contaminated.

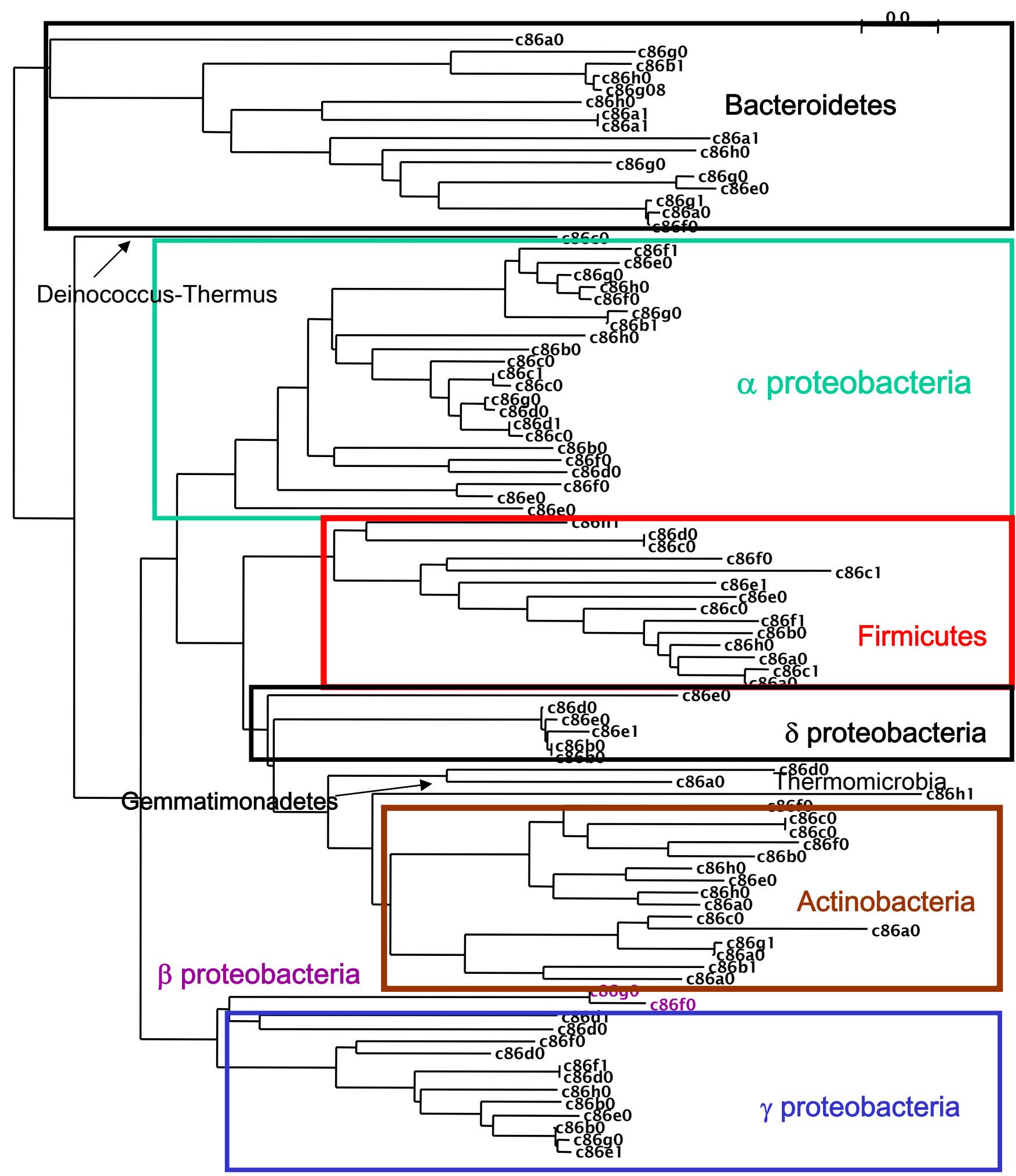


Figure 6. Cluster analysis of samples grouped by the relative proportion of 16S rRNA sequences in different eubacterial groups.

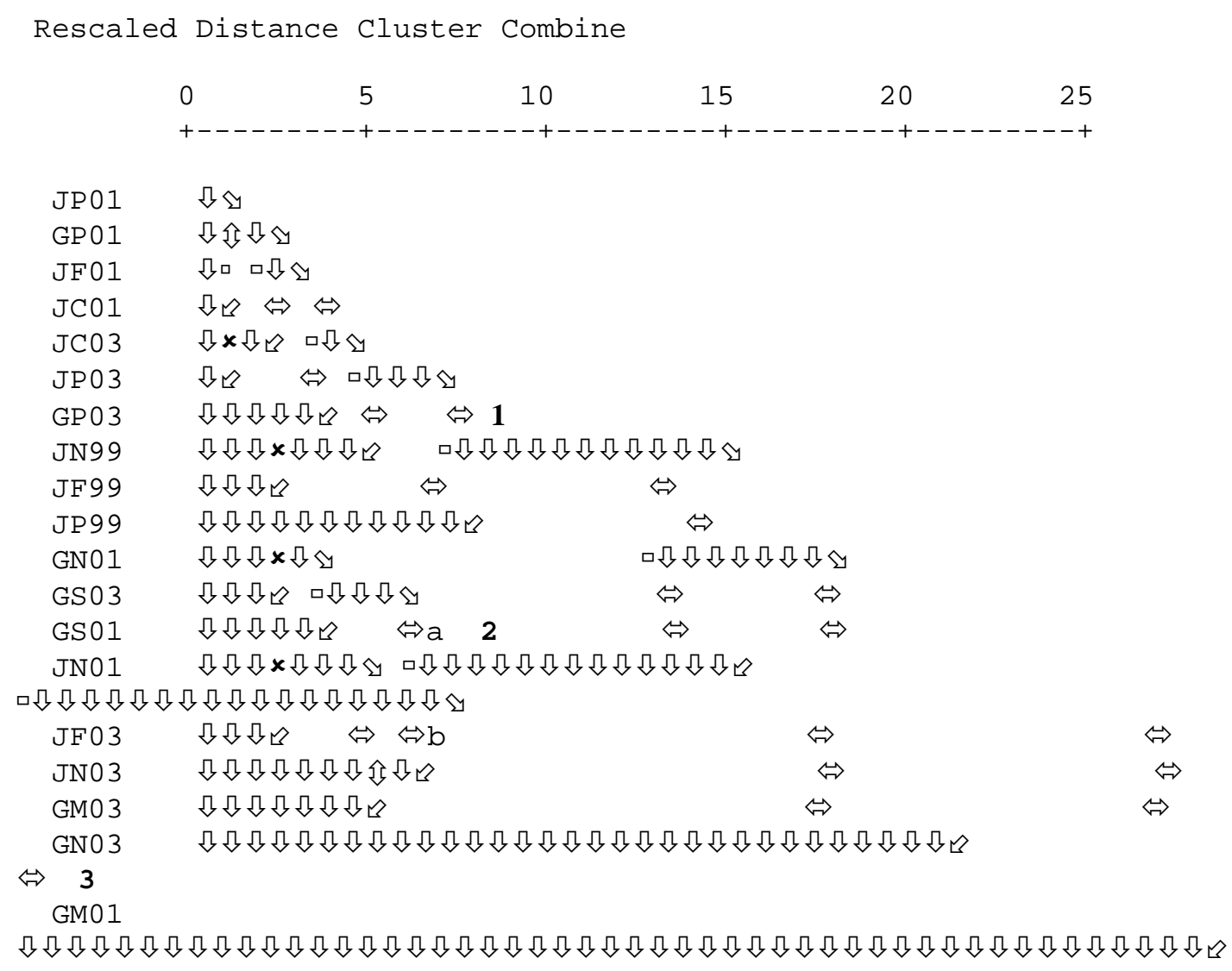


Figure 7.
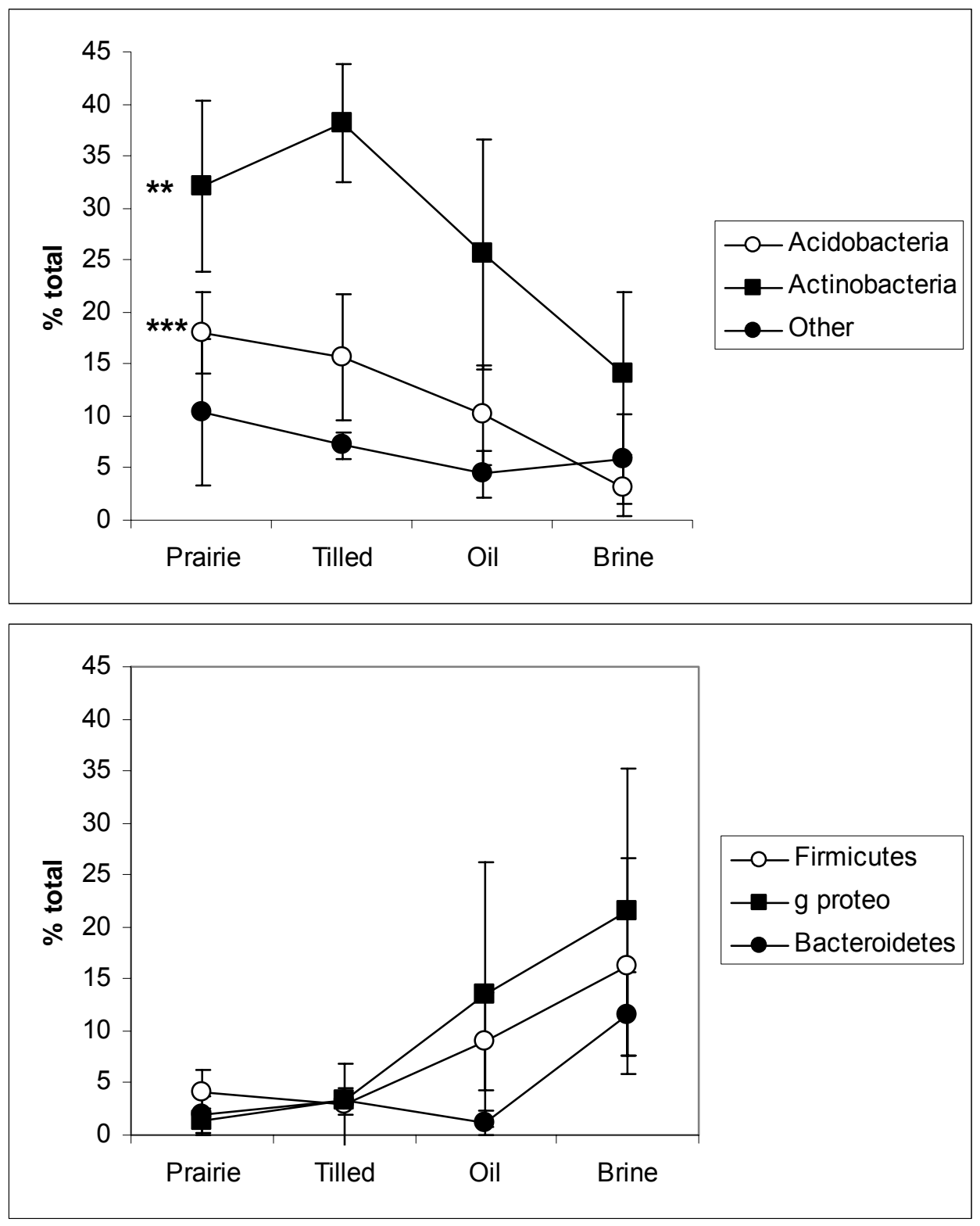


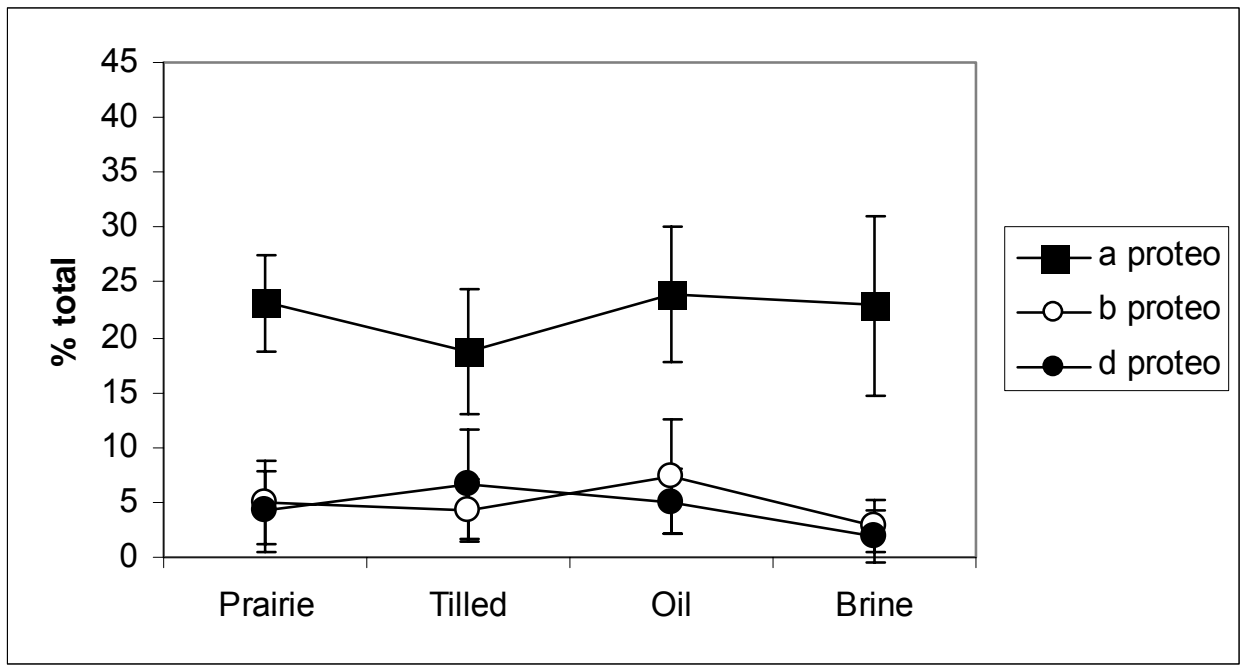


Figure 8. Canonical Discriminant Functions

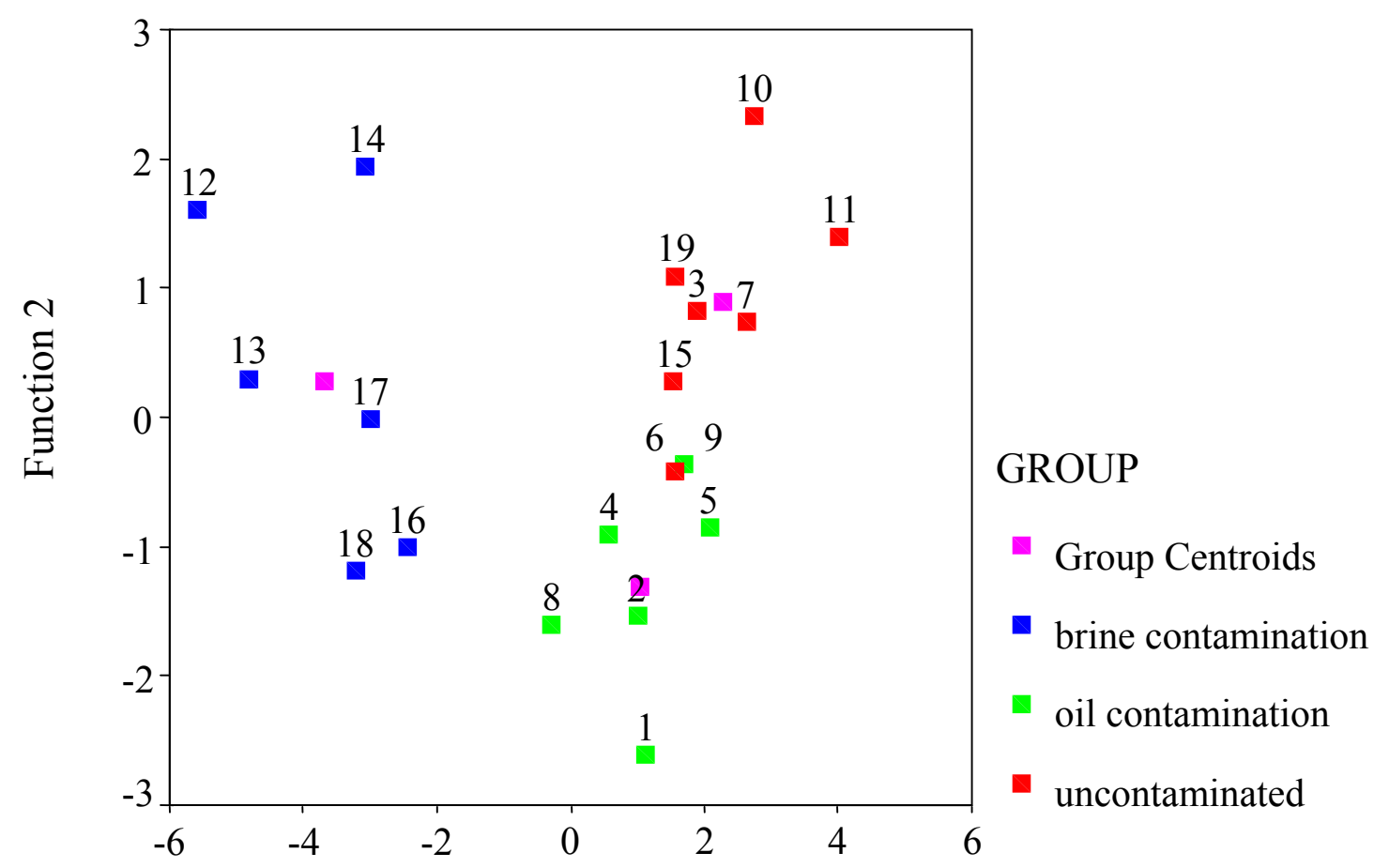

Function 1 


\title{
Chapter 4
}

\section{The Effect of Oil and Oil-field Brine Contamination on Ammonium-Oxidizing Bacteria in Tallgrass Prairie Soil}

\author{
Kathleen Duncan ${ }^{1 *}$, Bruce Roe ${ }^{2}$, Fares Najar ${ }^{2}$ \\ ${ }^{1}$ Dept. of Botany and Microbiology, ${ }^{2}$ Dept. of Chemistry and Biochemistry, \\ University of Oklahoma \\ Chintan Mehta, Aditya Moralwar, Kerry Sublette \\ Center for Applied Biogeosciences \\ University of Tulsa \\ Joshua Brokaw \\ Oklahoma State University \\ Dept. of Botany \\ Tim Todd \\ Kansas State University \\ Dept. of Plant Pathology \\ Greg Thoma \\ University of Arkansas \\ Dept of Chemical Engineering
}

* Corresponding author
770 Van Vleet Oval
University of Oklahoma
Norman, OK 73019

Phone: 405-325-6927

Fax: 405-325-3180

E-mail address: kathleen.e.duncan-1@ou.edu

Key words: crude oil/brine/bioremediation/ammonium-oxidizing bacteria/soil microbiology 


\begin{abstract}
Characterization of the $\beta$ Proteobacteria ammonium-oxidizing portion of the soil microbial community in tallgrass prairie soil and its response to oil-field contamination and remediation treatments was assessed by sequencing amo $A$ libraries derived from soil samples taken at various points in the contamination-remediation-recovery process. Sites that had been disturbed by tilling, contamination by a spill of crude oil or by a spill of oilfield brine were compared. Sequences with high similarity to Nitrosomonas sp. were found only in the brine-contaminated sites. Sequences from undisturbed prairie, tilled, and oil-impacted all had highest similarity to Nitrosospira sp., but differed in the relative proportions affiliated with different clades of Nitrosospira. The great majority of sequences (approximately 95\%) from tilled and native prairie samples were most similar to a clade of sequences previously derived from soil and/or associated with plant roots.

\section{Introduction}

Nitrogen cycling is a vital ecosystem function carried out by a diverse group of microorganisms. Spills of crude oil and oil-field brine, and subsequent bioremediation procedures involving the addition of nitrogenous compounds to enhance the rate of hydrocarbon removal might be expected to affect both the numbers and species composition of nitrogen-cycling bacteria. Disruption or alteration of nitrogen-cycling will in turn influence the restoration of the plant community.

Nitrification, the oxidation of ammonium first to nitrite and subsequently to nitrate, is carried out by two different groups of eubacteria, ammonium-oxidizing bacteria $(\mathrm{AOB})$ and nitrite-oxidizing bacteria. The process of nitrification is known to be sensitive to environmental conditions, such as oxygen and ammonium levels, water, $\mathrm{pH}$, and salt, 
among other factors (Kowalchuk and Stephen, 2001; Neijidat, 2005; Paul and Clark, 1989). However, the oxidation of ammonium to nitrite is generally acknowledged to be the rate-limiting step in nitrification (Kowalchuk and Stephen, 2001; Paul and Clark, 1989), hence the importance of determining environmental conditions that impact AOB.

Two monophylogenetic groups of AOB exist, one, members of the genus Nitrosococcus in the $\gamma$ subclass of the Proteobacteria, is associated with marine environments, the second consists of two genera, Nitrososomonas and Nitrosospira, in the $\beta$ subclass of the Proteobacteria (Belser 1979, Koops and Pommerening-Roser, 2001). $\beta$ subclass $\mathrm{AOB}$ are found in a variety of habitats--marine, freshwater, soils, and manmade environments such as sewage disposal plants (Koops and Pommerening-Roser, 2001; Kowalchuk and Stephen, 2001). Nitrosomonas and Nitrosospira have been subdivided into clusters of species, based on their phylogenetic affiliations (Kowalchuk and Stephen, 2001). Certain clusters appear to be associated with particular habitats or environmental conditions. Changes in the species composition of AOB have been demonstrated in soils impacted by mine wastes, simulated acid rain, salt, fertilizer use, differences in temperature, plant species and other factors (Avrahami and Conrad, 2003; Avrahami et al., 2003; Briones et al. 2002; Horz et al., 2004; Nejidat et al. 2005; Oved et al., 2001; Stephens et al., 1996; 1999).

Determining the impact of altered environmental conditions on AOB is not easy, because these chemolithotrophic bacteria are extremely difficult to culture and standard culture techniques are acknowledged to greatly underestimate the numbers and diversity of AOB (Aakra et al., 1999; Belser, 1979). Therefore, detection of these organisms by molecular techniques is becoming increasingly important. As well as primers designed to 
preferentially amplify the $16 \mathrm{~S}$ rRNA of $\mathrm{AOB}$, a growing database exists of sequences of an AOB-specific functional gene coding for a subunit of the first enzyme in the ammonium oxidation pathway, ammonium monooxygenase subunit A (amoA, Rotthauwe et al., 1997; Kowalchuk and Stephen, 2001).

Our goal is not only to document differences in the AOB species composition of oil-impacted and brine-impacted sites in a tallgrass prairie ecosystem (Tallgrass Prairie Preserve, Pawhuska, OK) but also, by comparing the same sites at different stages of remediation and restoration, to provide a time scale for restoration of this important portion of the soil microbial community. An additional objective is to compare the effect of different remediation treatments on this group of microorganisms.

Our study sites are in the Tallgrass Prairie Preserve (TGPP, Pawhuska, OK), a land highly valued because of prior preservation and current active restoration by the Nature Conservancy of a once wide-spread, but now poorly represented tallgrass prairie ecosystem (Risser et al., 1981). The same land is also highly valued for its long-term production of oil, a principal source of income for the Osage Nation and a significant factor in the economy of the region. Long-term production translates into an aging infrastructure, with few resources available to prevent environmental damage from accidents and severe limitations on the types of remediation possible: a situation common to most parts of the USA and the world. Our treatment of the contaminated study sites, e.g. the application of hay and fertilizer in a modification of landfarming, are those that our previous research indicated are effective in enhancing the removal of petroleum hydrocarbons (Duncan et al. 1998; Duncan et al., 1999; Sublette et al., 2002) and are feasible under these types of circumstances. However, since AOB populations differ in 
soils subject to agronomic manipulations such as treatment with different levels of ammonium or tilling (Avrahami et al., 2003; Bruns et al. 1999; Phillips et al. 2000), remediation treatments that include mechanical disturbance of the soil by tilling in hay and fertilizer and the addition of nitrogen-containing fertilizer may be responsible for some differences seen between oil- or brine-impacted remediated soils and undisturbed, uncontaminated soils. In this study therefore, the effects of the treatments themselves are considered as a possible sources of ecosystem perturbation and compared to the degree and type of disturbance caused by surface spills of crude oil and of oil-field brine.

The current study documents striking differences in the ammonia-oxidizing bacterial population $(\mathrm{AOB})$ in tallgrass prairie soil in response to contamination with crude oil or oil-field brine. However, although the AOB population in oil-contaminated soils is highly altered, sequences similar to those typically found in undisturbed prairie soil persist after contamination. The AOB population in brine-impacted samples differed still more from $\mathrm{AOB}$ populations in native prairie, and were noteworthy for the absence of the characteristic prairie $\mathrm{AOB}$ and the presence of a high proportion of Nitrosomonas.

\section{Materials and Methods}

Site description and remediation treatments

The Tallgrass Prairie Preserve (Osage County, OK) is managed by The Nature Conservancy with controlled burns and a bison herd to restore a tallgrass prairie ecosystem. The area has been producing crude oil since the early 1900's, and production, primarily by small independent oil and gas producers, continues today. Two sites were chosen for remediation, one, J6, was contaminated in January 1999 by an accidental pipeline break. Two areas (north and south) were contaminated by the flowing oil, 
however, the current study is focused exclusively on the more heavily contaminated north site (approx. $930 \mathrm{~m}^{2}$ ). Initial Total Petroleum Hydrocarbon (TPH) contamination levels were estimated to be approximately $33,500 \mathrm{mg} / \mathrm{kg}$ (dry weight, EPA Method 418.1). The contamination was crude oil, no brine (e.g. $\mathrm{NaCl}$ ) components were detected. The contaminated area was divided into two portions, JN and JF, by burying a corrugated PVC sheeting. Prairie hay was applied to the contaminated areas in May 1999, followed by the addition of fertilizer (ammonium nitrate, diphosphorus pentoxide, and potassium oxide) to JF in May 1999 and on 3 additional dates over the next two years, with the final application being April 2001 (after the 4/01 sampling was performed). Tilling was performed immediately after fertilizer was applied, and the $\mathrm{JN}$ site was tilled at the same time as JF. October 2001 was the last date of tilling. A nearby area of uncontaminated, native prairie (JC) was tilled at the same time as JN and JF in order to control for the effects of mechanical disturbance. A nearby area of uncontaminated native prairie (JP) was left undisturbed except for sampling, in order to serve as the standard for restoration.

The second contaminated area, G5, contained three separate but adjacent lobes (GN, GM, GS) of prairie contaminated by spills of crude oil and brine (1:10 oil:brine) from a gathering line in the fall and winter of 1999. This sloped area was extremely rocky, and treatment in 2000 consisted of removing as many rocks by hand as possible, ripping the sites, adding hay and fertilizer (ammonium nitrate, diphosphorus pentoxide, and potassium oxide) to GN and GS, and installing an gravel-filled interception trench containing slotted drainage pipe at the bottom of GN and GM. A nearby area of uncontaminated prairie (GP) served as the standard for restoration. Samples were taken, 
but no additional manipulations were performed at these sites. Details of the treatments and remediation outcomes can be found in Sublette et al. (2005).

Sampling and analytical

All J6 sites were sampled three times a year (spring, summer, fall) beginning May 1999 and ending October 2003. Additional samples were obtained in March 1999 from sites $\mathrm{J} 6 \mathrm{~N}, \mathrm{~J} 6 \mathrm{~F}$, and J6P prior to beginning remediation. G5 sites were sampled three times a year (spring, summer, fall) beginning June 2000 and ending October 2003. Five-fold composite samples were made from near-surface soil $(0-15 \mathrm{~cm})$ and analyzed for a number of biological and chemical parameters (soil moisture, plant-available nutrients, $\mathrm{TPH}$, brine components, phospholipid fatty acid analysis (PLFA), nematode numbers and diversity), as described in Mehta et al. 2005, were obtained. As reported in Duncan et al. 2005, a subsample of the composite sample (approximately $300 \mathrm{~g}$ wet weight) was transported on ice back to the Norman, OK laboratory where it was homogenized aseptically and $0.5 \mathrm{~g}$ aliquots dispensed into sterile cryovials for storage at $-85^{\circ} \mathrm{C}$ until DNA was extracted. No more than forty-eight hours lapsed between sample collection and storage at $-85^{\circ} \mathrm{C}$. Total petroleum hydrocarbon levels (TPH) were analyzed by Continental Laboratories (Salina, KS) by EPA 418.1 (1999-2001) or EPA 1664 (20022003) after shipment of samples overnight on ice in completely-filled glass jars with Teflon lids. Analysis of the phospholipid fatty acid (PLFA) content of the soil samples was performed by Microbial Insights, Inc. (Rockford, TN) to determine the living microbial biomass. PLFAs are an essential component of cell membranes, but quickly decompose when cells die. 
DNA isolation, PCR amplification, DGGE, cloning, and sequencing

The Fast DNA SPIN Kit for Soil (MP Biomedicals, Irvine, CA) was used to extract and purify DNA from soil using a bead-beating method (Mini Bead-Beater, BioSpec Products, Bartlesville, OK) to lyse bacterial cells and release DNA (Borneman et al. 1996, Duncan et al. 2003). To ensure the representation of DNA from cells that are more difficult to lyse, three successive bead-beating and extractions were performed on each sample. The three DNA extracts were pooled, the DNA concentration determined by fluorometry (Hoefer Inc., San Francisco, CA) and adjusted to $5 \mathrm{ng} / \mu \mathrm{L}$ with PCR-grade water. DNA fragment size was examined and the concentration verified by agarose gel electrophoresis of an aliquot of the DNA sample and viewing the ethidium bromidestained gel under UV transillumination. DNA extraction conditions resulted in fragments approximately $8-25 \mathrm{~kb}$ in size. Purity of the DNA extraction kit components and maintenance of aseptic conditions throughout the extraction procedure were assessed by extracting one "reagent control" blank (e.g. all reagents and kit components were used) for every seven samples processed. The reagent control blanks were examined by agarose gel electrophoresis and used as template DNA in PCR amplifications with universal eubacterial primers for 16S rRNA (GM5F and D907R, Muyzer et al., 1993). PCR amplification was performed in a Stratagene Robocycler (Stragene, La Jolla, CA), and followed the touch-down procedure described in Muyzer et al. (1993). Primers were synthesized by Invitrogen Corp. (Carlsbad, CA). Other reagents and enzymes were purchased from Fisher Scientific or Sigma-Aldrich. The same DNA samples were used in this study as were used in Duncan et al. 2005. 
amo $A$ PCR products approximately $491 \mathrm{bp}$ in size were obtained for cloning from the March 1999, April 2001, and April 2003 sites by amplification of 10-30 ng DNA per $25 \mu \mathrm{L}$ PCR reaction mix containing 8.75 pmol each of the primers amoA1F (5'GGGGTTTCTACTGGTGGT 3') and amoA2R (5'CCCCTCKGSAAAGCCTTCTTC3', both from Rotthauwe et al. 1997), each later modified to have a single extra $\mathrm{T}$ at the 5' end, 1x PCR buffer (Fisher), $2.5 \mathrm{mM} \mathrm{MgCl} 2$, 0.5 M betaine (Sigma-Aldrich, St. Louis, MO), $0.2 \mathrm{mM}$ of each deoxynucleoside triphosphate, and $0.625 \mathrm{U}$ Taq polymerase. PCR amplification was performed in a Stratagene Robocycler (Stragene, La Jolla, CA), for 35 cycles with an annealing temperature of $58^{\circ} \mathrm{C}$. The quality and concentration of the PCR products were assessed by agarose gel electrophoresis, and if found to be single discrete bands of the correct size, were cloned into the TOPO-TA vector (Invitrogen) following the manufacturer's recommendations to increase the number of transformants when cloning from a pool of sequences. White colonies were transferred with sterile toothpicks into 96-well microtiter plates containing $200 \mu \mathrm{L}$ TB medium (Elshahed et al., 2003), grown overnight at $37^{\circ} \mathrm{C}$ and stored at $-85^{\circ} \mathrm{C}$ until DNA isolation and sequencing was performed as described in detail in Elshahed et al. (2003). Two forward and two reverse trace files were generated and analyzed separately to generate a sequence.

Phylogenetic analysis

Initial phylogenetic assignments were made following BLAST searches (Basic Local Alignment Search Tool, Altshuler et al.,1997). Sequencher (Windows Version 4.2, Gene Codes Corp., Ann Arbor, MI) was used to trim vector regions from the cloned sequences and to group the clones into the $100 \%$ and $99 \%$ identical sequence types. The sequences 
were aligned using ClustalX (Thompson et al. 1997) and alignments corrected manually as needed. An evolutionary distance tree was constructed using the neighbor-joining algorithm, and bootstrap support for branches assessed by 1000 repetitions.

\section{Results and Discussion}

\section{Major groups of $\beta$ ammonium-oxidizing proteobacteria}

Although two genera, Nitrososomonas and Nitrosospira, of ammonia-oxidizing bacteria in the $\beta$ subgroup of Proteobacteria have been isolated from terrestrial environments, only sequences showing high similarity to those of Nitrosospira were found in the J6 study area. Sites sampled from the J6 area include those contaminated by a spill of crude oil (JN and JF) as well as an uncontaminated but tilled site (JC) and uncontaminated, undisturbed prairie (JP). Six hundred forty clones were sequenced and 127 unique sequences (differing by $1 \%$ or more) were obtained (Table 1, Figure 1, sequences representing more than one clone designate the \# clones by the number in bold following an underscore, e.g.c46a01_48 indicates 48 clones with the same $(99 \%$ similarity) sequence). Several major subdivisions within the genus Nitrosospira can be seen in Figure 1 and in the subsequent Figures, for the purposes of this report they will be referred to as "Nitrosospira A, B, C, D, and E". Although sequences from the same type of site tend to group together, e.g. sequences from the oil-impacted sites (red, blue) are dominant in "A", note that A also contains a single sequence from a prairie sample (brown) and two from tilled, uncontaminated samples (green). Although a great number of different sequences were found, individual samples tended to contain one dominant sequence (defined as comprising over $>50 \%$ of the clones from that sample), with the exception of a pretreatment contaminated sample (JF99) and a sample obtained from a 
contaminated site after two years of remediation (JN01). The latter two samples did not contain a single dominant sequence but rather several sequences that contained from 4 to 16 clones--no one sequence represented more than $30 \%$ of the sample.

Contamination with oil-field brine: G5

In contrast, although many fewer clones (76, Table 1) were sampled from the G5 study area, a substantial number were clearly from Nitrososomonas species (Figure 2), although other sequences were similar to the Nitrosospira B, C, and D groups seen in Figure 1. Note that sequences similar to Nitrosomonas were only obtained from two brine-impacted sites (GN-red, GS-green). Due to the few different sequences, it was difficult to say whether or not G5 samples typically contained one dominant sequence although this was the case for 3 out of 4 samples for which there were more than 4 clones (Table 1).

Comparison of oil-impacted, brine-impacted, tilled, and prairie samples

Table 2 enumerates the proportion of clones from the various sites affiliated with Nitrosomonas and the four major clusters of Nitrosospira. Half the sequences from brineimpacted sites are associated with Nitrosomonas, with most of the remainder in Nitrosospira C. The sequence most similar to the Nitrosomonas sequences was obtained from orchard soil irrigated with wastewater (AF354821, Oved et al. 2001). Sequences similar to those from Nitrosospira $\mathrm{C}$ were abundant in both oil-impacted and brineimpacted samples, but rarely found in uncontaminated samples (Table 2), perhaps reflecting a greater tolerance of these conditions than the typical prairie Nitrosospira B. Sequences similar to those in the $\mathrm{C}$ clade have been obtained from meadow and agricultural soils (AY177953, Avrahami et al. 2003; AY249747, AY249748, Avrahami 
and Conrad, 2003), two from low fertilizer treatments, one from a high fertilizer treatment, and two unpublished studies (AF239881, AY186237).

Sequences from the oil-impacted sites, JN and JF, were more evenly distributed among Nitrosospira clusters A, B, C, and D. Figure 3, which omits the J6 sequences representing one or two clones in order to clarify the relationship of sequences from J6 to those from G5, shows that the sequences from Nitrososospira A are primarily from the JF site, which was an oil-contaminated site remediated with hay and fertilizer. Interestingly, sequences similar to these were obtained from irrigated soils (AF353253, AF353254, Oved et al., 2001), rice root soil (AY050684, Briones et al., 2002), meadow soil (AY249666, Avrahami and Conrad, 2003), and from a microcosm soil treated with high levels of N-containing fertilizer (Avrahami et al. 2003). It is likely that organisms with this $a m o A$ sequence were present in low numbers in the uncontaminated soil (Fig. 1, clone from prairie, c98g02), and afterwards selected by the fertilizer treatment. Note that a clone with this sequence was found in the contaminated, pretreatment sample (JF99c43a08_16). Nitrosospira multiformis, also in A, is considered a common ammonia-oxidizing bacterium in soils.

The great majority of clones ( $>94 \%$ ) from the native prairie samples (JP and GP) and the tilled, uncontaminated samples (JC) fell into the Nitrosospira B clade. Approximately a quarter of the clones from oil-contaminated samples also were associated with this clade, but none of the brine-impacted samples. Note that very similar sequences ( $99 \%$ level) were found in different prairie sites and at the same site in different years. Therefore it seems likely that these sequences represent dominant Nitrosospira species in the Tallgrass Prairie Preserve grassland soil that are sensitive to 
brine components, and perhaps outcompeted by members of Nitrosospira groups A, C, and D in oil-impacted and/or fertilized soils.

Nitrosospira D sequences were obtained primarily from oil-impacted sites during the pretreatment and remediation time periods (Fig. 3, JF99, JN99, JN01, JF01). Similar sequences were obtained from cultured strains of Nitrosospira (AJ298697, AJ298698, Aakra et al. 2001; AY123834, Purkhold et al. 2003), and from agricultural soil treated with high levels of fertilizer (AY177939, Avrahami et al. 2003). Ease of culture is related to growth rate, so D sequences may be from species capable of a greater rate of increase under higher nitrogen conditions.

\section{Salt tolerance of Nitrosomonas and Nitrosospira}

Within the $\beta$ subclass of $\mathrm{AOB}$, salt tolerance or a salt requirement (obligate halophile) has been noted as an ecophysiological characteristic associated with certain clades of Nitrosomonas (Koops and Pommerening-Roser, 2001), while others have no requirement for $\mathrm{NaCl}$. Desert soils, selected for salt tolerant microorganisms by repeated watering with $400 \mathrm{mM} \mathrm{NaCl}$ brine, had $\mathrm{AOB}$ populations dominated by Nitrosomonas in contrast to the original Nitrosospira-dominated AOB population (Nejidat, 2005). It should be noted that nitrification occurred under these high-salt conditions (Nejidat, 2005), and that mineralization of $\mathrm{NH}_{4}-\mathrm{N}$ was demonstrated in soil sampled from the brine-impacted G5 sites (Moralwar 2004).

\section{Origin of Nitrosomonas and Nitrosospira C in brine-impacted sites}

The dominance of Nitrosomonas and Nitrosospira $\mathrm{C}$ in the brine-impacted sites and their absence or extreme rarity in undisturbed or tilled prairie sites, suggest that there has been very strong selection for these groups of ammonia-oxidizing bacteria in two 
years time, and/or that they were resident in the brine or oil and were inoculated into the sites when the spills occurred. We did not directly test the brine for the presence of AOB, so cannot rule out their origin from this source. Nitrososospira $\mathrm{C}$ sequences, but not those of Nitrosomonas, are also found in the oil-impacted sites, suggesting that the brine chemistry is especially important for the establishment of the Nitrosomonas. amoA sequences obtained from orchard and lysimeter soils irrigated with wastewater effluent for 9 months to a year included both Nitrososomonas and Nitrosospira, while soils irrigated with fertilizer-amended water only had Nitrosospira (Oved et al., 2001), indicating that substantial differences in ammonia-oxidizing bacterial populations can develop within the time scale of this study.

\section{Conclusions}

Native tallgrass prairie soils and tilled but uncontaminated tallgrass soils are very similar in their dominance by one clade of Nitrosospira, related to sequences obtained from grassland and plant-associated soils. Oil and brine contamination of tallgrass prairie soil alters the AOB population in significant and characteristic ways. Brine-impacted soils contain a high percentage of sequences related to those of Nitrosomonas, which were not found in our samples of uncontaminated soil, and no Nitrosospira sequences of the dominant prairie soil clade were obtained from the brine-impacted samples. Oilimpacted sites had a more even diversity of sequences related to major Nitrosospira clades, which include the typical prairie clade. These findings suggest that it may be less

difficult to restore the ammonium-oxidation capacity of oil-impacted than brine-impacted soil to that of the native prairie. 


\section{References}

Aakra, A., Utaker, J. B., Nes, I. F., Bakken, L. R. 1999. An evaluated improvement of the extinction dilution method for isolation of ammonia-oxidizing bacteria. J. Microbiol. Methods. 39: 23-31.

Aakra,A., Utaker,J.B. and Nes,I.F. 2001. Comparative phylogeny of the ammonia monooxygenase subunit $\mathrm{A}$ and 16S rRNA genes of ammonia-oxidizing bacteria. FEMS Microbiol. Lett. 205: 237-242.

Avrahami, S., Liesack, W. and Conrad, R. 2003. Effects of temperature and fertilizer on activity and community structure of soil ammonia oxidizers. Environ. Microbiol. 5: 691-705.

Avrahami,S. and Conrad,R. 2003. Patterns of community change among ammonia oxidizers in meadow soils upon long-term incubation at different temperatures. Appl. Environ. Microbiol. 69:6152-6164.

Briones,A.M., Okabe,S., Umemiya,Y., Ramsing,N.B., Reichardt,W. and Okuyama,H. 2002. Influence of different cultivars on populations of ammonia-oxidizing bacteria in the root environment of rice. Appl. Environ. Microbiol. 68: 30673075 .

Bruns, M. A., Stephen, J. R., Kowalchuk, J., Prosser, J. I., and Paul, E. A. 1999. Comparative diversity of ammonia oxidizer 16S rRNA gene sequences in native, tilled, and successional soils. Appl. Environ. Microbiol. 65: 2994-3000.

Dong,W., Eichhorn,P., Radajewski,S., Schleheck,D., Denger,K., Knepper,T.P., Murrell,J.C. and Cook,A.M. 2004. Parvibaculum lavamentivorans converts linear alkylbenzenesulphonate surfactant to sulphophenylcarboxylates, alpha,beta-unsaturated sulphophenylcarboxylates and sulphophenyldicarboxylates, which are degraded in communities. J. Appl. Microbiol. 96: 630-640.

Duncan, K. E., R. Kolhatkar, G. Subramanim, R. Narasimhan, E. Jennings, S. Hettenbach, A. Brown, C. McComas, W. Potter, K. Sublette. 1999. "Microbial dynamics in oil-impacted prairie soil". Applied Biochemistry and Biotechnology. 77-79: 421-434.

Duncan, K, E. Jennings, S. Hettenbach, W. Potter, K. Sublette, G. Subramaniam, and R. Narasimhan. 1998. "Nitrogen cycling and nitric oxide emissions in oil-impacted prairie soils". Bioremediation Journal. 1(3):195-208.

Duncan. K., Charles, E., Roe, B., Najar, F., Mehta, C., Moralwar, A., Sublette, K., Brokaw, J., Todd, T., and Thoma, G. 2005. Changes in microbial communities during remediation of crude oil and brine spills. Final Report to the National 
Petroleum Technology Office of U.S. Department of Energy (DE-FC2601BC15332).

Horz,H.-P., Barbrook,A., Field,C.B. and Bohannan,B.J.M. 2004. Ammonia-oxidizing bacteria respond to multifactorial global change. Proc. Natl. Acad. Sci. U.S.A. 101 (42):15136-15141.

Koops, H-P. and Pommerening-Roser, A. 2001. Distribution of the nitrifying bacteria emphasizing cultured species. FEMS Microbiol. Ecol. 37: 1-9.

Kowalchuk, G. A., and Stephen, J. R. 2001. Ammonia-oxidizing bacteria: a model for molecular microbial ecology. Ann. Rev. Microbiol. 55: 485-529.

Mehta, C., Moralwar, A., Sublette, K., Jennings, E., Duncan, K.. Brokaw, J., Todd, T., and Thoma, G, 2005. Monitoring soil ecosystem recovery following bioremediation of a terrestrial crude oil spill with and without a fertilizer amendment. Final Report to the National Petroleum Technology Office of U.S. Department of Energy (DE-FC26-01BC15332).

Mintie, A.T., Heichen,R.S., Cromack,K. Jr., Myrold,D.D. and Bottomley,P.J. 2003.Ammonia-oxidizing bacteria along meadow-to-forest transects in the Oregon Cascade Mountains. Appl. Environ. Microbiol. 69:3129-3136.

Moralwar, A. A. 2004. Remediation of soil contaminated by crude oil and brine. Masters Thesis, The University of Tulsa, 2004.

Nejidat, A. 2005. Nitrification and occurrence of salt-tolerant nitrifying bacteria in the Negev desert soils. FEMS Microbiol. Ecol. 52: 21-29.

Okano,Y., Hristova,K.R., Leutenegger,C.M., Jackson,L.E., Denison,R.F., Gebreyesus,B., Lebauer,D. and Scow,K.M. 2004. Application of real-time PCR to Study effects of ammonium on population size of ammonia-oxidizing bacteria in soil.Appl. Environ. Microbiol. 70: 1008-1016.

Oved T, Shaviv A, Goldrath T, Mandelbaum RT, Minz D. 2001.Influence of effluent irrigation on community composition and function of ammonia-oxidizing bacteria in soil. Appl Environ Microbiol.67:3426-3433.

Paul, E. A., and Clark, F. E. 1989. Soil microbiology and biochemistry. Academic Press, Inc. San Diego, CA.

Phillips, C. J., Harris, D., Dollhopf, S. L., Gross, K. L., Prosser, J. I., and Paul, E. A. 2000. Effects of agronomic treatments on structure and function of ammoniaoxidizing communities.

Purkhold,U., Wagner,M., Timmermann,G., Pommerening-Roser,A. and Koops,H.P. 2003. 16S rRNA and amoA-based phylogeny of 12 novel betaproteobacterial 
ammonia-oxidizing isolates: extension of the dataset and proposal of a new lineage within the nitrosomonads. Int. J. Syst. Evol. Microbiol. 53:1485-1494.

Risser, P.G., Birney, E. C., Blocker, H. D., May, S. W., Parton, W. J., and Wiens, J. A. 1981. The True Prairie Ecosystem. Hutchinson Ross Publishing Co. Stroudsburg, PA.

Rotthauwe,J.H., Witzel,K.P. and Liesack,W. 1997. The ammonia monooxygenase structural gene amoA as a functional marker: molecular fine-scale analysis of natural ammonia-oxidizing populations. Appl. Environ. Microbiol. 63: 46044712.

Stephen, J. R., McCaig, A. E., Smith, Z., Prosser, J. I., and Embley, T. M. 1996. Molecular diversity of soil and marine 16S RNA gene sequences related to subgroup ammonia-oxidizing bacteria. Appl. Environ. Microbiol. 62: 41474154.

Sublette, K.L., Kolhatkar, R., Pim, K., Kolhatkar, A., Duncan, K.E., Miller, B., Fogg, R., Rider, P., Stepp, A., Carey, M., Todd, T. and Cross, A. 2002. "Long-term impacts of a crude oil spill on a pristine soil ecosystem", Proceedings of the 25th Arctic and Marine Oilspill Program Technical Seminar, Calgary, Alberta, Volume 2, 979-1011.

Sublette, K. L., A. Moralwar, L. Ford, K. Duncan, G. Thoma, and J. Brokaw. 2005. Remediation of a spill of crude oil and brine without gypsum. Environ. Geosciences V. 12 (2): 115-125 
Table 1. Proportions of unique sequence types within samples.

\begin{tabular}{|c|c|c|c|c|c|}
\hline $\begin{array}{l}\text { Sample } \\
\text { code }\end{array}$ & $\begin{array}{l}\text { \# clones } \\
\text { sequenced }\end{array}$ & $\begin{array}{l}\text { \# unique } \\
\text { sequences } \\
(100 \% \text { identity) }\end{array}$ & $\begin{array}{l}\text { \# unique } \\
\text { sequences } \\
\text { (99\% identity) }\end{array}$ & $\begin{array}{l}\text { Dominant } \\
\text { sequences } \\
\#(\% \text { total }) *\end{array}$ & $\begin{array}{l}\text { Diversity } \\
\text { Type** }\end{array}$ \\
\hline JN99 & 62 & 21 & 7 & $1(84 \%)$ & $1 \mathrm{D}$ \\
\hline JF99 & 56 & 36 & 10 & $4(73 \%)$ & multiple \\
\hline JP99 & 1 & 1 & 1 & NA & NA \\
\hline JN01 & 102 & 92 & 30 & $9(63 \%)$ & multiple \\
\hline JF01 & 78 & 48 & 11 & $3(82 \%)$ & $1 \mathrm{D}$ \\
\hline $\mathrm{JC} 01$ & 79 & 52 & 17 & $2(78 \%)$ & 1D \\
\hline JP01 & 42 & 25 & 8 & $2(81 \%)$ & 1D \\
\hline JN03 & 79 & 52 & 7 & $2(89 \%)$ & 1D \\
\hline JF03 & 69 & 35 & 13 & $3(80 \%)$ & 1D \\
\hline $\mathrm{JC} 03$ & 33 & 26 & 9 & $1(76 \%)$ & $1 \mathrm{D}$ \\
\hline JP03 & 39 & 29 & 14 & $1(69 \%)$ & 1D \\
\hline GN01 & 8 & 5 & 1 & $1(100 \%)$ & 1D \\
\hline GM01 & 3 & 2 & 2 & NA & NA \\
\hline GS01 & 9 & 7 & 3 & $1(78 \%)$ & $1 \mathrm{D}$ \\
\hline GP01 & 26 & 12 & 3 & $2(96 \%)$ & $2 \mathrm{D}$ \\
\hline GN03 & 2 & 2 & 2 & NA & NA \\
\hline GM03 & 4 & 2 & 2 & NA & $\mathrm{NA}$ \\
\hline GS03 & 4 & 4 & 1 & NA & $\mathrm{NA}$ \\
\hline GP03 & 20 & 12 & 2 & $2(100 \%)$ & 1D \\
\hline
\end{tabular}

$\%$ unique sequences $(100 \%$ identity): \# of unique sequences remaining after two or more sequences with $100 \%$ match have been considered as one unique sequence.

$\%$ unique sequences ( $99 \%$ identity): \# of unique sequences remaining after two or more sequences with $99 \%$ or higher match have been considered as one unique sequence.

*: Dominant sequences: the first number is the number of dominant unique sequence (99\% identity level).

(\%): \# clones in dominant unique sequences/total \# clones, expressed as a percentage.

NA: not applicable due to the few numbers of clones.

**: Diversity types: "1D" = one dominant sequence type comprising $>50 \%$ of the total \# sequences. "Multiple": no one sequence type comprising $>30 \%$ of the total \# sequences. "2D": two sequences types in almost equal numbers $(12,13)$.

NA: not applicable due to the few numbers of clones. 
Table 2. Proportions (\%) of clones in major clusters

\begin{tabular}{|c|c|c|c|c|c|}
\hline Site Type & Nitrosomonas & \multicolumn{4}{|c|}{ Nitrosospira } \\
\hline & & $\mathrm{A}$ & $\mathrm{B}$ & $\mathrm{C}$ & $\mathrm{D}$ \\
\hline Brine-impacted & $50 \%$ & $0 \%$ & $0 \%$ & $43 \%$ & $7 \%$ \\
\hline Oil-impacted & $0 \%$ & $18 \%$ & $22 \%$ & $34 \%$ & $25 \%$ \\
\hline Tilled & $0 \%$ & $2.7 \%$ & $94.6 \%$ & $<1 \%$ & $<1 \%$ \\
\hline Prairie & $0 \%$ & $<1 \%$ & $96.9 \%$ & $0 \%$ & $1.5 \%$ \\
\hline
\end{tabular}

Site type: Brine-impacted samples (GN01, GM01, GS01, GN03, GM03, GS03: total 30), Oil-impacted (JN99, JF99, JN01, JF01, JN03, JF03: total 446), Tilled (JC01, JC03: total 112), Prairie (JP99, JP01, JP03, GP01, GP03: total 128).

Major clusters: as shown in Figure 3, does not include "Nitrosospira E". 
Figure legends

Figure 1. J6 sequence types (99\%). Phylogenetic relationship of amo $A$ cloned sequence types (sequences unique at the 99\% level) from the J6 sites with those of selected strains of Nitrosomonas and Nitrosospira and with the most closely matching sequences from Genbank. The phylogenetic tree is based on partial amo $A$ gene sequences (414 bp) and was constructed using the neighbor-joining algorithm. Percent numbers show the level of bootstrap support out of 1000 resamplings (values less than $80 \%$ are not shown). The bar indicates 0.02 nucleotide substitutions per nucleotide. Blue: sequences originating from JN samples (oil-impacted, not fertilized). Red: sequences originating from JF samples (oil-impacted, fertilized). Green: sequences originating from JC samples (tilled, not contaminated). Brown: sequences originating from JP samples (native prairie).

Figure 2. G5 sequence types (99\%). Phylogenetic relationship of amo $A$ cloned sequence types (sequences unique at the 99\% level) from the G5 sites with those of selected strains of Nitrosomonas and Nitrosospira and with the most closely matching sequences from Genbank. The phylogenetic tree is based on partial amoA gene sequences (414 bp) and was constructed using the neighbor-joining algorithm. Percent numbers show the level of bootstrap support out of 1000 resamplings (values less than $80 \%$ are not shown). The bar indicates 0.02 nucleotide substitutions per nucleotide. Blue: sequences originating from GN samples (brine-impacted). Red: sequences originating from GM samples (brineimpacted). Green: sequences originating from GS samples (brine-impacted). Brown: sequences originating from GP samples (native prairie). The first two letters and first two numbers indicate the sample site and sampling date, numbers in bold following an underscore (e.g. _5) indicate the number of clones per an individual sequence type.

Figure 3. G5 and major J6 sequence types (99\%). Phylogenetic relationship of amoA cloned sequence types (sequences unique at the 99\% level) from the G5 sites and major J6 sequence types (those comprising more than $60 \%$ of the total \# clones, see also Table 2 and text) with those of selected strains of Nitrosomonas and Nitrosospira and with the most closely matching sequences from Genbank. The phylogenetic tree is based on 
partial amoA gene sequences (414 bp) and was constructed using the neighbor-joining algorithm. Percent numbers show the level of bootstrap support out of 1000 resamplings (values less than $80 \%$ are not shown). The bar indicates 0.02 nucleotide substitutions per nucleotide. Blue: sequences originating from oil-impacted samples (JN, JF). Red: sequences originating from brine-impacted samples (GN, GM, GS). Green: sequences originating from tilled samples (JC). Brown: sequences originating from native prairie (JP, GP). The first two letters and first two numbers indicate the sample site and sampling date, numbers in bold following an underscore (e.g. _5) indicate the number of clones per individual sequence type. 


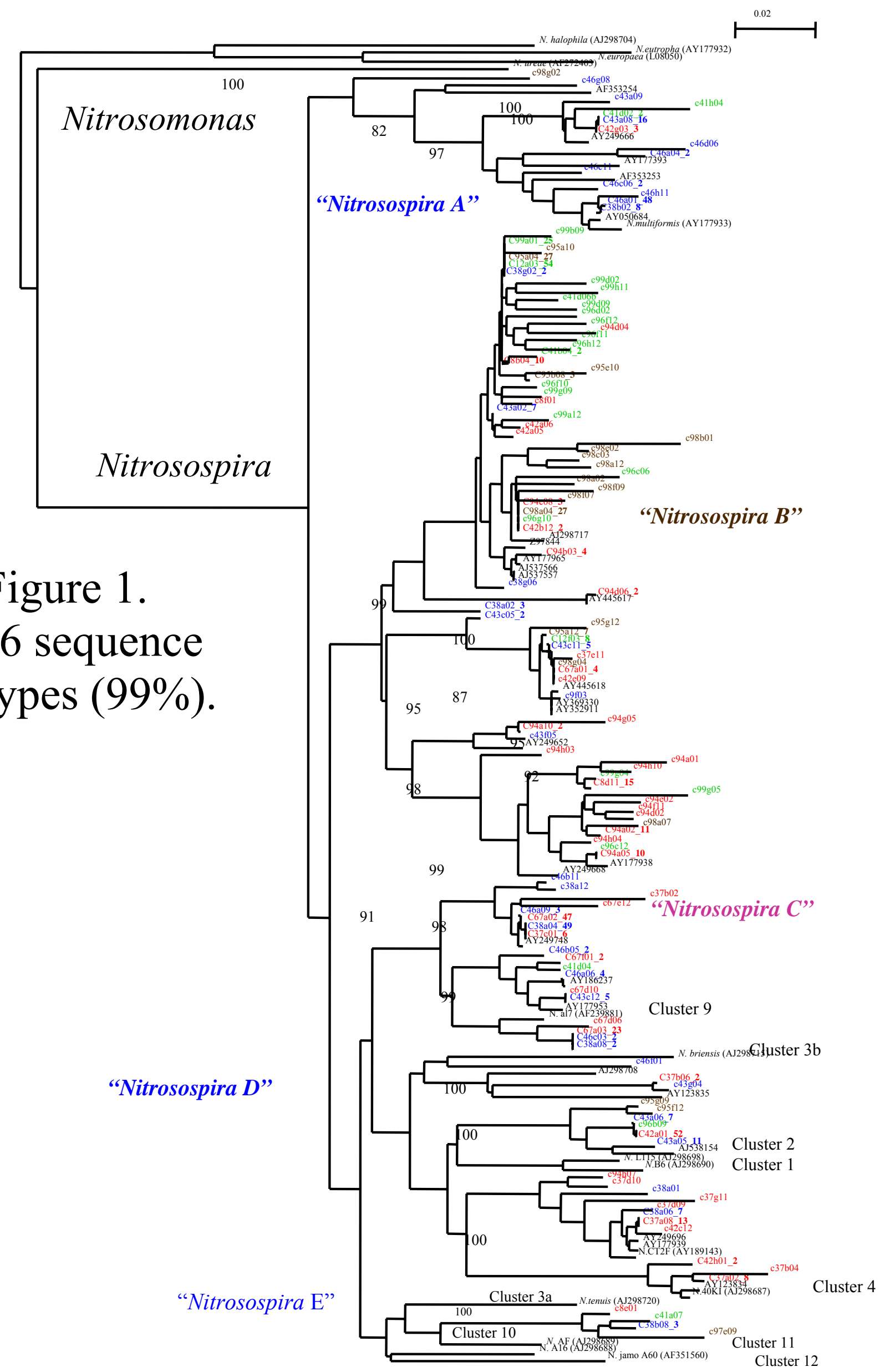




\section{Figure 2. G5 amoA sequences types (99\%)}

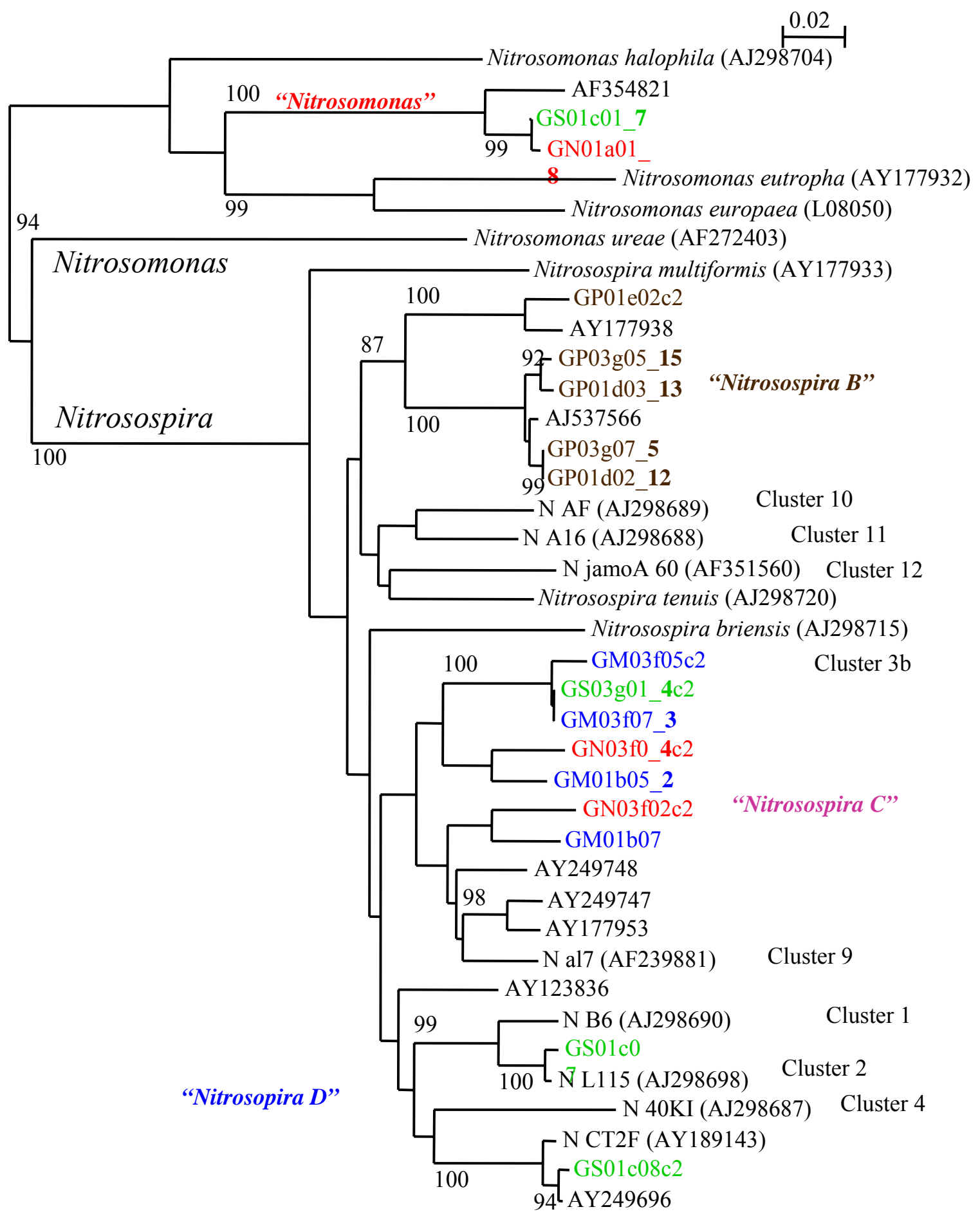




\section{Figure 3. G5 and major J6 sequence types}

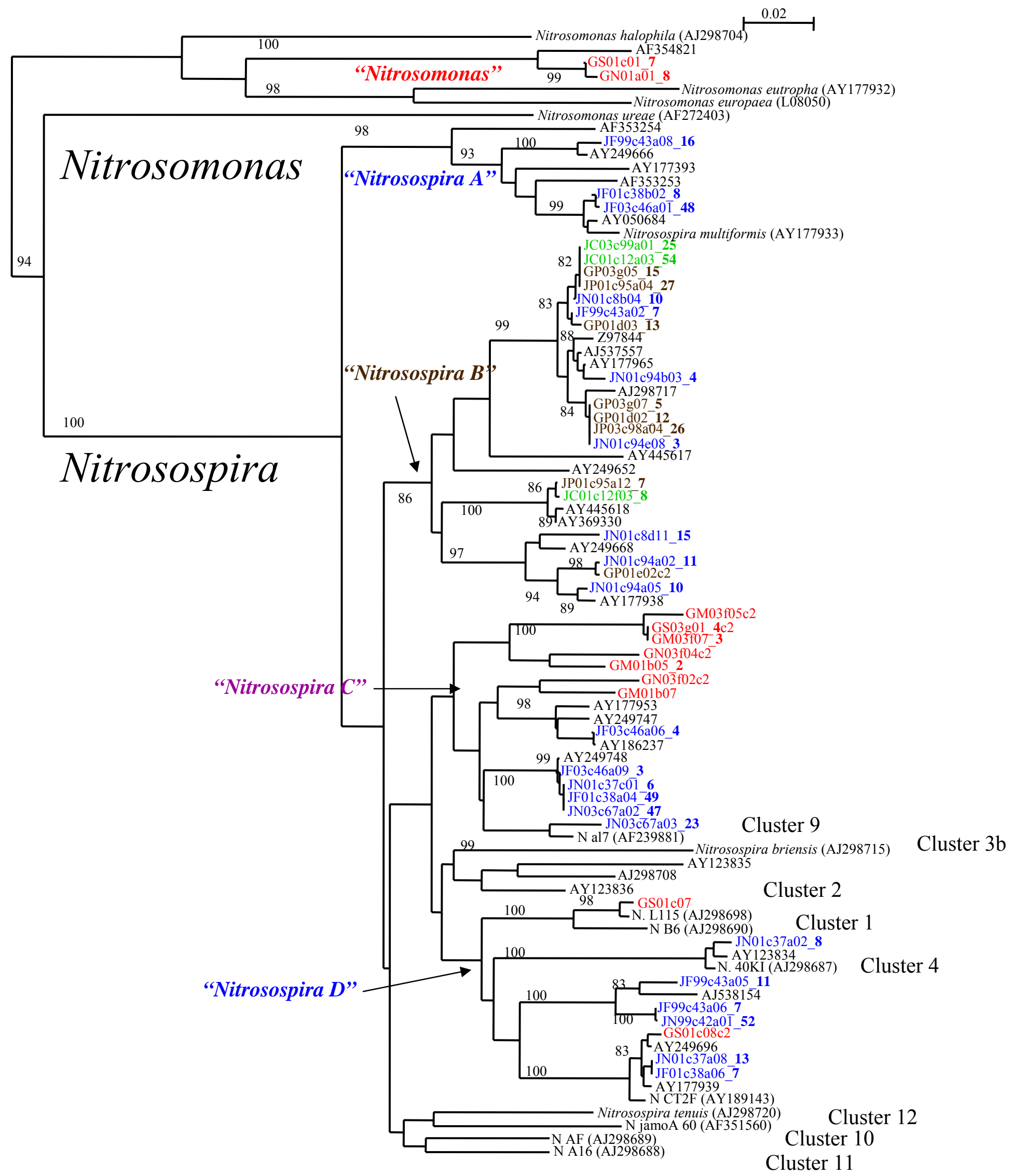




\title{
Chapter 5
}

\section{Probabilistic Reliability Modeling for Oil Exploration \& Production (E \& P) Facilities in the Tallgrass Prairie Preserve}

\author{
Greg Thoma*, Lyda Zambrano, Chun Yen Wong \\ University of Arkansas \\ Dept of Chemical Engineering \\ Kathleen Duncan \\ Dept. of Botany and Microbiology \\ University of Oklahoma \\ Kerry Sublette \\ Center for Applied Biogeosciences \\ University of Tulsa \\ Joshua Brokaw \\ Oklahoma State University \\ Dept. of Botany \\ Tim Todd \\ Kansas State University \\ Dept. of Plant Pathology
}

* Corresponding author

3202 Bell Engineering Center

University of Arkansas

Fayetteville, AR 72710

Phone: 479-575-4951

Fax: 479-575-7926

E-mail address: gthoma@uark.edu

Key Words: risk analysis; risk assessment; Monte Carlo simulation; reliability; equipment failure; oil production 


\begin{abstract}
The aging domestic oil production infrastructure represents a high risk to the environment because of the type of fluids being handled (oil and brine) and the potential for accidental release of these fluids into sensitive ecosystems. Currently, there is not a quantitative risk model directly applicable to oil exploration and production (E\&P) facilities. We report on a model developed for direct applicability to E\&P facilities. Reliability theory, Failure Modes and Effects Analysis (FMEA), and event trees were used to develop the model estimates of the failure probability of typical oil production equipment. Monte-Carlo simulation was used to translate the input parameter uncertainty to the model output. The model predicted failure rates were calibrated to available failure rate information through the use of Monte-Carlo simulations. The mean and standard deviation of normal variate distributions from which the Weibull distribution characteristic life was chosen were used as adjustable parameters in the model calibration. The model was applied to oil production leases in the Tallgrass Prairie Preserve, Oklahoma. We present the estimated failure probability due to the combination of the most significant failure modes of each type of equipment (pumps, tanks, and pipes). The results showed that the estimated probability of failure for tanks was about the same as that for pipes, but that pumps have much lower failure probability. The model can provide necessary equipment reliability information for risk management through allocation of maintenance resources to minimize both lost production and ecosystem damage.
\end{abstract}




\section{Introduction}

The oil exploration and production (E\&P) industry poses risks to the environment because of the type of fluids that are handled (oil and brine) and the potential for accidental release of these fluids into sensitive ecosystems. Because oil and brine spills are usually expensive to remediate, risk reduction measures should lead to cost savings in the form of retained revenue as well as mitigate environmental impacts. However, there are currently no quantitative risk assessment tools specific to operations and equipment in the E\&P industry.

The tools for risk identification and analysis that are available -- such as preliminary hazard Analysis (PHA), hazard and operability studies (HAZOP), failure mode and effects analysis (FMEA), and cause-consequence analysis -- provide primarily a qualitative analysis of the risk by identifying hazards and suggesting process design modifications ${ }^{1,5,6}$. By themselves, these techniques do not compare the risks that arise from hazards present in the process under study and do not highlight the areas of the process that need more attention or immediate action to reduce operational risk. The office for pipeline safety, the Environmental Protection Agency (EPA), and the American Petroleum Institute (API) have developed methods to estimate or assess (qualitatively and/or quantitatively) the risk associated with oil pipelines; however, the methods developed are specific to oil distribution and do not take into account other equipment typically present at an oil production site: e.g., pumps, tanks, and injection wells.

The nuclear industry developed a risk analysis technique, Probabilistic Risk Assessment (PRA) that addresses qualitative and quantitative aspects of risk assessment. 
In a PRA analysis, process hazards are not just identified, but the probability that an initiating event will lead to undesired consequences is also quantified. Consequences of undesired events are estimated and quantified as well. PRA analysis is not limited to the nuclear industry, and it can be applied to any industry ${ }^{7,8}$.

We have applied PRA to meet E\&P industry-specific requirements. In this work, the PRA frequency estimation step is combined with reliability theory, due to lack of detailed operational records, to create a model for estimating the probability of equipment failure typically found at an oil production site. We present the results of the failure probability estimation applied to specific oil production leases in the Tallgrass Prairie Preserve (TPP), in northeastern Oklahoma. Risk must be quantified in terms of economic, health, and environmental costs coupled with quantitative estimates of the likelihood of incurring those costs. A quantitative risk management tool such as PRA provides managers an opportunity to save money by targeting maintenance on high-risk areas and by helping during the decision-making process to allocate resources in prevention rather than in remediation. After being identified, the risks associated with a particular operation can be ranked, and management decisions can be made to reduce the total risk ${ }^{1,}$ $2,3,4$.

\section{Probabilistic Risk Assessment (PRA)}

PRA gives a general framework for quantitative risk which can be adapted to specific situations found in the system under study ${ }^{1,2}$. The general steps of a typical PRA study, system identification, event identification, frequency estimation, consequences analysis, risk estimations, and risk assessment were adapted to meet the specific requirements of the Tallgrass Prairie Preserve (TPP) as illustrated in Figure 1. 
The focus of this paper is failure frequency estimation, therefore, the steps completed were: system identification, event identification and frequency estimation. Additionally, an uncertainty analysis was performed because detailed operational records regarding equipment age, date of installation, cumulative years of operation do not exist; these and other uncertain input parameters were used as random variates in Monte-Carlo simulations of the equipment reliability. Consequence analysis (size of a spill and cleanup cost) and risk estimation for the TPP are presented in a companion paper.

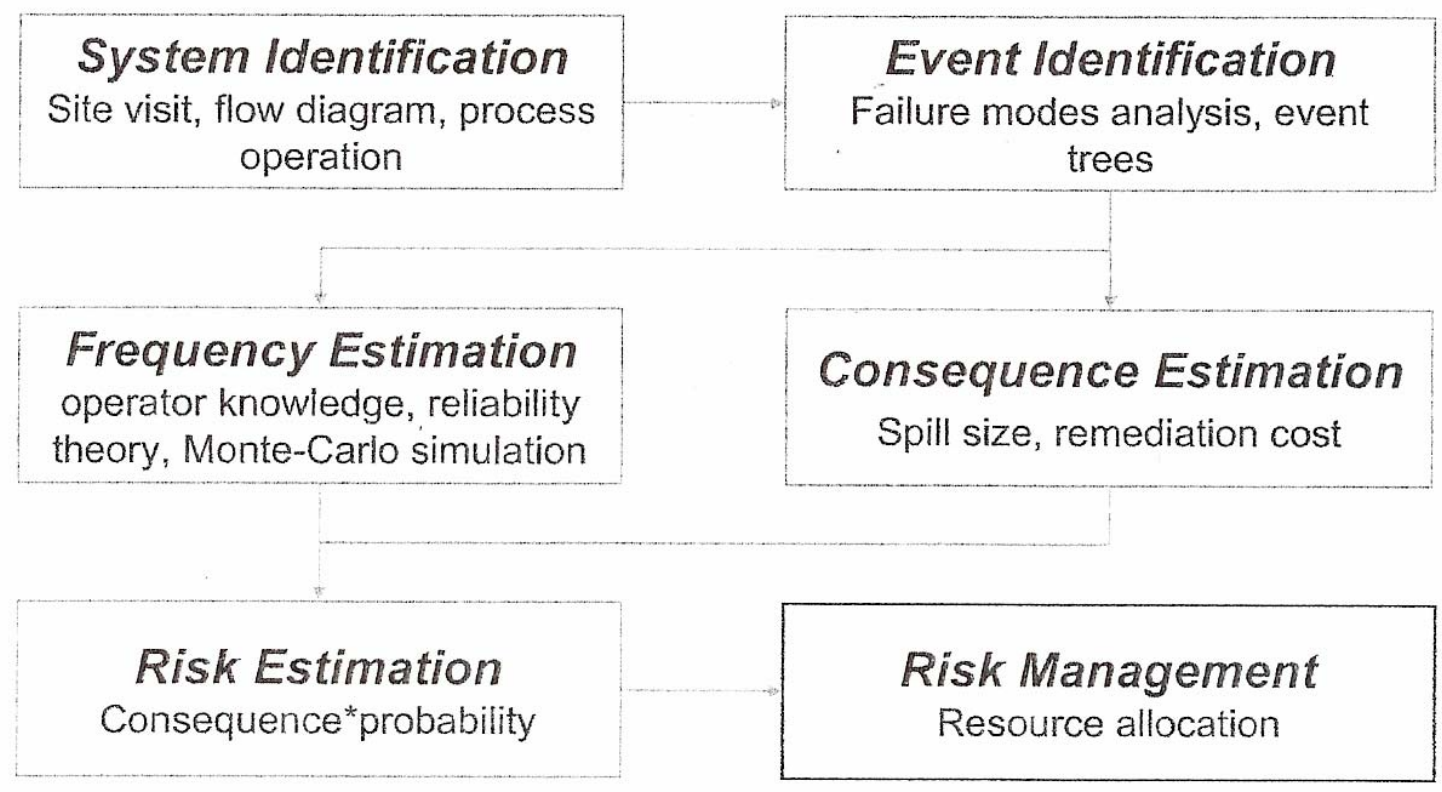

Figure 1. Schematic of probabilistic risk analysis procedure

\section{PRA in the Tallgrass Prairie Preserve}

\subsection{System Identification}

The Tallgrass Prairie is a national preserve, owned and managed by The Nature Conservancy, in northeastern Oklahoma and contains numerous leases that total over 100 active oil production wells with an average production of 1.5 to $2.0 \mathrm{bbl} /$ day of crude oil and up to $20 \mathrm{bbl} /$ day of brine. 
Each oil lease has several components, including well pumps (turbine or motor driven), gathering lines, oil-water separators, storage tanks, re-injection wells, and electric systems, any of which may fail and cause an accidental release of crude oil and/or brine into the environment. The equipment currently present at the leases was identified and categorized through site visits where GPS was used to locate pumps, tanks and gathering pipelines. Environmental characteristics of the site, operational procedures, and other land use activities that may interact with the oil production to cause accidents, were identified. Figure 2 presents the layout of the leases used as models.

\subsection{Event Identification}

The event identification was completed with the use of two techniques: Failure Modes and Effects Analysis (FMEA) and Event Tree analysis. After identifying components that are part of a typical lease through site visits and discussions with lease operators and constructing simple process flow diagrams, the analysis of individual component failure modes leading to spills was conducted. Each failure mode of each lease component was assumed to begin with an initiating event, the first branch of the event tree. Using inductive logic, events that follow the initiating event were identified, and for each initiating event an event tree was developed which describes the sequence of events for the specific failure mode that could lead to the release of produced fluids. The likelihood of the undesired outcome, a spill, is the product of the initiating event probability and all succeeding conditional event probabilities leading to that outcome ${ }^{1}$.

Table 1 presents the summary of the failure modes by components identified through the FMEA analysis. The type of service was also accounted for in construction of the event trees for pipes, resulting in separate event trees for pipes with different fluid 
service (oil, brine or mixed fluids). In addition a separate set of event trees were generated for buried pipe and pipe on the ground surface.

\subsection{Frequency Estimation}

Because of the lack of detailed operational records of the leases in the TPP, and of the E\&P industry in general, the failure probability (or reliability) estimation of individual pieces of equipment could not be based on historical records. Failure probabilities were therefore estimated using reliability functions. Information collected during interviews with lease owners was used as guidance for the failure probability estimation. In particular, estimates of equipment age and time of service were obtained anecdotally from lease operators.

The choice of probability density function for reliability estimation was based on the classification of a particular event (i.e., a single branch of an event tree) as random, wear out or 'early failure'. The Weibull distribution was used as the reliability model. The equations used were the cumulative failure probability at some time, $F(t)$, is obtained from the integral of the probability density function $f(t)^{9}$ :

$$
\begin{aligned}
& f(t)=\frac{m}{t}\left(\frac{t}{c}\right)^{m} \exp \left(-\left(\frac{t}{c}\right)^{m}\right) \\
& F(t)=\int_{0}^{t} f(u) d u=1-e^{-(t / c)^{m}} \\
& R(t)=1-F(t)=e^{-(t / c)^{m}}
\end{aligned}
$$




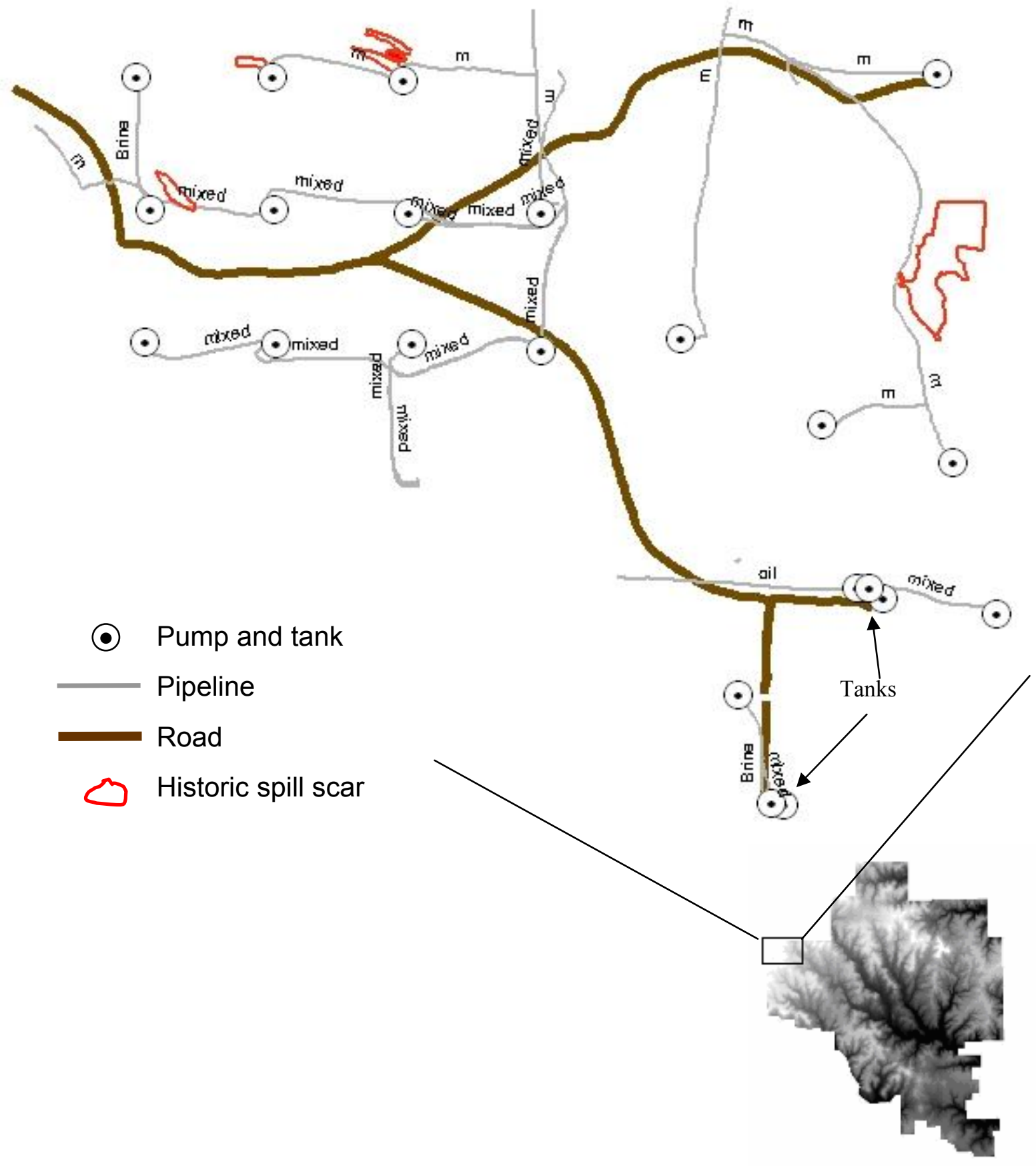

Figure 1. Lease layout at field site in the Tallgrass Prairie Preserve. 
Table 1. Failure modes identified by each type of equipment at the TPP.

\begin{tabular}{|c|c|c|c|}
\hline ITEM & $\begin{array}{l}\text { FAILURE } \\
\text { MODES }\end{array}$ & CAUSES OF FAILURE & EFFECTS \\
\hline MIXED FLUIDS PIPE & Pipe break & $\begin{array}{l}\text { Corrosion; Heavy traffic } \\
\text { Buffalo } \\
\text { Blockage/overpressure } \\
\text { Liquid hammer }\end{array}$ & $\begin{array}{l}\text { Spill of mixed } \\
\text { fluids }\end{array}$ \\
\hline OIL PIPE & Pipe break & $\begin{array}{l}\text { Corrosion; Heavy truck step } \\
\text { Buffalo damage; Blockage of piping } \\
\text { Liquid hammer; Fire (plastic pipe } \\
\text { melts) }\end{array}$ & Spill of oil \\
\hline BRINE PIPE & Pipe break & $\begin{array}{l}\text { Corrosion; Heavy truck } \\
\text { Buffalo damage; Blockage of piping; } \\
\text { Liquid hammer }\end{array}$ & Spill of brine \\
\hline OIL TANK & $\begin{array}{l}\text { Overflow } \\
\text { Leakage } \\
\text { Rupture }\end{array}$ & $\begin{array}{l}\text { Outlet flow nozzle plugged; } \\
\text { Corrosion; Level glass plugged or } \\
\text { dirty }\end{array}$ & Spill of oil \\
\hline BRINE TANK & $\begin{array}{l}\text { Overflow } \\
\text { Leakage } \\
\text { Rupture }\end{array}$ & $\begin{array}{l}\text { Outlet flow nozzle plugged; } \\
\text { Corrosion; Level glass plugged or } \\
\text { dirty; Lightning strike }\end{array}$ & Spill of brine \\
\hline SEPARATOR & $\begin{array}{l}\text { Overflow } \\
\text { Leakage } \\
\text { Rupture }\end{array}$ & $\begin{array}{l}\text { Outlet flow nozzles plugged; } \\
\text { Corrosion; Level glass plugged or } \\
\text { dirty; Internal element damage; } \\
\text { Lightning stfike }\end{array}$ & $\begin{array}{l}\text { Spill of mixed } \\
\text { fluids }\end{array}$ \\
\hline ELECTRIC SUPPLY & Short circuit & $\begin{array}{l}\text { Conduit damage; Wires cut; Wires } \\
\text { exposed to the environment }\end{array}$ & $\begin{array}{lr}\text { Grass } & \text { fire } \\
\text { (melts } & \text { plastic } \\
\text { pipe) } & \end{array}$ \\
\hline $\begin{array}{lr}\text { STUFFING } & \text { BOX } \\
\text { (ELECTRIC } & \text { MOTOR } \\
\text { PUMP) } & \end{array}$ & $\begin{array}{l}\text { Seal failure } \\
\text { Bearing failure }\end{array}$ & $\begin{array}{l}\text { Blocked pipe downstream; Plugged } \\
\text { outlet; Lubrication Failure; Suction } \\
\text { obstruction ; Improper shaft } \\
\text { alignment; Short circuit }\end{array}$ & $\begin{array}{l}\text { Spill of mixed } \\
\text { fluids }\end{array}$ \\
\hline $\begin{array}{ll}\text { STUFFING } & \text { BOX } \\
\text { (NATURAL } & \text { GAS } \\
\text { MOTOR PUMP) } & \end{array}$ & $\begin{array}{l}\text { Seal failure } \\
\text { Bearing failure }\end{array}$ & $\begin{array}{l}\text { Blocked pipe downstream; Plugged } \\
\text { outlet; Lubrication Failure; Suction } \\
\text { obstruction ; Improper shaft } \\
\text { alignment }\end{array}$ & $\begin{array}{l}\text { Spill of mixed } \\
\text { fluids }\end{array}$ \\
\hline
\end{tabular}

Where $\mathrm{c}=$ characteristic life, the age at which $63 \%$ of the population will have failed; $\mathrm{m}=$ shape parameter, usually between 0.5 and 2.0. Its value is 1.0 for random failure modes. A value of 5 was used to model random failures associated with wear-out 
mechanisms. $R(t)$ is the reliability, or probability that an item will still be in service at age t. For mechanisms of corrosion and water hammer descriptions of the underlying physical phenomena were used in the estimation of the failure probability.

3.3.1 Corrosion. In the development of the event trees for failure related to corrosion, it was assumed that the equipment was already corroded and that the initiatingevent-probability would be based on the comparison between the estimated depth of corrosion and the corrosion allowance. The corrosion allowance (CA) was fixed at 0.125 inches, which is a typical for equipment with similar service to those found at the TPP. The corrosion rate (CR) of pipes and metallic equipment was based reports in the literature. The corrosion rate is a function of the fluid handled, the fluid temperature and pressure, the flow velocity in the pipe, and the specific composition of the fluid, in particular the $\mathrm{CO}_{2}$ and $\mathrm{H}_{2} \mathrm{~S}$ concentrations. In general, this level of detail is not available and to approximate the corrosion dependence on fluid service in the TPP we have assumed constant corrosion rates as follows:

Brine service ${ }^{(11-13)}: 0.2 \mathrm{~mm}$ per year

Oil service: $0.02 \mathrm{~mm}$ per year

Mixed fluid service: \%Brine*Brine corrosion rate

Finally, the thickness or depth of the corrosion is estimated for the age of the pipe

as:

$$
\mathrm{C}=\mathrm{CR} \times \text { Age }
$$

Where: $\mathrm{CR}=$ corrosion rate, $\mathrm{mm} /$ year

$$
\begin{aligned}
& \text { Age }=\text { item age, years } \\
& \mathrm{C}=\text { corrosion depth, } \mathrm{mm}
\end{aligned}
$$


The initiating event probability was set to unity if the predicted corrosion exceeds the corrosion allowance; this of course does not mean that simply because the corrosion is larger than the allowance the pipe will fail, simply that it is more likely to fail; the initiating event probability was set equal to the ratio $\mathrm{C} / \mathrm{CA}$ if predicted corrosion is less than the allowance:

If $\mathrm{C} / \mathrm{CA}>1$, then $\mathrm{F}_{1}(\mathrm{t})=1$

If $\mathrm{C} / \mathrm{CA}<1$, then $\mathrm{F}_{1}(\mathrm{t})=(\mathrm{C} / \mathrm{CA})$

3.3.2 Water Hammer. The calculation of water hammer applies only to pipes, specifically to the failure mode 'pipe blocked'. The probability of failure for the second branch of the related event tree, after the initiating event of blockage, depends on the value of the water hammer overpressure resulting from the blockage. The water hammer overpressure was calculated based on correlations found in literature ${ }^{(14,15)}$.

$$
\begin{aligned}
& a=\frac{12}{\sqrt{\frac{\rho}{g}\left(\frac{1}{K}+\frac{D_{i}}{E W}\right)}} \\
& K=10^{5.722708-0.00819^{\circ} \mathrm{API}-0.00219 T} \\
& \Delta P o=\frac{a \times B P D \times s g}{6260 \times D_{i}^{2}}
\end{aligned}
$$

where: $\mathrm{a}=$ wave velocity, $\mathrm{ft} / \mathrm{s}$

$$
\begin{aligned}
& \rho=\text { density of fluid, } \mathrm{lb} / \mathrm{ft} 3 \\
& \mathrm{~K}=\text { compressibility modulus of fluid, psi } \\
& \mathrm{Di}=\text { internal diameter of pipe, inch } \\
& \mathrm{E}=\text { pipe Young's modulus, psi } \\
& \quad 30 \times 10^{6} \text { for Carbon Steel }
\end{aligned}
$$




$$
\begin{aligned}
& \qquad 2.34 \times 10^{13} \text { for PVC } \\
& \mathrm{W}=\text { pipe wall thickness, inch } \\
& \mathrm{API}=\text { API fluid density } \\
& \mathrm{BPD}=\text { pipe flowrate, barrels per day } \\
& \mathrm{Sg}=\text { fluid specific gravity }
\end{aligned}
$$

If the overpressure caused by the water hammer is larger than the design pressure of the pipe, then the probability of failure of that branch (the second after blockage occurrence) would be one otherwise it would take the value of zero.

3.3.3 Probability of spill. The probability that an undesired event will occur by the time an item has reached age $t$ years as the result of a particular failure mode is calculated as the product of all probabilities of upper branches of the event tree that lead to failure for that failure mode:

$$
P_{i}(t)=\prod_{i=1}^{N} F_{i}(t)
$$

The summation is over the all of the branches a single event tree. After computing the probability that a certain piece of equipment will fail due to a specific failure mode, the probability that the equipment will fail as a combined result of all possible failure modes is estimated:

$$
F(t)_{\text {total }}=1-\prod_{i=1}^{N} R_{i}(t)=1-\prod_{i=1}^{N}\left[1-F_{i}(t)\right]
$$

The summation is over all of the failure modes for an item. This calculation is necessary because each of the failure modes is independent of the others. $F(t)_{\text {total }}$ is the combined 
probability that a piece of equipment will fail by at least one of the possible failure modes.

3.3.4 Failure likelihood in time horizon: Practical application of these reliability estimates requires an estimation of the failure probability within a pre-specified time horizon that is meaningful with regard to budget decisions. In this case the overall failure probability is computed from:

$$
F(\Delta t)=F(t+\Delta t)-F(t)
$$

Where $F(\Delta t)$ is the failure probability due to all failure modes for an individual piece of equipment during the time window between time $\mathrm{t}$ and $\mathrm{t}+\Delta \mathrm{t}$.

3.3.5 Comparability of reliability estimates: Ultimately the failure probability

estimate from equation (10) $F(\Delta t)=F(t+\Delta t)-F(t)$ (10) will be used as a component of a risk assessment for the lease as a whole, or possibly for comparison across multiple leases. The consequences of a spill are naturally related to the duration that the failure remains undiscovered, which is not accounted for in equation (10). To provide comparability of the reliability estimates between different items (tanks and pipes) and across leases, the probability that the duration of the spill is $24 \mathrm{hr}$ or less should also estimated and coupled with the probability that a spill occurs, to obtain the probability of 24-hr spill duration at different locations. The probability that the spill will last for $24 \mathrm{hr}$ can be estimated from a Weibull distribution using a shape factor less than one to simulate 'early failure', where the 'age', $\mathrm{t}$, in this case is $24 \mathrm{hr}$. The logic for this choice of probability density function is that for a typical lease an operator will visit the site each day and therefore the likelihood of a spill remaining undiscovered for more than a 24 hour period is low and could be treated as a worst-case scenario. For the Weibull 
distribution a shape factor less than one gives a rapidly decreasing failure rate for longer times (the short-time behavior of the well-known 'bathtub' failure distribution). The characteristic life for accident discovery was chosen as a uniform variate between 1 and 3 hours which results in a range from 86 to $99 \%$ chance of discovering the accident within the first 24 hours for shape factors in the range of $[0.3,0.7]$. However, it also means that there is a $63 \%$ chance of discovery within the first 3 hours, and this may be more optimistic than actual discovery rates in practice. The model allows for this parameter to be modified if less frequent lease inspection is common for other locations. Thus equation (8) would be modified to include an additional 'branch' for each event tree with the 'failure probability' for that branch, the discovery of the failed equipment, given from equation (2) with the parameters discussed above. This modified failure probability would then be utilized in risk analysis at the lease level.

\section{Model Structure and Calibration}

\subsection{Structure}

The program is designed for lease level analysis of equipment reliability. A multiple linked list data structure is used to facilitate the addition of equipment, failure modes, and individual event tree branches as shown in Error! Reference source not

found.. The computer program has been structured to read a tagged text file that contains item lists with the item properties including each failure mode and associated event tree. As the program reads input file the data structure is dynamically filled and therefore simple addition of branches to event trees or complete failure modes is accomplished through insertion of several lines in the input file. The program flow for lease level analysis is to follow the linked list structure in Error! Reference source not found. by 
starting with a piece of equipment, then going to the first failure mode event tree, parsing the tree and choosing a failure probability from a Weibull random distribution based on the event type as described above.

After parsing each failure mode for the item, its reliability is computed and the next item is chosen; however for Monte-Carlo simulations, new parameters for that item are chosen till the required number of simulations is completed, then the next item is evaluated. After all the items have been summary statistics are written to an output file. The number of Monte Carlo simulations used in the model was 5,000. After this number of runs the estimated probability of failure did not change.

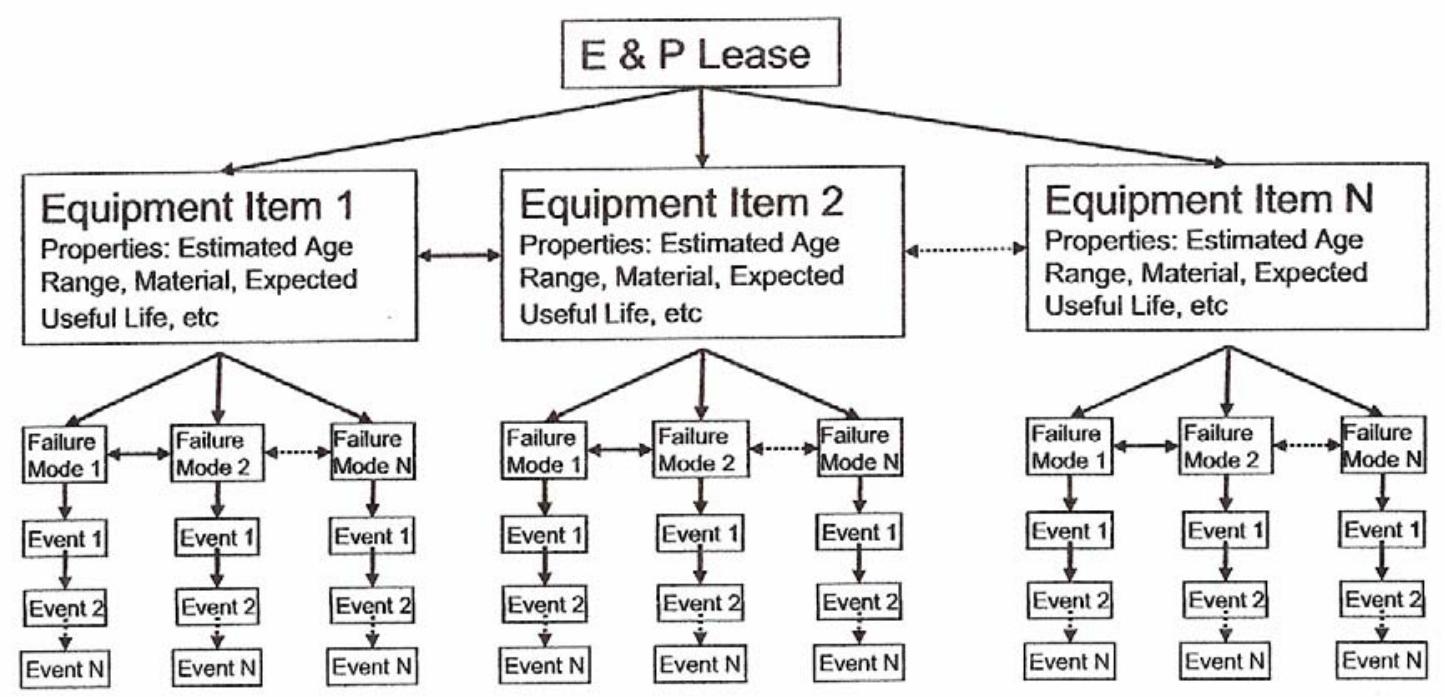

Figure 3. Schematic of lease level linked list structure

\subsection{Calibration and Uncertainty Analysis}

4.2.1 Calibration: The Oklahoma Corporate Commission (OCC:

http://www.occ.state.ok.us) database is a compilation of the causes, sources and quantity of released oil and brine from exploration and production (E\&P) operations in Oklahoma 
in the last ten years (1993 - 2003). Fisher and Sublette (2005) analyzed the database and reported the number of spills associated with various pieces of equipment.

However, the spills database does not directly provide information about annual failure probabilities. Combining the information from the spills database with the annual report data on active leases from the OCC website allowed the estimation of failure probabilities for specific types of equipment. The assumptions made to calculate the probabilities were:

- Number of active leases $=51,611$ (active leases in 2003)

- Number of wells per lease $=5$ (approximated from reported number of successful oil wells drilled since 1904 less the number of known plugged/abandoned wells divided by estimated average of 50,000 active leases during the past decade).

- Number of tanks per lease $=1$ (oil and brine).

- Length of oil pipe per lease $=2$ miles.

- Length of brine pipe per lease $=1$ mile.

Table 2 presents a summary of the primary sources of fluids released and the associated probability of occurrence on an annual basis.

Table 2: Failure probabilities estimated from OCC database

\begin{tabular}{|l|l|l|}
\hline Source & Oil Release & Brine Release \\
\hline Lines & 0.002 & 0.0046 \\
\hline Tanks & 0.0036 & 0.0035 \\
\hline Wells (pumps) & 0.0005 & 0.001 \\
\hline
\end{tabular}




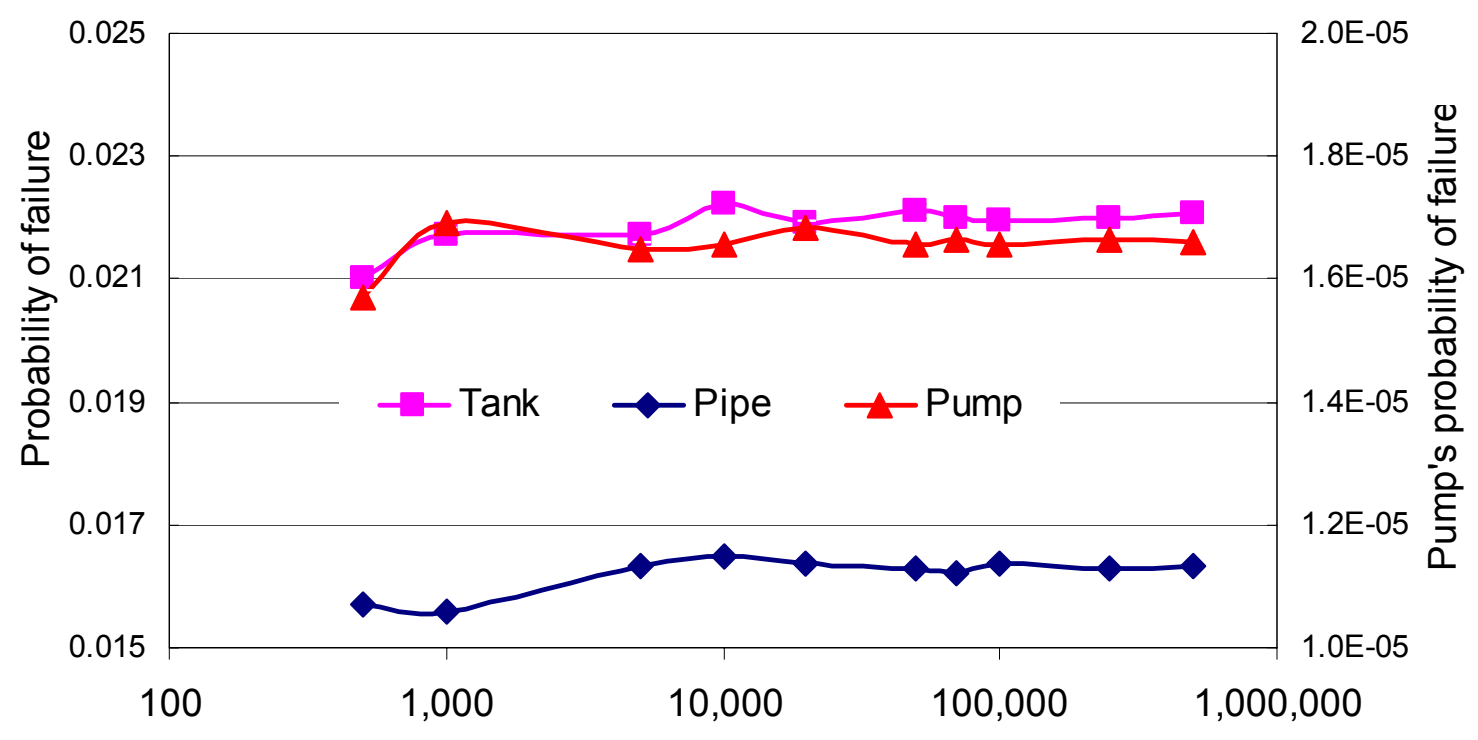

Number of Monte-Carlo simulations

Figure 2. Sensitivity of equipment failure probability to the number of Monte-Carlo runs

These estimated failure probabilities, were used to calibrate the model parameters used in the Monte-Carlo simulation. In particular, the characteristic lifetimes for random events (corrosion and non corrosion related) were used as adjustable parameters for matching the modeled failure probability with the OCC database derived estimate. The values determined, by trial and error, were 600 years with a standard deviation of 120 years for random failures; while, the characteristic lifetime for random events related to corrosion was set to 200 years with a standard deviation of 50 years. Thus individual event failure probabilities in non-corrosion failure modes were chosen from a Weibull distribution with a shape factor of 5 (for wear-out failures, which is equivalent to an equipment reliability of $95 \%$ when the equipment age is $55 \%$ of the characteristic life) 
with a characteristic life chosen as a normal variate with a mean of 600 years and standard deviation of 120 years. The final estimate of the failure probability for these events was not sensitive to the choice of the shape factor in the range of 2 to 5 .

4.2.1 Uncertainty Analysis: A number of important parameters are not known with certainty. One method of estimating the uncertainty in model predictions is through the use of Monte-Carlo simulations. For the calibration above we were interested only in the mean value of the estimated failure probabilities; however, as shown in Figure 3 the distribution of failure probabilities is log normal. The mean and variance of the population of failure probabilities is estimated from the log transformed data through the following equations:

$$
\mu=\exp (M+V / 2) \quad \sigma^{2}=(\exp (2 M+V))(\exp (V)-1)
$$

Where $\mathrm{M}$ is the arithmetic mean of the log-transformed data and $\mathrm{V}$ is the variance of the $\log$-transformed data.

\subsection{Failure Probabilities at the Tallgrass Prairie Preserve}

After calibration of the parameters we applied the model to a specific lease on the TPP and estimated the probability of failure within a one year time horizon (Equation 10). The location was determined during a site visit with the help of geographic positioning system (GPS). For all the calculations the pre-specified time horizon was 1 year.

Due to the lack of operational records for the leases in the Tallgrass Prairie, parameters such as average lifetime or average time to failure are not known with certainty. As described above we have estimated the uncertainty in the model output with 
Monte Carlo simulation. Thus during each Monte Carlo simulation a new item age was chosen as a normal variate with a mean of the estimated age and standard deviation of 2 years. The parameters necessary to calculate cumulative failure frequency for individual branches of the event trees were chosen randomly from distributions representative of the expected valid range for the specific parameter and equipment item. Table 3 presents the model parameters and the distributions used to calculate them.

Results obtained for representative equipment from the lease are shown on Table 4 and represent the probability that an item will fail in a 1-year time window. Note that these failure probability estimates do not include the probability the spill will be discovered within a specified time, and are thus directly comparable to the failure probabilities extracted from the OCC data. 


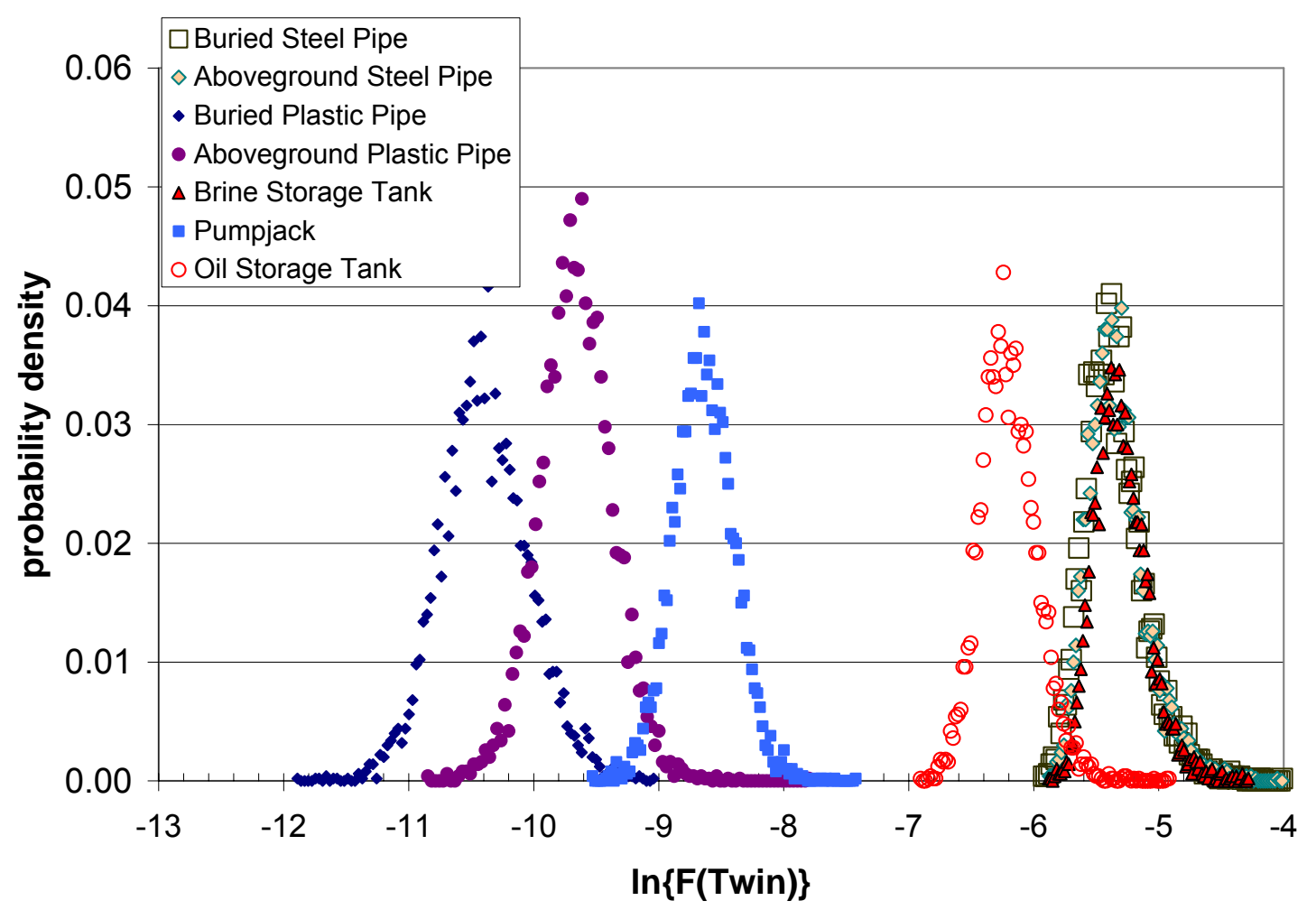

Figure 3. Probability density functions for the MCS estimated failure probability of different equipment and service in the TPP. 5000 MCS runs with 100 'bins' for frequency estimation. The log-transformed data is normally distributed, allowing the expected value (mean) to be computed using equation 11.

Table 3. Monte Carlo simulation parameters

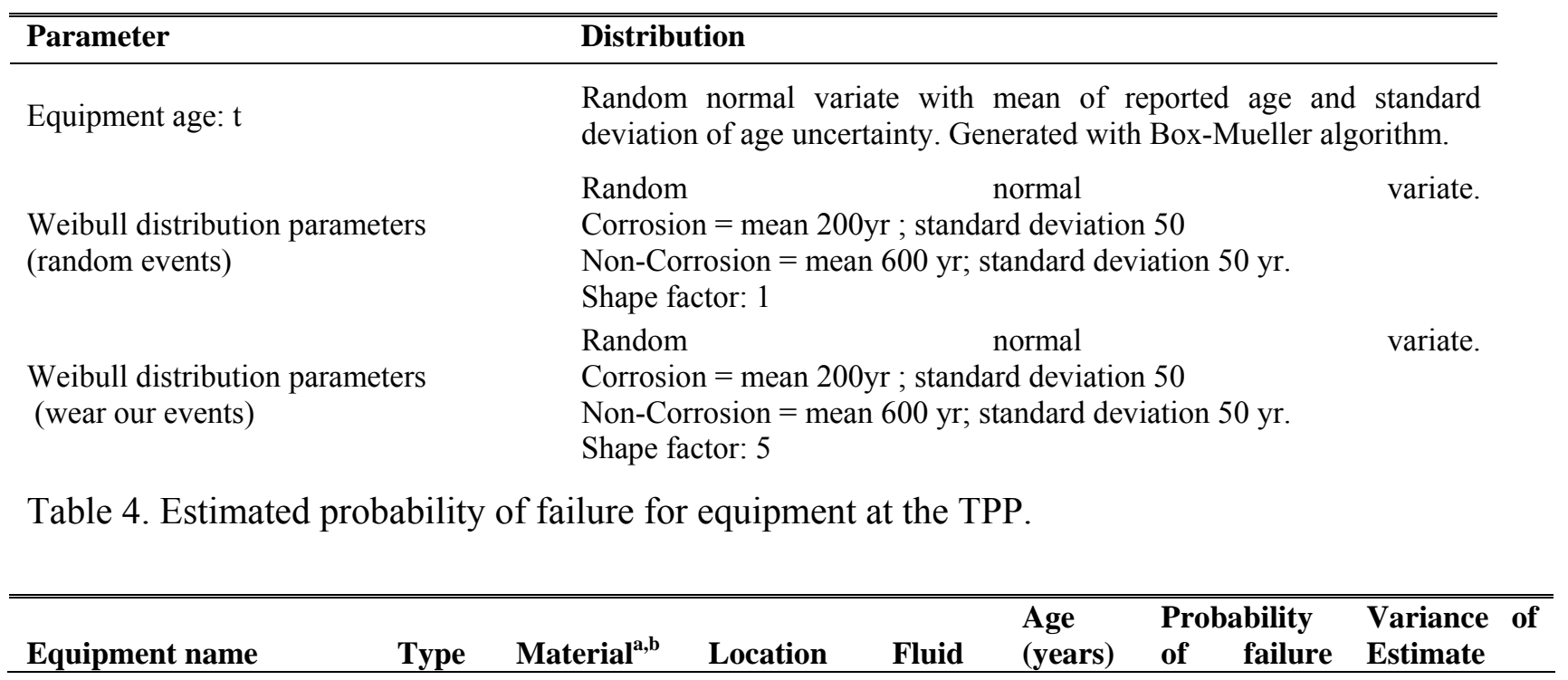




\begin{tabular}{|c|c|c|c|c|c|c|c|}
\hline & & & & & & (annua & \\
\hline Oil Water Separator & $\operatorname{tank}$ & $\mathrm{cs}$ & $\begin{array}{l}\text { Above } \\
\text { ground }\end{array}$ & mixed & 15 & $5.1 \mathrm{E}-3$ & $1.2 \mathrm{E}-6$ \\
\hline Brine Tank & $\operatorname{tank}$ & $\mathrm{cs}$ & $\begin{array}{l}\text { Above } \\
\text { ground }\end{array}$ & brine & 15 & $5.1 \mathrm{E}-3$ & $1.2 \mathrm{E}-6$ \\
\hline Mixed Fluid Pipe \#1 & pipe & $\mathrm{cs}$ & Buried & mixed & 20 & 4.9E-3 & $1.4 \mathrm{E}-6$ \\
\hline Oil Tank \#1 & tank & cs & $\begin{array}{l}\text { Above } \\
\text { ground }\end{array}$ & oil & 15 & $2.1 \mathrm{E}-3$ & $2.2 \mathrm{E}-7$ \\
\hline Oil pipe \#1 & pipe & cs & $\begin{array}{l}\text { Above } \\
\text { ground }\end{array}$ & oil & 20 & $1.8 \mathrm{E}-3$ & $1.3 \mathrm{E}-6$ \\
\hline Pumpjack \#2 & pump & cs & $\begin{array}{l}\text { Above } \\
\text { ground }\end{array}$ & mixed & 25 & $3.0 \mathrm{E}-4$ & $4.1 \mathrm{E}-9$ \\
\hline Pumpjack \#1 & pump & cs & $\begin{array}{l}\text { Above } \\
\text { ground }\end{array}$ & mixed & 25 & $2.9 \mathrm{E}-4$ & $3.8 \mathrm{E}-9$ \\
\hline Pumpjack \#9 & pump & $\mathrm{cs}$ & $\begin{array}{l}\text { Above } \\
\text { ground }\end{array}$ & mixed & 15 & $1.8 \mathrm{E}-4$ & $2.0 \mathrm{E}-9$ \\
\hline Mixed Fluid Pipe \#2 & pipe & plastic & $\begin{array}{l}\text { Above } \\
\text { ground }\end{array}$ & mixed & 5 & $6.6 \mathrm{E}-5$ & $4 \mathrm{E}-10$ \\
\hline Mixed Fluid Pipe \#5 & pipe & plastic & Buried & mixed & 5 & $3.3 \mathrm{E}-5$ & $1.4 \mathrm{E}-10$ \\
\hline
\end{tabular}

According to observations at the TPP, most of the failures were due to corrosion problems, and pipes are more likely to fail than any other equipment present at the site; consequently the value of $\mathrm{F}(\mathrm{t})$ for pipes should be higher than the probability of failure of the other equipment.

The results did not fully reflect the situation observed in the TPP showing that the estimated probabilities of failure for tanks are about the same order of magnitude as that for carbon steel pipes, which does not match the reality at the site. According to the available historical information at the TPP, seven pipe failures, one tank overflow, and one pump failure have been observed in the past 10 years. All the pipe failures can be attributed to corroded pipes. Therefore, the calculated value of probability of failure for pipes should be higher than the value calculated for tanks at this lease. However, the estimated probabilities are in reasonably close agreement with the OCC database which is a much larger population of equipment and therefore a more valid comparison data set. 
The model prediction for the failure rate of brine pipes is not in the correct range. This indicates a need for a more detailed treatment of the corrosion related failure modes. While sophisticated corrosion models have been published, the data requirements are generally more detailed than are readily available for a screening model.

\section{Conclusions and Recommendations}

The model is capable of estimate cumulative failure and failure within a future time horizon. However, the calculated failure probabilities for the equipment at the TPP are larger than the limited historical information available suggest they should be. This can be attributed to the fact that the corrosion model used for tanks is the same that for pipes. In the model, tanks are exposed to similar failure modes of pipes, and corrosion is the biggest cause of failure.

Nevertheless, both the order of magnitude and some of the characteristics of the OCC data set are reproduced in the TPP lease simulation: Oil service is less likely to fail than brine service, pumps are less likely to fail than pipes and tanks. The one characteristic that is not yet properly captured is that the OCC data show that brine injection well pipelines have the highest likelihood of failure, and the model does not show this behavior. Not surprisingly, plastic pipelines are significantly less risky than the aging steel infrastructure at the site.

The code is highly functional and easily expandable to accommodate additional equipment, failure modes, and event trees. It is of course critical that site specific information regarding the equipment history is available. For future work an inclusion of a more site-specific and equipment-specific corrosion models should allow more accurate probability of failure estimations. Additionally, the model needs to be validated with 
information from databases of equipment and equipment failure for similar sites to the

one under study.

\section{REFERENCES}

1. Center for Chemical Process Safety. (2000). Guidelines for Chemical Process

Quantitative Risk Analysis. New York: American Institute of Chemical Engineers.

2. Henley Ernest J. and Kumamoto Hiromitsu. (1996). Probabilistic Risk Assessment and Management for Engineers and Scientist. New York: IEEE Press.

3. Johnson, Robert W. (2000). Analyze Hazards, Not Just Risks. CEP Magazine, July, 31-40.

4. Post Robert L..; Hendershot Dennis C. and Kers Patrick. (2002). Synergistic Design yields Great Benefits. Approach to Safety and Reliability. CEP Magazine, January, 60-66.

5. Center for Chemical Process Safety. (1998). Guidelines for Design Solutions for Process Equipment Failures. New York: American Institute of Chemical Engineers.

6. Center for Chemical Process Safety. (1985). Guidelines for Hazard Evaluation Procedures. American Institute of Chemical Engineers. New York.

7. Fisher, J. Berton and Sublette, Kerry. (2004) "Environmental Releases from E\&P operations in Oklahoma: Type, Volume, Causes and Prevention",

8. Ghahremani, K., Grigoriani, \& S., Nourai, F. (2002). Simplify Reliability Analysis of Chemical Processes. CEP Magazine, July, 68-73.

9. Hogue, Cheryl. (2000). Describing Chemical Risk. $C \& E N$, September, 34-36.

10. Tobias, Paul A, Trindade, David C. (1986). Applied Reliability. Van Nostrand Reinhold Company.

11. Shreir, L.L.; Jarman, R.A.; Burstein, G.T. (1994). Corrosion (3rd Edition) Volumes 1-2. (pp. 2:65). Elsevier. Online version available at: http://www.knovel.com/knovel2/Toc.jsp?BookID=713\&VerticalID $=0$

12. Per Olav Gartland, Roy Johnsen and Ingar Øvstetun, "Application Of Internal Corrosion Modeling In The Risk Assessment Of Pipelines," http://www.corrocean.com/attachments/servlet/attachments?id=230

13. Bhongale, S., Gopal, M.,\& Jepson, W. (1996). Predictive Model for Sweet Corrosion in Horizontal Multiphase Slug Flow. In NACE Corrosion96. Paper No. 19.

14. API 5L. (1995). Specifications for Line Pipe. American Petroleum Institute.

15. Parmakian, John. (1955). Water Hammer Analysis. New York: Prentice-Hall. 


\title{
Chapter 6
}

\section{Consequences Analysis of Produced Fluids Spills and Risk Index Generation for the Tallgrass Prairie Preserve}

\author{
Greg Thoma*, Chun Yen Wong, Lyda Zambrano \\ University of Arkansas \\ Dept of Chemical Engineering \\ Kathleen Duncan \\ Dept. of Botany and Microbiology \\ University of Oklahoma \\ Kerry Sublette \\ Center for Applied Biogeosciences \\ University of Tulsa \\ Joshua Brokaw \\ Oklahoma State University \\ Dept. of Botany \\ Tim Todd \\ Kansas State University \\ Dept. of Plant Pathology
}

* Corresponding author

3202 Bell Engineering Center

University of Arkansas

Fayetteville, AR 72710

Phone: 479-575-4951

Fax: 479-575-7926

E-mail address: gthoma@uark.edu

Key words: exploration and production; probabilistic risk analysis; risk management 


\begin{abstract}
A significant problem facing the domestic oil industry is high production expenses due to environmental compliance measures. Reactive approaches such as risk based corrective action (RBCA) allow cost-effective allocation of limited resources among multiple impacted sites for minimizing human health and ecosystem risks. We present a method aimed at reducing the likelihood of contaminant releases into the environment through a proactive risk management strategy. This proactive risk management strategy has the potential of increasing revenue through avoidance of lost production and postspill remediation expenses.
\end{abstract}

A physical transport model was developed to quantify the extent of a spill on soil surface. The governing continuity equation for the 2-Dimensional surface flow of constant fluid density including infiltration was solved numerically using the method of lines. Model validation was performed through comparison of predicted spill areas from both artificial surface and real topography tests. When applied to an historic brine scar, physical transport model prediction for the areal extent of the release, on a digital elevation model of the site, was within $30 \%$ of the actual scar area. A sensitivity analysis was performed to determine the effect of input parameters on model output that showed the infiltration rate was the principal factor affecting the areal extent of brine spills, but that more complex surface flow factors were important for oil spill spreading.

Coupling the probability of an equipment failure with the predicted areal spill extent and a natural resources damage assessment for the predicted spill can be used to generate a ranked risk index for a particular production lease. In this paper we report on linking the spill model to a geographic information system that provides a platform for 
generation of a consistent risk-ranked map of two active oil production leases located in the Tallgrass Prairie Preserve, located in Osage county, Oklahoma. The model is readily exportable to other E\&P sites for which the necessary input information is available or can be generated.

\subsection{Introduction}

In order to ensure the quality of human health and the environment, risk assessment that integrates a wide range of scientific disciplines from chemistry, and mathematics to geology and statistics, has been established. Quantitative environmental consequence analysis has become more effective and reliable because of: (1) technological advances in data collection, storage, and processing; (2) better understanding of chemical, physical, and transport properties of spilled fluids in the environment; (3) modern computational capabilities. Utilizing quantitative information on the environmental consequences of past anthropogenic activities, a proactive risk management tool has the potential to help risk managers identify the high risk processes of a system with the aim of preventing the occurrence of undesired outcomes.

The Osage Environmental Audit Survey sponsored by the Oklahoma Corporation Commission (OCC) on marginal producing oil and gas wells reports that the maturing of the domestic oil and gas production fields, old infrastructure, and increasingly strict environmental compliance requirements have put the marginal oil and gas industry at risk of extinction (Lamb, 1991). Currently, most marginal oil wells are operated by small, independent lease operators on the lower edge of profitability with an average production of 2 to 3 barrels per day. Nevertheless, the contribution of these wells to the total onshore 
oil productions of the United States (not including Alaska and Florida) was approximately 323 million barrels of oil in 2002 (IOGCC, 2003).

According to the OCC complaint database, the estimated volume of crude oil released in Oklahoma alone from the E\&P operations for the 10-year period from1993 to 2002 was about 2.2 times the oil lost from the Exxon Valdez incident (National Oceanic and Atmospheric Agency, 1992). Fisher et al. (2004) summarized the OCC complaint database and reported that the amount of produced fluids spilled in Oklahoma during the 10-year period averaged $10 \mathrm{bbl}$ per oil spill (8,529 reported) and $40 \mathrm{bbl}$ per brine spill (7,916 reported). These smaller and more frequent accidental releases continually introduce contaminants into the environment and measures to reduce the frequency of occurrence of these accidental releases are needed.

Current regulations such as the Oil Pollution Act of $1990 § 4301$ (a) and (c) rely on a system of fines and penalties to reduce accidental oil releases. Fines and penalties have successfully reduced the number of large oil spills; however, this approach is less effective for regulating small oil spills because there are no specific requirements for reporting spills that do not directly impact surface water. In order to help the small oil producers to remain viable and to continue contributing to the nation's economic growth, a proactive approach aimed at preventing accidental produced fluids release is needed.

Existing risk assessment tools such as the Risk Based Corrective Action (RBCA) program have gained regulatory acceptance in determining remediation strategies for leaking underground storage tanks (ASTM, 1995). RBCA is actually a reactive risk management tool for allocation of limited resources among multiple impacted sites with the goal of providing the maximum mitigation of an existing health or ecosystem risk. A 
proactive risk management strategy is a more effective control for reducing contaminant releases into the environment. As a result, proactive risk management has the potential of generating cost savings. One study showed that about $15-25 \%$ of marginal oil production revenue was spent on regulatory compliance (Lamb, 1991). Therefore, the development of proactive risk management tools for oil and gas exploration and production (E\&P) operations would be beneficial to the domestic oil and gas industry, especially to the marginal oil and gas productions through reduction in the frequency of accidental releases and the associated cleanup expense. There are still 402,072 marginal oil wells in the United States (IOGCC, 2003).

The necessary components of a proactive risk management tool are: 1) a method to estimate the likelihood of an accidental spill at a specific location, 2) a model to predict the extent of the spill and its proximity to sensitive receptors (e.g. streams or water wells), and 3) a damage assessment model to provide quantitative cost-estimate information for the remediation of the impacted site. Probabilistic Risk Assessment (PRA) is a proactive approach to risk minimization by quantifying the likelihood of certain outcomes and the consequences of those events. Probabilistic Risk Assessment development involves six major steps: 1) system identification, 2) event identification, 3) frequency analysis, 4) consequences analysis, 5) risk estimation, and 6) risk assessment. The first three steps are presented in the companion report (Thoma, et al., 2005).

\subsection{Risk Assessment Models}

In environmental management, risk assessment is the process by which the results of a risk analysis are used to make decisions through relative ranking of risk reduction 
strategies (Wagner, 1998). Risk analysis requires the estimation of the likelihood and consequences of a potential accident.

Two different types of risk assessment are found in the industry: (1) qualitative analysis including preliminary hazard analysis (PHA), hazard and operability study (HAZOP) and failure mode and effects analysis (FMEA); (2) quantitative analysis including fault-tree analysis (FTA), event-tree analysis (ETA), and cause-consequence analysis. Actually, applications of risk assessment have been used in industry for a long time; for example, Probabilistic Risk Assessment (PRA) based on ETA was originally developed by the nuclear industry, and has been used for at least 30 years (Thomson, 1987). In the nuclear industry, PRA has allowed risk managers to focus on processes and operational procedures that required more attention to reduce operating risk.

Due to its systematic, qualitative, and quantitative analysis, other industries including chemical, and hazardous materials transport have also developed PRA tools to minimize operating risk (Vedat et al., 2001).

\subsection{Oil Spill Models}

To quantify environmental impacts resulting from onshore oil and gas E\&P operations, mathematical models are required to simulate the fate and transport of spilled

fluids in the environment. In early 1970's, oil spill modeling was used by Fay (1971) and Hoult (1972) to estimate the spreading of oil in calm waters as one dimensional or axissymmetric process. Fay identified the forces that govern the spreading processes:

gravitational, inertial, viscous, and surface tension forces and suggested three stages of oil spreading in water: gravity-inertial, gravity-viscous, and viscous-surface tension. 
Later, Buckmaster (1973) examined Fay's and Hoult's discussions and derived an explicit expression of gravity-viscous process for the size of a spill as function of time.

Over the past decades, the scale of offshore oil production and ocean transport of oil has increased tremendously to meet growing energy needs. As a result, more sophisticated models have been developed to more realistically simulate oil movement in space and time by including other fate processes such as evaporation, dispersion, dissolution, emulsification, , and biodegradation. (Cuesta, et. al, 1990; Liu et al., 2000).

Over 50 two-dimensional (2-D) or three-dimensional (3-D) oil spill models have been developed, but most of these models were developed to simulate oil spill trajectory on water rather than on land. As examples, the National Oceanic and the Atmospheric Administration (NOAA) model On-Scene Spill Model (OSSM) and Atmospheric Environment Service (AES) of Environment Canada model were used to examine major aquatic oil spills such as the Exxon Valdez and Amoco Cadiz spills (ASCE Task Committee, 1996). However, models describing oil spills for terrestrial applications remain very limited.

The number of small and frequent accidental oil spills occurring on shore has stimulated the attention of environmental regulatory groups, making the development of oil spill models to quantify the releases on land necessary.

\subsubsection{Physical Fate and Transport Models:}

A physical transport model is a scientific tool to predict the distribution of contaminants in the environment. Unfortunately, extensive modeling information associated with the behavior of crude oil or brine spills over terrestrial terrain are limited. Terrestrial spill models have to be derived from surface flow models or from the 
fundamental conservation relationships. The continuity and momentum equations for incompressible fluids flows are expressed:

$$
\begin{aligned}
& \nabla \cdot v=0 \\
& \rho \frac{D v}{D t}=\rho g-\nabla p+\nabla \cdot \tau
\end{aligned}
$$

Generally, spill models are constructed by linking mathematic algorithms to describe spill fate and transport processes, and a mass balance approach is applied to track the amount of fluid in each matrix (atmosphere, soil surface, subsurface, and groundwater). In this project, two linked models were used to simulate the areal extent of oil or brine spilled on soil: (1) surface flow spreading; (2) infiltration, assuming the effects due to volatilization were negligible over the time scale of interest (hours to days).

\subsubsection{Surface Flow Spreading:}

Because of the similarity of surface spill spreading processes with those in surface water flows, the governing equations of surface water flow were adopted to predict areal extents of oil or brine spills over time. Surface water flows are commonly simulated by solving St. Venant equations consisting of a 2-D continuity equation and two momentum equations:

$$
\begin{aligned}
& \frac{\partial h}{\partial t}+\frac{\partial(h u)}{\partial x}+\frac{\partial(h v)}{\partial y}-R F+I N=0 \\
& \frac{\partial(h u)}{\partial t}+\frac{\partial\left(h u^{2}\right)}{\partial x}+\frac{\partial(h u v)}{\partial y}+h g \frac{\partial(h+z)}{\partial x}+g h S_{f x}=0 \\
& \frac{\partial(h v)}{\partial t}+\frac{\partial(h u v)}{\partial x}+\frac{\partial\left(h v^{2}\right)}{\partial y}+h g \frac{\partial(h+z)}{\partial y}+g h S_{f y}=0
\end{aligned}
$$

(for definitions of symbols, see nomenclature section at the end of this document) 
Due to the complexity of St. Venant equations, several simplifying assumptions are frequently made. Table $0-1$ shows the summary of selected surface water flow models with numerical solution techniques and assumptions. For example, (1) the dynamic wave approximation has no practical computational advantage; (2) the kinematic wave approximation is suitable for long overland flow with sufficient slope; (3) the non-inertial wave approximation is able to account for the effects of downstream backwater (Morita et al., 2002; Moore et al., 1990).

Among the simplified forms of the St. Venant equations, the non-inertial assumption is more suitable for situations where low velocities are encountered. The noninertial assumption is valid for Froude numbers less than 0.3 as reported by Guardo et al. (2000). The Froude number is defined as the ratio of inertial force to gravitational force. A study by Emmett (1978) verified that surface water flow encountered on natural hillslopes has Froude number less than 0.2. Therefore, we have considered the non-inertial assumption to be valid for the natural surface flow model.

\section{Table 0-1 Selected Surface Flow Models}

\begin{tabular}{|l|l|l|l|}
\hline Investigator & Dimension & Assumption & Solution Technique \\
\hline Morita et al. (2002) & 2-D & $\begin{array}{l}\text { Non-inertia wave - neglecting } \\
\text { local and convective acceleration } \\
\text { terms }\end{array}$ & Saul'yev \\
Finite difference \\
\hline Jaber et al. (2002) & 1-D & $\begin{array}{l}\text { Kinematic wave - neglecting } \\
\text { inertia and pressure terms }\end{array}$ & $\begin{array}{l}\text { Finite element } \\
\text { Dynamic-time step }\end{array}$ \\
\hline Playan et al. (1994) & 2-D & $\begin{array}{l}\text { Dynamic wave - neglecting } \\
\text { local acceleration term }\end{array}$ & Leapfrog \\
\hline
\end{tabular}




\subsection{Infiltration}

Infiltration is water movement across the soil surface into subsurface and is limited by either infiltrability or water supply rate. Infiltrability is defined as the maximum rate at which water can be absorbed by a soil under a specific condition and is a function of initial soil moisture content and the hydraulic properties of soil (Hillel, 1971). Other factors that influence overall infiltration rate include water supply duration, slope, surface roughness, vegetation, and soil physical properties.

Infiltration can be simulated either by empirical or physical-based functions: (1) empirical infiltration functions containing parameters without physical significance; (2) Green and Ampt and Richards developed more complicated infiltration functions with physical soil parameters that can be measured independently (Knight, 1983). Among these infiltration models, the Green-Ampt model is the most popular because of its simplicity, adaptability to varying scenarios, and the availability of characteristic parameter values for various soil textures and conditions.

Assumptions of the Green-Ampt model include: (1) a piston-type water content profile with a well-defined wetting front. Soil between the ground surface and the wetting front is saturated, and at the wetting front the saturated water content drops instantaneously to the initial water content; (2) homogeneous soil and uniform initial moisture content; (3) The soil-water pressure head at the wetting front is assumed to be $h_{f}$ (negative), and at the ground surface, $h_{s}$, is assumed to be equal to surface flow depth, $\mathrm{H}_{\mathrm{s}}$. Many approximate solutions of infiltration based on Green-Ampt concept have been determined by analytical methods with boundary conditions or numerical methods such as finite difference and finite element techniques. Thus, any simple mathematical model 
in derivative form that describes the vertical infiltration would be considered applicable in this project.

The modified form of Green-Ampt model developed by Smith and Parlange (1978) was chosen for this project because: (1) it relates the infiltration rate to soil hydraulic properties and moisture deficit; (2) required soil hydraulic parameters can be easily obtained from the published literature; (3) no site-specific measurement of all the parameters is necessary if the model is used for screening level contaminant transport. The Smith and Parlange infiltration equation is expressed as:

$$
\frac{d I}{d t}=\frac{K_{s w}}{1-\exp \left(\frac{-I}{\Delta \theta \psi_{f}}\right)}
$$

where $\Delta \theta=\theta_{s}-\theta$ and (Grove, 1989)

$$
\psi_{f}=\psi_{a}\left(\frac{\theta-\theta_{r}}{\theta_{s}-\theta_{r}}\right)^{-1 / \lambda}
$$

\subsubsection{Hydraulic Conductivity of Soil to Water and Oil:}

Knowledge of soil properties such as hydraulic conductivity, moisture content, and capillary pressure head is important for models to accurately predict the movement of water or other fluids during surface runoff, infiltration, or evaporation. Studies have been done to determine the relationship between the water moisture content and capillary pressure head, and the relationship between the unsaturated hydraulic conductivity and the capillary pressure head or moisture content. The most widely used soil hydraulic 
properties empirical functions for water are the Brooks-Corey model (Brooks and Corey, 1964):

$$
\begin{aligned}
& \theta=\theta_{r}+\left(\theta_{s}-\theta_{r}\right)\left(\frac{\psi_{a}}{\psi_{f}}\right)^{\lambda} \\
& K(\theta)=K_{s w}\left[\frac{\theta-\theta_{r}}{\theta_{s}-\theta_{r}}\right]^{3+2 / \lambda}
\end{aligned}
$$

and the model of van Genuchten (1980):

$$
\begin{aligned}
& \theta=\theta_{r}+\left(\theta_{s}-\theta_{r}\right)\left(1+\left[\alpha\left|\psi_{f}\right|\right]^{\beta}\right)^{-\gamma} \\
& K(\theta)=\left[\frac{\theta-\theta_{r}}{\theta_{s}-\theta_{r}}\right]^{1 / 2}\left[1-\left(1-\left[\frac{\theta-\theta_{r}}{\theta_{s}-\theta_{r}}\right]^{1 / \gamma}\right)^{\gamma}\right]^{2}
\end{aligned}
$$

However, soil hydraulic properties functions for organic liquids such as crude oil are not readily available. Therefore, methods of scaling soil-water flow equations to organic liquid flow by varying only viscosity and interfacial tensions are used for predicting organic liquids infiltration. A number of relationships have been proposed to estimate the hydraulic conductivity of an organic liquid as a function of the liquid contents and pore size distribution of the porous medium (Parker et al., 1987; Cary et al., 1989). Cary and colleagues derived two hydrocarbon conductivity functions and conducted water and oil infiltration tests in silt loam and loamy sand. The observed infiltration and distribution of oil into soils were in good agreement with those predicted by the following equation (Cary et al., 1989): 


$$
K_{o}=K_{s w} \frac{\mu_{w}}{\mu_{o}}\left[\left(\frac{\theta_{w}+\phi}{\theta_{S}}\right)^{2 \lambda+3}-\left(1+\frac{(2 \lambda+3) \phi}{\theta_{w}}\right)\left(\frac{\theta_{w}}{\theta_{S}}\right)^{2 \lambda+3}\right]
$$

Other researchers have measured the hydraulic properties of soils for oil. The study concluded that permeability coefficients are ranked by hydrocarbon viscosity in sandy gravel and silty fine sand, but permeability coefficients for diesel are higher than those of petrol in silt and clay. Studies that predict permeability of oil in porous medium for more complex systems such as three-phase flow and oil-water systems with mixed wettability are not applicable in this project because the focus is on simple vertical infiltration process (Senneset et al., 1995; Lenhard et al., 1998; Dicarlo et al., 2000).

\subsection{Roughness Coefficient}

Hydraulic roughness is an important parameter to be used in determining flow velocity during surface runoff. The hydraulic roughness can be determined by balancing the bed shear force against the force of gravity. The most widely used hydraulic roughness correlations are the Manning and Darcy-Weisbach coefficients. For rangelands or prairies, hydraulic roughness coefficients are difficult to measure and to predict because of the variability in soil surface, microtopography, standing vegetation, residue cover and rocks lying on the surface. Some studies reported a lumped-term roughness coefficient, which did not separate the influences of the above factors (e.g. Roels, 1984). On the other hand, a number of studies have been carried out to determine the roughness coefficient of each factor (Gilley et al., 1990; Gilley et al., 1991; Lawrence, 1997). 
Gilley and Finkner (1991) developed two empirical relationships relating both random roughness of surface and local flow Reynolds number to Darcy-Weisbach roughness coefficient and Manning roughness coefficient, respectively:

$$
\begin{aligned}
& f_{d}=\frac{6.3 R R^{1.75}}{\operatorname{Re}^{0.661}} \\
& n=\frac{0.172 R R^{0.742}}{\operatorname{Re}^{0.282}}
\end{aligned}
$$

Another study by Gilley and colleagues (1991) reported the roughness coefficient of residue materials from regression analysis in terms of percent cover and Reynolds number, where $\mathrm{a}, \mathrm{b}$, and $\mathrm{c}$ are regression coefficients.

$$
f_{r s}=\frac{\mathrm{a}(\text { Percent Cover Of Residual Material })^{\mathrm{b}}}{\operatorname{Re}^{\mathrm{c}}}
$$

According to Weltz et al.'s (1992) and Roels' (1984) experimental results, the friction associated with rock is relatively small compared to a lumped-term roughness coefficient. One of the possible explanations is the presence of rocks creates interference of the wakes, which tends to decrease the friction. Weltz and colleagues (1992) also suggested using the sub-factor approach to estimate effective Darcy-Weisbach roughness coefficient, $f_{d}$, where the roughness coefficients caused by each of these sub-factors are summed as:

$$
f_{d}=f_{r s}+f_{r r}+f_{g c}+f_{p b}
$$

The subfactor approach as implemented for this project is described in more detail later in this report. 


\subsection{Environmental Impact Assessment Models}

Environmental impact assessment is one of the important components of PRA. The need for quantitative assessment of environmental impact and natural resource damage resulting from a spill has prompted regulators and industry to develop damage assessment models. Under the Comprehensive Environmental Response, Compensation and Liability Act (CERCLA), two types of damage assessment methodologies have been developed: (1) Type A, standard simplified procedures which require minimal field observations, (2) Type B, more complex and detailed studies (ASTSWMO, 2000). An example of Type A assessment models is Natural Resource Damage Assessment Models for Great Lakes Environments and Coastal and Marine Environments (NRDAM/GLE and NRDAM/CME), and the schematic overview of damage assessment model is illustrated in Figure 0-1 (Reed et al. 1996). The NRDAM/GLE and NRDAM/CME was originally designed for assessing environmental impacts in water-bodies; therefore, the computer modeling of chemical fate and transport is not suitable for this project. However, the NRDAM framework was adopted for developing a terrestrial environmental impact assessment model associated with onshore oil and gas E\&P operations.

Recently, Applied Science Associates (ASA) has developed a model called Spill Impact Model Application Package (SIMAP), originating from NRDAM/GLE and NRDAM/CME, to estimate the potential impacts and natural resource damage assessment resulting from oil spills onto water bodies. SIMAP utilizes a stochastic technique to determine an objective measure of the magnitude, range, and variability of impacts to natural resources for potential spills. SIMAP demonstrates that statistically 
quantified potential impacts and financial consequences could be used in ecological risk assessment and cost-benefit analysis (McCay et al., 2004).

\subsection{Geographical Information System}

Geographical Information System (GIS) is a technology originally used to handle geographical data in digital form used to:

1. Preprocess data from large stores into a form suitable for analysis (e.g. re-formatting, change of projection, re-sampling).

2. Provide direct support for analysis and modeling (e.g. form of analysis, calibration of models, prediction).

3. Post-process of results (e.g. reformatting, report generation, tabulation, mapping).

In past twenty years, GIS has evolved dramatically and its applications now range from sophisticated analysis and modeling of spatial data to simple inventory and management. One of the most successful application areas of GIS is in environmental problem-solving. For instance, an environmental simulation model is typically defined as a computer-based technique to simulate the real-world processes, such as hydrodynamic fluid flow, agricultural non-point source pollution, integrating forest and grassland growth, forest fire management, and ecological development. ArcGIS is a commercial GIS tool developed by ESRI, and it runs under the Window operating system. ArcGIS is widely used in both the public and private sectors, therefore, ArcGIS - ArcMap 8.3 was selected as the platform of PRA model development for TPP. 


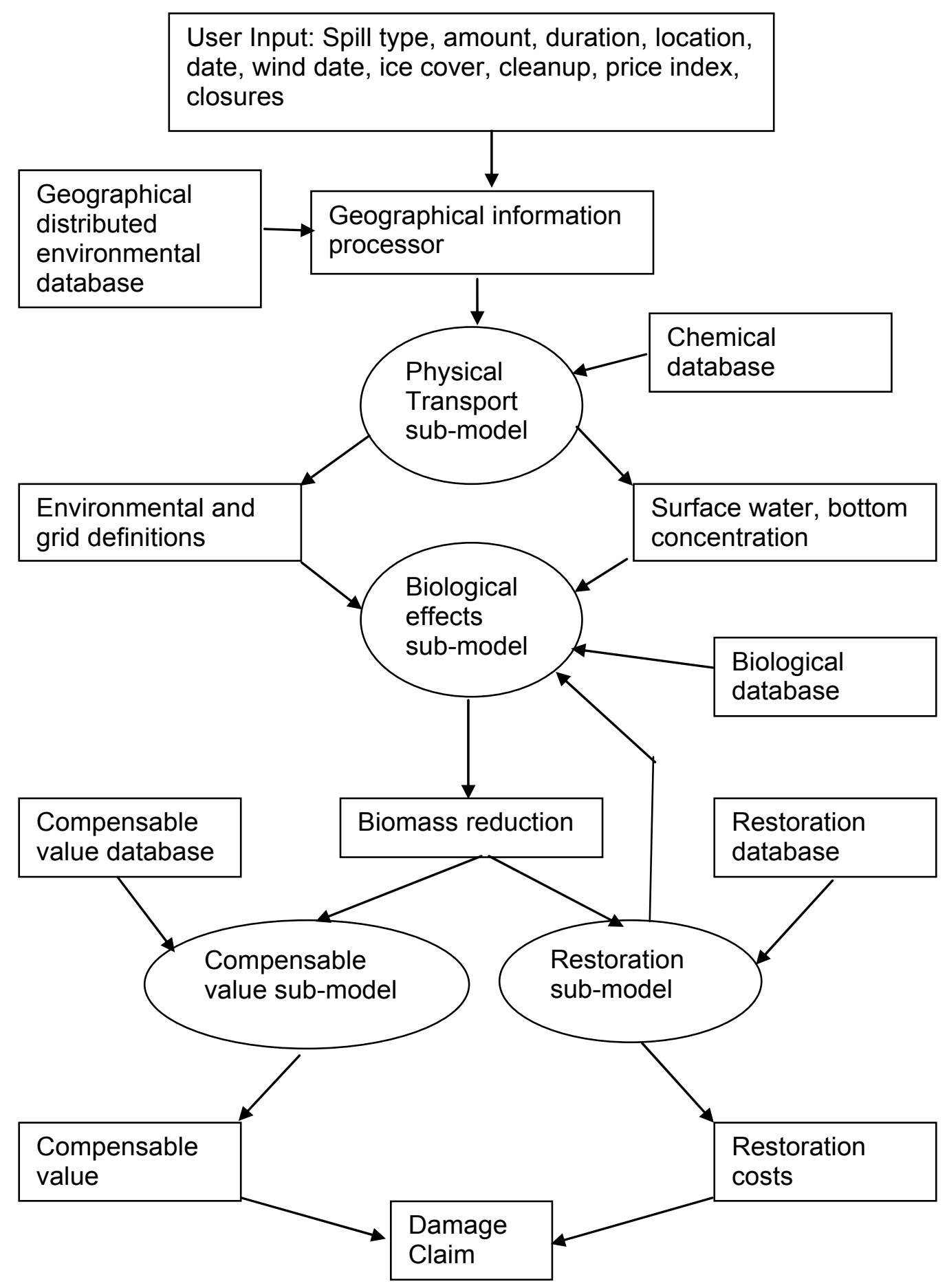

Figure 0-1. Schematic of Environmental Damage Assessment Model (Reed, et al. 1996) 


\subsection{Methods}

\subsection{Mathematics of Spill Spreading}

The basic model for spill spreading on the ground surface, as indicated earlier, is defined by the conservation equations $0-1$ and $0-2$. The shear stress and pressure forces acting on a differential volume element of the spreading fluid are shown in Figure 0-1. Several assumptions have been made to simplify the momentum equations:

1. Non-inertial assumption: $\frac{\partial V x}{\partial x}$ and $\frac{\partial V y}{\partial y}$ are both very small, and therefore, $\tau_{x x}$ and $\tau_{y x}$ become negligible.

2. At the ground surface $V_{z}=0 ; V_{z} \frac{\partial V_{z}}{\partial z}=0$

3. Quasi steady state flow conditions.

Thus, Equation 0-2 for the flow in $\mathrm{x}$ direction is reduced to:

$$
0=\rho g_{x}-\frac{\partial P}{\partial x}+\left[\frac{\partial \tau_{z x}}{\partial z}\right]
$$

where the pressure in $\mathrm{x}$ direction is estimated by the hydrostatic potential energy for fluid depth on the surface, $h$, expressed as:

$$
\frac{\partial P}{\partial x}=\rho g \frac{\partial h}{\partial x}
$$




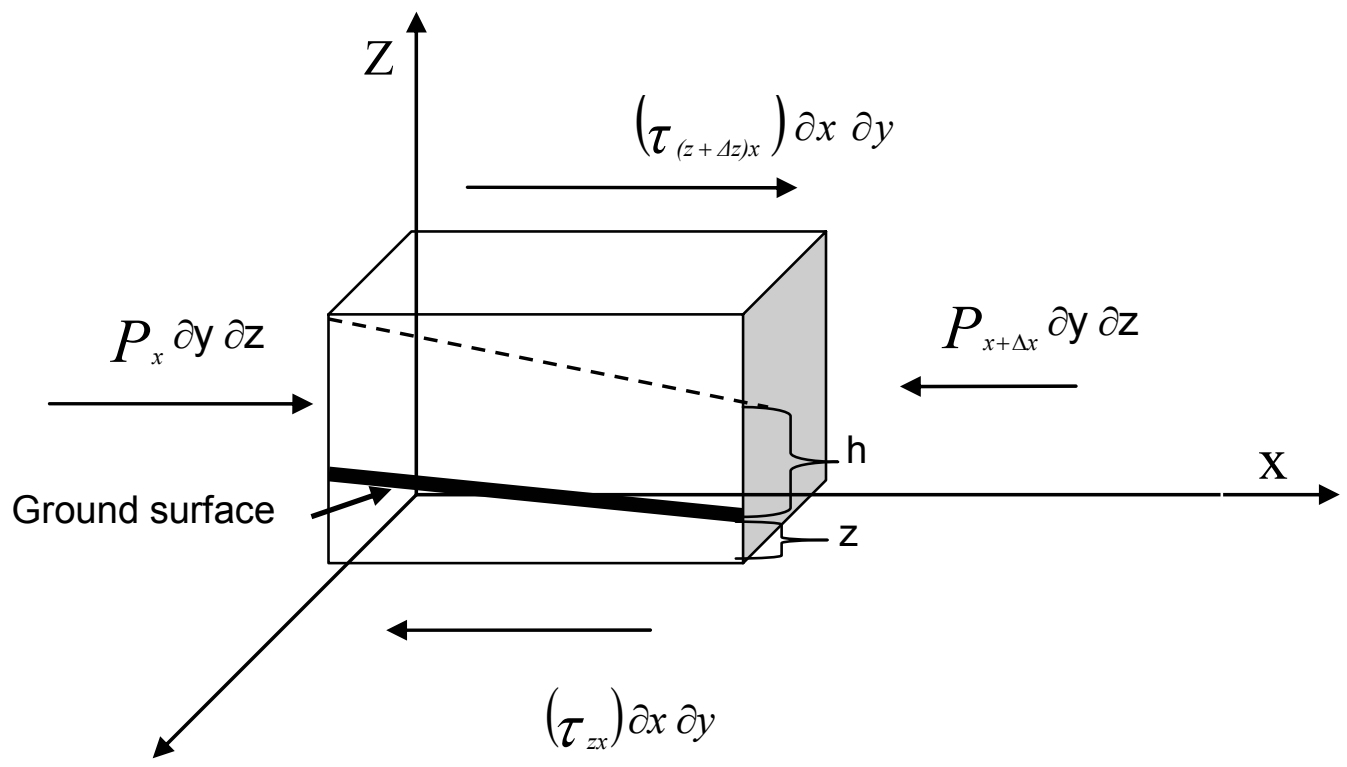

Figure 0-1. Shear Stress Components Diagram

the gravitational acceleration in x direction times ground surface slope, $S_{o x}$

$$
\rho g_{x}=\rho g S_{o x}
$$

the shear stress within flow in z direction is estimated from the energy slope, $S_{f x}$

$$
\frac{\partial \tau_{z x}}{\partial z}=-\rho g S_{f x}
$$

Thus, the simplified form of momentum equation in $\mathrm{x}$ and $\mathrm{y}$ directions are:

$$
0=S_{o x}-\frac{\partial h}{\partial x}-S_{f x} \text { and } 0=S_{o y}-\frac{\partial h}{\partial y}-S_{f y}
$$

Where the ground slopes are defined: $S_{O X}=-\frac{\partial z}{\partial x}, S_{O y}=-\frac{\partial z}{\partial y}$. The friction slopes (free fluid surface slope) in $\mathrm{x}$ and $\mathrm{y}$ directions can be written as follows, where $\mathrm{z}$ is the elevation of the soil surface:

$$
S_{f x}=-\left(\frac{\partial[h+z]}{\partial x}\right) \text { and } S_{f y}=-\left(\frac{\partial[h+z]}{\partial y}\right)
$$


The negative sign indicates friction force is acting on the opposite direction of flow.

\subsection{Flow resistance}

A resistance relationship is derived by balancing the bed shear force against the force of gravity. The frequently used formulas such as Chezy, and Mannings are commonly used to mathematically describe turbulent overland flows. However, DarcyWeisbach formula is usually recommended to estimate friction slopes for laminar flows, which can be written as (Lal, 1998):

$$
V=\sqrt{\frac{8 g}{f_{d}}} h^{1 / 2} S_{f}^{1 / 2}
$$

where $V=\sqrt{V_{x}^{2}+V_{y}^{2}}$ is the magnitude of the velocity vector; $S_{f}=\sqrt{\left(S_{f x}\right)^{2}+\left(S_{f y}\right)^{2}}$ is the fluid free surface slope; $f_{d}=$ dimensionless Darcy-Weisbach flow resistance coefficient. When introducing the Darcy-Weisbach formula into the continuity equation, $0-3, V_{x} h$ and $V_{y} h$ can be written as follows:

$$
\begin{aligned}
& V_{x} h=-D_{x} \frac{\partial H}{\partial x} \text { and } V_{y} h=-D_{y} \frac{\partial H}{\partial y} \\
& D_{i}=\left\{\begin{array}{cc}
\sqrt{\frac{8 g h_{i}^{3}}{f_{d}}}\left|S_{f i}\right|^{-1 / 2} \text { if } & \left|S_{f}\right|>0.001 m \text { and } h>0.001 m \\
0 & \text { otherwise }
\end{array}\right.
\end{aligned}
$$

$\left|S_{f}\right|$ and $h$ limits were imposed to reduce the computational time and avoid convergence problems in numerical solution (Lal, 1998). After substituting equations 0-8 into equation $0-3$, the governing continuity equation for the surface flow of a constant density fluid is described by the partial differential equation: 


$$
\frac{\partial h}{\partial t}=\frac{\partial}{\partial x}\left(D_{x} \frac{\partial H}{\partial x}\right)+\frac{\partial}{\partial y}\left(D_{y} \frac{\partial H}{\partial y}\right)+V_{s}-\frac{d I}{d t}
$$

$\mathrm{h}$ is the fluid depth $(\mathrm{L}) ; \mathrm{V}_{\mathrm{s}}$ is spill rate $(\mathrm{L} / \mathrm{T})$; $\mathrm{t}$ is time $(\mathrm{T})$ and

$\frac{\mathrm{dl}}{\mathrm{dt}}$ is the infiltration rate $(\mathrm{L} / \mathrm{T})$ from equation $0-6$.

All the parameters in equation 0-10 are functions of space and time.

\subsection{Numerical Algorithms}

Analytical solutions of equation 0-10 are rarely possible. Thus, numerical methods must be employed to obtain approximate solutions. In this project, the Method of Lines was employed to convert the partial differential equation into a set of ordinary differential equations by expanding the spatial derivatives using explicit backward finite differences and leaving the time derivatives unchanged. The resulting system of coupled ODE's, one ODE for each spatial node, was then solved numerically using a $4^{\text {th }}$ order Runge-Kutta algorithm in the MatLab computational environment.

\subsubsection{Discretization convention:}

A spatial discretization of a ground surface with a mesh of cubical cells can be described in terms of rows, columns, and layers where each cell is named by an $\mathrm{i}, \mathrm{j}, \mathrm{k}$ indexing system. Cartesian coordinates can be inferred from the cell index, where the k index denotes the vertical $\mathrm{z}$ axis; $\mathrm{j}$ row index is parallel to the $\mathrm{x}$ axis; and the $\mathrm{i}$ column index is considered parallel to the y axis. We have chosen a block-centered grid system is selected for this model because the ground surface elevations are stored in the similar fashion. The grid dimensions of ground surface for the width of cells in the row and 
column directions is the same where $\Delta \mathrm{x}=\Delta \mathrm{y}$. Since this a 2-D surface spreading model, the $\Delta \mathrm{z}$ value is not defined.

\subsubsection{Finite difference equation formulation:}

A finite difference form of surface flow equation follows the principle of mass balance: the sum of all flows into and out of the cell must be equal to the rate of change in flow depth within the cell. The terms $\frac{\partial}{\partial x}\left(D_{x} \frac{\partial H}{\partial x}\right), \frac{\partial}{\partial y}\left(D_{y} \frac{\partial H}{\partial y}\right)$ of equation 0-10 are the net fluid flow in the $\mathrm{x}$ and $\mathrm{y}$ direction, respectively. Therefore, the difference of flows across the east and west faces is equal to the net flow of $\mathrm{x}$ direction, and the difference of flows across the north and south faces is equal to the net flow of y direction.

$$
\frac{d h}{d t}=\frac{1}{\Delta x}\left(-D_{E} \frac{d H}{d E}-D_{W} \frac{d H}{d W}\right)+\frac{1}{\Delta y}\left(-D_{N} \frac{d H}{d N}-D_{S} \frac{d H}{d S}\right)+V_{s}-\frac{d I}{d t}
$$

where $D_{i}$ is given by equation $0-9$,

$h_{i}=$ average flow depth of two adjacent cells, $L$

$\mathrm{S}_{\mathrm{fi}}=$ friction slope, $\mathrm{L} / \mathrm{L}$

$f_{\mathrm{d}}=$ Darcy-Weisbach friction coefficient

$\mathrm{i}=\mathrm{E}$ (east face), W (west face),

$\mathrm{N}$ (north face), S (south face) 
Figure 0-2 illustrates cell $(\mathrm{i}, \mathrm{j})$ and four adjacent ground surface cells. The continuity equation for this system is developed on cell $(i, j)$, and flows are considered positive if they are flowing out of the cell. The direction of the flow is determined by the sign of the fluid surface gradient across the cell face which is estimated:

East face: $\frac{d H}{d E}=\frac{H_{i, j}-H_{i+1, j}}{\Delta x}$; West face: $\frac{d H}{d W}=\frac{H_{i, j}-H_{i-1, j}}{\Delta x}$;

South face: $\frac{d H}{d S}=\frac{H_{i, j}-H_{i, j+1}}{\Delta y} ;$ North face: $\frac{d H}{d N}=\frac{H_{i, j}-H_{i, j-1}}{\Delta y}$.

Therefore, if the fluid surface gradient is positive, flow will be out of the cell (i j) across that face, otherwise flow will enter the cell $(i, j)$ at that face. Fluid depth $h(i, j, t)$ at each face is calculated by taking the average of computed fluid depths at two adjacent nodes :

$$
h_{E}=\frac{h_{i+1, j}+h_{i, j}}{2} ; h_{W}=\frac{h_{i-1, j}+h_{i, j}}{2} ; \quad h_{N}=\frac{h_{i, j-1}+h_{i, j}}{2} ; \quad h_{S}=\frac{h_{i, j+1}+h_{i, j}}{2}
$$

The friction slope, $S_{f}(i, j, t)$, at each face can be evaluated by the following

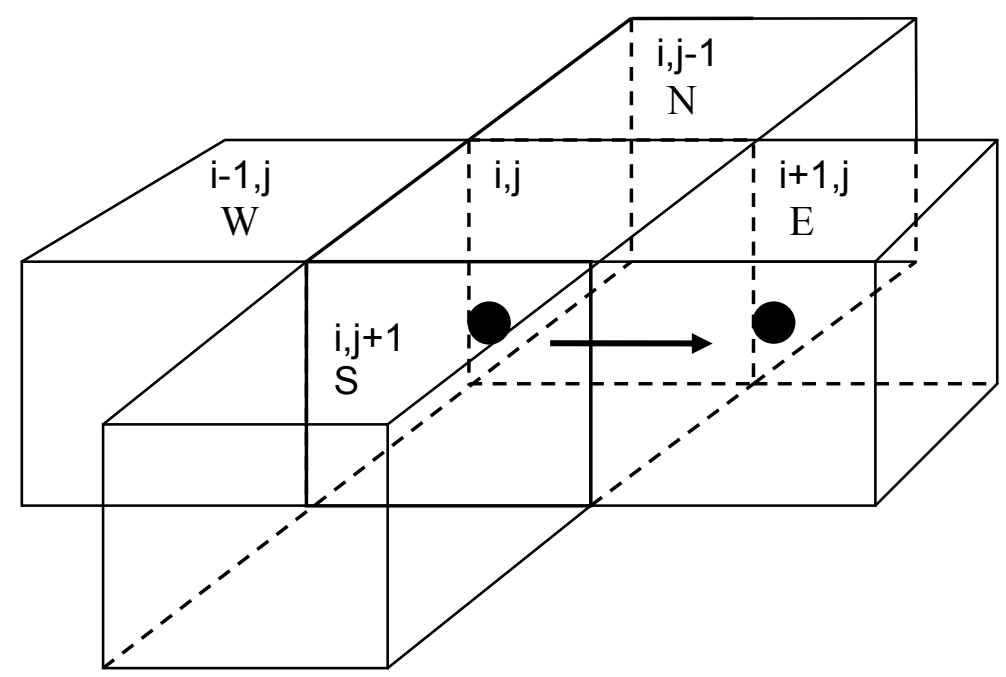

Figure 0-2. Cell (i, j, k) and adjacent cells 
equation which requires six adjacent cells (Lal, 1998). For the special case where the spatial grid is equal in the $\mathrm{x}$ and $\mathrm{y}$ directions:

East:

$$
S_{t E}^{2}=\frac{1}{(\Delta x)^{2}}\left[\begin{array}{l}
\left(H_{i+1, j}-H_{i, j}\right)^{2}+ \\
\frac{1}{16}\left(H_{i+1, j+1}-H_{i+1, j-1}+H_{i, j+1}-H_{i, j-1}\right)^{2}
\end{array}\right]
$$

$$
\text { South: } \quad S_{f S}^{2}=\frac{1}{(\Delta y)^{2}}\left[\begin{array}{l}
\left(H_{i, j+1}-H_{i, j}\right)^{2}+ \\
\frac{1}{16}\left(H_{i+1, j}-H_{i-1, j}+H_{i+1, j+1}-H_{i-1, j+1}\right)^{2}
\end{array}\right]
$$

North: $\quad S_{f N}^{2}=\frac{1}{(\Delta y)^{2}}\left[\begin{array}{l}\left(H_{i, j-1}-H_{i, j}\right)^{2}+ \\ \frac{1}{16}\left(H_{i+1, j-1}-H_{i-1, j-1}+H_{i+1, j}-H_{i-1, j}\right)^{2}\end{array}\right]$

West: $\quad S_{f W}^{2}=\frac{1}{(\Delta x)^{2}}\left[\begin{array}{l}\left(H_{i-1, j}-H_{i, j}\right)^{2}+ \\ \frac{1}{16}\left(H_{i, j-1}-H_{i, j+1}+H_{i-1, j-1}-H_{i-1, j+1}\right)^{2}\end{array}\right]$

The friction coefficient $f_{d}$ Dary-Weisbach roughness coefficient was predicted using the sub-factor approach developed by Weltz and colleagues (1992) as follows:

$$
f_{d}=f_{r s}+f_{r r}+f_{g c}+f_{p b}
$$

Based on the measured data of 11 sites located throughout the eastern United States, the roughness coefficient for soil induced roughness, $f_{r s}$, was estimated to be 1.11 (Gilley et al., 1990). The parameter for random roughness of a site, RR, is estimated by its appearance as illustrated in Figure $0-3$ with the relationship: $f_{r r}=22.76(1-\exp (-0.773 R R))$. The effects of litter, 
$f_{g c}=113.73\left(\mathrm{om}^{0.3}\right)$ and standing vegetation, $f_{p b}=125.91\left(\mathrm{sv}^{0.8}\right)$ are dependent on seasonally variable fraction of organic matter or litter, om, and standing vegetation, $s v$. Table 0-1 provides the average seasonal percent ground cover composed of organic litter, live plant, and bare soil for tallgrass habitats.

Since, $f_{d}$, is function of both the roughness of soil surface and flow Reynolds number, a modification to equation 0-16 was required to match the conditions of the TPP. An approximate correction, based on reported non-linear dependence on the Reynolds number (Dunkerley, 2001; Thoms, 2003; Takken et al., 2000) was used:

$$
f_{\text {dadj }}=f_{d}\left(\frac{\mathrm{Re}_{\text {old }}}{\mathrm{Re}_{T P P}}\right)^{0.65}
$$

Where $\mathrm{Re}_{\text {old }}$ is the estimated Reynolds number from the study where the correlations were developed and $\mathrm{Re}_{\mathrm{TPP}}$ is computed for the simulation.

\section{Table 0-1. Seasonal Percent Ground Cover}

\begin{tabular}{|l|l|l|l|}
\hline Season & Live plant \% & Organic litter \% & Bare soil \% \\
\hline Winter & 9.7 & 46 & 44.3 \\
\hline Spring & 25.2 & 37.4 & 37.4 \\
\hline Summer & 90 & 5 & 5 \\
\hline
\end{tabular}

(Jamison et al., 2002)

Finally, the finite difference form for the flow in the East direction is expressed as following: 


$$
\begin{aligned}
& D_{x E} \frac{d H}{d E}=\sqrt{\frac{8 g\left(\frac{h_{i+1, j}+h_{i, j}}{2}\right)^{3}}{f_{\text {dadj }}}} * \\
& \left|\frac{1}{(\Delta x)^{2}}\left[\begin{array}{l}
\left(H_{i+1, j}-H_{i, j}\right)^{2}+ \\
\frac{1}{16}\left(H_{i+1, j+1}-H_{i+1, j-1}+H_{i, j+1}-H_{i, j-1}\right)
\end{array}\right)^{2}\right|^{-1 / 4} * \frac{H_{i, j}-H_{i+1, j}}{\Delta x}
\end{aligned}
$$

Similar expressions can be written approximating for the remaining faces. The spill source term, $V_{S}$, in this study was defined as the volumetric spill rate divided by the area of the cell at the spill location. The infiltration rate was calculated by equation $0-6$ for each flow grid element with the Brooke-Corey fluid entry suction head calculation from equation $0-7$, and the hydraulic conductivity for oil was estimated using the correction presented by Carey et al., (1989) as equation 0-12.

The resulting system of equations was solved using the ODE45 Rungga-Kutta $4^{\text {th }}$ order numerical solver in Matlab 7.0. The code was compiled with the MatLab Compiler $^{\circledR}$ and used as a standalone program that is executed from within the ArcGIS 8.3 environment. 

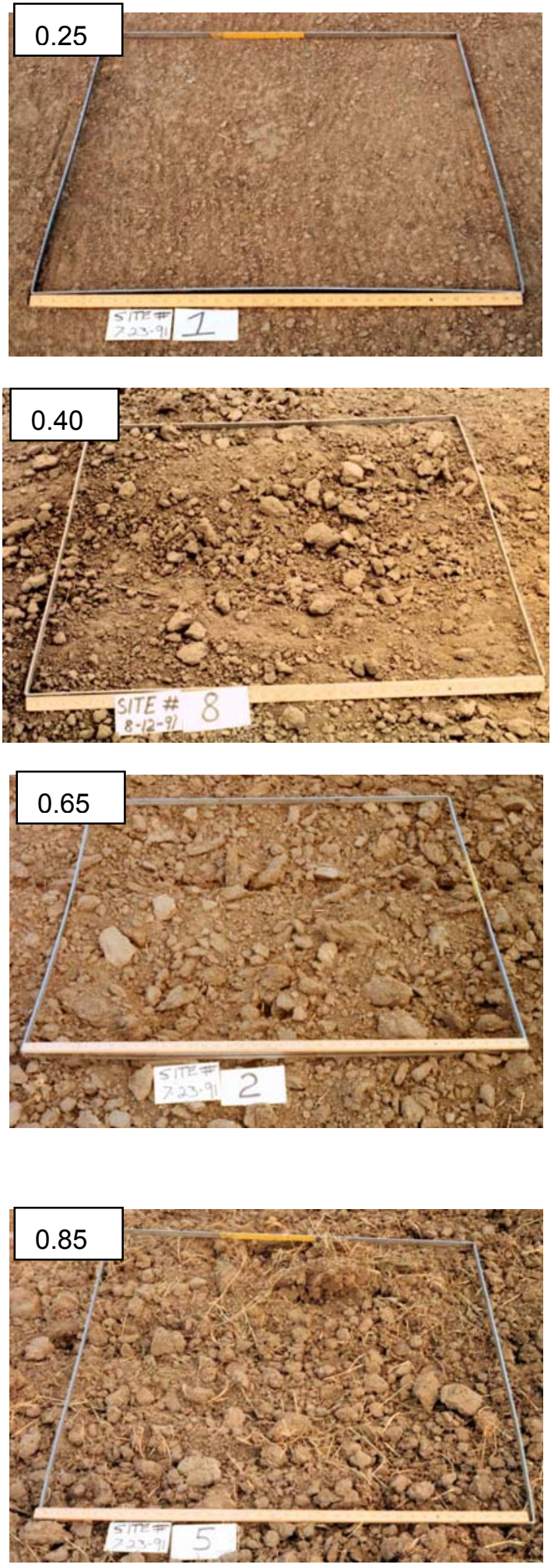
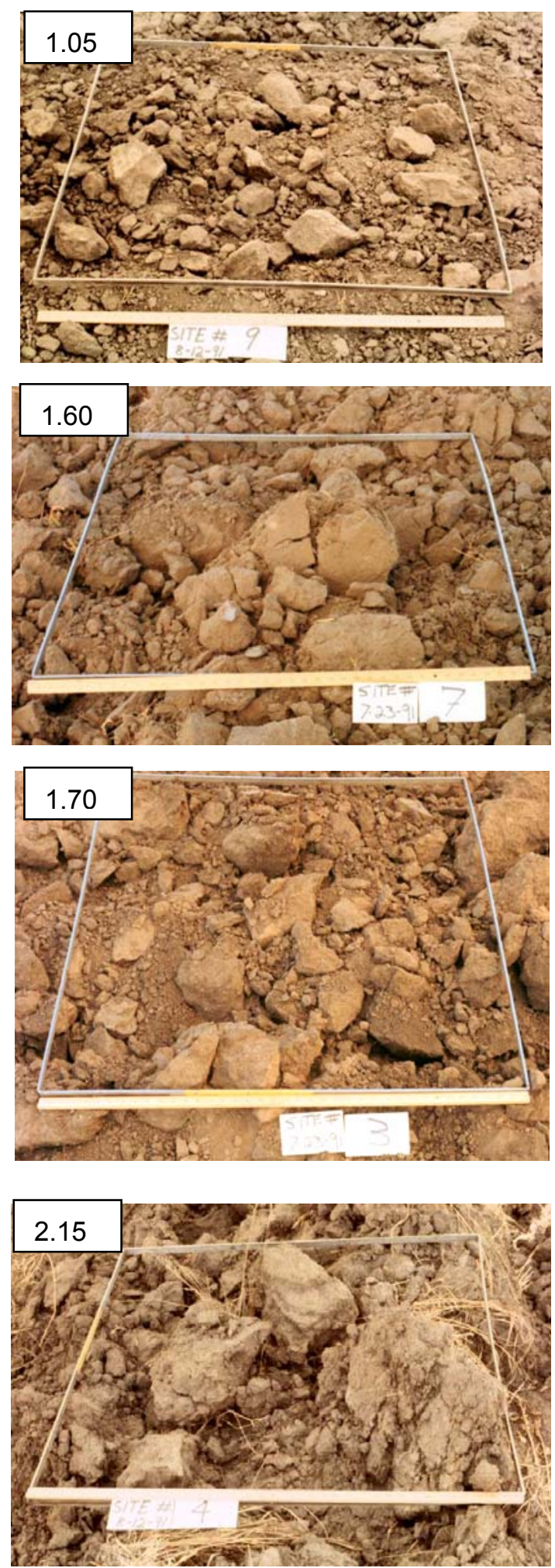

Figure 0-3. Random Roughness Based on the Appearance of Soil Surface

(Agriculture Handbook Number 703-USDA-ARS) 


\subsection{Model Validation Methods}

To evaluate the physical transport model, a series of tests was established on various surfaces: artificial surface, real surface data representing topography, and real spill scar mapping on the actual impacted site.

\subsubsection{Artificial surface:}

Simple representative topographic features were generated, and a known volume of fluid was released. The results can be used to evaluate the predictions of the developed model and to verify realistic representation of spill plumes. Three artificial surfaces were created: (1) planar sand surface, (2) inclined sand surface, and (3) inclined sand surface with a barrier. All these artificial surfaces were designed to demonstrate that the physical transport model is capable of simulating the fundamental expected behavior of surface flow model such as: (1) spreading outward on a flat surface, (2) flowing downward on an inclined surface, (3) flowing around a barrier.

\subsubsection{Calibration to an historic spill scar:}

Three spills that occurred between 9/18/1999 and early January 2000 were considered for the surface flow calibration. The outlines of the historic spill scars were mapped on-site by real-time differentially corrected GPS. The middle spill scar was used for calibration of the spill model. Other model parameter values associated with soil texture conditions, soil surface roughness, and fluid properties were estimated based on the climatology of the TPP, vegetation density data, appearance of the soil surface, and oil $\mathrm{E} \& \mathrm{P}$ operations literature. Because the spill rate and duration are not known for the incidents, these two parameters were used as adjustable parameters. The model 
calibration requires matching the shape of the spill. It is not sufficient to correctly predict the spill area alone; however, matching the shape will insure that the spill area is also matched. Therefore, minimizing the sum of squared residuals in eight principal directions was chosen as the criterion for the best fit parameter values. This is shown schematically in Figure 0-4.

Based on reasonable estimates from known production history at this lease, the allowable ranges for spill rate and spill duration were considered to be $2 \mathrm{bbl} /$ day to 40
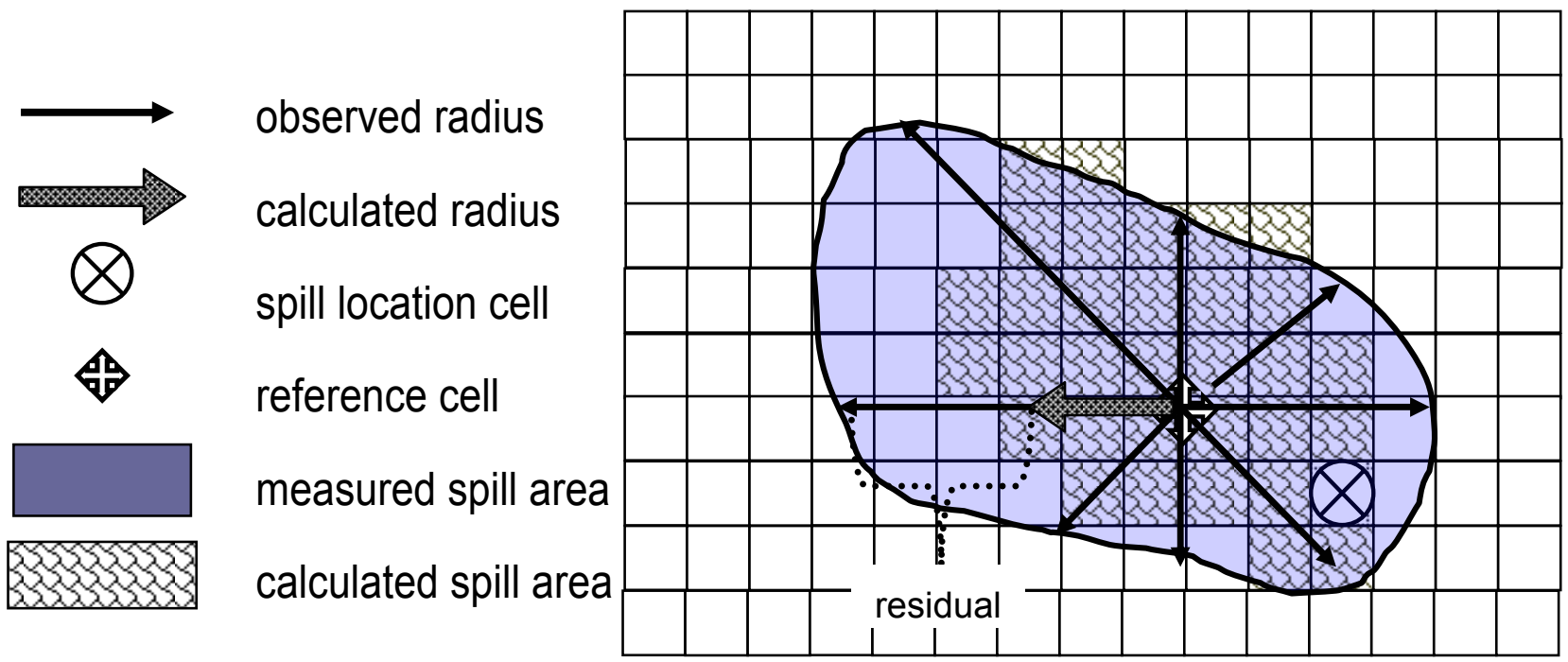

Figure 0-4. Conceptual model for calculation of residuals used for parameter estimation

$\mathrm{bbl} /$ day and 1 to 7 days, respectively. A reference point was set at a location near the center of observed spill scar; results were discarded is the calculated spill did not reach the reference cell, which was kept at the same location..

\subsubsection{Real topography surface:}

An area of interest in the northwest corner of the TPP was selected to evaluate the predictions using an actual digital elevation model of real topography. This was 
preliminary testing of the model as it is intended to be used for risk analysis when coupled to the damage and cost estimation models.

\subsection{GIS Data Layers}

During the development of the consequences analysis model, a combination of raster and vector data layers for TPP shown in Table 0-2 was required. The following section describes how and where the information was obtained.

\subsubsection{Topography:}

Thirty-meter DEMs were used as the original topographic data for this project. The TPP site area is larger than a single quad sheet; as a result, it was necessary to mosaic adjoining DEMs together into a single, larger DEM.

Table 0-2. Description of GIS Data Layers

\begin{tabular}{|l|l|l|l|l|}
\hline Category & Description & File format & $\begin{array}{l}\text { Source of } \\
\text { Information }\end{array}$ & Method of Acquisition \\
\hline Topography & $\begin{array}{l}30 \text { m digital } \\
\text { elevation model }\end{array}$ & Raster & $\begin{array}{l}\text { Oklahoma } \\
\text { State } \\
\text { University } \\
\text { The Nature } \\
\text { Conservancy }\end{array}$ & $\begin{array}{l}\text { Personal request } \\
\text { Internet download } \\
\text { http://oklahomanature.org/OK/ } \\
\text { tallgrass_science.html }\end{array}$ \\
\hline Soils & $\begin{array}{l}\text { soils polygon }- \\
\text { spatial detail } \\
\text { Attribute tables }\end{array}$ & Shapefile & $\begin{array}{l}\text { The Nature } \\
\text { Conservancy }\end{array}$ & $\begin{array}{l}\text { Internet download } \\
\text { http://oklahomanature.org/OK/ } \\
\text { tallgrass_science.html }\end{array}$ \\
\hline $\begin{array}{l}\text { E\&P } \\
\text { features }\end{array}$ & $\begin{array}{l}\text { Wells Pipelines, } \\
\text { Crude oil storage } \\
\text { tank, Brine } \\
\text { storage tank } \\
\text { Separator tank }\end{array}$ & $\begin{array}{l}\text { Shapefile } \\
\text { Shapefile } \\
\text { Shapefile } \\
\text { Shapefile } \\
\text { Shapefile }\end{array}$ & $\begin{array}{l}\text { University of } \\
\text { Arkansas }\end{array}$ & Field studies (GPS) \\
\hline Streamflow & $\begin{array}{l}\text { Stream across the } \\
\text { TPP }\end{array}$ & Shapefile & $\begin{array}{l}\text { The Nature } \\
\text { Conservancy }\end{array}$ & $\begin{array}{l}\text { Internet download } \\
\text { http://oklahomanature.org/OK/ } \\
\text { tallgrass_science.html }\end{array}$ \\
\hline $\begin{array}{l}\text { Cultural } \\
\text { feature }\end{array}$ & $\begin{array}{l}\text { Road (paved, dirt, } \\
\text { gravel) }\end{array}$ & Shapefile & $\begin{array}{l}\text { The Nature } \\
\text { Conservancy }\end{array}$ & $\begin{array}{l}\text { Internet download } \\
\text { http://oklahomanature.org/OK/ } \\
\text { tallgrass_science.html }\end{array}$ \\
\hline
\end{tabular}


Typical spill volumes in the TPP are on the order of a few to a few 10's of barrels of produced fluids and most of the historic scars would not cover a single $30 \mathrm{~m} \times 30 \mathrm{~m}$ grid element of the available DEM. A higher resolution DEM and more accurate representation of geographic features were required to make spill spreading calculations more realistic. Thus, the spatial analysis tools of ArcMap were used to re-sample DEM data from 30 meter into 2 meter resolution by utilizing the inverse distance weighted interpolation function. Generating high resolution DEM is costly, and as the model is intended to be used as a screening tool, the inaccuracy associated with this interpolation, and the inability to capture small scale features like ditches is deemed acceptable. In situations where higher resolution DEMs are available, the model can be used without modification other than eliminating the re-sampling step.

\subsubsection{Soil data layer:}

The United States Department of Agriculture Natural Resource Conservation Service maintains two soils databases: Soil Survey Geographic (SSURGO) and State Soil Geographic (STATSGO). STATSGO data are mapped at 1:250,000 scale; SSURGO mapping scales range from 1:12,000 to 1:63,360. SSURGO dataset consists of map data, attribute data, and metadata. (www.ncgc.nrcs.usda.gov/products/ datasets/ssurgo/). Metadata and attribute data are distributed in ASCII format with DLG-3 map file. All the existing soil types from the soil attribute table were categorized into six major groups as shown in Table 0-3. Additional information of soil physical properties of each soil texture, such as saturated hydraulic conductivity, air entry suction head, porosity, rain infiltration rate, saturated and residue moisture contents, and pore size distribution index 
obtained from the literature, were stored in text file format and are presented in Table $0-3$.

Table 0-3. Soil Hydraulic and Physical Properties Database

\begin{tabular}{|l|l|l|l|l|l|c|}
\hline Texture Group & $\begin{array}{l}\text { Loamy } \\
\text { Sand }\end{array}$ & $\begin{array}{l}\text { Sandy } \\
\text { loam }\end{array}$ & Loam & $\begin{array}{l}\text { Sandy clay } \\
\text { loam }\end{array}$ & $\begin{array}{l}\text { Silty clay } \\
\text { loam }\end{array}$ & Silty clay \\
\hline $\begin{array}{l}\text { Saturated Hydraulic } \\
\text { Conductivitym } / \mathrm{hr}\end{array}$ & 0.10002 & 0.03498 & 0.00648 & 0.01302 & 0.00078 & 0.0003 \\
\hline $\begin{array}{l}\text { Saturated Soil Moisture } \\
\text { Content, } \\
\mathrm{m}^{3} / \mathrm{m}^{3} \mathrm{~V}_{\text {water }} / \mathrm{V}_{\text {total }}\end{array}$ & 0.43 & 0.45 & 0.47 & 0.42 & 0.48 & 0.49 \\
\hline $\begin{array}{l}\text { Residual Soil Moisture } \\
\text { Content, } \\
\mathrm{m}^{3} / \mathrm{m}^{3} \mathrm{~V}_{\text {water }} / \mathrm{V}_{\text {total }}\end{array}$ & 0.04 & 0.05 & 0.08 & 0.1 & 0.08 & 0.11 \\
\hline $\begin{array}{l}\text { Air Entry Suction } \\
\text { Head, } \mathrm{m}\end{array}$ & 0.05 & 0.075 & 0.135 & 0.075 & 0.4 & 0.65 \\
\hline $\begin{array}{l}\text { Pore-Size Distribution } \\
\text { Index }\end{array}$ & 0.43 & 0.38 & 0.31 & 0.23 & 0.23 & 0.2 \\
\hline Infiltration Rate,cm/day & 121.96 & 60.96 & 30.48 & 24.38 & 18.29 & 10.5 \\
\hline
\end{tabular}

\subsubsection{Data Projection:}

Hall et al. (2001) suggested Universal Transverse Mercator (UTM) projection is the best suited for the size of area and type of modeling planned for the TPP. In order to use spatial data from different sources in conjunction with one another, each GIS data file must be converted into a common map projection. The parameters for the map projection used in this project are listed in Table $0-4$. 
Table 0-4. Map Projection Parameters

\begin{tabular}{|l|l|}
\hline Projection & Transverse Mercator \\
\hline Datum & D_Clark_1866 \\
\hline Units & Meters \\
\hline Spheroid & GCS North American 1927 \\
\hline Scale_Factor & 0.999600 \\
\hline Central meridian- & 99.00 \\
\hline Latitude of projection's origin & 0.00 \\
\hline False easting (meters) & 500000.00 \\
\hline False northing (meters) & 0.00 \\
\hline
\end{tabular}

\subsection{Consequence Analysis}

The damage and resulting cleanup costs that result from an accidental release of produced fluids are the consequences of the accident in a risk management sense.

Coupled with the probability of a failure at a specific location within a lease, a risk index can be generated. The evaluation of the consequence of a spill includes evaluation of the risk or hazard the spill imposes, which will determine the required cleanup goal for the spill. The lower the required cleanup level, the longer and more expensive the cleanup will be. Thus the location of receptors (e.g., streams or wells) is an important factor in assigning the required cleanup level. To obtain a risk management map for a lease, each piece of equipment and pipe on the lease is evaluated by simulating a spill with a magnitude (i.e., rate and duration) from the reliability analysis (Thoma et al., 2005) followed by the consequence analysis described below:

\subsubsection{Ecological Risk Factors Estimation:}

The Petroleum Risk Factor Index Table from the Oklahoma Corporation Commission (Table 0-5) was applied to assess accidental releases on the soil surface.

First the spill duration and rate are obtained from the reliability analysis and the DEM for 
the location of the specific item is loaded into the spill spreading module. The areal extent of the spill is computed as described above. Based on the proximity of other features in the GIS database, the various factors in Table 0-5 are evaluated. Information about the distance to groundwater, if not available for a specific site, can be estimated from USGS water resources databases. The soil type is loaded from the SSURGO database for the specific site. Hydrologic data such as background concentration (total dissolved solids) was obtained from USGS water resources. The average annual precipitation was obtained from the TPP climatology database (1994-2000) or NOAA database.

Table 0-5. Petroleum Risk Factor Index Table

\begin{tabular}{|l|l|l|l|}
\hline Risk Factor & Low risk & Moderate risk & High risk \\
\hline Quantity of spill & $\begin{array}{l}<5 \mathrm{bbl} \text { to soil } \\
2 \text { points }\end{array}$ & $\begin{array}{l}5-50 \mathrm{bbl} \text { to soil } \\
6 \text { points }\end{array}$ & $\begin{array}{l}>50 \mathrm{bbl} \text { to soil } \\
10 \text { points }\end{array}$ \\
\hline $\begin{array}{l}\text { Distance from ground } \\
\text { surface to groundwater } \\
\text { table }\end{array}$ & $\begin{array}{l}>\text { points } \\
\text { Distance from the } \\
\text { impacted soil to nearest } \\
\text { surface water or potable } \\
\text { water wells }\end{array}$ & $\begin{array}{l}2 \text { points } \\
1320 \mathrm{ft}\end{array}$ & $\begin{array}{l}<\text { points } \\
\text { with surface water } \\
10 \text { points }\end{array}$ \\
\hline $\begin{array}{l}\text { Background } \\
\text { concentration of water } \\
\text { bodies in term of TDS }\end{array}$ & $\begin{array}{l}>5,000 \mathrm{mg} / \mathrm{L} \\
0 \text { points }\end{array}$ & $\begin{array}{l}330-1320 \mathrm{ft} \\
6 \text { points }\end{array}$ & $\begin{array}{l}<330 \mathrm{ft} \text { or contact } \\
\text { with surface water } \\
10 \text { points }\end{array}$ \\
\hline $\begin{array}{l}\text { Predominant soil type in } \\
\text { the impacted area }\end{array}$ & $\begin{array}{l}\text { Tight soil, } \\
\text { "unfractured clay" } \\
0 \text { points }\end{array}$ & $\begin{array}{l}\text { Silt, clay/silt/sand } \\
\text { mixture } \\
4 \text { points }\end{array}$ & $\begin{array}{l}\text { Sand, gravel, } \\
\text { fractured clays } \\
8 \text { points }\end{array}$ \\
\hline $\begin{array}{l}\text { Average annual } \\
\text { precipitation }\end{array}$ & $\begin{array}{l}<28 \text { in } \\
0 \text { points }\end{array}$ & $\begin{array}{l}28-40 \text { in } \\
4 \text { points }\end{array}$ & $\begin{array}{l}>40 \text { in } \\
8 \text { points }\end{array}$ \\
\hline
\end{tabular}

(Oklahoma Corporation Commission, 2002) 
With all necessary information for the spill site, each risk factor can be assigned a point value. After assigning the appropriate point to each risk factor, the total score of these risk factors can be used to determine the category of clean-up limits (Table 0-6).

Table 0-6. Clean up levels required for different PRFIT ${ }^{*}$ Categories

\begin{tabular}{|l|l|l|l|}
\hline & Category I & Category II & Category III \\
\hline PRFIT score & $6-21$ points & 22-38 points & $39-54$ points \\
\hline $\begin{array}{l}\text { Chemical of } \\
\text { Concern }\end{array}$ & $\begin{array}{l}\text { Maximum allowable levels for Non Sensitive Area/Non } \\
\text { Residential Soils }\end{array}$ \\
\hline $\begin{array}{l}\text { TPH from } \\
\text { crude oil }\end{array}$ & $\begin{array}{l}10,000 ~ \mathrm{mg} / \mathrm{kg} \leq 2 \mathrm{ft} \text { deep } \\
20,000 \mathrm{mg} / \mathrm{kg}>2 \mathrm{ft} \text { deep }\end{array}$ & $10,000 \mathrm{mg} / \mathrm{kg}$ & $5,000 \mathrm{mg} / \mathrm{kg}$ \\
\hline $\mathrm{NaCl}^{* *}$ & $1300 \mathrm{mg} / \mathrm{kg}$ & $1300 \mathrm{mg} / \mathrm{kg}$ & $68 \mathrm{mg} / \mathrm{kg}$ \\
\hline
\end{tabular}

\subsubsection{Clean-Up and Restoration Costs:}

The time to achieve a specified remediation level is estimated on the basis of several remediation studies performed at the TPP (Moralwar et al., 2004; Harris et al., 2004). The first order rate constants for TPH biodegradation and brine removal were estimated for three different contaminated sites. The average rate constants for TPH and brine were approximately 0.08 months $^{-1}$ and 0.02 months $^{-1}$, respectively. These rate constants are used in the consequences estimation module through equation $0-18$. The initial concentration of a simulated release is calculated by dividing the total mass of contaminant released by the total contaminated soil volume calculated from the modeled infiltration depth and areal extent of the spill. The following first order reaction rate equation was used to calculate the time required for biodegradation of crude oil and removal of brine: 


$$
t=\frac{\ln \left(\frac{C_{a}}{C_{a o}}\right)}{- \text { RateConstant }}
$$

The selected remediation treatment of a release on TPP involved the application of hay and fertilizer, and for brine spills, a subsurface drainage system (SDS). The total cost resulting from a spill was evaluated based on type of spill, volume of contaminated soil, and contaminated medium: soil or water. The remediation cost was divided into: (1) hay and fertilizer, (2) labor, (3) operating equipment rental, (4) subsurface drainage system. The itemized remediation costs are showed in Table 0-7. Total financial loss of an accidental release would be the summation of remediation costs plus production loss (\$42/bbl of oil) for the duration of the spill.

Table 0-7. Estimated remediation cost factors

\begin{tabular}{|l|l|}
\hline Item & Cost \\
\hline Bulldozer rental & $\$ 225 /$ day \\
\hline Labor & $\$ 35 / \mathrm{hr}$ \\
\hline Hay & $\$ 8.5 /$ square bale \\
\hline Fertilizer & $\$ 0.72 / \mathrm{lb}$ \\
\hline SDS & $\$ 3,500 /$ acre \\
\hline
\end{tabular}

\subsection{Risk Estimation and Assessment}

Risk was estimated by multiplying the probability of a failure generated from the reliability model with the damage incurred in terms of financial loss. In general, the estimated risks were normalized by the following relationship:

$$
\operatorname{Risk}_{N}=\frac{\text { Risk }_{i}}{\text { MaxRisk }_{i}}
$$

Because of the large range in magnitude of the failure probability for tanks, pumps, and pipelines, a single equipment item in a lease may dominate the risk. In order to enhance 
the visualization of the risks across an entire lease (allowing comparison of relative risks within a level as well as across the lease), the normalized risk is calculated at three different risk levels based on the probability of a failure:

- First risk level - all equipment with failure probability greater than 1e-3

- Second risk level - all equipment with failure probability between 1e-3 and 1e4.

- Third risk level - all equipment with failure probability less than or equal to 1e4.

This risk normalization method provides a better visual presentation of risk profile at TPP. Then, a Risk Index Map generated in this project is the risk ranked profile that provides a risk-based decision tool for resource allocation.

\subsection{Analysis and Results}

\subsection{Results of Model Validation}

\subsubsection{Artificial Surface Simulations:}

Several tests were conducted to measure the distribution of water and viscous oil (gear oil) on flat and inclined surfaces. The simulated conditions for artificial surface tests included: (1) soil texture - sandy loam, (2) soil layer thickness - 1mm, (3) surface roughness -1.11 soil induced roughness only; no vegetation effects, and (4) initial moisture content set close to saturation.

1. Water spreading on a flat sand surface:

An experiment was conducted at a spill rate of $0.1087 \mathrm{bbl} /$ day and spill duration of 1 minute. Both measured and simulated results are shown in Figure 0-1A. The modeled 
areal extent was a circular plume with a diameter of $140 \mathrm{~mm}$, which was approximately $35 \%$ less than that of the measured water mark. The total calculated area only covered $40.5 \%$ of the actual spill area. The significant difference is due to the horizontal capillary force acting in the physical model, but not accounted for in the simulation.

2. Water spreading on an inclined sand surface

A test was carried out at a spill rate of $0.075 \mathrm{bbl} /$ day and spill duration of 1 minute on a surface inclined at $8.5 \%$. Figure $0-1 \mathrm{~B}$ shows the measured and calculated distribution of water. An oval plume was generated from the simulation with symmetric water spreading on the y axis. Comparing the calculated and observed results, shows that the calculated areal extant is approximately $51 \%$ of the observed; although the general shape is the same. The reason for the difference is also due to the capillary spreading in the physical model.

A second test was carried out to determine whether a larger slope would mitigate the effect of the capillary spreading force. The experiment was conducted at these conditions: spill rate of $0.1214 \mathrm{bbl} / \mathrm{say}$, spill duration of $1 \mathrm{~min}$, and slope of $17.2 \%$; the result is shown in Figure 0-1C. The smaller capillary force effect is obvious when compared to Figure $0-1 \mathrm{~B}$, and the difference between calculated and measured areas of water spreading is less than $3 \%$. The shape of the spill is not matched with the same precision as the areal extent, suggesting that capillary spreading remains important in the physical model..

3. Water spreading on a $4.7 \%$ inclined slope with a barrier:

A test was performed at a spill rate of $0.1123 \mathrm{bbl} /$ day and spill duration of 1.5 minute on a sand surface inclined at $4.7 \%$. A cylindrical barrier with one inch in diameter 
was placed at approximately 4 inches downhill from the spill point. The measured and calculated of water spill extents are illustrated in Figure 0-1D. A leaf shaped plume was generated from the simulation because of the presence of a barrier in the flow path. The simulated area was only approximately $62 \%$ of total measured area. Again, it is likely that at this lower inclination the capillary spreading effect in the physical model is the reason for the discrepancy.

\section{Gear oil spreading on a flat sand surface:}

Viscous gear oil was used in the following experiments to examine the model predictions for a fluid not expected to be as strongly affected by capillary force effects. The spill rate and duration were set at $0.0888 \mathrm{bbl} /$ day and 1 minute, respectively. The measured data was taken at 10 min after spill stop, and same amount of time was used to simulate the spill. The simulated result is in good agreement with the measured data, as shown in Figure 0-1E.

\section{Gear oil spreading on an inclined slope of $7.5 \%$ :}

The same gear oil was used in this experiment, and the test was run at a spill rate of $0.0833 \mathrm{bbl} /$ day and spill duration of 1 minute. The measured area was taken at $10 \mathrm{~min}$ after the stopping the spill. It was observed that the oil depth at the front of plume was approximately $1 \mathrm{~mm}$; however, it took $100 \mathrm{~min}$ simulation run time to match the observed oil depth on the surface. These results are presented in Figure 0-1E and F, where the error between the measured and calculated areas is approximately $12 \%$.

In summary, the physical transport model is a valid tool to be used in predicting fluid distribution of a release on soil surface, where the horizontal capillary force effect is negligible. This is expected to be the case in most field applications. 


\subsubsection{Mapping A Real Historic Spill Scar:}

Parameters that used in this simulation included: 1. random roughness (1.6 inches), 2. organic litter (5\%) and standing vegetation (90\%) for summer habitat, 4. soil texture (silty clay loam), 5. kinematic viscosity $\left(0.00344 \mathrm{~m}^{2} / \mathrm{hr}\right), 6$. and initial moisture content (0.48) at saturation, because it was a rainy week when the accident happened.

Given the initial conditions stated above, the optimized model mapped $78 \%$ of the measured historic spill area with a fitted flow rate of 14bbl/day and $33 \mathrm{hr}$ spill duration. The calculated surface spreading of brine followed the same direction of measured historic scar, and matched the topography around the spill point closely, as illustrated in Error! Reference source not found.. Some of the discrepancy in the prediction is likely due to the re-sampling of the DEM from the original 30m resolution map. It is certain that some of smaller topographical features of the site were lost. Nevertheless, there is a very reasonable match to the historic scar given the uncertainty in the input DEM. In conclusion; the physical transport model has the potential to predict areal extent of a release with error less than $30 \%$, if the initial conditions are known.

\subsection{Sensitivity analysis of transport model input parameters}

There is uncertainty involved with specifying the soil parameter values as listed in Table 0-3. In addition, the spatial discretization has significant influence on model accuracy; therefore, grid size is also an important parameter to be considered. A sensitivity analysis of the model's predicted spill area as a function of input parameter 


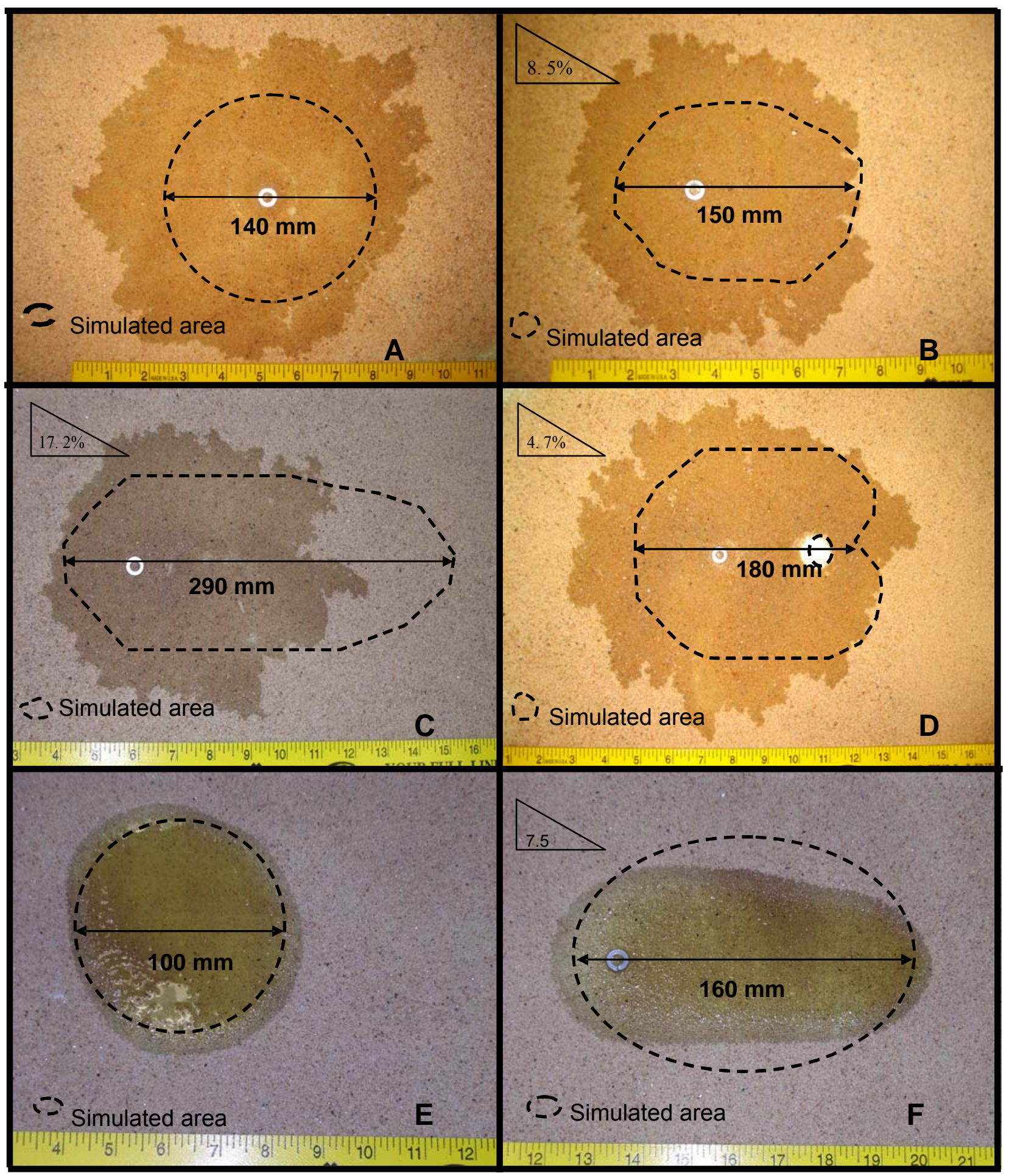

Figure 0-1. Small scale physical model of spilled fluid compared to simulated spill extents for water and oil on sand surface. 
values was performed to identify those parameters which have the greatest influence and should therefore be evaluated to a higher level of accuracy prior to using the simulation model. A factorial experimental design with regression analysis was used to identify important input factors.

In this uncertainty analysis, seven input parameters, including hydraulic conductivity, initial soil moisture content, random roughness, fraction of standing vegetation, fraction of organic litter, kinematic viscosity, and grid size, were evaluated at two levels in a $2^{7}$ factorial design. In this study, the high and low levels were set $\pm 20 \%$ from the expected value for each factor. Data analysis by multiple linear regression was performed using Microsoft Excel.

\subsubsection{Brine Spill Simulation Analysis:}

For the brine spill simulation, the results indicate that the friction coefficient factors (random roughness, standing vegetation, and organic litter) did not have significant influence on the model calculated spill area; thus, seven-factor test could be reduced into five-factor design by combining these three friction coefficient factors. However, the predicted spill area is very sensitive to hydraulic conductivity and initial soil moisture content. This implies that infiltration is the dominant mechanism determining the extent of damage for brine spills.

An additional three-level factorial test was used to determine the relationship of 
model output over the range of the factor levels selected. Plots generated from this $3^{5}$ factorial experiment present more precise relationships of model predicted spill area with selected factors. As observed from Figure 0-3, predicted spill area has an inverse linear relationship with hydraulic conductivity, and area has a non-linear dependence on with initial moisture content of soil.

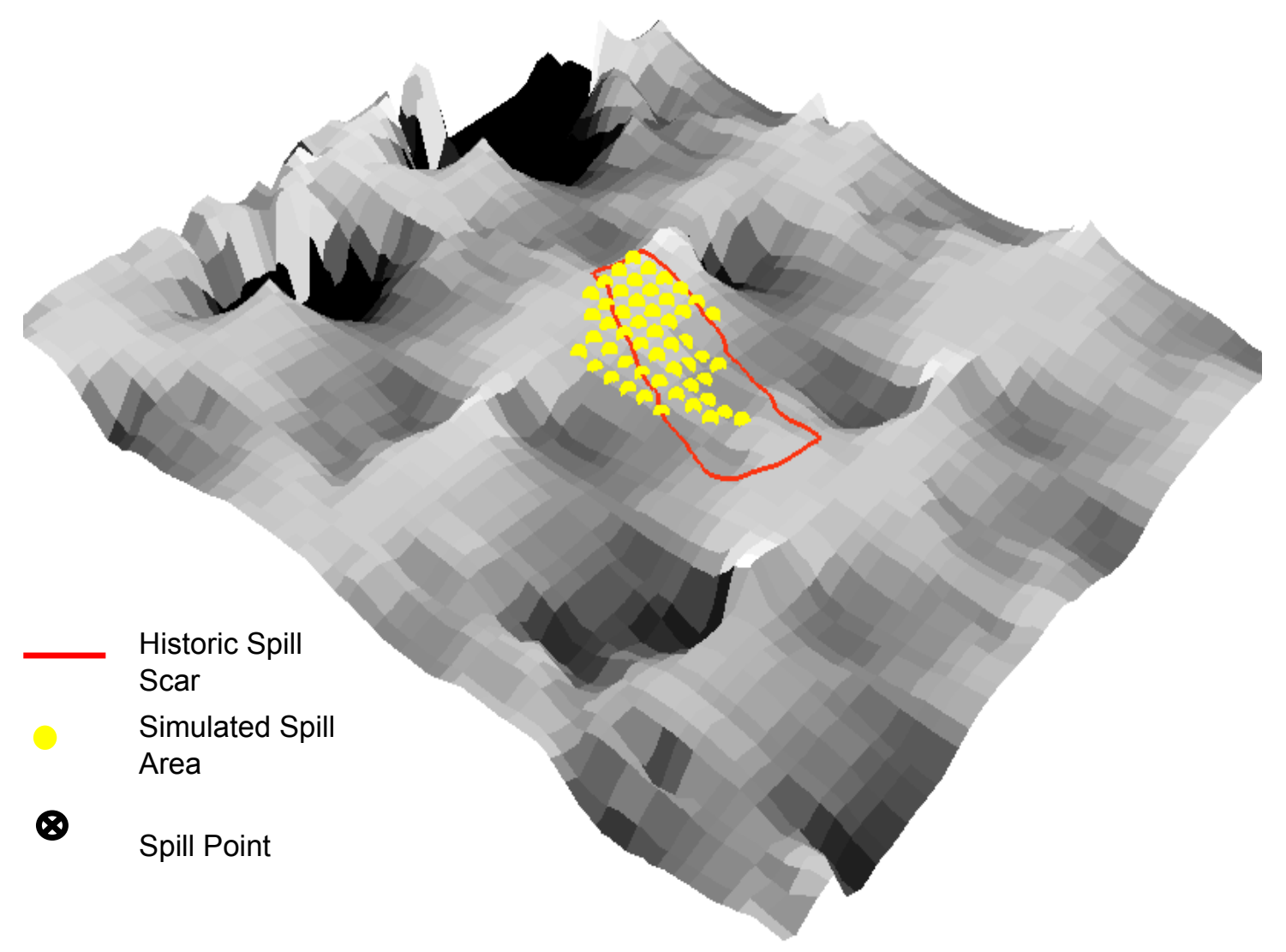

Figure 0-2. Simulation of an historic spill scar. Vertical exaggeration: 10x 
Obviously, there are two clusters of data; one with large predicted spill area and a second with smaller area for the same total spill volume. This was observed in both factorial experimental runs. Further analysis of the into two clusters: (1) area greater than $300 \mathrm{~m}^{2}$, and (2) less than $300 \mathrm{~m}^{2}$ show that the cluster with the smaller area was generated at low moisture content and vice versa. In addition, model predictions did not have a significant response to hydraulic conductivity at low moisture content, but does becomes more sensitive at high soil moisture content, which indicates, not surprisingly that when soil is saturated, hydraulic conductivity governs the infiltration.

In a final test, the effect of spill rate for a fixed total spill volume showed that, again, infiltration is the most important factor because larger spill areas were observed for higher spill rates.
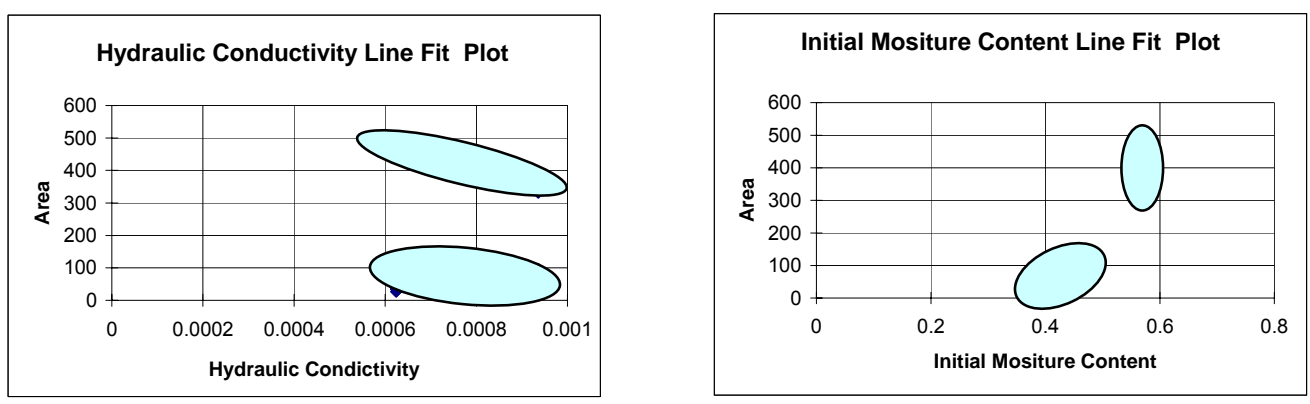

Figure 0-3. Results of sensitivity analysis. Data clusters are associated with initial moisture content. The larger areas are associated with simulations where the soil column was initially fully saturated with water. 


\subsubsection{Oil Spill Simulation Analysis:}

Similar analyses were performed for oil spill calculations. The results shown in Table $0-1$ indicate that all factors other than hydraulic conductivity $(\mathrm{p}=0.13)$ have a significant influence; however, although the friction coefficient has a significant $\mathrm{P}$ value, the slope is small indicating that the effect on spill size will be less than for the other factors. For the situation when infiltration is not as significant, grid size, friction coefficient, and kinematic viscosity also become important in predicting spill extent on the soil surface. Thus for modeling oil spill spreading more detailed knowledge of the site conditions is needed to achieve a similar level of confidence in the predicted spill extent.

\section{Risk Index Map}

Methods of calculating relative risk are discussed in section 0 . In order to make this risk model user friendly, an interface has been developed to link the necessary GIS database with both the consequences analysis model and probabilistic reliability

Table 0 -1. Regression summary statistics for 3 level, 5 factor sensitivity analysis for oil spill spreading

\begin{tabular}{lr}
\hline \multicolumn{2}{c}{ Regression Statistics } \\
\hline Multiple R & 0.84 \\
R Square & 0.71 \\
Adjusted R Square & 0.70 \\
Standard Error & 48.68 \\
Observations & 243 \\
\hline
\end{tabular}

\begin{tabular}{lrrrrr} 
ANOVA & \multicolumn{1}{c}{ SS } & \multicolumn{1}{c}{ MS } & $F$ & Significance $F$ \\
\hline Regression & $d f$ & & \multicolumn{1}{c}{ SS } & & \\
Residual & 5 & 1345380 & 269076 & 114 & $7.19 \mathrm{E}-61$ \\
Total & 237 & 561628 & 2370 & & \\
\hline
\end{tabular}

\begin{tabular}{lrrrrrr}
\hline & Coefficients & Standard Error & \multicolumn{1}{c}{ Stat } & P-value & Lower 95\% & Upper 95\% \\
\hline Intercept & 1443 & 51 & 28.1 & $2.8 \mathrm{E}-77$ & 1341 & 1544 \\
& & & & & & -75 \\
Grid Size & -82 & 3.8 & -21.5 & $1.9 \mathrm{E}-57$ & -90 & -4928 \\
Kinematic Viscosity & -8353 & 1738 & -4.8 & $2.8 \mathrm{E}-06$ & -11778 & -0.55 \\
Friction Coefficient & -1.1 & 0.26 & -4.1 & $6.9 \mathrm{E}-05$ & -1.58 & 401 \\
Initial Mositure Content & 323 & 40 & 8.1 & $2.8 \mathrm{E}-14$ & 244 & 10946 \\
Hydraulic Condictivity & -37354 & 24517 & -1.5 & $1.3 \mathrm{E}-01$ & -85653 & \\
\hline
\end{tabular}


estimation model. The necessary information and procedures required to generate or to update the Risk Index Map are described in a separate document (Thoma et al., 2005). Information related to risk index calculations, such as total contaminated area, total financial loss, probability of an equipment failure, risk, and normalized risk are stored and updated in the equipment layer's attributes table within the ArcGIS 8.3 environment. The layout of the lease equipment at the TPP field site is shown in Figure .

The relative Risk Index for each piece of equipment of interest illustrated in Figure 0-1 was calculated based on the following simulation conditions: (1) 0.45 initial moisture content (approximately 80\% saturated), (2) 45 in of precipitation annually, (3) $16 \mathrm{ft}$ from the contaminated plum to ground water table, (4) $25 \%$ standing vegetation, (5) 1.6 inch of random roughness, (6) $25 \%$ organic litter, and (7) 4500 ppm of TDS. In Figure $0-1$, the diameter of the circles is used to illustrate the relative risk within each risk level. The legend shows the circle size associated with the normalization risk level for each of the risk categories. GIS map layers including the DEM, equipment, streams, and soil type are also displayed. The ARCGIS "identify" tool can be used to retrieve detailed information. The items with the highest risk in this simulation are the two tank batteries in the southeast region of the lease and a steel pipe that is crossing a small stream in the northwest region. A second typical aboveground steel pipe at the eastern edge of the study area also presents a relatively high risk which would be expected for the age of most of the steel lines at this lease site (not all pipe sections were included in the simulation). The primary driver for the risk of the tanks is the potentially large spill associated with a failure that was assumed for this simulation. By far, the lowest risk at the lease is associated with the plastic pipe (green circle on northern edge); it is 
approximately two orders of magnitude lower risk than the steel pipe crossing the stream. Reliability simulations for buried PVC pipe suggest that the risk can be halved again compared to PVC simply placed on the ground surface.

This model allows users to make changes on the Risk Index Map. For example, if the carbon steel pipe laid close to the creek was replaced with PVC pipe, this would reduce the probability failure at that location, and an updated map would show a green circle instead of the red one.

\subsection{Conclusions}

This report summarizes the procedures for quantifying the consequences of a terrestrial produced fluid spill and for calculating a Risk Index for oil E\&P equipment located in the Tallgrass Prairie Preserve, Oklahoma. A physical transport model is the main quantitative tool developed for consequence analysis. Given suitable base data sets, the physical transport model can be used to estimate the extent of a produced fluid release and is able to predict terrestrial flow paths. The spill model is robust, producing results that correspond to expected results on artificial surfaces and real topography. The physical transport model was also designed to predict the extent of a spill on surfaces having different surface characteristics, and variable density of standing vegetation and organic litter. This model also includes the freedom to change the fluid viscosity for different types of spilled fluids such as brine, crude oil, or processed products such as gasoline, diesel or jet fuel. 


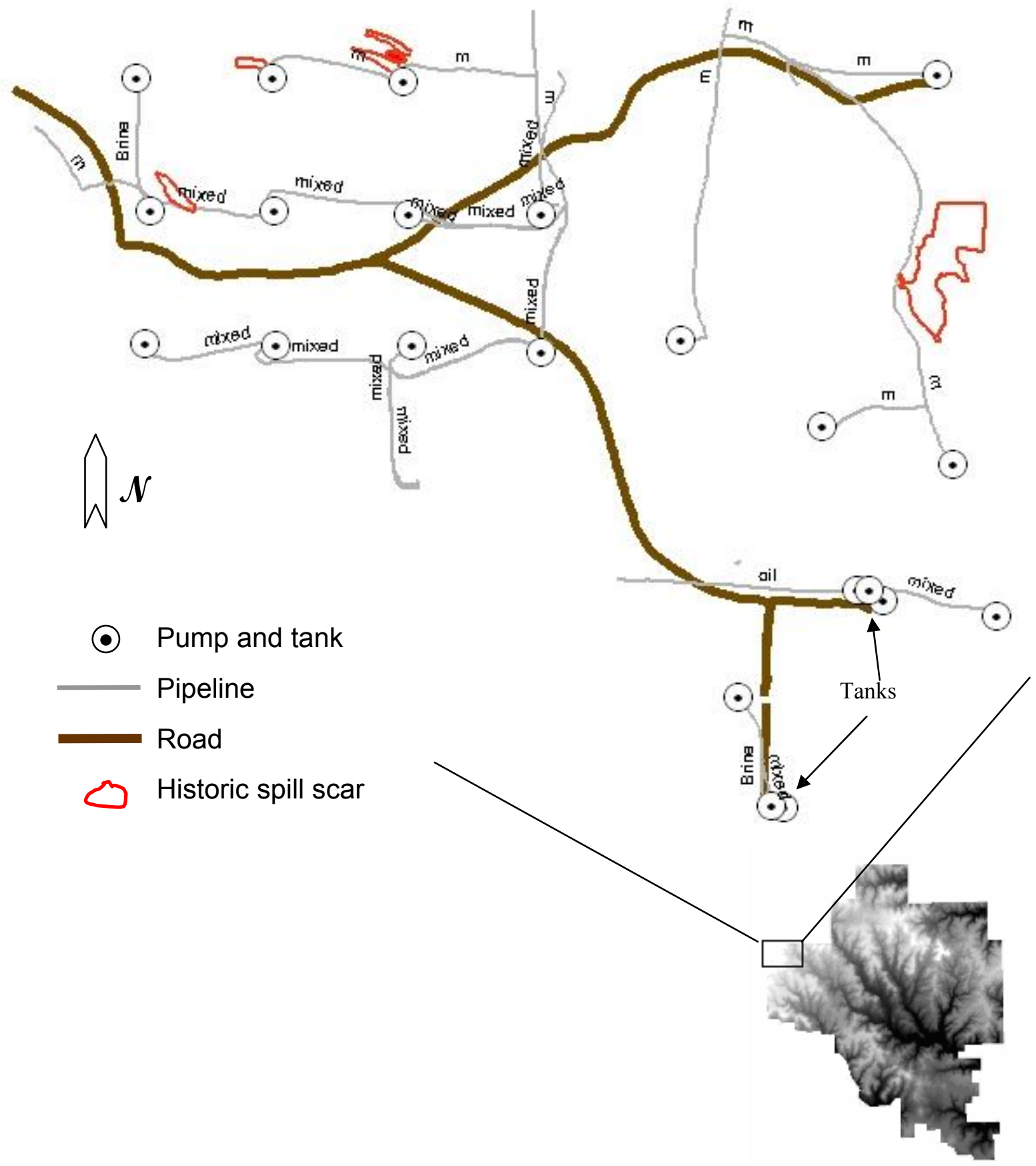

Figure 0-1. Lease layout at field site in the Tallgrass Prairie Preserve. 


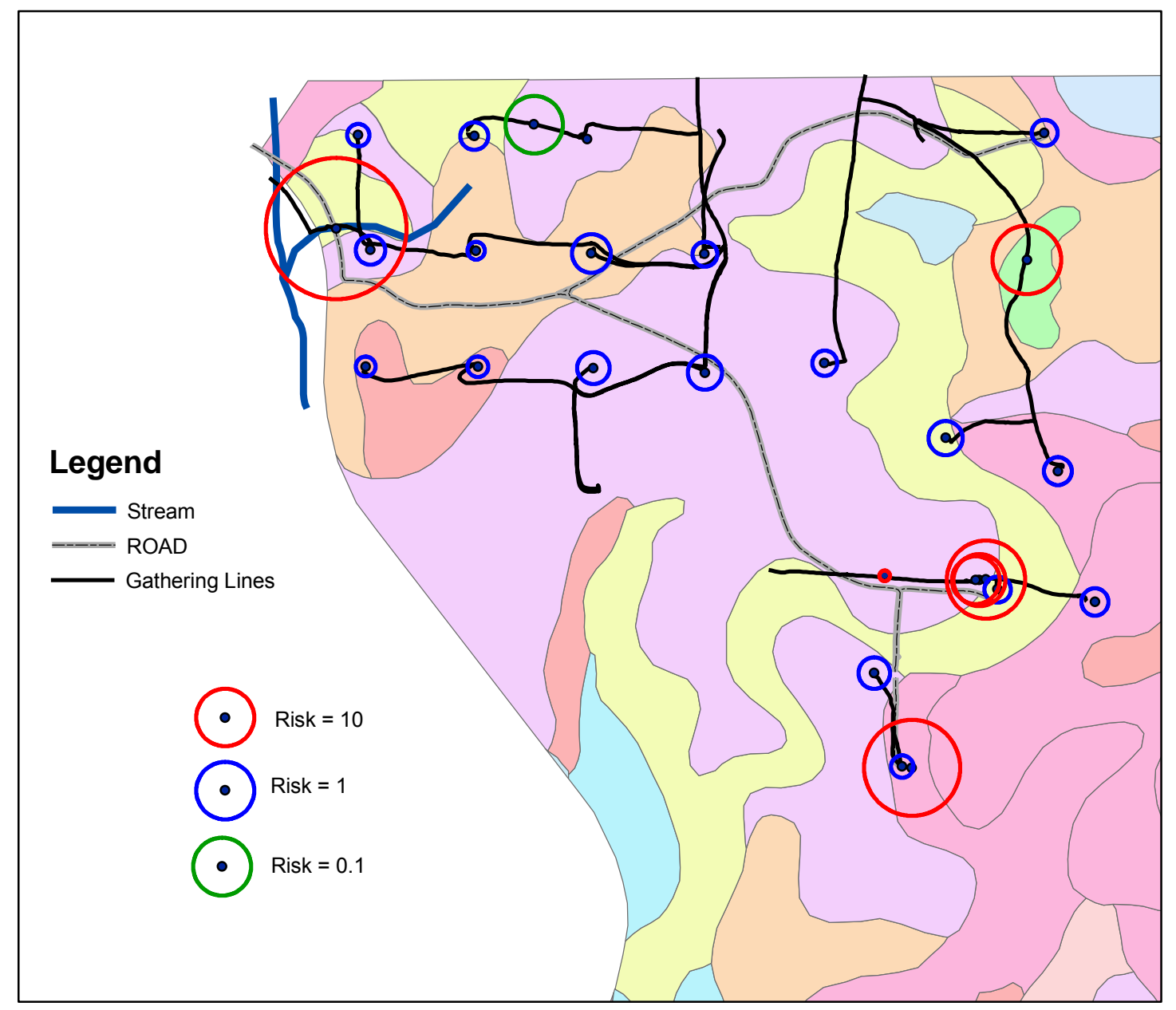

Figure 0-1. Ranked risk index map for E\&P equipment at the TPP field site. Shaded areas represent SSURGO soil types at the TPP site.

An ecological risk factor estimation model defines a risk category for each simulated accidental release incident which in turn determines the necessary cleanup level for that spill. A cost estimation module is called to estimate the expense of cleanup to the required level. In this study, risk is defined as the product of financial consequence and probability of failure of an item of equipment at a particular location. The risk is normalized across the lease to provide a simple comparison of the risks so that limited maintenance resources can be allocated to those locations and equipment that will result 
in the most significant reduction in overall lease level risk. The proposed proactive risk management approach should result in both cost savings to the independent producer as well as lead to a reduction in the ecological impact of exploration and production activities in sensitive ecosystems.

\section{References}

1. Agriculture Handbook Number 703-USDA-ARS, Predicting Soil Erosion by Water: A Guide to Conservation Planning with the Revised Universal Soil Loss Equation (RUSLE) pp. 340-347.

2. ASCE Task Committee on Modeling of Oil Spills of Water Resources Engineering Division, 1996, State-Of-The-Art Review of Modeling Transport and Fate of Oil Spills, Journal of Hydraulic Engineering, Nov 1996, pg 564-609.

3. ASTM, 1995, Standard Guide for Risk Based Corrective Action Applied at Petroleum Release Sites. ASTM E 1739-95. American Society for Testing Materials.

4. ASTSWMO Association of State and Territorial Solid Waste Management Officials, 2000, Compendium of Restoration Methodologies.

5. Brooks, R.H., A.T. Corey, 1964, Hydraulic Properties of Porous Media. Hydrology paper 3, Colorado State University, Fort Collins, Co.

6. Buckmaster, J. 1973, Viscous-Gravity Spreading of an Oil Slick, Journal of Fluid Mechanics, Vol.59, No. 3, pp 481-491.

7. Cary, J.W., C.S. Simmons, J.F. McBride, 1989, Predicting Oil Infiltration and

8. Cuesta, I., F.X. Grau, F. Giralt, 1990, Numerical Simulation of Oil Spills in a Generalized Domain, Oil and Chemical pollution, 7, pp 143-159.

9. Dicarlo, D.A., A. Sahni, M.J. Blunt, 2000. The Effect of Wettability on Three-Phase Relative Permeability. Transport in Porous Media, vol. 30, pp. 347-366.

10. Dunkerley, D., 2001. Estimating the Mean Speed of Laminar Overland Flow Using Dye Injection-Uncertainty on Rough Surfces. Earth Surf.Process.Landforms, vol. 26, pp.363-374.

11. Emmett, W.W., 1978, Overland flow. In Kirkby, M.J. (ed), Hillslope Hydrology, John Wiley, Chichester, pp. 145-176.

12. Fay, J.A., 1971, Physical Processes in the Spreading of Oil on a Water Surface, Proceedings of Joint Conference on Prevention and Control of Oil Spills, American Petroleum Institute, Washington D.C., pp 463-467.

13. Fisher, J. B. and Sublette, K.L. (2005) "Environmental Releases from E\&P operations in Oklahoma: Type, Volume, Causes and Prevention", Environmental Geosciences; June 2005; v. 12; no. 2; p. 89-99; DOI: 10.1306/eg.11160404039

14. Gilley, J.E., E.R. Kottwitz, G.A. Wieman, 1991. Roughness Coefficients for Selected Residue Materials. Journal of Irrigation and Drainage Engineering, vol. 117(4), pp. 503-514. 
15. Gilley, J.E., E.R. Kottwitz, J.R. Simanton, 1990. Hydraulic Characteristics of Rills. Trans $A S A E$ vol. 33, No. 6, pp. 1900-1906.

16. Gilley, J.E., S.C. Finkner, 1991. Hydraulic Roughness Coefficients as Affected by Random Roughness. Transactions of the ASAE, vol.34, pp. 897-903.

17. Grove, J.R., 1989, A Practical Soil Moisture Profile Model, Water Resources Bulletin, vol.25, No. 4, pp 875-879.

18. Guardo, M., T.H., Podmore, 2000, Comparision of Zero-Inertia and Volume Balance Advance-Infiltration Models, Journal of Hydraulic Engineering, vol. 126, no. 6, pp 457-465.

19. Hall, C., Neher, L., Wilder, L., Carlsen, T., Ashwood, T., Washington-Allen, R., and Efroymson, R. 2001. Data Collection Protocol for Developing Geographical Information Systems to Investigate and Manage Ecological Impacts at Petroleum Exploration and Production Sites. Lawrence Livermore National Laboratory Contract \#W-7405-Eng-48; Oak Ridge National Laboratory contract \#DE-AC0500OR222725.

20. Harris, T.M., J. Bryan Tapp, K.L., Sublette, 2004. "Remediation of Oilfield BrineImpacted Soil Using a Subsurface Drainage System”, Unpublished.

21. Hillel, D., 1971, Soil and Water: Physical Principles and Processes, Academic Press, New York, New York.

22. Hoult, D.P., 1972, Oil Spreading on the Sea, Annual Review of Fluid Mechanics, pp 341-367.

23. Interstate Oil and Gas Compact Commission (IOGCC) "Marginal Oil and Gas: Fuel for Economic Growth", 2003 edition.

24. Jaber, F.H., R.H. Mohtar, 2002, Dynamic Time Step for One-Dimensional Overland Flow Kinematic Wave Solution, Journal of Hydrologic Engineering, January/February, pp.3-11.

25. Jamison, B.E., J.A. Dechant, D.H. Johnson, L.D. Igl, C.M. Goldade, and B.R. Euliss, 2002. Effects of Management Practices on Grassland Birds: Lesser Prairie-Chicken. Northern Prairie Wildlife Research Center, Jamestown, ND.

26. http://www.npwrc.usgs.gov/resource/literatr/grasbird/lpch/lpch.htm

27. Knight, J.H., 1983, 'Infiltration Functions From Exact and Approximate Solutions of Richards' Equations', Advanced in Infiltration, Proceeding of the National Conference on Advances in Infiltration, December 12-13, 1983. Chicago, Illinois.

28. Lal, A.M. Wasantha, 1998. Performance Comparison of Overland Flow Algorithms, Journal of Hydraulic Engineering, p342-349 April 1998.

29. Lamb, R.L. and S.R. Wilkerson, 1991. "The Osage Environmental Audit", April 29 1999, The Oklahoma Commission on Marginally Producing Oil and Gas Wells. http://www.state.ok.us/ marginal/osageaudit.htm

30. Launo', R, W. Focht, A. Cross, and K. Duncan, 2002. Development of Relevant Ecological Screening Criteris (RESC) for Petroleum Hydrocarbon-Contaminated Exploration and Production Sites-Final Report. Oklahoma State University; University of Oklahoma. EPA funded project -research category: Ecorisk Assessment. 
31. Lawrence, D.S.L, 1997. Macroscale Surface Roughness and Frictional Resistance in Overland Flow. Earth Surface Processes and Landforms, vol. 22, pp.365-382.

32. Lenhard, R.J., M. Oostrom, 1998. A Parametric Model for Predicting Relative Permeability-Saturation-Capillary Pressure Relationships of Oil-Water Systems in Porous Media with Mixed Wettability. Transport in Porous Media, vol. 31, pp. 109131.

33. Liu, Y., H. Liu, H. Zhang, G. Miao, 2000, Simulations of Oil Spread on a Water Surface, Pro Instn Mech Engrs, Vol 214 Part C.

34. McCay, D.F., J.J. Rowe, N. Whittier, S. Sankaranarayanan, D.S. Etkin, 2004, Estimation of Potential Impacts and Natural Resource Damages of Oil, Journal of Hazardous Materials, 107, pp 11-25.

35. Moore, I.D., G.R. Foster, 1990, Hydraulics and Overland Flow. In Anderson, M.G. (ed), T.P., Burt, Process Studies in Hillslope Hydrology, John Wiley \& Sons, Chichester, pp. 215-254.

36. Moralwar, A., K.L. Sublette, L. Ford, K. Duncan, G. Thoma, J. Brokaw, 2004. "Remediation of a Spill of Crude Oil and Brine Without Gypsum", Unpublished.

37. Morita, M, B.C. Yen, 2002, Modeling of Conjunctive Two-Dimensional Surface Three-Dimensional Subsurface Flows, Journal of Hydraulic Engineering, February, pp 184-200.

38. National Oceanic and Atmospheric Agency, 1992. Oil Spill Case Histories 19671991, Summaries of Significant U.S. and International Spills. Report No. HMRAD 92-11.

39. Oklahoma Corporation Commission -_Pollution Abatement Department, Oil and Gas Conservation Division, 2002, "Guardian Guidance for the Assessment and Cleanup of Complex Crude Oil, Condensate, and Other Hydrocarbon Release Sites, Including Historically Impacted Sites" http://www.occ.state.ok.us/Divisions/OG/ogtaxapp/ogguardian/guard1.htm

40. Oklahoma-Tallgrass Prairie, 2001, http://www.oklahomanature.org/tallgrass.html

41. Parker, J.C., R.J. Lenhard, T. Kuppusamy, 1987, A Parameter Model for Constitutive Properties Governing Multiphase Flow Porous Media. Water Resour. Res. Vol. 23, pp. 618-624.

42. Playan, E., W.R. Walker, G.P. Merkley, 1994, Two Dimensional Simulation of Basin Irrigation, 1: Theory, J.Irrig.Drain Eng. Vol.120, No.5, pp.837-856.

43. Reed. M, P. French Deborah, S.S Feng, F.W. French III, E. Howlett, K. Jayko, W. Knauss, J. McCue, Pavignano, S. Puckett, and H. Rines, 1996, The CERCLA Type A Natural Resource Damage Assessment Model for the Great Lakes Environments (NRDAM/GLE), Technical Documentation, vol. 1, U.S. Department of the Interior.

44. Roels, J.M. 1984. Flow Resistance in Concentrated Overland Flow on Rough Slope Surface. Earth Surface Processes and Landforms, vol. 9, pp. 541-551.

45. Senneset, K., O. Torsaeter, S. Lone, T. Wiig, 1995. Two-Phase Flow and Permeability of Oil in Poroues Media. Geotechnical Special Publication, American Society of Civil Engineers, vol. 46, pp. 389-405.

46. R. E. Smith and J. -Y. Parlange, "A Parameter-Efficient Hydrologic Infiltration Model," Water Resources Research 14, no. 3 (1978): 533-538; 
47. Takken, I., G. Govers, 2000. Hydraulics of Interrill Overland Flow on Rough, Bare Soil Surfaces. Earth Surf. Process. Landforms, vol.25, pp.1387-1402.

48. Thoma, G.J., L. Zambrano, K.L. Sublette, K. Duncan, 2005. "Probabilistic Reliability Modeling for Oil Exploration \& Production (E \& P) Facilities in the Tallgrass Prairie Preserve." Final Report to National Petroleum Technology Office of U.S. Department of Energy (DE-FC26-01BC15332)

49. Thoms, R.B., 2003. Simulating Fully Coupled Overland and Variably Saturated Subsurface Flow Using MODFLOW. OGI School of Science and Engineering at Oregon Health and Science University, Master Thesis.

50. Thomson, J.R., 1987, Engineering Safety Assessment. $1^{\text {st }}$ ed. Longman Group UK

51. Van Genuchten, M. Th., 1980, A Closed-Form Equation for Predicting the Hydraulic Conductivity of Unsaturated Soils. Soil Sci. Soc. Am. J., vol. 44, pp. 892-898.

52. Vedat, V. and Y.K. Bahar, 2001, A GIS-Based Framework for Hazardous Materials Transport Risk Assessment. Risk Analysis Vol. 21 No.6.

53. Wagner, J., 1998, Powerpoint Presentation "Risk Assessment/ Consequence Analysis", Center for Chemical Process Safety of the American Institute of Chemical Engineers.

54. Weltz, M.A., A.B. Arslan, L.J. Lane, 1992. Hydraulic Roughness Coefficients for Native Rangeland. Journal of Irrigation and Drainage Engineering, vol. 118(5), pp. 776-790.

55. Zambrano, L, 2004. Probabilistic Risk Assessment for Exploration and Production Facilites in the Tallgrass Prairie Preserve. Master thesis, University of Arkansas. 


\section{NOMENCLATURE}

\begin{tabular}{|c|c|}
\hline$\nabla+\cdots \cdots \cdots \cdots \cdots$ & gradient operator \\
\hline$v, u \cdots \cdots \cdots \cdots$ & velocity, L/T \\
\hline$\rho \cdots \cdots \cdots \cdots \cdots \cdots \cdots$ & density, $\mathrm{M} / \mathrm{L}^{3}$ \\
\hline$\tau$ & viscous stress tensor, dynes/ $\mathrm{L}^{2}$ \\
\hline$n_{p} \cdots \cdots \cdots \cdots \cdots \cdots$ & soil porosity \\
\hline$\lambda \ldots \ldots \ldots \ldots \ldots \ldots$ & pore size distribution index \\
\hline$\alpha$ & inverse characteristic length of the soil pores, $1 / \mathrm{L}$ \\
\hline$\beta, \gamma \cdots \cdots \cdots \cdots$ & the degree of pore size uniformity, $\gamma=1-1 / \beta$ \\
\hline a......... & viscosity of water, $\mathrm{L}^{2} / \mathrm{T}$ \\
\hline$\mu_{o} \cdots \cdots \cdots \cdots \cdots \cdots$ & viscosity of oil, $\mathrm{L}^{2} / \mathrm{T}$ \\
\hline -......... & volume fraction of oil \\
\hline$\psi_{f} \cdots \cdots \cdots \cdots \cdots$ & wetting front suction head, L \\
\hline$\psi_{a} \cdots \cdots \cdots \cdots \cdots \cdots$ & air entry suction head, L \\
\hline$\theta \ldots \ldots \ldots \ldots \ldots \ldots$ & soil moisture content \\
\hline$\theta_{r} \cdots \cdots \cdots \cdots \cdots \cdots \cdots$ & soil residual moisture content \\
\hline$\theta_{s} \cdots \cdots \cdots \cdots \cdots \cdots \cdots \cdots$ & soil-water saturated moisture content \\
\hline$\theta_{w}$ & volume fraction of water \\
\hline$C_{a} \ldots \ldots \ldots \ldots \ldots \ldots$ & concentration of desired level, $\mathrm{M} / \mathrm{L}^{3}$ \\
\hline$C_{a o}$ & initial concentration, $\mathrm{M} / \mathrm{L}^{3}$ \\
\hline$D \ldots \ldots \ldots \ldots \ldots$ & Darcy hydraulic coefficient \\
\hline (n................ & friction factor \\
\hline$f_{d} \cdots$ & Darcy-Weisbach roughness coefficient \\
\hline$f_{r s} \ldots \cdots \cdots \cdots \cdots$ & friction factor associated with grain roughness of the soil \\
\hline$f_{r r} \ldots \ldots \cdots \cdots \cdots$ & friction factor associated with microtopography \\
\hline$f_{g c}$ & friction factor associated with ground surface cover \\
\hline$f_{p b} \cdots \cdots \cdots \cdots \cdots$ & friction factor attributed to standing vegetation \\
\hline
\end{tabular}




\begin{tabular}{|c|c|}
\hline$g(\cdots \cdots \cdots \cdots \cdots \cdots$ & gravitational acceleration, $\mathrm{M} / \mathrm{T}^{2}$ \\
\hline$h \ldots \ldots \ldots \ldots \ldots \ldots$ & surface flow depth, L \\
\hline$H$ & elevation of free surface, $\mathrm{H}=\mathrm{h}+\mathrm{z}, \mathrm{L}$ \\
\hline$I+\cdots \cdots \cdots \cdots \cdots \cdots$ & cumulative infiltration depth, $\mathrm{L}$ \\
\hline$I N, \frac{d I}{d t}$ & Infiltration rate, $\mathrm{L} / \mathrm{T}$ \\
\hline$k \ldots \ldots \ldots \ldots \ldots \ldots$ & kinetic rate constant \\
\hline$K$ & hydraulic conductivity, $\mathrm{L} / \mathrm{T}$ \\
\hline$K_{s w} \ldots \cdots \cdots \cdots \cdots$ & soil-water saturated hydraulic conductivity, L/T \\
\hline$n \ldots \ldots \ldots \ldots \ldots \ldots$ & Manning roughness coefficient, $\mathrm{T} / \mathrm{L}^{-1 / 3}$ \\
\hline om ……........... & fraction of organic matter \\
\hline$p s \ldots \ldots \ldots \ldots . .$. & fraction of plant stems \\
\hline$p$ & pressure, $\mathrm{F} / \mathrm{L}^{2}$ \\
\hline$Q_{s}$ & volumetric flow rate of source, $\mathrm{L}^{3} / \mathrm{T}$ \\
\hline$Q_{\text {inf }} \ldots \ldots \ldots \ldots \ldots$ & volumetric flow rate of infiltration, $\mathrm{L}^{3} / \mathrm{T}$ \\
\hline$R$ & hydraulic radius, $\mathrm{L}$ \\
\hline$R F \ldots \ldots \ldots \ldots$ & rainfall rate, $\mathrm{L} / \mathrm{T}$ \\
\hline$R R \ldots \ldots \ldots \ldots$ & random roughness \\
\hline$S \ldots \ldots \ldots \ldots \ldots \ldots \ldots$ & the surface slope of flow \\
\hline$S_{f x} \ldots \ldots \ldots \ldots \ldots$ & friction slope in $\mathrm{x}$ direction \\
\hline$S_{f y} \ldots \ldots \ldots \ldots \ldots$ & friction slope in y direction \\
\hline$t$ & time, $\mathrm{T}$ \\
\hline$V_{s} \cdots \cdots \cdots \cdots \cdots$ & flow rate of spill source, $\mathrm{L} / \mathrm{T}$ \\
\hline$V_{\text {inf }} \quad \cdots \cdots \cdots \ldots \ldots$ & flow rate of infiltration, $\mathrm{L} / \mathrm{T}$ \\
\hline$V_{x} \quad \cdots \cdots \cdots \cdots \cdots$ & velocity in $\mathrm{x}$ direction, $\mathrm{L} / \mathrm{T}$ \\
\hline$V_{y} \quad \cdots \cdots \cdots \cdots \cdots$ & velocity in $\mathrm{y}$ direction, $\mathrm{L} / \mathrm{T}$ \\
\hline 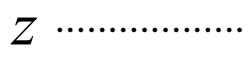 & elevation of soil surface, $\mathrm{L}$ \\
\hline
\end{tabular}

